\title{
Type 2 diabetes mellitus : pathology and treatment
}

Citation for published version (APA):

Wolffenbuttel, B. H. R. (1991). Type 2 diabetes mellitus : pathology and treatment. [Doctoral Thesis, Maastricht University]. Maastricht University. https://doi.org/10.26481/dis.19910524bw

Document status and date:

Published: 01/01/1991

DOI:

10.26481/dis.19910524bw

Document Version:

Publisher's PDF, also known as Version of record

\section{Please check the document version of this publication:}

- A submitted manuscript is the version of the article upon submission and before peer-review. There can be important differences between the submitted version and the official published version of record.

People interested in the research are advised to contact the author for the final version of the publication, or visit the DOI to the publisher's website.

- The final author version and the galley proof are versions of the publication after peer review.

- The final published version features the final layout of the paper including the volume, issue and page numbers.

Link to publication

\footnotetext{
General rights rights.

- You may freely distribute the URL identifying the publication in the public portal. please follow below link for the End User Agreement:

www.umlib.nl/taverne-license

Take down policy

If you believe that this document breaches copyright please contact us at:

repository@maastrichtuniversity.nl

providing details and we will investigate your claim.
}

Copyright and moral rights for the publications made accessible in the public portal are retained by the authors and/or other copyright owners and it is a condition of accessing publications that users recognise and abide by the legal requirements associated with these

- Users may download and print one copy of any publication from the public portal for the purpose of private study or research.

- You may not further distribute the material or use it for any profit-making activity or commercial gain

If the publication is distributed under the terms of Article $25 \mathrm{fa}$ of the Dutch Copyright Act, indicated by the "Taverne" license above, 


\title{
Type 2 diabetes mellitus
}

\author{
Pathology and treatment
}


Cover:

"The Georg Ebers papyrus, dating from 1550 B.C., discovered at Thebes in 1872 , contains an extensive medical therapeutic text covering many subjects, among them pharmacologic means of treatment. Possible remedies against a disease with excessive urinary output are mentioned. 


\title{
Type 2 diabetes mellitus
}

\author{
Pathology and treatment
}

\section{PROEFSCHRIFT}

ter verkrijging van de graad van doctor

aan de Rijksuniversiteit Limburg te Maastricht,

op gezag van de Rector Magnificus, Prof. mr. M.J. Cohen, volgens het besluit van het College van Dekanen,

in het openbaar te verdedigen

op vrijdag, 24 mei 1991 om 16.00 uur

door

Bruce Herbert Ralph Wolffenbuttel 
Promotores:

prof. dr. A.C. Nieuwenhuijzen Kruseman

prof. dr. J.C. Birkenhäger

Beoordelingscommissie: prof. dr. H.F.J.M. Crebolder (voorzitter)

prof. dr. P.J. Brombacher

prof. dr. P.J. Lefêbvre (Liège, Belgium)

prof. dr. P.B. Soeters

prof. dr. R.C. Tumer (Oxford, England)

CIP-DATA KONINKLIJKE BIBLIOTHEEK, DEN HAAG

Wolffenbuttel, Bruce Herbert Ralph

Type 2 diabetes mellitus, pathology and treatment : Bruce

Herbert Ralph Wolffenbuttel. - Maastricht : Datawyse. -

III.

Thesis Maastricht. - With ref. - With summary in Dutch.

ISBN 90-5291-049-9

NUGI 742

Subject headings: diabetes.

(C) 1991 No part of this book may be reproduced in any form, by print, photoprint, microfilm or any other means, without written permission of the author and the respective editors of the journals, in which the various articles appeared in print.

Produktie en Layout: Datawyse Maastricht, Ruud Leliveld Druk: Krips Repro Meppel

The studies in this thesis were made possible by support of Novo Nordisk Farma BV, and the Diabetes Research Foundation.

Publication of this thesis was made possible by Novo Nordisk Farma BV. 
Some things turn out all wrong, and some things turn out all right, Some things don"t turn out at all, but then again they might.

J. Walsh, 1981. 


\section{Contents}

INTRODUCTION

Scope of this thesis

CHAPTER 1

Type 2 diabetes mellitus: pathophysiology and treatment

CHAPTER 2

Clinical characteristics of patients with type 2 diabetes treated in a hospital outpatient-clinic: treatment, metabolic derangements, late complications

CHAPTER 3

Clinical characteristics and management of diabetic patients residing in a nursing home

CHAPTER 4

The value of fasting blood glucose and serum fructosamine in the evaluation of metabolic control in type 2 diabetic patients

CHAPTER 5

Dietary management of type 2 diabetes

CHAPTER 6

Treatment of patients with type 2 diabetes failing on dietary therapy: oral hypoglycaemic agents or insulin?

CHAPTER 7

Insulin therapy in type 2 diabetic patients with secondary failure to oral hypoglycaemic agents

CHAPTER 8

Combination of insulin and sulphonylurea in patients with type 2 diabetes mellitus 
CHAPTER 9

Determinants of the behaviour 'injecting insulin' in elderly patients with diabetes mellitus

CHAPTER 10

General discussion

CHAPTER 11

Summary

CHAPTER 12

Samenvatting

CHAPTER 13

Evaluation and treatment of patients with type 2 diabetes (practical guidelines)

NAWOORD 



\section{Scope of this thesis}

In the studies that are described in this thesis we tried to answer a number of questions which are related to the management of the patient with type 2 diabetes mellitus in everyday practice, either by the family physician or by the endocrinologist/diabetologist. A central question in this case is by which way we can aim to achieve as-near-as-normal blood glucose levels in (elderly) patients with type 2 diabetes, in order to improve quality of life and reduce the risk for the development of late micro- and macrovascular complications and neuropathy.

The specific problems that are studied within the scope of this thesis are:

1. The frequency by which secondary complications develop in patients with type 2 diabetes, and the consequences of these complications for the daily life of the patient (Chapter 2).

A more specific question in this respect is which clinical conditions predispose for admission of patients to a nursing home (Chapter 3).

2. The severity of vascular complications and quality of blood glucose control of a certain subgroup of patients, namely those who are chronically admitted to a nursing home; their metabolic control and degree and extent of complications is compared with a group of ambulatory diabetic patients (Chapter 3).

3. The metabolic parameters that should be monitored for the everyday control of type 2 diabetic patients. In more detail it is explored whether the determination of fasting blood glucose levels, as advocated by the Dutch Society for General Practice, is sufficient to ensure adequate follow-up of metabolic control, or whether others measures (blood glucose profiles, glycosylated haemoglobin, fructosamine) are necessary (Chapter 4).

4. The effects of intensified dietary therapy on glucose and lipid metabolism and residual islet $\mathrm{B}$-cell function in obese and non-obese ambulatory patients with recent-onset or longer duration of diabetes (Chapter 5).

5. The best mode of treatment for type 2 diabetic patients, who are unsufficiently controlled by diet alone. Should we then -as is common practice at the momentstart oral hypoglycaemic agents, or is insulin therapy a more rational choice for such patients (Chapter 6). 
6. When insulin therapy is instituted, which insulin regimen should be used? Is a combination of oral agents and insulin a feasible and safe approach, and is this scheme preferred above treatment with insulin alone? What are the advantages and disadvantages of the combined therapy regarding lipid metabolism, incidence of hypoglycaemias, and costs of the treatment (Chapters 7 and 8 ).

7. The psychological and social factors that may be of influence when a patient is transferred from treatment with oral agents to insulin therapy (Chapter 9).

In Chapter 1 aspects of pathophysiology and treatment of type 2 diabetes are reviewed. 
CHAPTER

Type 2 diabetes mellitus

Pathophysiology and treatment 
Non-insulin-dependent or type 2 diabetes mellitus is a heterogeneous disorder, characterized by impaired insulin secretion by the islet B-cells, diminished peripheral insulin action, and increased hepatic glucose production. The major therapeutic goals in type 2 diabetic patients are to optimize blood glucose control, to reduce overweight and to normalize lipid disturbances and elevated blood pressure, in order to improve the well-being of the patient and reduce the risk for the development of late diabetic complications. Exercise and diet, aiming at weight reduction are the cornerstones of therapy. However, often pharmacologic treatment is necessary, in which case sulphonylurea, metformin or insulin may be employed 


\section{INTRODUCTION}

The main hormone regulating glucose homeostasis is insulin. This hormone is produced by the B-cells of the islets of Langerhans in the pancreas. An increase in the blood glucose level, for instance after a meal, leads to a stimulation of insulin release. Insulin exerts its glucose-regulating action by stimulating glucose uptake in muscle and fat tissue and by suppressing the glucose production in the liver after binding to a specific receptor in the cell membrane. Further, insulin's action comprises the stimulation of lipogenesis and inhibition of lipolysis, and it increases net protein synthesis by enhancing the use of aminoacids, by stimulation of DNA and RNA synthesis, and by inhibition of protein catabolism (1).

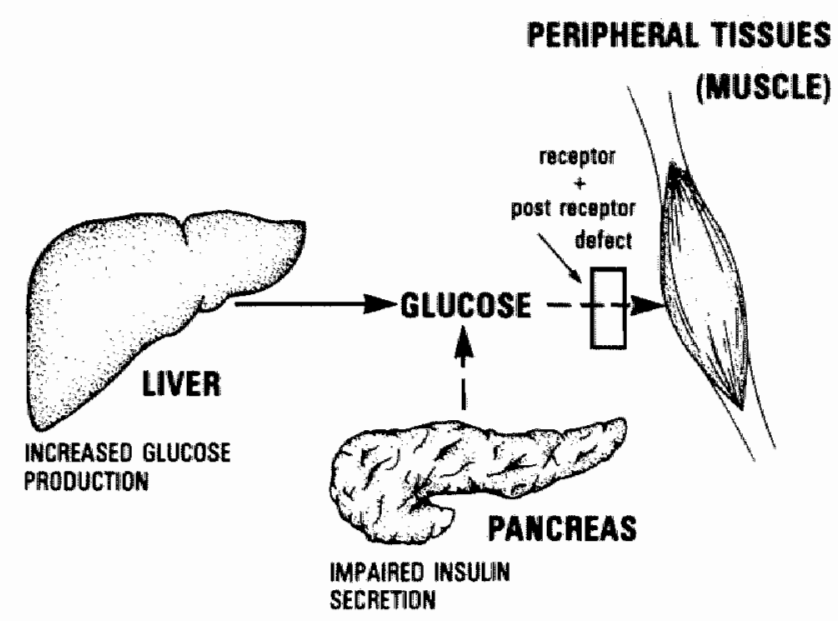

Figure 1. Organ sites involved in the regulation of blood glucose levels. From: Olefsky JM, et al. Am J Med 1988; 85 (suppl 5A): 86-105.

Diabetes mellitus is defined by the WHO (2) as a chronic elevation of the concentration of blood glucose, which characteristically poses a long-term risk to the patient of developing progressive disease of the retina and kidney, damage to peripheral nerves, and aggravated atherosclerotic disease of the heart, legs, and brain. Hyperglycaemia can be caused by a decreased production or by an impaired action of insulin or both $(3,4)$. There are several other hormonal and neural influences that can modulate glucose homeostasis, for instance cortisol and glucagon.

Diabetes was originally considered as a state of insulin deficiency, but the last 25 years the concepts about the disease have changed. In fact, many diabetic patients do secrete insulin. Diabetes can be distinguished in the lean, ketosis- 
Table 1. Characteristics of type 1 and type 2 diabetes.

$\begin{array}{lll}\text { Characteristic } & \text { Type 1 } & \text { Type 2 }\end{array}$

Weight at diagnosis

non-obese

Age at diagnosis

Peak age

Sex

Incidence

Seasonal variation

Prevalence

Onset

Ketosis

Remission

Duration at onset of

late complications

Islet-cell antibodies

Pathology islet Langerhans

HLA-association

Coincidence with other

auto-immune diseases

Familial occurrence

Treatment usually $y<30$ years

12-14 years

slight male predominance

$11 / 10^{5}(<20$ years $)$

present

$0.2-0.5 \%$

rapid-gradual

symptoms severe

usual

often occurs temporarily

after several years

present in 70-95\% of

cases at diagnosis; may

preceed development of

disease for more than 9 years

inflammatory lesions and.

progressive loss B-cells

DR-3, DR-4 or both

in $5.10 \%$ of all cases
$80 \%$ obese, $20 \%$ non-obese

usually $>40$ years

65 years

female predominance

$?$

? absent

$?>2 \%$

mild; insidious

incidental finding

uncommon

? absent

may be present at diagnosis

usually absent

amyloid deposition (40\%)

no

strong hereditary component

diet \& oral hypogl. agents

may require insulin 
prone, juvenile-onset type (insulin-dependent or type 1, IDDM) and the obese, non-ketosis-prone, maturity-onset form (non-insulin-dependent or type 2, NIDDM) (2). Principle differences between these two types of diabetes mellitus are listed in table 1.

\section{AETIOLOGY AND PATHOGENESIS OF TYPE 2 DIABETES}

Type 2 diabetes is a heterogeneous disorder, characterized by defects in insulin secretion as well as insulin action (5). Subjects with modest hyperglycaemia have basal and stimulated insulin levels that are normal or often even increased (6). In patients with more severe hyperglycaemia, absolute insulin levels appear to be normal, but they are inappropriately low in relation to the prevailing blood glucose concentration (7). Insulin response after stimulation with glucose or other secretagogues is normal or increased with modest hyperglycaemia, but severely impaired when glucose levels exceed $11 \mathrm{mmol} / 1$. There exists a defective recognition of glucose signals by the B-cells ("desensitization"), which is suggested to be secondary to hyperglycaemia, and partially restored by normalization of glucose levels (7). Insulin action is impaired: in the basal state this insulin resistance is most pronounced at the level of the liver, the consequent overproduction of glucose primarily causing fasting hyperglycaemia (8). In the post-absorptive state insulin resistance at the level of the peripheral tissues (5), together with the apparent inability to suppress hepatic glucose production (9), and defects in insulin secretion, are responsible for the excessive rise of blood glucose. Although a small decrease in insulin receptor number has been demonstrated (10), the major defect of insulin action is situated at the postreceptor level (11). Impaired glucose uptake, and disturbances of glucose conversion to glycogen (glycogen synthetase) and to a lesser extent- glucose oxidation (pyruvate dehydrogenase) are the main features $(12,13)$.

\section{ISLET B-CELL DYSFUNCTION AS THE PRIMARY DEFECT?}

As mentioned before, glucose is the most important regulator of insulin secretion. A rise of blood glucose level is rapidly sensed by the pancreatic B-cells. It is assumed that the enzyme glucokinase (ATP-D-glucose-6-phosphotransferase) acts as 'glucose sensor' of the B-cell (14). This enzyme determines the metabolic flux through the Embden-Meyerhof glycolysis pathway. It is hypothesized that abnormalities in the regulation of the biosynthesis or degradation 


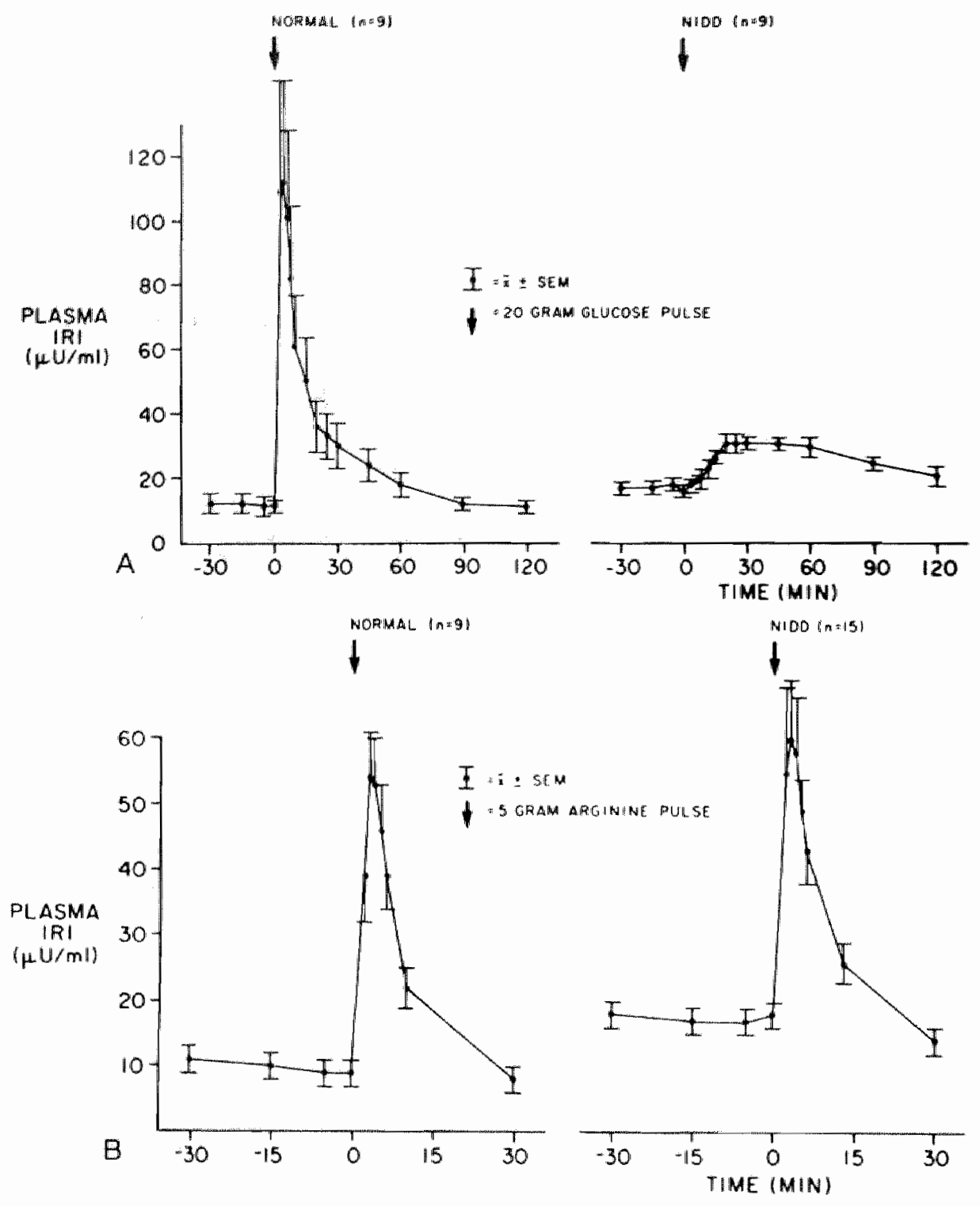

Figure 2. Insulin secretion in type 2 diabetes: A. after iw glucose; B. after iv arginine. From: Pfeifer MA, Halter JB, Porte D Jr. Am J Med 1981; 70: 579-588.

of glucokinase in the beta-cells are involved in the pathogenesis of insulin secretion disturbances in type 2 diabetes (15).

The abnormalities of insulin secretion in patients with type 2 diabetes can be characterized by the following features: 
1. normal or elevated basal plasma insulin levels $(4-6,16,17)$;

2. absence or reduction of first phase insulin secretion following glucose $(4,18$, 19) (figure 2A);

3. diminished second phase insulin secretion $(18,20)$;

4. 'normal' secretory reaction following non-glucose stimuli, as arginine or glucagon $(8,19,20)$ (figure $2 B$ );

5. diminished responsiveness to the potentiating effect of glucose $(20,21)$;

6. changes in oscillatory secretion of insulin $(22,23)$.

In the fasting state, levels of plasma insulin and C-peptide in type 2 diabetic individuals have been reported to be lower, equal to, or higher than in control subjects $(16,17)$. These differences can be accounted for by several factors, such as differences in age, race and body weight of the subjects who were studied, their level of fasting blood glucose, and the specific (radio-immuno)assay used for the determination (17).

When blood glucose levels are elevated, acute insulin response to intravenous glucose is impaired $(8,19,24)$. The response to other secretagogues as intravenous isoproterenol, arginine, or glucagon appears to be near-normal (4). It must be stressed that most responses in the diabetic patients are measured at elevated blood glucose levels, and it has been demonstrated that the response of the B-cells depends on the prevailing blood glucose (24-26). When the blood glucose of non-diabetic subjects is raised to levels similar to those in diabetic patients the release of insulin is greatly enhanced (20). The insulin response to a maximal potentiating glucose level was 5 times higher in healthy control subjects in comparison with diabetic patients. The glucose level at which half maximal potentiation of the insulin response is reached is identical in both groups. This means that the islets in the patient with type 2 diabetes are not totally 'blind' to glucose, but that -in addition to a change in islet sensitivityislet responsiveness is greatly diminished. However, when insulin instead of C-peptide measurements are used, this approach may result in an overestimation of B-cell responsiveness, as saturation of the hepatic insulin receptors may lead to reduced insulin clearance and peripheral hyperinsulinaemia (25).

\section{Pulsatility of insulin secretion}

Pulsatile hormone secretion is found in several endocrine feedback loop systems. Regular pulsatory insulin release is metabolically more efficient in maintaining normal blood glucose levels than non-pulsatory secretion (22). These oscillations are sollicited by an intrapancreatic 'pacemaker' that probably is influenced by the vagus nerve (27). In healthy persons insulin is secreted in regular pulses every 12-15 minutes (23). Pulsatile secretion of insulin is already 
decreased in mildly glucose-intolerant subjects who have a family history of type 2 diabetes, despite the fact that first phase insullin secretion is normal in these persons (23). Such persons are at high risk for developing type 2 diabetes, and this implies that loss of pulsatile secretion may be the earliest detectable abnomality of insulin secretion in this disease, either as a specific early defect or as a disturbance caused by minimally elevated blood glucose levels. In patients with established type 2 diabetes, regular oscillatory insulin secretion is lacking, and insulin is characteristically secreted in an irregular fashion (28). Others have not found differences in number of pulses, although the pulses appeared to be less regular and exhibited lower amplitudes (22).

\section{Histology of the pancreas in type 2 diabetes}

The observed pathologic changes in the pancreas of type 2 diabetic patients are very variable. A slight reduction in the number of $\mathrm{B}$-cells may be demonstrated (29). The same reduction already can be seen in many elderly healthy persons. Already in 1901, deposits of a hyaline substance have been demonstrated within the islets of Langerhans of diabetic patients (30). This material was later identified as amyloid. Recent studies, however, revealed that the peptide structure differs from systemic amyloid peptides. Thus, the term Islet Amyloid Poly Peptide (IAPP) was introduced (31). It is a 37 amino acid peptide, which shows a $46 \%$ homology with calcitonin-gene-related peptide, a hormone formed in the C-cells of the thyroid by alternate DNA processing of the calcitonin gene.

Considerable variation in the occurrence of islet amyloid in type 2 diabetic patients has been reported, with a prevalence as determined from examination of post-morten material varying from 25 to $92 \%$ (for review see 32,33 ). In a recent study in Pima Indians, deposition of IAPP could be demonstrated in pancreatic islets of $77 \%$ of diabetic persons, while this was found in less than $10 \%$ of non-diabetic individuals (34). No relation could be found between the occurrence of amyloid deposits and body mass index, fasting blood glucose level or age.

Histologically, the amyloid is seen between the islet capillaries and the endocrine cells. The fibrils lie in invaginations of the plasma membranes. IAPP probably originates from the insulin-producing beta-cells. Its presence was also demonstrated inside the beta-celis of both diabetic and non-diabetic subjects. Its physiological role is far from clear. Both involvement in the intracellular processing of insulin, regulation of enzymatic activity and paracrine modulation of insulin secretion have been suggested as main action of the peptide (32). Its co-secretion with insulin and possible vasodilating effects (like CGRP) may increase islet blood flow during insulin secretion (35). However, direct para- 
crine inhibition of insulin secretion might be a more direct effect. In addition, modulation of insulin action, and production of insulin resistance by LAPP have been shown in vitro, as well as in vivo in the rat (36).

Until now it is not known whether the formation of islet amyloid precedes the onset of glucose intolerance and diabetes, or whether it is formed secondarily after the onset of the disease, either directly released or linked to increased insulin biosynthesis. It seems plausible to state, however, that accumulation of amyloid over many years can lead to slowly progressive disruption of the islet architecture and possibly to the abnormalities in the secretion of insulin, as found in type 2 diabetic patients (37).

\section{INSULIN RESISTANCE AS THE PRIMARY LESION?}

Insulin resistance is a characteristic feature of type 2 diabetes. It is due to abnormalities in insulin action at the level of the target tissues, resulting in decreased glucose uptake by these tissues. It can be a consequence of receptor or postreceptor defects $(3,5,9,11,38-41)$. Until now it is unknown whether the defects in insulin action precede the onset of the disease and can be regarded as causative factors, or whether these are the consequence of the diabetic state and arise secondary to the exposure to elevated blood glucose levels $(39,42)$.

The insulin receptor (figure 3 ) consists of two identical alpha-subunits, which are situated extracellular, and two beta-subunits, which have an extracellular, a transmembrane, and a cytoplasmic domain $(1,43)$. The alpha-subunit contains

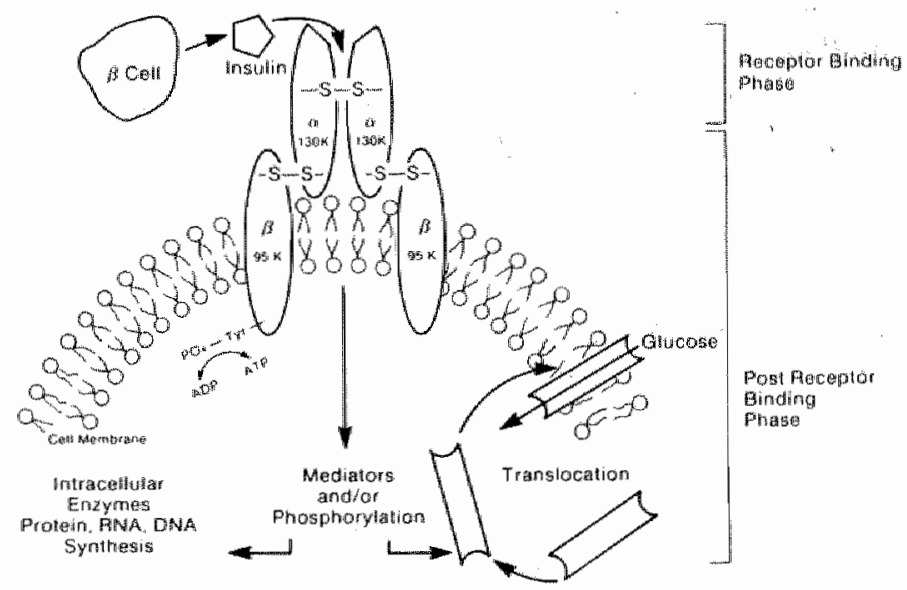

Figure 3. The insulin receptor. From: Olefsky JM, et al. Am J Med 1.988; 85 (suppl 5A): 86-105. 
the insulin binding site. Insulin binding generates a transmembrane signal, that sollicits a chain of intracellular events, such as activation of the receptor tyrosine-kinase, enhanced transport of glucose across the cell membrane, and initiation of a series of phosphorylation-dephosphorylation reactions, eventually leading to stimulation of certain anabolic pathways through activation of specific enzymes $(1,44,45)$.

After transduction of the signal, specific tyrosine residues in the beta-subunit will undergo autophosphorylation. The activated receptor stimulates through an unresolved mechanism the activity of phospholipase $C$, which is capable to hydrolyse specific glycosyl-phosphoinositides localized in the plasma membrane. The generation of phospho-inositolglycan and diacylglycerol causes selective stimulation of protein phosphatases, which dephosphorylate and thereby activate or inactivate intracellular enzymes involved in carbohydrate metabolism (46).

Based on our knowledge of normal insulin action the effects of receptor versus postreceptor defects on the insulin dose-response curve can be predicted (figure 4). A decrease in the number of insulin receptors or their biological function leads to a rightward shift in the insulin dose-response curve, whereas there is no change in maximal insulin action; this is called a decrease in insulin sensitivity. A pure postreceptor defect in insulin action affects the translation of the insulin signal into intracellular metabolic changes. This will lead to a reduction in biological effects at all insulin concentrations; this situation is termed a decrease in insulin responsiveness (47).

The dose-response curve of in vivo insulin action is often assessed with the so-called multiple euglycaemic glucose clamp (48). Similar studies can be performed in vitro with isolated adipocytes, monocytes or fibroblasts. In patients with type 2 diabetes the dose-response curve exhibits a rightward shift as well as a marked decrease in the maximal rate of glucose disposal. Insulin resistance in these patients therefore is caused by a combination of a postreceptor defect in insulin action and a decrease in the number of insulin receptors.

\section{Receptor defects}

Measurements of insulin binding to circulating monocytes and isolated adipocytes have shown that the ability of these cells to bind insulin was reduced due to a decreased number of cellular insulin receptors, both in patients with type 2 diabetes and in subjects with impaired glucose tolerance. Compared to normal persons binding of insulin to its receptors is already $20 \%$ lower in overweight persons, and $50 \%$ lower in obese type 2 diabetic patients (48). 


\section{Post-receptor defects}

Receptor phosphorylation sites

There seem to be 2 different populations of insulin receptors. In healthy individuals $40 \%$ of the receptors is capable to autophosphorylate, while $60 \%$ is not. In patients with type 2 diabetes only $14 \%$ is capable to autophosphorylate. Such disturbances may be caused by changes in the structure of the beta-subunit, for instance based on a change in aminoacid sequence. A different spatial configuration would lead to different acceptor places for phosphorylation. Also, it is possible that serine residues are phosphorylated in preference, which would inhibit the addition of phosphate to tyrosine.

Figure 4. The dose-response curve of insulin action. From: Olefsky JM, Molina JM. In: Diabetes Mellitus, Theory and Practice. p.126.

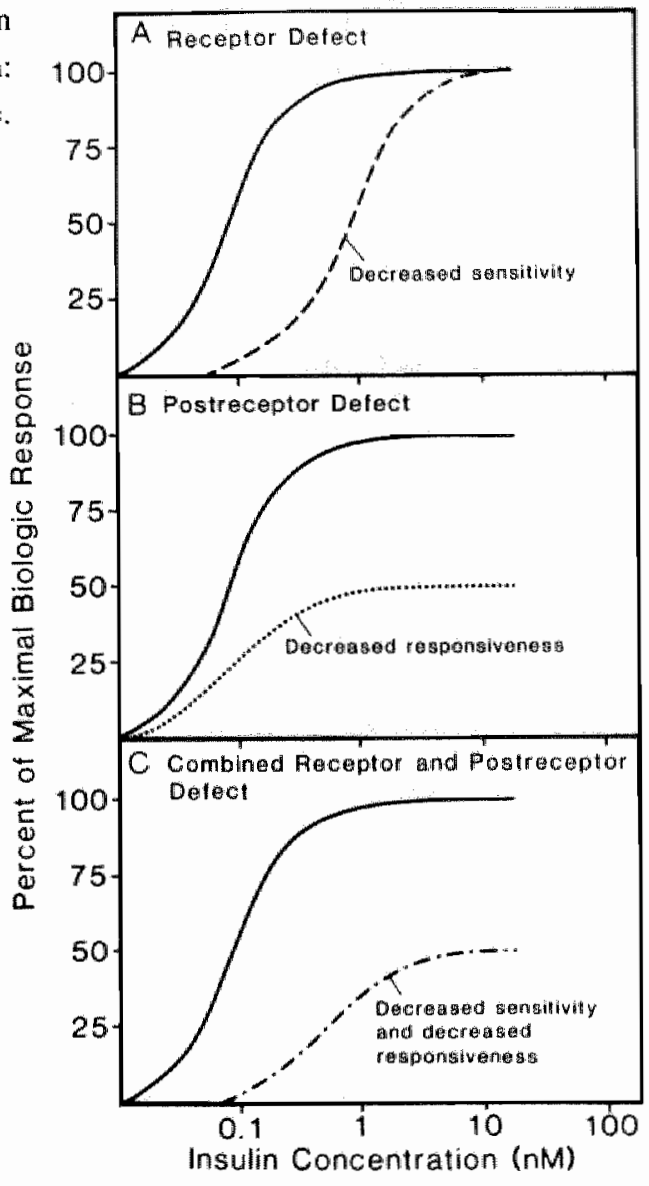




\section{Giucose transporters}

It has recently been demonstrated that the number of glucose transporters is decreased in patients with type 2 diabetes, both in the basal state and in the postprandial -stimulated- state $(49,50)$. Their function is possibly also diminished. Possible causes of the reduction in activity may be changes in structure, dysbalance of other regulatory factors (cAMP, ATP, adenosine), or increased breakdown or turnover $(51,52)$. The latter is supported by the finding that the number of glucose transporters in the intracellular high density subfraction is normal, which may point to a normal (or even increased) rate of synthesis of glucose transporters.

\section{Glucose metabolism}

Insulin-mediated, non-oxidative metabolism of glucose is due largely to glycogen synthesis by skeletal muscle. With the application of nuclear magnetic resonance spectroscopy it was demonstrated during a hyperinsulinaemic-glucose-clamp that insulin resistance in type 2 diabetic patients results from a defect in this pathway. Thus, in type 2 diabetic patients impaired glycogen synthesis is the major intracellular metabolic defect responsible for the decrease in nonoxidative and whole-body glucose metabolism (12). Activation by insulin of glycogen synthase phosphatase, an enzyme that dephosphorylates and thus activates glycogen synthase, was shown to be reduced in persons with insulin resistance, and responsible for these findings (13). The mechanism responsible for the reduction of insulin-mediated glucose metabolism is not known. A reduced activity of phospholipase $\mathrm{C}$ or diminished synthesis of intermediate messengers like diacylglycerol (DAG) and phospho-inositolglycan (PIG) have been postulated.

\section{Hepatic glucose production}

The rate of basal hepatic glucose production is increased compared to normals in both obese and non obese patients with fasting hyperglycaemia. The dose-response curve for suppression of hepatic glucose production by insulin is shifted to the right both in patients with impaired glucose tolerance and in patients with type 2 diabetes. However, hepatic glucose output can be totally suppressed in all patients with sufficient concentrations of circulating insulin. This demonstrates that on the level of the hepatocytes the defect in insulin sensitivity is due to a decreased number of insulin receptors, whereas it suggests that little or no postreceptor defect is present. 


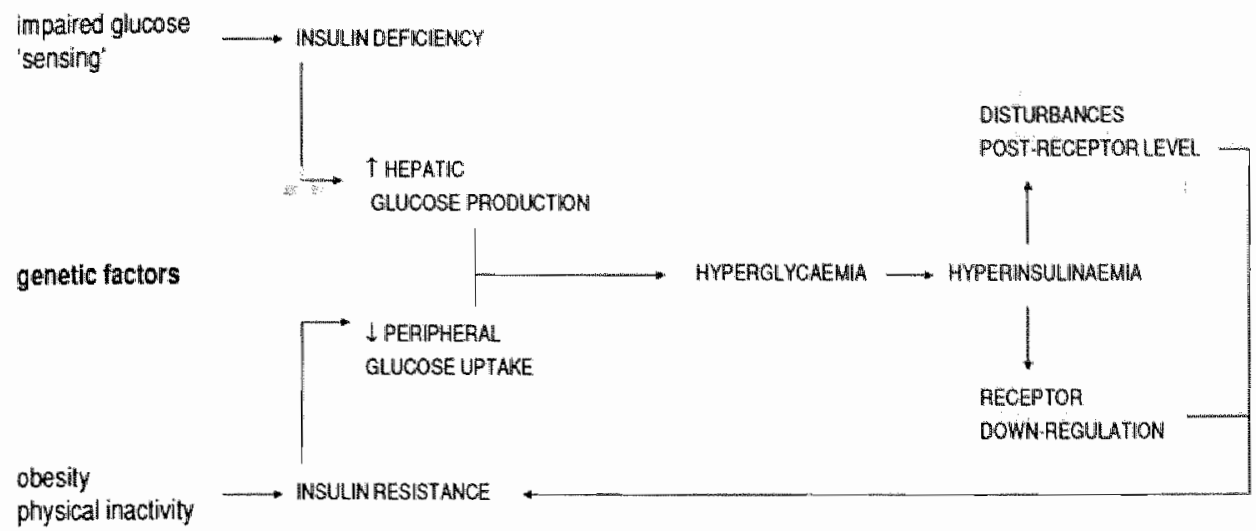

Figure 5. Pathophysiology of type 2 diabetes: the simplified view.

\section{GLUCOSE TOXICITY}

A few years ago it was suggested that hyperglycaemia per se could directly impair the secretion of insulin and reduce the insulin-mediated uptake of glucose in peripheral tissues $(42,53)$. This is called the theory of 'glucose toxicity'. It supposes that the basic metabolic derangements in patients with type 2 diabetes are pertubated by the resulting hyperglycaemia (figure 5). Insulin release after intravenous administration of glucose is already impaired in persons with only mild fasting hyperglycaemia (blood glucose $>6.4 \mathrm{mmol} / \mathrm{l}$ ). With blood glucose levels exceeding $11 \mathrm{mmol} / \mathrm{l}$ the $\mathrm{B}$-cells become unresponsive to other secretagogues. The disturbances in insulin release are restored by reducing hyperglycaemia and normalizing glycaemic control, independent of the mode of treatment (diet, sulphonylureas, insulin, or phlorizin, a drug induc ing glucuresis) $(54,55)$. There is some experimental evidence suggesting that high glucose levels not only cause functional disturbances, but even may cause irreversible damage to the B-cells. Some, but not all, investigators found that damage could be prevented by reduction of the hyperglycaemia. In addition, in hyperglycaemic states related to obesity insulin resistance is a main feature. Insulin therapy in such cases, and the resulting reduction of blood glucose levels, readily improves insulin action. These beneficial changes may be maintained for a few weeks after insulin withdrawal $(56,57)$. 
Reaven (39) has suggested that type 2 diabetes is not a distinct clinical disorder, but part of a complex of risk factors for cardiovascular disease. This complex comprises disturbances as glucose intolerance, insulin resistance, hyperinsulinaemia, increased very-low-density lipoprotein triglycerides, decreased highdensity lipoprotein cholesterol, and hypertension. This approach has considerable implications for the treatment of patients with type 2 diabetes. It necessitates not only the pursuit of good blood glucose control, but places greater emphasis on the treatment of dyslipidaemia, hypertension and obesity to reduce the risk of coronary heart disease $(58,59)$.

\section{CONSEQUENCES OF TYPE 2 DIABETES LATE COMPLICATIONS}

Secondary complications (table 2 ) are frequently observed in patients with type 2 diabetes (60). Estimations of the prevalence of the various complications differ considerably between studies. In the Netherlands, no good epidemiologic surveys concerning the incidence and prevalence of type 2 diabetes in general, and of its complications in particular, are available. The true risk of cardiovascular disease (and other macrovascular and microvascular sequelae) in type 2 diabetic patients is difficult to assess from the literature because of several reasons:

1. Details on the type of diabetes, mode of treatment, severity of associated dyslipidaemia and hypertension are often not given.

2. Bias is introduced due to selection of patients studied (hospital-based surveys, or patients belonging to the practice of a general practitioner).

3. The duration of diabetes, which is sometimes difficult to assess with certainty in type 2 diabetic patients, is often not recorded or not reported.

4. Between different study populations and racial groups, and even within one country large differences in incidence can be found.

5. An increase of cardiovascular disease can already be found in patients with impaired glucose tolerance.

6. Different tools or devices are used to assess the presence or absence of a complication. For instance, the use of sophisticated doppler measurements may increase the number of patients diagnosed to have peripheral arterial disease. 
Table 2. Consequences of type 2 diabetes meilitus.

1. Diminished quality of life

2. Increased mortality

3. Acute metabolic complications

- hyperlipidaemia

- hyperosmolar non-ketotic coma

4. Chronic complications

- macroangiopathy: ischaemic heart disease

cerebrovascular accidents

peripheral vascular disease

- hypertension, congestive heart failure

- peripheral neuropathy: diabetic foot, pain

- amputations

- autonomic neuropathy: gastroparesis urinary bladder dysfunction

- microangiopathy: retinopathy, nephropathy

- cataract

\section{Macrovascular disease}

The role of diabetes as a risk factor for cardiovascular disease is well established. Annual incidence of cardiovascular disease among diabetic patients is increased almost 3-fold compared to non-diabetic persons. Atherosclerosis in diabetic patients shows identical development compared to non-diabetic persons, but occurs 10-20 years earlier (61). The risk ratios appear to decrease slightly with advancing age. This may be caused by an increased mortality of diabetic patients due to cardiovascular disease at a younger age. Several factors are involved in the pathogenesis of macrovascular abnormalities in type 2 diabetic patients (table 3). Besides these, the diabetic state is a risk factor itself.

It seems that the development and extent of macroangiopathy is not related to the severity of diabetes $(61,62)$, nor to the form of therapy. Both oral and insulin therapy have failed to lower cardiovascular mortality compared to diet alone (61), although the degree of glycaemic control that was reached might have been insufficient. Some authors have demonstrated a relation between increasing duration of diabetes and the incidence of macrovascular complications; this item however is disputed by others (63). In the Whitehall survey, there was no significant relationship between duration of diabetes and mortality from coro- 
Table 3. Possible factors involving earlier atherosclerosis in type 2 diabetes.

Diabetic factors

Cuassical factors (non-specific)

1. abnormal lipoprotein metabolism

2. 'non-enzymatic' glycosylation of proteins

3. glucose toxicity

4. hyperinsulinaemia

5. genetic factors
1. hypertension

2. hypercholesterolaemia.

3. obesity

4. sedentary lifestyle

5. smoking

nary heart disease. Thus, it was stated that type 2 diabetes and coronary heart disease are associated disorders, but that an increased risk of coronary heart disease precedes the development of hyperglycaemia $(64,65)$. However, one confounding factor is the fact that elevated blood glucose levels may already be present for several months or even years before the diagnosis of type 2 diabetes is made. Hence, the true duration of type 2 diabetes can not easily be estimated. As in non-diabetic individuals there exists a clear relationship between the prevalence of macroangiopathy and the age of the patient.

\section{Hypertension}

Hypertension is a well-known risk factor for the development of cardiovascular complications. The combination of hypertension and diabetes means a higher risk for retinopathy, nephropathy, myocardial infarction, stroke and peripheral vascular disease. Both diseases occur quite often in one person. Diabetic patients show a prevalence of hypertension 1.2-4.7 times that of non-diabetic persons $(66,67)$. Essential hypertension accounts for the majority of cases of hypertension in diabetes mellitus. Diabetic nephropathy, which occurs in every third individual with type 1 and in every fifth individual with type 2 diabetes after 15 years of diabetes, is another important cause of hypertension. Treatment of hypertension seems to decrease the risk for cardiovascular complications in general, and in patients with diabetic nephropathy it was already shown that normalization of an elevated blood pressure can slow down the decline of kidney function. However, there are no studies yet to establish whether effective antihypertensive treatment may prevent the development or progression of other diabetic angiopathic complications such as retinopathy. 


\section{Dyslipidaemia}

Lipid abnormalities are often found in type 2 diabetic patients. Elevations of both VLDL ("very-low-density-lipoproteins') and -less frequently- LDL ("lowdensity-lipoproteins') are reported, as well as decreases in the levels of HDL ('high-density-lipoproteins') (68,69). An increase in VLDL-levels occurs as a consequence of increased synthesis and secretion by the liver, combined with decreased clearance from the circulation. VLDL contain greater amounts of triglycerides. Increased synthesis probably is caused by a higher supply of fatty acids to the liver due to insufficient suppression of peripheral lipolysis based on insulin insensitivity. VLDL clearance is lower due to reduced activity of the enzyme lipoprotein lipase (LPL) (70). Improved diabetic control increases LPL activity, and stimulates VLDL breakdown. The mechanisms responsible for elevated LDL and lower HDL levels are poorly understood (71).

In diabetic patients, elevated triglyceride levels seem to be an independent risk factor for the development of macrovascular disease. In epidemiologic studies it was shown that about $30-35 \%$ of diabetic men and $30 \%$ of women, aged 50-65 years, showed combined hyperlipidaemia, whereas half of these persons also have low HDL concentrations (72). Combination of diabetes and hypercholesterolaemia conveys a very high risk of developing coronary heart disease and of mortality due to myocardial infarction (73).

\section{Hyperinsulinaemia}

Several studies have suggested a relationship between hyperinsulinaemia and ischaemic heart disease (74). Hyperinsulinaemia is associated with a number of cardiovascular risk factors, i.e. high blood pressure, raised triglyceride- and LDL-cholesterol levels, and lower HDL-levels (75). Insulin stimulates arterial smooth muscle cell proliferation, promotes lipid uptake and synthesis in the arterial vascular wall (76), and possibly increases platelet aggregation (77). Although treatment with exogenous insulin may result in high peripheral insulin levels, the hyperglycaemia found in unsatisfactorily controlled diabetics may be more damaging in the longer term.

\section{Non-enzymatic glycosylation}

With elevated blood glucose levels glycosylation of proteins will occur. These so-formed Schiff bases then rearrange and will form stable glycosylation products (Amadori rearrangements). Some of these 'early' glycosylation products undergo a complex series of chemical reactions, which will result in the formation of irreversible advanced glycosylation end-products. These products accumulate by forming covalent bonds with amino groups of other proteins, resulting in irreversible changes of function of the various tissue (vessel wall, 
collagenous tissue). Cross-linking of extravasated glycosylated plasma lipoproteins has been suggested to play a major role in the development of atherosclerosis in diabetes (78).

\section{Aldose reductase}

The polyol pathway has been implicated in the develpoment of diabetic complications, especially in neuropathy and vasculopathy. In the tissues, glucose is converted to sorbitol by the enzyme aldose reductase. Accumulation of sorbitol may result in myo-inositol depletion, which impairs Na,K-ATPase activity through a decrease of intracellular protein kinase $C$ activity (79). This is associated with slowing of nerve conduction, capillary basement membrane thickening, and increased leakage of proteins from the vascular compartiment to the interstitium (80).

\section{Coronary heart disease}

In general, a two- to three-fold increase of morbidity and mortality attributed to coronary heart disease (CHD) is demonstrated in diabetic patients over 45 years of age compared with the non-diabetic population (81). The prevalence of CHD is already 3 times elevated in newly-diagnosed non-insulin-dependent diabetes as compared with control subjects (82), and may be as high as $30-40 \%$ in this group or among patients with longer term diabetes (83). Diabetic patients have a greater number of vessels involved by coronary artery disease, and an increased extent of fatty streaks, raised atherosclerotic and advanced calcified lesions. CHD is the cause of death in as many as 40-50\% of type 2 diabetic patients $(61,83)$.

As recorded in the Framingham Study, the incidence of coronary heart disease was 39.1 per 1000 in men with diabetes between 45 and 74 years, and 27.2 per 1000 for women. In the population of patients without diabetes these figures were 19.1/1000 and 10.2/1000, respectively (81). Asymptomatic myocardial ischaemia, which is an independent predictor of mortality in patients with symptomatically controlled angina pectoris, has been demonstrated in $35 \%$ of a group of type 2 diabetic patients $(84,85)$. Prognosis after myocardial infarction is poorer in diabetic patients compared to non-diabetic subjects, with a higher risk of developing cardiogenic shock or arrhythmias. Poor metabolic regulation may aggravate the prognosis for myocardial infarction (86). 


\section{Peripheral vascular disease}

There exists an increased prevalence of peripheral vascular disease (PVD) among diabetic patients compared to nondiabetic subjects. The incidence and prevalence figures vary because of differences in definition of PVD, the type of diabetes in the patients studied, their age and treatment, and the study methods used. In diabetic PVD the vessels most frequently involved are those below the knee, the tibials and peroneals, and their smaller branches, while the occlusions are often multisegmental. It is evidenced by the presence of intermittent claudication, absence of dorsalis pedis pulses, or arterial calcification (87). At time of diagnosis (when hyperglycemia usually is present for a number of years) $8 \%$ of type 2 diabetic patients have evidence of PVD. After 10 years the cumulative incidence averages $30 \%(88)$, and after 20 years even $50 \%(89)$. Other studies (90) give even higher prevalence figures: absence of $\geq 2$ peripheral vascular pulses was noted in $60 \%$ of the diabetic patients between 60 and 79 years, against $40 \%$ in the nondiabetic individuals. In the Framingham study diabetes was associated with a two- to threefold excess risk of intermittent claudication (81). The presence of PVD predisposes for acute cardiovascular events, such as myocardial infarction and stroke (91).

Sequelae of PVD may be serious infections or ulcers and gangrene, sometimes necessitating amputation (88). The amputation rate in individuals with diabetes is 15 times that of people without diabetes (92). This implies that yearly 1500 amputations are performed in diabetic patients in the Netherlands. Outcome of patients after lower-extremity amputation is rather poor: the 3-year survival rate averages $50 \%$ (93). Smoking, hypertension, hyperlipidaemia, hyperglycaemia and neuropathy are known risk factors for amputation (89). Improvement of patient education and foot-care may prevent at least $50 \%$ of the amputations within the diabetic population.

\section{Cerebrovascular disease}

Stroke occurs two to six times more frequently in diabetic patients compared with nondiabetic subjects $(66,94)$. Type 2 diabetic patients show a 2 - to 4 -fold increase in risk for death from cerebrovascular disease compared to nondiabetic persons. Stroke accounts for $15 \%$ of all deaths in patients with type 2 diabetes (83). The extent and degree of brain damage, as well as short term mortality after an ischaemic stroke is higher in diabetic patients than in nondiabetic persons (94), probably due to the deleterious effects of hyperglycaemia itself (95). Diabetic stroke patients more often have a history of hypertension than diabetic control patients without stroke (96). A greater proportion of diabetic 
patients, who have recovered from stroke, will be dependent on others for daily living activities, or admitted to a nursing home for continuous care $(97,98)$.

\section{Microvascular disease}

\section{Retinopathy}

Retinopathy is observed in 20 to $50 \%$ of type 2 diabetic patients, depending on the duration of follow-up after diagnosis of diabetes has been made (99). Almost $80 \%$ of patients with diabetes diagnosed at age 30 or older (mainly type 2 diabetic patients) had retinopathy after 15 or more years (100). However, at presentation already $10-20 \%$ of patients may have signs of retinopathy. The development of diabetic retinopathy is related to long-term glycaemic control (101-104). The severity of retinopathy was related to a younger age at diagnosis, higher systolic blood pressure, use of insulin and presence of proteinuria (100). Again in the Framingham study, a clear association was observed between the presence of diabetic retinopathy and the occurrence of cardiovascular events (coronary heart disease, stroke, claudication) (105).

\section{Nephropathy}

It is estimated that $60 \%$ of all patients with end-stage renal disease caused by diabetes have type 2 diabetes. The incidence of diabetic nephropathy is however lower $(0-15 \%)$ in type 2 compared to type 1 diabetic patients (106). The presence of microalbuminuria is a strong predictor of mortality in type 2 diabetic patients, especially due to cardiovascular disease $(107,108)$. Only 5-10\% of them die from renal disease. Progression from micro- to macroalbuminuria may proceed rather rapidly, although considerable intraindividual variation exists (109).

\section{TREATMENT OF PATIENTS WITH TYPE 2 DIABETES}

Treatment of patients with type 2 diabetes aims at several goals (110-113):

- relieve of complaints of hyperglycaemia

- improvement in quality of life

- improvement of metabolic derangements (table 4):

blood glucose control

lipid disturbances

hyperinsulinaemia

- reduction of increased body weight 
- reduction of increased blood pressure

- reduction of incidence of late complications

It is essential to educate and motivate patients for optimal therapy. Many patients with type 2 diabetes may have frank hyperglycaemia and are prone to develop diabetic complications more rapidly, yet specific symptoms due to the hyperglycaemia seldomly are experienced. A number of therapeutic possibilities exist in the treatment of patients with type 2 diabetes. Dietary advices, aiming at reduction of body weight, and encouragement of regular physical exercise $(114,115)$ form the comerstone of treatment. In addition, drugs may be prescribed, which decrease the postprandial blood glucose increase, stimulate insulin secretion or improve peripheral insulin action. In a number of cases, administration of insulin may be necessary.

Table 4. Goals of therapy in type 2 diabetes.

\begin{tabular}{|c|c|c|c|}
\hline & Good & Fair & Poor \\
\hline \multicolumn{4}{|l|}{ Body mass index $\left(\mathrm{kg} / \mathrm{m}^{2}\right)$} \\
\hline male & $22-25$ & $25-27$ & $>27$ \\
\hline female & $22-24$ & $24-26$ & $>26$ \\
\hline \multicolumn{4}{|l|}{ Blood glucose $(\mathrm{mmol} / 1)^{\#}$} \\
\hline fasting & $4.4-6.7$ & $6.7-8.0$ & $>8.0$ \\
\hline postprandial & $4.4-9.0$ & $9.0-11.0$ & $>11.0$ \\
\hline $\mathrm{HbA}_{1}(\%)^{*}$ & $<8.0$ & $8.0-9.5$ & $>9.5$ \\
\hline Total cholesterol (mmol/li) & $<5.2$ & $5.2-6.5$ & $>6.5$ \\
\hline HDL-cholesterol (mmol//) & $>1.1$ & $0.9-1.1$ & $<0.9$ \\
\hline Triglycerides (mmol/l) & $<1.7$ & $1.7 \cdot 2.2$ & $>2.2$ \\
\hline \multicolumn{4}{|l|}{ Blood pressure (mmHg) } \\
\hline systolic & $<140$ & $140-160$ & $>160$ \\
\hline diastolic & $<85$ & $85-100$ & $>100$ \\
\hline
\end{tabular}

\footnotetext{
*HbAlc: value x 0.8 ;

\#dependent on age and specific goals.
} 


\section{Dietary advices}

The nutritional composition of the diabetic diet is similar to the diet advised for the general population by the Dutch government (116). Diet is the most difficult aspect of treatment (table 5); compliance with the diet is generally low. The amount of calories should be such, that the desirable ('ideal') body weight can be achieved and maintained (117). This means a restriction of energy intake for the obese patients, at an average of $500-1000 \mathrm{kcal}$ below requirements. Although initial dietary prescriptions can result in improved control when serious dietary errors are made (118), weight reduction is necessary to achieve and maintain improved metabolic control on the long term (119-122). Fat intake in the Western population is high; advices concerning fat usually imply a restriction of the intake, ideally to $30 \%$ of total energy intake, with less than $10 \%$ in the form of saturated fatty acids, about 6 to $8 \%$ in the form of polyunsaturated fatty acids, and the remainder as mono-unsaturated fatty acids. Cholesterol intake should not exceed $300 \mathrm{mg}$ per day. Daily protein need averages $12-20 \%$ of total dietary energy content.

The amount of carbohydrate should be liberalized to 55-60\% of total energy intake, comprising especially complex carbohydrates and foods with high fibre content. Addition of sucrose to the diet (up to 50 grams per day) does not worsen blood glucose control $(123,124)$, nor leads to more marked hypertriglyceridaemia (125). Thus, fastly-resorbed (refined) sugars may be allowed up to $5 \%$ of carbohydrate energy intake if incorporated in the normal meals in patients with normal body weight, who do not have carbohydrate induced hyperlipidaemia. For the obese patients the use of sugar is not advisable.

Table 5. Points to consider when prescribing a diabetic diet

1. Treatment: diet, oral hypoglycaemic agents, insulin

2. Body weight

3. Normal daily activities

4. Usual dietary intake and meal pattern

5. Support from family

6. Cooking and shopping abillities; dependence on family or community services

7. Other medical problems or physical disabilities

8. Intelligence; ability to understand the role of diet in the control of diabetes, ability to follow a dietary advice 
Partial replacement of complex carbohydrates with mono-unsaturated fatty acids may improve blood glucose control, lower plasma triglycerides and increase HDL-cholesterol (126). The long term effects of diets high in monounsaturated fatty acids still needs to be determined.

Diets with a very low amount of calories have been used in several instances $(127,128)$. Although on short term a striking reduction of body weight may be achieved, together with improvement of dyslipidaemia and blood pressure (129), there is little evidence that the weight loss actually is maintained on longer term (130).

\section{Adjuvants to dietary therapy}

The use of additional medication may help to control postprandial blood glucose increase, or to achieve weight reduction. The effects of fiber additives, such as guar, have been disappointing, both because of its unpleasant gastrointestinal side-effects, and the little effects on blood glucose control. Their effects on plasma lipids are generally beneficial $(131,132)$. Drugs that exert a competitive inhibition of the enzyme $\alpha$-glucosidase in the intestine may reduce the postprandial blood glucose rise $(133,134)$. Their place in the long-term therapy of patients with type 2 diabetes has not been established yet. The effects of fish-oil supplementation may be beneficial in case of dyslipidaemia, but detrimental for blood glucose control (135).

\section{Oral hypoglycaemic therapy}

Oral hypoglycaemic agents are used in the diabetic patients, who cannot achieve adequate glycaemic control with diet alone. Sulphonylureas (SU) are first line therapy. These drugs promote the release of insulin from the B-cells (136). This effect is possibly evoked by specific receptors on these cells. In addition to this direct effect, sulphonylurea therapy improves B-cell function as a consequence of the reduced blood glucose levels $(53,55,137)$. The improvement of insulin action seen during SU therapy are still a matter of debate: some authors argue that $\mathrm{SU}$ exert their major effects on the liver by improving insulin-mediated glycogen formation and lipogenesis and by inhibiting glycogenolysis and gluconeogenesis (138), while others (139) suggested that its effects are secondary to an improvement of postreceptor defects. A decrease of hepatic insulin extraction may be secondary to the increased rate of insulin secretion (136). 
There is some evidence that chronic treatment with SU may desensitize the B-cells to this stimulus (139). High concentrations of SU may inhibit insulin biosynthesis in vitro (140), and perhaps also in vivo $(139,141)$. Resorption of SU may decrease with higher prevailing blood glucose levels (142).

A variety of available SU compounds differ in potency, onset of action and duration of effect (138). Subjective side-effects of sulphonylurea are usually low. Hypoglycaemic reactions are the most serious side-effects, and these may be very prolonged in elderly patients, leading to neurologic damage and even death $(136,137,143)$. The risk of hypoglycaemia is the highest with long-acting compounds, such as chlorpropamide and glibenclamide. Drug interactions (aspirin, sulphonamides), reduced energy intake, and alcohol consumption are precipitating factors (136).

The mechanisms of action of metformin are a matter of debate $(136,144)$. Increasing glucose transport across the cell membrane in skeletal muscle is one of the main effects (145), together with a suppression of hepatic glucose production (136), and reduced gastrointestinal absorption of glucose. Several authors, however, failed to show any improvement of insulin action with metformin $(146,147)$. Metformin has beneficial effects on elevated LDL-cholesterol and plasma triglyceride levels. The drug rarely causes hypoglycaemia or weight gain. Side effects (gastrointestinal discomfort, diarrhoea) occur in $10-20 \%$ of patients. Metformin is contraindicated in patients with renal or hepatic insufficiency, and patients with cardiovascular abnormalities in whom tissue hypoperfusion and anoxia and altered cellular metabolism may cause lactic acid production.

Comparison of sulphonylurea and metformin slightly favoured the glucoselowering effect of sulphonylurea, although weight loss was greater during metformin (148-150). In the U.K. Prospective Diabetes Study metformin was compared with sulphonylurea in the obese patients only, and resulted in nearly similar reduction of fasting blood glucose $(151,152)$.

\section{Secondary failure to oral agents}

Failure to oral hypoglycaemic therapy after an initial favourable response may occur in approximately $5-10 \%$ of patients on a yearly basis (153). However, the reported frequency varies considerably, because of the lack of a widely accepted definition of secondary drug failure, and how strict the levels of blood glucose are regarded acceptable or unacceptable. Several factors can attribute to the occurrence of secondary failure, both patient- and disease-related, such as non-compliance with diet or drug therapy, inadequate dose of drug, interruption of drug treatment, intercurrent illness or real failure (islet B-cell "exhaustion") (152-154, table 6). 
1. non-compliance with diet

2. non-compliance with drug therapy

3. inadequate dose of drug

4. interruption of drug treatment

5. intercurrent illness

6. disturbances resorption of sulphonylurea?

7. reduced B-cell responsiveness to drug

8. real failure (islet B-cell "exhaustion")

Patients failing to sulphonylureas had a lower relative body weight, and lower basal and glucagon-stimulated plasma C-peptide concentrations than patients who were well controlled. There was not a critical $\mathrm{C}$-peptide level discriminating between nonresponders and responders. A subset of patients with specific immunologic characteristics could be determined with a high risk of secondary drug failure and subsequent insulin requirement (154). Recently, it was demonstrated that occurrence of secondary failure was related to the diabetes itself, and probably not due to patient-related factors, such as daily energy intake or physical activity (155).

\section{Insulin therapy}

In patients compliant with diet, who show deterioration of blood glucose control on oral hypoglycaemic agents, temporary or permanent insulin therapy is warranted (156). This treatment however poses new problems, such as weight gain, and the risk of hypoglycaemias. Further, the occasional necessity of administering high insulin doses, especially in obese patients, may result in high peripheral insulin levels, which are associated with an increased risk for the development of atherosclerosis and hypertension.

Initial use of insulin in a type 2 diabetic patient is warranted, when there is gross evidence of deficient insulin secretion and action. This can be assessed by biological factors, such as the presence of ketosis or ketonuria, weight loss, or severe hyperglycaemic symptoms, or by biochemical factors, when fasting blood glucose levels exceed $15 \mathrm{mmol} / 1$, or stimulated C-peptide levels are lower than $0.2 \mathrm{nmol} / \mathrm{l}$. 
There are few studies which compare the effects of sulphonylurea and insulin on blood glucose control in type 2 diabetic patients who have failed on dietary therapy. Tolazamide and insulin equally improved blood glucose control in obese patients (157). In non-obese type 2 diabetic patients insulin therapy resulted in better blood glucose control than sulphonylureas $(158,159)$. In the U.K. Prospective Diabetes Study an equal effect of sulphonylurea and insulin on blood glucose control in both obese and non-obese patients was found.

Various insulin injection schemes have been proposed, such as once daily regimes of long-acting insulin on waking or retiring, or twice-daily injections. In a small number of patients even multiple subcutaneous injections or CSII have been employed. Twice-daily administration of intermediate-acting or a mixture of fast- and intermediate-acting insulin can be safely instituted on an outpatient base as first regimen (160). In the majority of patients this regimen can optimize blood glucose control. More complicated schemes, such as multiple daily injections or combination of insulin and oral hypoglycaemic agents may be warranted in the younger type 2 diabetic patients, in whom the twice daily regimen fails to restore adequate control (160).

Weight gain during insulin treatment may be troublesome, especially in the obese patient. A small increase in body weight is caused by rehydration, salvage of glucosuric calories, and a positive nitrogen balance. Overinsulinization with the resulting occurrence of overt or inapparent hypoglycaemias, direct stimulation of the appetite by insulin, reduction of energy expenditure and reducton in hyperglycaemic satiety are possible explanations for inadvertent weight gain. Hypoglycaemia during insulin therapy was reported to be as frequent as with chlorpropamide in the U.K. Prospective Study. The incidence of severe hypoglycaemia in insulin-treated patients is reported to be 0.07 per patient and year; this seems to be lower in insulin-treated type 2 diabetic patients (161).

The combined insulin-sulphonylurea therapy in patients with type 2 diabetes mellitus may have several advantages, such as lower insulin requirement, improved and more stable blood glucose control, and less hyperinsulinaemia, and therefore possibly a lower risk for the progression of atherosclerosis (162, 163). The mechanisms by which metabolic control is improved involve an increase in endogenous insulin secretion and possibly extrapancreatic actions of the sulphonylureas on liver and muscle (164). The possible negative effects on lipoprotein metabolism still have to be further explored. 


\section{Treatment of dyslipidaemia}

In the treatment of diabetic dyslipidaemia dietary advices, weight reduction, regular physical exercise and cessation of smoking take a central place, but their effect is only limited. For drug therapy HMG CoA reductase inhibitors may be the drugs of choice in type 2 diabetic patients with elevated LDL-cholesterol and moderate hypertriglyceridaemia $(165,166)$. Alternatively "gemfibrozil (167) or other fibrate derivatives (168) may be more beneficial in patients with severe hypertriglyceridaemia and moderately elevated LDL-cholesterol. These drugs also increase HDL levels to a greater extent than the inhibitors of cholesterol synthesis. Although the combination of HMG CoA reductase inhibitors with gemfibrozil looks very promising considering the mode of action of these drugs, caution should be taken because of recent reports concerning the occurrence of side-effects, such as severe rhabdomyolysis (169).

\section{Treatment of elevated blood pressure}

In diabetes, there is a relationship between hyperinsulinaemia, insulin resistance and hypertension as well (170). This stresses the importance of antihypertensive drugs that, ideally, should not alter glucose and lipid metabolism (171). However, drug treatment of hypertension in patients with diabetes mellitus may cause problems. Often used drugs as diuretics and beta-adrenoreceptor blocking agents have a clearly negative effect on glucose and lipoprotein metabolism (172). Thiazide diuretics may lead to deterioration of diabetic control, possibly mediated through hypokaliaemia with impaired release of insulin and an increase in insulin resistance. Most diuretics also cause an increase of plasma cholesterol and triglycerides. Although studies in non-diabetic hypertensive patients have shown that these alterations in lipoproteins may be transient, this is not shown for diabetes. Betablockers can worsen glucose tolerance by a direct inhibition of insulin secretion and/or increased alpha-receptor-mediated hepatic glycogenolysis. Further, they can mask some of the signs and symptoms of low blood glucose levels and also impair the recovery from hypoglycaemia. Betablockers have also tumed out to increase serum triglyceride levels and reduce HDL-cholesterol levels. Another adverse effect of betablockers is impotence, especially, but not only, in patients with autonomic neuropathy. The alpha adrenergic inhibitor prazosin, the vasodilator hydralazine and central sympatholytic agents as methyldopa and clonidine can lead to orthostatic hypotension. These drugs have no unfavourable effect on glucose tolerance or the lipid profile. The effects of newer antihypertensive drugs as ACE-inhibitors $(173,174)$ and calcium entry blockers on glucose 
tolerance and the lipid profile have not been fully established yet. Literature data so far have indicated no important negative effects of both drugs on glucose tolerance, neither in non-diabetic persons with hypertension, nor in patients with diabetes mellitus $(175,176)$. Hence, these drugs appear to be a good choice for use in diabetic patients with cardiovascular diseases.

\section{THE COSTS OF TYPE 2 DLABETES MELLITUS}

Estimations on the social impact of type 2 diabetes mellitus have to take into account the economic burden of the disease as well as its related morbidity and mortality. Thus, the total economic costs in 1986 in the U.S.A. regarding diabetes care, costs attributable to an excess prevalence of vascular complications, and productivity lost due to disability, morbidity and premature mortality were estimated to amount 20 billion U.S. dollar (177). In this study, prevalence of type 2 diabetes was estimated to be 55 per 1000 persons between 45 and 65 years, and 100 per 1000 persons older than 65 years. Thus, a total number of 5.8 million persons were suffering from diabetes. The yearly costs of diabetes care to the National Health Service of 279 million U.K. pounds may be an underestimation (178). There are clear signs of a rapidly rising prevalence of persons with type 2 diabetes, both due to a real increase and to earlier detection of the disease. In addition, to every known diabetic subject there is another person whose diabetes is still undiscovered (179). It is estimated that within 15 years the number of persons in the Netherlands suffering from type 2 diabetes will have increased with $40 \%$. This will place a large burden on financial and personal resources of the (Dutch) Health Care system (180).

\section{REFERENCES}

1. Espinal J. Understanding insulin action: principles and molecular mechanisms. 1989, Ellis Horwood Limited, Chichester, UK.

2. WHO Expert Committee on Diabetes Mellitus. Technical Report Series 646. Geneva: World Health Organization, 1985.

3. Defronzo RA. The triumvirate: beta-cell, muscle, liver: a collusion responsible for NIDDM. Diabetes $1988 ; 37: 667-687$.

4. Efendic S, Luft R, Wajngot A. Aspects of the pathogenesis of type 2 diabetes. Endocrine Rew 1984; 5: 395-410.

5. DeFronzo RA, Ferrannini E, Koivisto $V$. New concepts in the pathogenesis and treatment of noninsulin-dependent diabetes mellitus. Am J Med 1983; 74 (suppl): 52-81. 
6. Bogardus C, Lillioja S, Howard BV, Reaven GM, Mot D Relationships between insulin secretion, insulin action, and fasting plasma glucose concentrations in nondiabetic and non-insulin-dependent diabetic subjects. J Clin Invest $1984,74: 1238-1246$.

7. Robertson RP. Type II diabetes, glucose "non-sense", and islet desensifization. Diabetes $1989 ; 38: 1501-1505$.

8. Ward WK, Beard JC, Halter JB, Pfeifer MA. Porte D Jr. Pathophysiology of insulin secretion in non-insulin dependent diabetes mellitus. Diabetes Care 1984; 7: 491-502.

9. DeFronzo RA, Simonson D, Ferrannini E. Hepatic and peripheral insulin resistance: a common feature of type II (noninsulin-dependent) and type I (insulin-dependent) diabetes mellitus. Diabetologia 1982; $23: 313-319$.

10. Olefsky JM. The insulin receptor: its role in insulin resistance in obesity and diabetes. Diabetes $1976 ; 25: 1154-1165$.

11. Rizza RA, Mandarino LJ, Gerich JE. Mechanism and significance of insulin resistance in non-insulin-dependent diabetes mellitus. Diabetes 1981;30:990-995.

12. Shulman GI, Rothman DL, Jue T, Stein P, DeFronzo RA, Shulman RG. Quantitation of muscle glycogen synthesis in normal subjects and subjects with non-insulin-dependent diabetes by ${ }^{13} \mathrm{C}$ nuclear magnetic resonance spectroscopy. New Engl I Med 1990; 322 : 223-228.

13. Bogardus C, Lillioja $\mathrm{S}$. Where all the glucose doesn't go in non-insulin-dependent diabetes mellitus. New Engl J Med 1.990; 322; 262-263.

14. Meglasson MD, Matschinsky FM. Pancreatic islet glucose metabolism and regulation of insulin secretion. Diabetes/Metab Rev 1986;2:215-241.

15. Lenzen S, Panten U. Signal recognition by pancreatic B-cells. Biochem Pharmac 1988 , $37: 371-378$.

16. Saad MF, Knowler WC, Pettitt DJ, Nelson RG, Mott DM, Benmett PH. Sequential changes in serum insulin concentration during development of non-insulin-dependent diabetes. Lancet 1989; 1: 1356-1359.

17. Temple RC, Carrington CA, Luzio SD, et al. Insulin deficiency in non-insulin-dependent diabetes. Lancet 1989; i: 293-295.

18. Hosker JP, Rudenski AS, Burnett MA, Matthews DR, Turner RC. Similar reduction of first-and second-phase B-cell responses at three different glucose levels in type II diabetes and the effect of gliclazide therapy. Metabolism 1989; 38; 767-772.

19. Pfeifer MA, Halter JB, Porte D Jr. Insulin secretion in diabetes mellitus. Am J Med 1981 ; 70: $579-588$.

20. Ward WK, Bolgiano DC, McKnight B, Halter JB, Porte Jr D. Diminished B cell secretory capacity in patients with non-insulin-dependent diabetes mellitus. J Clin Invest 1984; 74: $1318-1328$

21. Van Haeften TW. Insulin secretion; stimulation by arginine and hyperglycemic glucose clamp (Thesis). 1990, Amsterdam.

22. Polonsky KS, Given BD, Hirsch LJ, et al. Abnormal patterns of insulin secretion in non-insulin-dependent diabetes mellitus. N Engl J Med 1988; 318: 1231-1239.

23. O’Rahilly S, Tumer RC, Mathews DR. Impaired pulsatile secretion of insulin in relatives of patients with non-insulin-dependent diabetes. N Engl J Med 1988; $318: 1225-1230$.

24. Brunzell JD, Robertson RP, Lerner RL, Hazzard WR, Ensinck JW, Bierman EL, Porle D Jr. Relationships between fasting plasma glucose levels and insulin secretion during intrawenous glucose tolerance tests. J Clin Endocrinol Metab 1976; 42: 222-229. 
25. Gjessing HI, Reinholdt B, Pedersen $\mathrm{O}$. The plasma $\mathrm{C}$-peptide and insulin responses to stimulation with intravenous glucagon and a mixed meal in well-controlled type 2 (non-insulin-dependent) diabetes mellitus: dependency on actuty established hyperglycaemia Diabetologia 1989; $32: 858-863$.

26. Scheen $\mathrm{AJ}$, Paolisso $\mathrm{G}_{\text {, Juchmes }} \mathrm{J}$, Lefebvre PJ. Insulin secretion rate after intravenous glucagon injection: kinetics reproducibility and potentiation by increasing intial blood glucose levels. Diabetologia 1989; 32:538A.

27. Lefebvre PJ, Paolisso G, Scheen AJ, Henquin JC. Pulsatility of insulin and glucagon relesise: physiological significance and phamacological implications. Diabetologia 1987; 30: $443-452$.

28. Lang DA, Mathews DR, Turner RC. Brief, irregular oscillations of basal plasma insulin and glucose concentrations in diabetic man. Diabetes $1981 ; 30: 435-439$.

29. Rahier J. The diabetic pancreas: a pathologist"s view. In: The pathology of the endocrine pancreas in diabetes. Jefebvre PJ, Pipeleers DG (eds). Springer-Verlag, Berlin, 1988.

30. Opie $\mathrm{E}$. The relation of diabetes mellitus to lesions of the pancreas. Hyaline degeneration of the islets of Langerhans. J Exp Med 1901; 5:527-540.

31. Westermark P, Wernstedt $C$, Wilander $E$, Hayden DW, $\mathrm{O}^{\prime}$ Brien TD, Johnson KH. Amyloid fibrils in human insulinoma and islets of Langerhans of the diabetic rat are derived from a neuropeptide-like protein also present in nomal islet cells. Proc Natl Acad Scil 1987; $84: 3881-3885$.

32. Clark A. Islet amyloid and type 2 diabetes. Diabetic Med 1989; 6: 561-567.

33. Maloy AL, Longnecker DS, Greenberg ER. The relation of islet amyloid to the clinical type of diabetes. Human Pathol 1981; 12:917-922.

34. Clark A, Saad MF, Nezzer T, et al. Islet amyloid polypeptide in diabetic and non-diabetic Pima Indians. Diabetologia 1990; 33: 285-289.

35. Brain SD, Williams TJ. Substance $P$ regulates the vasodilator activity of calcitonin gene-related peptide. Nature 1988; 335: 73-75.

36. Molina JM, Cooper GJS, Leighton B, Olefsky JM. Induction of insulin resistance in wivo by amylin and calcitonin gene-related peptide. Diabetes $1990 ; 39: 260-265$.

37. Johnson $\mathrm{KH}$, O'Brien TD, Betsholtz C, Westermark. P. Islet anyloid, islet-amyloid polypeptide, and diabetes mellitus. N Engl J Med 1989; 321: 513-518.

38. Reaven GM. Insulin secretion and insulin action in non-insulin-dependent diabetes mellitus: which defect is primary? Diabetes Care 1984; 7 (suppl. 1): 17-24.

39. Reaven GM. Role of insulin resistance in human disease. Diabetes 1988; 37: 1595-1607.

40. Chen $Y$, Swislocki A, Reaven G. Resistance to insulin suppression of plasma free fatty acid concentrations and insulin stimulation of glucose uptake in non-insulin-dependent diabeles mellitus J Clin Endocrinol Metabol 1987; 64: 17-21.

41. Fraze E, Domer CC, Swislocki ALM, Chiou Y-AM, Chen Y-DI, Reaven GM. Ambient plasma free fatty acid concentrations in non-insulin-dependent diabetes mellitus: evidence for insulin resistance. J Clin Endocrinol Metabol 1985; $61: 807-811$.

42. Unger RH, Grundy S. Hyperglycaemia as an inducer as well as a consequence of impaired islet cell function and insulin resistance: implications for the management of diabetes. Diabetologia 1985; 28:119-121.

43. Becker AB, Roth RA. Insulin receptor structure and function in normal and pathological conditions. Annu Rev Med 1990; 41: 99.115.

44. Rosen OM. Structure and function of insulin receptors. Diabetes 1989; 38: 1508-1511. 
45. Carpentier $J-L$. The cell biology of the insulin receptor Diabetologia $1989,32: 627-635$.

46. Saltiel AR. Second messengers of insulin action. Diabetes Care 1990, 13:244-256.

47. Olefsky JM, Molina JM. Insulin resistance in man. In: Ellenberg and Rifkin's Diabetes Mellitus: Theory and Practice. Rifkin H., Porte D Jr, Eds; 4 th Edition, Elsevier Science Publishing Co, New Hyde Park, NY, 1990.

48. Olefsky JM, Garvey WT, Henry RR, Brillon D, Mathai S, Freidenberg GR. Cellular mechanisms of insulin resistance in non-insulin-dependent (type II) diabetes. Am J Med $1988 ; 85$ (suppl. 5A): 86-105.

49. Klip A, Paquet MR. Glucose transport and glucose transporters in muscle and their metabolic regulation. Diabetes Care 1990; 13: 228 243 .

50. Kahn BB, Flier JS. Regulation of glucose-transporter gene expression in vitro and in vivo. Diabetes Care 1990; 13:548-564.

51. Kasanicki MA, Pilch PF. Regulation of glucose-transporter function. Diabetes Care 1990; 13: $219-227$.

52. Joost HG, Weber TM. The regulation of glucose transport in insulin-sensitive cells. Diabetologia 1988; $32: 831-838$.

53. Rossetti L, Giaccari A, DeFronzo RA. Glucose toxicity. Diabetes Care 1990; 13:610-630.

54. Hughes TA, Gwyne JT, Switzer BR, Herbst $C$, White $G$. Effects of caloric restriction and weight loss on glycemic control, insulin release and resistance, and atheroselerotic risk in obese patients with type II diabetes mellitus. Am J Med 1984; 77:7-17.

55. Kosaka K, Kuzuya $T$, Akanuma $Y$, Hagura $R$. Increase in insulin response after treatment of overt maturity-onset diabetes is independent of the mode of treatment. Diabetologia 1980; 18: 23-28.

56. Kolterman $O \mathrm{G}$, Olefsky JM. The impact of sulfonylurea treatment upon the mechanisms responsible for the insulin resistance in type II diabetes. Diabetes Care 1984; 7 (suppl.1): $81-88$.

57. Scarlett J, Gray R, Griffin J, Olefsky J, Kolterman OG. Insulin treatment reverses the insulin resistance of type II diabetes mellitus. Diabetes Care 1982; 5: 353-363.

58. Zimmet P. Non-insulin-dependent (type 2) diabetes mellitus: does it really exist? Diabetic Med 1989; 6: 728-735.

59. Editorial. Type 2 diabetes or NIDDM: looking for a better name. Lancet 1989; i: 589-590.

60. Nathan DM, Singer DE, Godine JE, Perlmuter LC. Non-insulin-dependent diabetes in older patients - complications and risk factors. Am J Med 1986:81:837.842.

61. Fein FS, Scheuer J. Heart disease in diabetes. In: Ellenberg and Rifkin's Diabetes mellitus: Theory and Practice. Rifkin H. Porte D Jr, Eds. 4th Edition, Elsevier Science Publishing Co, New Hycle Park, NY, 1990.

62. Keen H, Jarrett RJ, Fuller JH, McCartney P. Hyperglycaemia and arterial disease. Diabetes $1981 ; 30$ (suppl. j: $49-53$.

63. Jarrett RJ. Epidemiology and public health aspects of non-insulin-dependent diabetes mellitus. Epidemiol Rev 1989; 11: 151-171.

64. Jarrett RJ. Type II (non-insulin-dependent) diabetes mellitus and coronary heart disease - chicken, egg or neither? Diabetologia 1984; 126: 99.102.

65. Haffner SM, Stern MP, Hazuda HP, Mitchell BD, Patterson JK. Cardiowascular risk factors in confimed prediabetic individuals - does the clock for coronary heart disease start ticking before the onset of clinical diabetes? JAMA 1990; 263: 2893-2898. 
66. Roccella EJ, on behalf of the Working Group on Hypertension in Diabetes. Statement on hypertension in diaberes mellitus. Arch Intem Med 1987; 147: 830-842.

67. Drury PL. Non-insulin-dependent diabetes and hypertension. In: Baillière's Clinical Endocrinology and Metabolism, Non-insulin-dependent diabetes. Nattrass M. Hale PJ, Eds: London, 1988.

68. Reaven GM. Abnormal hpoprotein metabolism in non-insulin-dependent diabetes mellitus. Am J Med 1987;83 (suppl.3A): 31-40.

69. Betteridge DJ. Lipids, diabetes and vascular disease: the time to act. Diabetic Med 1989; 6: $195-218$.

70. Billingham MS, Milles JJ, Bailey CJ, Hall RA. Lipoprotein subfraction composition in non-insulin-dependent diabetes treated by diet, sulphonylurea, and insulin. Metabolism 1989: $38: 850-857$.

71. Elkeles RS, Rains SGH, Wilson GA, Richmond W. Does glycaemic control affect high density lipoprotein cholesterol (HDL-C) in type II diabetes. A prospective study. Diabetologia 1987; 30 (suppl.): 516 a.

72. Assmann $\mathrm{G}$, Schulte $\mathrm{H}$. Diabetes mellitus and hypertension in the elderly: concomitant hyperlipidemia and coronary heart disease risk. Am J Cardiol 1989; 63: 33H-37H.

73. Rosengren A, Welin L, Tsipogianni A. Wilhelmsen L. Impact of cardiovascular risk factors on coronary heart disease and mortality among middle aged diabetic men: a general propulation study. Br Med J 1989; 299: 1127-1131.

74. Stout RW. Insulin and atheroma - 20-yr perspective. Diabetes Care 1990; 13:631-654.

75. Jarrett RJ. Is insulin atherogenic? Diabetologia $1988 ; 31: 71-75$.

76. Stolar MW. Atherosclerosis in diabetes: the role of hyperinsulinemia. Metabolism 1988; 37 (suppl. 1): 1\%9.

77. Robertson DA, Hale PJ, Nattrass M. Macrovascular disease and hyperinsulinaemia. In: Baillière's Clinical Endocrinology and Metabolism, Non-insulin-dependent diabetes. Nattrass M, Hale PJ, Eds. London, 1988.

78. Brownlee $\mathrm{M}$, Cerami A, Vlassara $\mathrm{H}_{\text {. }}$ Advanced glycosylation end products in tissue and the biochemical basis of diabetic complications. N Engl J Med 1988; 318: 1315-1321.

79. Cogan DG. Aldose reductase and complications of diabetes. Ann Intern Med 1984; 101: $82-91$.

80. Tilton $\mathrm{RG}$, Chang K, Pugliese $\mathrm{G}$, et al. Prevention of hemodynamic and vascular albumin filtration changes in diabetic rats by aldose reductase inhibitors. Diabetes $1989 ; 37$ : $1258-1270$.

81. Kannel WB, McGee DL. Diabetes and cardiovascular risk factors: the Framingham study. Circulation 1979; 59:8-13.

82. Uusitupa $M_{n}$ Sitonen $O$, Aro A, Pyorala $K$. Prevalence of coronary heart disease, left ventricular failure and hypertension in middle-aged, newly diagnosed type 2 (non-insulindependent) diabetic subjects. Diabetologia 1985; $28: 22-27$.

83. Panzram $\mathrm{G}$. Mortality and survival in type 2 (non-insulin-dependent) diabetes mellitus. Diabetologia 1987; $30: 123-131$.

84. Koistinen MI. Prevalence of asymptomatic myocardial ischaemia in diabetic subjects. Brit Med J 1990; 301: 92-95.

85. Chiariello M, Indolfi C, Cotechia MR et al. Asymptomatic transient ST changes during ambulatory ECG monitoring in diabetic patients. Am Heart J 1985; 110: 529-535. 
86. Rytter L, Troelsen S, Beck-Nielsen H. Prevalence and mortality of acute myocandial infarction in patients with diabetes. Diabetes Care 1985;8:230-234.

87. Laakso M, Ronnema $T$, Pyorala K, Kallio V, Punkka P. Penttia I. Atherosclerotic vascular disease and its risk factors in non-insulin-dependent diabetic and non-drabetes subjects in Finland. Diabetes Care 1988; 11: 449-463.

88. Kreines $\mathrm{K}$, Johnson $\mathrm{E}$, Albrink $\mathrm{M}$, et al. The course of peripheral vascular disease in non-insulin-dependent diabetes. Diabetes Care $1985 ; 8: 235-243$.

89. Lewin ME, Sicard GA. Peripheral vascular disease in the person with diabetes. In: Ellenberg and Rifkin's Diabetes mellitus: Theory and Practice. Rifkin H, Porte D Jr, Eds. 4th Edition, Elsevier Science Publishing Co, New Hyde Park, NY, 1990.

90. Pyörälä K, Laakso M. Macrovascular disease in diabetes mellitus. In: Mann J, Pyörảlia $\mathrm{K}$, Teuscher $\mathrm{K}$, eds. Diabetes in epidemiological perspective. Edinburgh-London, Churchill-Livingstone 1983: 183-231.

91. Abbott RD, Brand FN, Kannel WB. Epidemiology of some peripheral arterial findings in diabetic men and women: experiences from the Framingham study. Am J Med 1990; 88: 376-381.

92. Bild DE, Selby JV, Sinnock P, Browner WS, Braveman P, Showstack JA. Lower-extremity amputation in people with diabetes - epidemiology and prevention. Diabetes Care $1989 ; 12: 24 \times 31$

93. Osmundson PJ, O'Fallon WM, Zimmerman BR, Kazmier FJ, Langworthy AL, Palumbo PJ. Course of peripheral occlusive arterial disease in diabetes: vascular laboratory assessment. Diabetes Care 1990; 13: 143-152.

94. Asplund K, Hägg E, Helmers C, Lithner F, Strand T, Wester P.O. The natural history of stroke in diabetic patients. Acta Med Scand 1980; 207: 417-424.

95. Pulsinelli WA, Levy DE, Sigsbee B, Scherer P, Plum F. Increased damage after ischemic stroke in patients with hyperglycemia with or without established diabetes mellitus. Am J Med 1983; 74: 540-544.

96. Lithner F, Asplund K, Eriksson S, Hagg E, Strand T, Wester P-O. Clinical characteristics in diabetic stroke patients. Diabete \& Metabolisme 1988; 14: 15-19.

97. Mooradian AD, Osterweil D, Petrasek D, Morley JE. Diabetes mellitus in elderly nursing home patients. A survey of clinical characteristics and management. J Am Geriatr Soc $1988 ; 36: 391-396$.

98. Wolffenbuttel BHR, Van Vhet S, Knols AJF, Slits WLHH, Sels JPJE, Nieuwenluuijzen Kruseman AC. Clinical characteristics and management of diabetic patients residling in a nursing home. submitted;

99. Pirart J. Diabetes mellitus and its degenerative complications: a prospective study of 4400 patients observed between 1947 and 1973. Diabetes Care 1978; 1; 168-188 and 252-263.

100. Klein R, Klein BEK, Moss SE, Davis MD, De Mets DL. The Wisconsin Epidemiologic study of diabetic retinopathy. III. Prevalence and risk of diabetic retinopathy, when age at diagnosis 30 or more years. Arch Ophthalmol 1984; 102:527-532.

101. Nathan DM, Singer DE, Godine JE, Hodgson C, Harrington $\mathrm{CH}_{3}$ Perlmutter LC. Retinopathy in older type II diabetics. Association with glucose control. Diabetes 1986; 35: 797-801.

102. Klein R, Klein BEK, Moss SE, Davis MD, De Mets DL. Glycosylated hemoglobin predicts the incidence and progression of diabetic retinopathy. JAMA 1988; 260: 28642871. 
103. MeCance DR, Atkinson AB, Hadden DR, Archer DB, Kennedy L. Long-term glycaemic control and diabetic retinopathy. Lancet $1989 ;$ ii: $824-828$.

104. Howard Willams J, Hillson RM, Bron A, Awdry P, Mann J, Hockaday DK. Retinopathy is associated with higher glycaemia in maturity-onset diabetes. Diabetologia $1984 ; 27$; 198-202.

105. Hiller R, Sperduto RD, Podgor MJ, Ferris FL, Wilson PWF. Diabetic retinopathy and cardiowascular disease in type II diabetics. The Framingham heart study and the Framingham eye study. Am J Epidemiol 1988; 128; 402-409.

106. Selby JV, FitzSimmons SC, Newman JM, Katz P, Sepe S, Showstack. I. The natural history and epidemiology of diabetic nephropathy - implications for prevention and control. JAMA 1990; 263; 1954-1960.

107. Mogensen CE. Microalbuminuria predicts clinical proteinuria and early montality in maturity-onset diabetes. New Engl J Med 1984; 310: 356-360.

108. Schmitz $A$, Vaeth M. Microalbuminuria: a major risk factor in non-insulin-dependent diabetes. A 10-year follow-up study of 503 patients. Diaberic Med 1988; 5: 126-134.

109. Cooper ME, Frauman A, O'Brien RCO, Seeman E, Murray RML, Jerums G. Progression of proteinuria in type 1 and type li diabetes. Diabetic Med 1988; $5: 361-368$.

110. Alberti KGMM, Gries FA. Management of non-insulin-dependent diabetes mellitus in Europe: a consensus view. Diabetic Med 1988; $5: 275-281$.

111. Skyler IS. Non-insulin-dependent diabetes mellitus: a clinical strategy. Diabetes Care, 1984; 7 (suppl.1): 118-129.

112. Lipson LG, Lipson M. The therapewtic approach to the obese maturity-onset diabetic patient. Arch Intern Med 1984; 144: 135-138.

113. Jaspan JB. Monitoring and controlling the patient with non-insulin-dependent diabetes mellitus. Metabolism 1987; 36 (suppl. 1): 22-27.

114. Schneider SH, Ruderman NB. Exercise and NIDDM. Technical Review. Diabetes Care $1990 ; 13: 785-789$.

115. Bogardus C, Ravussin E, Robbins DC, Wolfe RR, Horton ES, Sims EAH. Effects of physical training and diet therapy on carbohydrate metabolism in patients with glucose tolerance and non-insulin-dependent diabetes mellitus. Diabetes 1984; 33: 311-318.

116. Heine RJ, Schouten JA. Het diabetes-dieet: niet anders dan voeding voor gezonde mensen. Ned Tijdschr Geneeskd 1984; 128: 1524-1528.

117. Wales JK. Treatment of type 2 (non-insulin-dependent) diabetic patients with diet alone. Diabetologia 1982:23:240-245.

118. Wolfenbuttel BHR, Weber RFA, Verschoor L. Improved insulin secretion in NIDDM by strict dietary control not accompanied by weight reduction. Diab Res Clin Pract 1985; 1: $\$ 607$.

119. Hadden DR, Montgomery DAD, Skelly RJ, et al. Maturity onset diabetes mellitus: response to intensive dietary management. $\mathrm{Br}$ Med J 1975; 2: 276-278.

120. Hadden DR, Blair ALT, Wilson EA, et al. Natural history of diabetes presenting age 40-69 years: a prospective study of the influence of intensive dietary therapy. Quart J Med 1986; 59: 579-598.

121. Henry RR, Wallace P, Olefsky JM. Effects of weight loss on mechanisms of hyperglycemia in obese non-insulin-dependent diabetes mellitus. Diabetes 1986; 35:990-998. 
122. Wolffenbuttel BHR, Weber RFA, Koetsveld PM van, Verschoor L. Limitations of dietary therapy in the treatment of patients with type II diabetes mellitus. Int I Obesity 1989; 13: $173-182$.

123. Bantle JP, Laine DC. Thomas JW. Metabolic effects of dietary fructose and sucrose in types I and II diabetic subjects. JAMA 1986; 256:3241-3246.

124. Peterson DB, Lambert J, Gerring $S$, et al. Sucrose in the diet of diabetic patients - just another carbohydrate? Diabetologia 1986; 29:216-220.

125. Jellish WS, Emanuele MA, Abraira C. Graded sucrose/carbohydrate diets in overtly hypertriglyceridemic diabetic patients. Am J Med 1984; 77:1015-1022.

126. Garg A, Bonanome A, Grundy SM, Zhang Z-J, Unger RH. Comparison of a high carbohydrate diet with a high-monounsaturated-fat diet in patients with non-insulin-dependent diabetes mellitus. New Engl J Med 1988; 319: 829-834

127. Henry FR, Wiest-Kent TA, Schaeffer OG, Olefsky JM. Metabolic consequences of a very-low-caloric diet therapy in obese non-insulin-dependent diabetic and non-diabetic subjects. Diabetes $1986 ; 35: 155-164$

128. Krotkiewski M, Toss L, Bjorntorp P, Holm G. The effects of a very-low calorie diet with and without chronic exercise on thyroid and sex homones, plasma proteins, oxygen uptake, insulin and $\mathrm{C}$-peptide concentrations in obese women. Int J Obesity 1981; 5:287-293.

129. Uusitupa MIJ, Laakso M, Sarlund H, Majander H, Takala J, Pentilla I. Effects of a very-low-calorie diet on metabolic control and cardiovascular risk factors in the treatment of obese non-insulin-dependent diabetics. Am J Clin Nutr 1990; 51: 768-773.

130. Van Dale D. Diet and exercise in the treatment of obesity (thesis). University of Limburg, 1989.

131. Sels JPJE, Postmes ThJ, Wolffenbuttel BHR, Nieuwenhuijzen Kruseman AC. Dietary fibre in the management of diabetes mellitus. Neth J Med 1991; 38: (in press).

132. O'Dea $K$, Traianedes $K$, Ireland $P$, et al. The effects of diet differing in fat, carbohydrate, and fiber on carbohydrate and lipid metabolism in type II diabetes. J Am Diet Assoc 1989; 89: 1076-1086.

133. Hillebrand I. Pharmacological modification of digestion and absorption. Diabetic Medicine $1987 ; 4: 147-150$.

134. Kingma PJ, Menheere PPCA, Sels JPJE, Nieuwenhuijzen Kruseman AC. Efficacy of the alpha-glucosidase inhibitor miglitol (BAY m 1099) in relation to the starch content in food in NIDDM subjects. Diabetes Care 1991 (in press).

135. Borkman M, Chisholm DJ, Furler SM, et al. Effects of fish oil supplementation on glucose and lipid metabolism in NIDDM. Diabetes 1989; 38: 1314-1319.

136. Gerich JE. Drug therapy - oral hypoglycemic agents. New Engl J Med 1989; 321: $1231-1245$.

137. Lebovitz HE. Oral hypoglycemic agents. In: The Diabetes Annual/3. Albert KGMM and Krall LP (eds), Elsevier, Amsterdam, The Netherlands, 1987.

138. Beck-Nielsen $\mathrm{H}$, Hother-Nielsen $\mathrm{O}$, Pedersen $\mathrm{O}$. Mechanism of action of sulphonylureas with special reference to the extrapancreatic effect: an overview. Diabetic Med 1988; 5 : $613-620$

139. Melander A. Sulphonylureas in the treatment of non-insulin-dependent diabetes. In: Baillière"s Clinical Endocrinology and Metabolism, Non-insulin-dependent diabetes. Nattrass M, Hale PJ, Eds. London, 1988. 
140. Andtrsson A, Borg LAH. Effects of glipizde on the insulin production by isolated mouse pancreatic islets. Actá Endocrinol 1980; 239 (suppl): 37-41.

141. Stenmari S, Groop P-H, Laakkonen K, Wahlin-Boll E, Melander A. Relationship between Salfonylurea dose and metabolic effect. Diabetes 1990,39 (suppl 1): 108A.

142. Groop LC, Luzi L, DeFronzo RA, Melander A. Hyperglycaemia and absorption of sulphonylurea drags. Lancet 1989; ii: 129-130.

143. Asplund $\mathrm{K}$, Wholm B-E, Lithner F. Glibenclamide-associated hypoglycaemia: a report on 57 cases. Diaberologia $1983 ; 24: 412-417$.

144. Vigneri $\mathbb{R}$, Goldfine $\mathbb{N D}$. Role of metformin in treatment of diabetes mellitus. Diabetes Care 1987; 10: 118-122.

145. Klip A, Leiter LA. Cellular mechanism of action of metformin. Diabetes Care 1990; 13 ; 696-704.

146. Pedersen $O$, Hother-Nielsen $O$, Bak J, Richelsen B, Beck-Nielsen $\mathrm{H}_{3}$ Schwartz Sorensen $N$. The effects of metformin on adipocyte insulin action and metabolic control in obese subjects with type 2 diabetes. Diabetic Med 1988; 6:249-256.

147. Wu M-S, Johnston P, Sheu WH-H, et al. Effect of metformin on carbohydrate and lipoprotein metabolism in NDDM patients. Diabetes Care 1990;13:1-8.

148. Rains SGH, Wilson GA, Richmond W, Elkeles RS. The effect of glibenclamide and metformin on serum lipoproteins in type 2 diabetes. Diabetic Med 1988; 5: 653-658.

149. Josephkutty S, Potter JM. Comparison of tolbutamide and metformin in elderly diabetic patients. Diabetic Med 1990; 7:510-514.

150. McAlpine LG, McAlpine CH, Waclawski ER, Storer AM, Kay JW, Frier BM. A comparison of treatment with metformin and gliclazide in patients with non-insulin-dependent diabetes. Eur J Clin Pharmacol 1988; 34: 129-132.

151. UK Prospective study of therapies of maturity-onset diabetes: I. Effect of diet, sulphonylurea, insulin or biguanide therapy on fasting plasma glucose and body weight over one year. Diabetologia 1983; 24: 404-411.

152. UK Prospectiwe study of therapies of maturity-onset diabetes: II. Reduction in Hbalc with basal insulin supplement, sulfonylurea, or biguanide therapy. Diabetes 1985; 34:793-798.

153. Thoelke H, Ratzmann KP. Häufigkeit des Sekundärversagens einer Sulfonylharnstofftherapie - Epidemiologische Untersuchung. Dtsch Med Wschr 1989; 114: 580-583.

154. Groop LC, Pelkonen R, Koskimies S, Bottazzo GF, Doniach D. Secondary failure to troatment with oral antidiabetic agents in non-insulin-dependent diabetes. Diabetes Care $1986 ; 9: 129-133$.

155. Groop L, Schalin C, Franssila-Kallunki A, Widén E, Ekstrand A, Eriksson J. Characteristics of non-insulin-dependent diabetic patients with secondary failure to oral antidiabetic therapy. Am J Med 1989; 87: 183-190.

156. Heine RJ. Insulin treatment of non-insulin-dependent diabetes mellitus. In: Baillière"s Clinical Endocrinology and Metabolism, Non-insulin-dependent diabetes. Nattrass M, Hale PJ, Eds. London, 1988.

157. Firth RG, Bell PM, Rizza RA. Effects of tolazamide and exogenous insulin on insulin action in patrents with non-insulin-dependent diabetes mellitus. New Engl J Med 1986; 314: $1280-1286$.

158. Samanta A, Burden AC, Kinghom A. A comparative study of sulphonylurea and insulin therapy in non-insulin dependent diabetics who had failed on diet therapy. Diabetes Res $1987 ; 4: 183-185$. 
159. Wolffenbuttel BHR, Weber RFA, Verschoor L. A randomized cross-over study of sulfonylurea and insulin treatment in patients with non-insulin-dependent diabetes mellitus failing on diet therapy. Diabetic Med 1989; 6:520-525.

160. Wolffenbuttel BHR, Weber RFA, Weeks L, Wan Koetsveld PM, Verschoor L. Twice daily insulin therapy in patients with type 2 diabetes with secondary failure to sulphonylurea. Diabetes Res $1990 ; 13: 79-84$.

161. Nilsson A, Tideholm B, Kalen J, Katzman P. Incidence of severe hypoglycemia and its causes in insulin-treated diabetics. Acta Med Scand 1988; 224: 257-262.

162. Wolffenbuttel BHR. Combined use of insulin and oral hypoglycaemic agents in the treatment of patients with diabetes mellitus. Eur I Intern Med 1989; 1: 89-95.

163. Bailey TS, Mezitis NHE. Combination therapy with insulin and sulfonylureas for type II diabetes. Diabetes Care 1990; 13:687-695.

164. Lebovitz HE, Pasmantier R. Combination insulin-sulfonylurea therapy. Diabetes Care $1990 ; 13: 667-675$.

165. Garg A, Grundy SM. Management of dyslipidemia in NTDDM. Diabetes Care 1990; 13 : 153-169.

166. Van Deursen RTAM, Nieuwenhuijzen Kruseman AC, DegenaarCP, Wolffenbuttel BHR. De effecten van de cholesterolsyntheseremmer simvastatine bij patienten met hypercholesterolemie met en zonder diabetes mellitus. Ned Tijdschr Geneeskd $1990 ; 134$ : 2142-2146.

167. Winocour PH, Laker MF. Drug therapy for diabetic dyslipoproteinaemia: a practical approach. Diabetic Med 1990; 7: 292-298.

168. Seviour PW, Teal TK, Richmond W, Elkeles RS. Serum lipids, lipoproteins and macrovascular disease in non-insulin-dependent diabetics: a possible new approach to prevention. Diabetic Med 1988; 5: 166-171.

169. Pierce LR. Myopathy and rhabdomyolysis associated with lovastatin-gemfibrozil combination therapy. JAMA 1990; 264: 271 275.

170. Reaven GM, Hoffman BB. A role for insulin in the aetiology and course of hypertension? Lancet 1987; ii: $435-437$.

171. Raskin P. How to treat hypertension in diabetic patients. Postgrad Med 1988; 83: 213-232.

172. Lardinois CK, Neuman SL. The effects of antihypertensive agents on serum lipids and lipoproteins. Arch Intern Med 1988; 148: 1280-1288.

173. Ferriere M, Lachmkar H, Richard J-L, Bringer J, Orsett A, Mirouze J. Captopril and insulin sensitivity. Ann Intern Med 1985; 102: 134-135.

174. Moore MP, Elliot TW, Nicholls MG. Hormonal and metabolic effects of enalapril treatment in hypertensiwe subjects with NIDDM. Diabetes Care 1988; 11:397-401.

175. Schoen RE, Frishman WH, Shamoon H. Hormonal and metabolic effects of calcium channel antagonists in man. Am J Med 1988; 84: 492-504.

176. Kingma PJ, Simons JPFHA, Nieuwenhuijzen Kruseman AC, Wolffenbultel BHR. Cal cium entry blockers and their effects on glucose metabolism. Neth J Med 1990; 36: 32-38.

177. Huse DM, Oster G, Killen AR, Lacey MJ, Colditz GA. The economic costs of non-insulin-dependent diabetes mellitus. JAMA 1989; 262: 2708-2713.

178. Alexander WD and South East Thames Diabetes Physicians Group. Diabetes Care in a UK health region: activity, facilities ans costs. Diabetic Med 1988; 5: 577-581. 
179. Hortulanus-Beck D, Lefebvre PJ, Jeanjean MF. Diabetes in the Belgian Province of Luxembourg: frequency, importance of the oral glucose tolerance test and of a fasting glycaemia discretely increased. Diabete \& Metabolisme 1990; 16: 311-317.

180. Stuurgroep Toekomstscenario"s Gezondheidszorg. Chronische ziekten in het jaar 2005. Deel 1: Scenario"s over diabetes mellitus 1990-2005. Bohn, Scheltema \& Holkema, Utrecht, 1990. 


\section{CHAPTER}

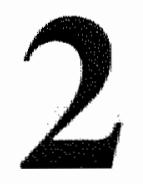

\section{Clinical characteristics of patients with type 2 diabetes treated in a hospital outpatient-clinic}

Treatment, metabolic derangements, late complications

Bruce H.R. Wolffenbuttel, Rob van Kimmenade, Simon Verhoeven, Jean-Pierre J.E. Sels, Arie C. Nieuwenhuijzen Kruseman

Submitted 
In order to attain more information on the quality of metabolic control and presence of secondary complications in type 2 diabetic patients treated in a hospital outpatient-clinic, we held a survey among a nonselect sample of 124 of our diabetic patients (56 males, 68 females, mean age $65 \pm 11$ years, median duration of diabetes 9 (range 1-32) years. The presence of diabetic complications was assessed by specific questionnaires and detailed physical examination. In the 9 diet-treated patients, metabolic control was near-normal $\left(\mathrm{HbA}_{1 \mathrm{c}} 6.3 \pm 0.7 \%\right.$ ), whereas $\mathrm{HbA}$ lc levels were higher in patients treated with oral hypoglycaemic agents $(7.9 \pm$ $1.3 \%, \mathrm{n}=56)$, with insulin $(8.0 \pm 1.5 \%, \mathrm{n}=36)$ or with insulin combined with oral agents $(8.6 \pm 1.8 \%, \mathrm{n}=23)$. Plasma cholesterol and triglyceride levels tended to be lower in the insulin-treated patients. The prevalence of vascular abnormalities was high: $48 \%$ of patients had complaints or signs indicating coronary artery disease, $56 \%$ had hypertension, $15 \%$ cerebrovascular disease and $35 \%$ signs of peripheral artery disease. Retinopathy was present in 35 patients ( $28 \%$ ), of whom 18 had received lasercoagulation treatment. Microalbuminuria was found in 31 patients $(25 \%)$, overt proteinuria in 18 patients $(14 \%)$. The use of cardiovascular medication was high: 57 patients used antihypertensive therapy (of whom 24 a beta-blocking and 20 a calcium entry blocking drug), 37 used diuretics, and 26 long-acting nitrates. Only 25 patients took no medication in addition to their diabetes therapy. The presence of microalbuminuria and proteinuria was a strong indicator for cardiovascular disease, polyneuropathy and retinopathy. In comparison with a population of patients treated by their family physician more of our patients were treated with insulin ( $48 \%$ vs. $24 \%, \mathrm{p}<0.01)$. In addition, they showed a higher prevalence of hypertension $(56 \%$ vs. $38 \%)$, coronary artery disease ( $48 \%$ vs. $40 \%$ ), and cerebrovascular disease ( $15 \%$ vs. $6 \%$ ). This study confirms the clustering of risk factors for cardiovascular disease in type 2 diabetes mellitus, indicating the need for both optimal blood glucose control and adequate treatment of hypertension and dyslipidaemia. 


\section{INTRODUCTION}

Secondary complications are frequently observed in patients with type 2 diabetes mellitus (1). Estimations of the prevalence of the various complications differ considerably between studies. This is caused by several factors such as poor definition of the disease state, bias in the selection of patients (hospitalbased surveys against patients belonging to the practice of a general practitioner), and differences in the tools or devices that are used to assess the presence or absence of a complication.

The role of diabetes as an independent risk factor for cardiovascular disease is well established (2-5). In type 2 diabetic patients, a two-to three-fold increase of morbidity and mortality attributed to coronary heart disease (CHD) is demonstrated. A comparable increased occurrence of peripheral vascular disease was demonstrated (6-11). Microvascular abnormalities can be found in a considerable number of patients. Retinopathy is observed in 12 to $44 \%$ of diabetic patients 10 years after diagnosis (12-15). Diabetic nephropathy is less frequently $(0-15 \%)$ found in type 2 compared to type 1 diabetic patients $(16,17)$.

A number of risk factors for CHD can be demonstrated in diabetic patients. Twenty to $50 \%$ of them suffer from hypertension $(18,19)$. Lipid abnormalities, comprising elevations of both LDL-cholesterol and VLDL-triglycerides, as well as decreases in the levels of HDL-cholesterol (20-22) are reported to occur in at least $30 \%$ of patients $(23,24)$. In diabetic patients, elevated triglyceride levels seem to be an independent risk factor for the development of macrovascular disease.

In the Netherlands, only few data are available concerning the occurrence of late complications in type 2 diabetic patients. The present survey was undertaken to characterize the treatment, degree of metabolic (de)compensation and presence of late complications in a cohort of type 2 diabetic patients, treated in the out-patient clinic of a large teaching hospital. Where possible, this colnort of patients is compared with a recently published survey of patients belonging to the practices of four general practitioners (25).

\section{MATERIALS AND METHODS}

\section{Patients}

From the 940 patients with type 2 diabetes mellitus, who regularly attend the outpatient-clinic of the Department of Internal Medicine of the University Hospital Maastricht, a sample of 124 patients, who consecutively visited the 
clinic in a three-week period, was drawn. Patients attending our clinic are for $95 \%$ residing in the most south-eastern part of The Netherlands, within a defined geographic area occupied by approximately 200.000 inhabitants.

Previous medical events, present well-being and complaints, presence of specific complaints related to secondary complications (vascular, nephrologic, ophthalmologic), and concomitant use of medication were recorded. Data of routine physical examination, including height $(\mathrm{cm})$, body weight $(\mathrm{kg})$, blood pressure, heart rate, vascular abnormalities, and neurologic examination (tendon reflexes, vibration sense at the medial malleolus and the dorsal aspect of the big toe, and presence of sensory disturbances in the lower extremity) were collected.

\section{Methods}

\section{Blood pressure}

Systolic and diastolic (Korotkov V) bloodpressure were measured with a standard sphygmomanometer with the patient in the supine position and one minute after standing. The presence of hypertension was scored positive, when a patient was treated with antihypertensive drugs, or when on two repeated occasions after the initial measurement systolic blood pressures above 170 $\mathrm{mmHg}$ or diastolic blood pressures equal to or of above $95 \mathrm{mmHg}$ were noted.

\section{Coronary heart disease (CHD)}

Four questions to assess the presence of ischaemic heart disease were asked (appendix), which were in part derived from the Rose questionnaire (26). The electrocardiogram was assessed for the presence of definite or probable ischaemia.

\section{Cerebrovascular disease}

Questions related to previous cerebrovascular events were asked.

\section{Peripheral vascular disease (PVD)}

Four questions exploring the presence of PVD were posed. Peripheral vascular pulsations were recorded by palpation of the dorsal pedal and posterior tibial artery. Peripheral vascular disease was defined as complaints of intermittent claudication, absence of two or more pedal arteries, or amputations made necessary by vascular causes. 


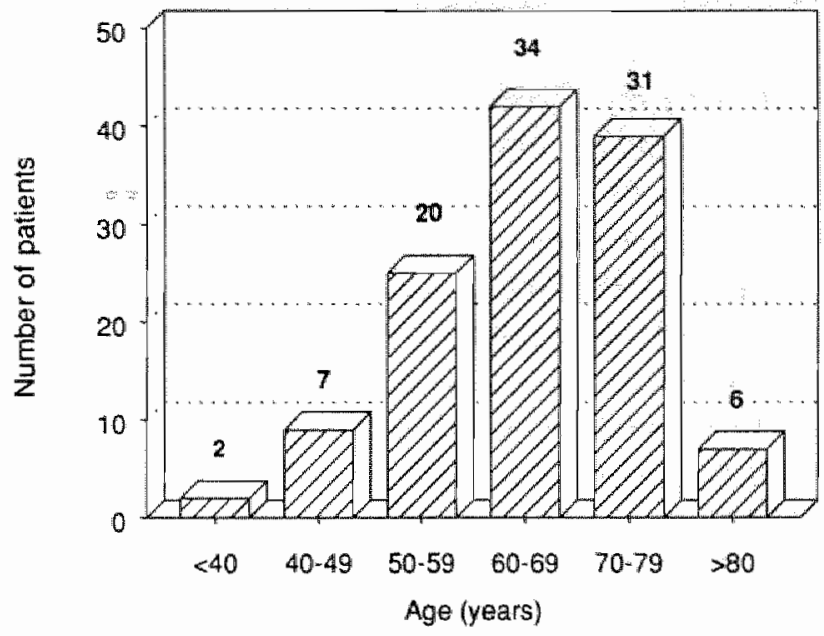

Figure 1. Age distribution of all 124 patients. Data shown above the bars indicate the percentage of patients in a certain subgroup. Thirty-six patients (29\%) were younger than 60 years. Age distribution was the same for males and fernales.

\section{Neuropathy}

Neuropathy was scored as: 0 . none; 1 . complaints, suggestive for peripheral neuropathy, based on the criteria by Boulton $(27) ; 2$. decreased vibration sense or signs of sensory disturbances without complaints; 3 . sensory complaints and reduced vibration sense or sensory defects.

\section{Retinopathy}

Eye examination was performed by the ophthalmologist. Visual acuity was assessed with the use of a Snellen chart. Fundoscopy was carried out after dilation of the pupils. Retinopathy was scored as: 0 . none; 1 . background; 2 . exsudative or preproliferative, but lasercoagulation not yet performed; 3. lasercoagulation performed.

\section{Laboratory determinations}

Blood glucose control was assessed by fasting blood glucose, serum fructosamine and glycosylated haemoglobin ( $\mathrm{HbA} / \mathrm{c})$. In addition, serum creatinine and lipids (cholesterol, HDL-cholesterol and triglycerides), and the presence of microalbuminuria or proteinuria in the first urine voided after waking up on two consecutive days were determined. 
Fasting blood glucose was measured in venous whole blood with an automated hexokinase method. Serum fructosamine was determined according to Johnson et al. (28) after alkalinising and reduction with nitroblue tetrazolium (Sigma) on the Cobas Bio analyser. Calibration was performed with 1-desoxy1-morfolinofructose (Sigma) in an albumin solution. The reference values of this assay were lower than those of the commercially-available Fructosamin Roche kit, due to the use of a different standard and reductor. Comparison with the Roche kit was excellent $(r=0.98 ; y=1.16 x+2, p<0.001)$. Between-assay coefficient of variation of our fructosamine determination is $4 \%$. HbAlc was determined with high pressure liquid chromatography (DIAMAT, Bio-Rad Laboratories, Richmond, Ca., USA). Normal values are 4.4-6.2\%, betweenassay $\mathrm{cv}$ is $2.6 \%$. Serum creatinine was determined by the Jaffé method. Total cholesterol and triglycerides (TG) were measured with enzymatic methods, HDL-cholesterol was measured after precipitation of VLDL and LDL with polyethyleneglycol 6000 . LDL-cholesterol was calculated from the Friedewald formula (LDL-cholesterol $=$ total chol - HDL-chol $-0.45 \times$ TG). Urinary albumin was determined by nephelometry in the first morning urine sample and considered elevated when the albumin/creatinine ratio was above $3.0 \mathrm{mg} / \mathrm{mmol}$. Overt proteinuria (macroalbuminuria) was defined as urinary albumin concentration of $>200 \mathrm{mg} / \mathrm{l}$.

ECG's were grouped according to the results of Minnesota coding: 1) coronary heart disease probable: major $Q$ waves or complete left bundle branch block (Minnesota codes 1-1, 1-2, 7-1); 2) coronary heart disease possible: ST-segment abnormalities accompanied by abnormal T-waves, or minor Q/QS wave changes (Minnesota codes 1-3, or any of 4-1,4-2, 4-3, if accompanied by $5-1$ or $5-2$ or $5-3$ ); 3) coronary heart disease unlikely (all other Minnesota codes).

\section{Statistical analyses}

All data are expressed as means $\pm S D$, or median and range, when not normally distributed. Calculations were performed with the SPSS/PC+ version 3.1 statistical software package (SPSS Inc, Chicago, IL, USA). Differences between group means were tested with one-way analysis of variance. Student-NewmanKeuls test was applied to correct for multiple comparisons. When data were not normally distributed, Kruskal-Wallis analysis of variance was used. For categorical parameters Fisher's exact test (two-sided) was used. Correlations were tested by linear regression analysis. $P$ values $<0.05$ were considered statistically significant. 


\section{RESULTS}

Of the 124 patients, 56 were malles and 68 females. Mean ( \pm SD) age was $65 \pm$ 11 years, mean body mass index was $27.7 \pm 4.8 \mathrm{~kg} / \mathrm{m}^{2}$. Sixty-two patients were obese (BMI $>27.0 \mathrm{~kg} / \mathrm{m}^{2}$ ). Median known duration of diabetes was 9 years (range 1-32 years). Distribution of the various treatments of diabetes is depicted in table 1. A similar number of obese patients is treated with insulin, compared to normal-weight patients. Variables of blood glucose control were identical in males compared to females. Only in female patients, total plasma cholesterol $(6.6 \pm 1.2 \mathrm{vs} .6 .1 \pm 1.1 \mathrm{mmol} / \mathrm{l}, \mathrm{p}=0.024)$ and HDL-cholesterol $(1.20 \pm 0.37 \mathrm{vs}$. $1.03 \pm 0.27 \mathrm{mmol} / \mathrm{l}, \mathrm{p}=0.008$ ) were significantly higher than in males.

The results concerning blood glucose control and lipid variables in the different treatment groups are listed in table 2 . In diet-treated patients, HbA ic was $6.3 \pm 0.7 \%$, implying that metabolic control was near-normal. In the patients treated with insulin, levels of fasting blood glucose and $\mathrm{HbA} 1 \mathrm{c}$ were slightly higher compared to diet- and tablet-treated patients, whereas cholesterol and triglyceride levels tended to be lower. The duration of insulin therapy averaged 2 years, with a range from 1 month to 22 years. Twelve patients used insulin therapy for less than 6 months, and had therefore not yet reached stable metabolic control. $\mathrm{HbA}_{1 \mathrm{c}}$ was $7.9 \pm 1.2 \%$ in the patients who were on insulin for longer than 1 year, against $8.6 \pm 2.0 \%$ in the patients who recently had switched to insulin.

Patients in acceptable $\left(\mathrm{HbA} A_{1 c}<8.0 \%, n=75\right)$ and poor control $\left(\mathrm{HbA}_{1 \mathrm{c}}>8.0 \%\right.$, $\mathrm{n}=49$ ) were similar with regards to body mass index, systolic and diastolic blood pressure, plasma creatinine, total and HDL-cholesterol and triglycerides, and degree of proteinuria. Obese patients had slightly higher diastolic blood pressure ( $83 \pm 9$ vs. $80 \pm 9 \mathrm{mmHg}, \mathrm{p}=0.04)$, total cholesterol $(6.6 \pm 1.1$ vs. 6.2

Table 1. Treatment of the 124 patients studied.

All patients

$\mathrm{BMI}<27.0$

$\mathrm{BMI}>27.0$

Diet

Sulphonylurea

37

3

6

Biguanides

Sulphonylurea + biguanides

23

14

Insulin

18

0

1

Insulin + sulphonylurea

36

6

12

19

17

23

11

12 
$\pm 1.3 \mathrm{mmol} / \mathrm{l}, \mathrm{p}=0.085)$, and triglycerides $(2.65 \pm 1.54$ vs. $1.91 \pm 1.23 \mathrm{mmol} / \mathrm{l}$, $\mathrm{p}=0.0048$ ).

Data related to the presence of micro- and macrovascular complications in the different treatment groups are depicted in table 3. Hypertension (56\%), coronary heart disease $(48 \%)$ and peripheral vascular disease $(35 \%)$ were the most prevalent accompanying disturbances. Based on the criteria for hypertension, as described in the Methods Section, three new cases of hypertension were identified. Thirty-one patients $(25 \%)$ had microalbuminuria, and 18 (14\%) manifest proteinuria. Besides a slightly higher prevalence of microalbuminuria in insulin-treated patients, no differences in accompanying problems were observed between diet- or tablet-treated and insulin-treated patients.

Table 2. Characteristics of the 124 patients studied.

\begin{tabular}{|c|c|c|c|c|}
\hline & Diet & Oral agents & Insulin & Ins.+OHA \\
\hline Number of patients & 9 & 56 & 36 & 23 \\
\hline Average age (years) & $60 \pm 12$ & $64 \pm 11$ & $65 \pm 11$ & $67 \pm 9$ \\
\hline Known duration & $2^{*}$ & 8.5 & 9.5 & 10 \\
\hline of diabetes (years) & $(1-16)$ & $(1-30)$ & $(1-32)$ & $(1-27)$ \\
\hline Sex ratio $(\mathbb{F} / \mathrm{M})$ & $3 / 6$ & $31 / 25$ & $19 / 17$ & $15 / 8$ \\
\hline Body mass index $\left(\mathrm{kg} / \mathrm{m}^{2}\right)$ & $29.5 \pm 6.0$ & $27.7 \pm 4.9$ & $26.6 \pm 3.7$ & $28.8 \pm 5.4$ \\
\hline Fasting bloot glucose (mmol/1) & $6.5 \pm 1.3^{*}$ & $8.3 \pm 2.3$ & $8.1 \pm 3.0$ & $9.0 \pm 2.7$ \\
\hline Glycosylated haemoglobin (\%) & $6.3 \pm 0.7^{*}$ & $7.9 \pm 1.3$ & $8.0 \pm 1.5$ & $8.6 \pm 1.8$ \\
\hline Serum fructosaminc (mmol/l) & $0.12 \pm 0.20^{*}$ & $1.40 \pm 0.20$ & $1.40 \pm 0.26$ & $1.49 \pm 0.32$ \\
\hline Total chalesterol (mmol/l) & $6.9 \pm 1.8$ & $6.5 \pm 1.1$ & $6.4 \pm 1.2$ & $6.0 \pm 1.1$ \\
\hline HDLacholesterol (mmol/l) & $1.05 \pm 0.34$ & $1.09 \pm 0.32$ & $1.16 \pm 0.38$ & $1.16 \pm 0.33$ \\
\hline Triglycerides (mmol/l) & $2.77 \pm 1.89$ & $2.33 \pm 1.60$ & $2.21 \pm 1.27$ & $2.05 \pm 1.00$ \\
\hline LDL-cholesterol (mmol/l) & $4.10 \pm 1.52$ & $4.43 \pm 1.01$ & $4.26 \pm 0.95$ & $3.92 \pm 0.75$ \\
\hline Systolic blood pressure ( $\mathrm{mmHg}$ ) & $150 \pm 20$ & $150 \pm 19$ & $147 \pm 18$ & $152 \pm 19$ \\
\hline Diastolic blood pressure (mmHg) & $82 \pm 10$ & $82 \pm 10$ & $82 \pm 9$ & $80 \pm 9$ \\
\hline Serum creatinine $(\mu \mathrm{mol} / \mathrm{)})$ & $88 \pm 19$ & $88 \pm 22$ & $91 \pm 27$ & $87 \pm 16$ \\
\hline
\end{tabular}

Data as mean $\pm \mathrm{SD}$, or median (range); $\mathrm{OHA}=$ oral hypoglycaemic agents;

* 00.05 ws. tablet- and insulin-treated patients 

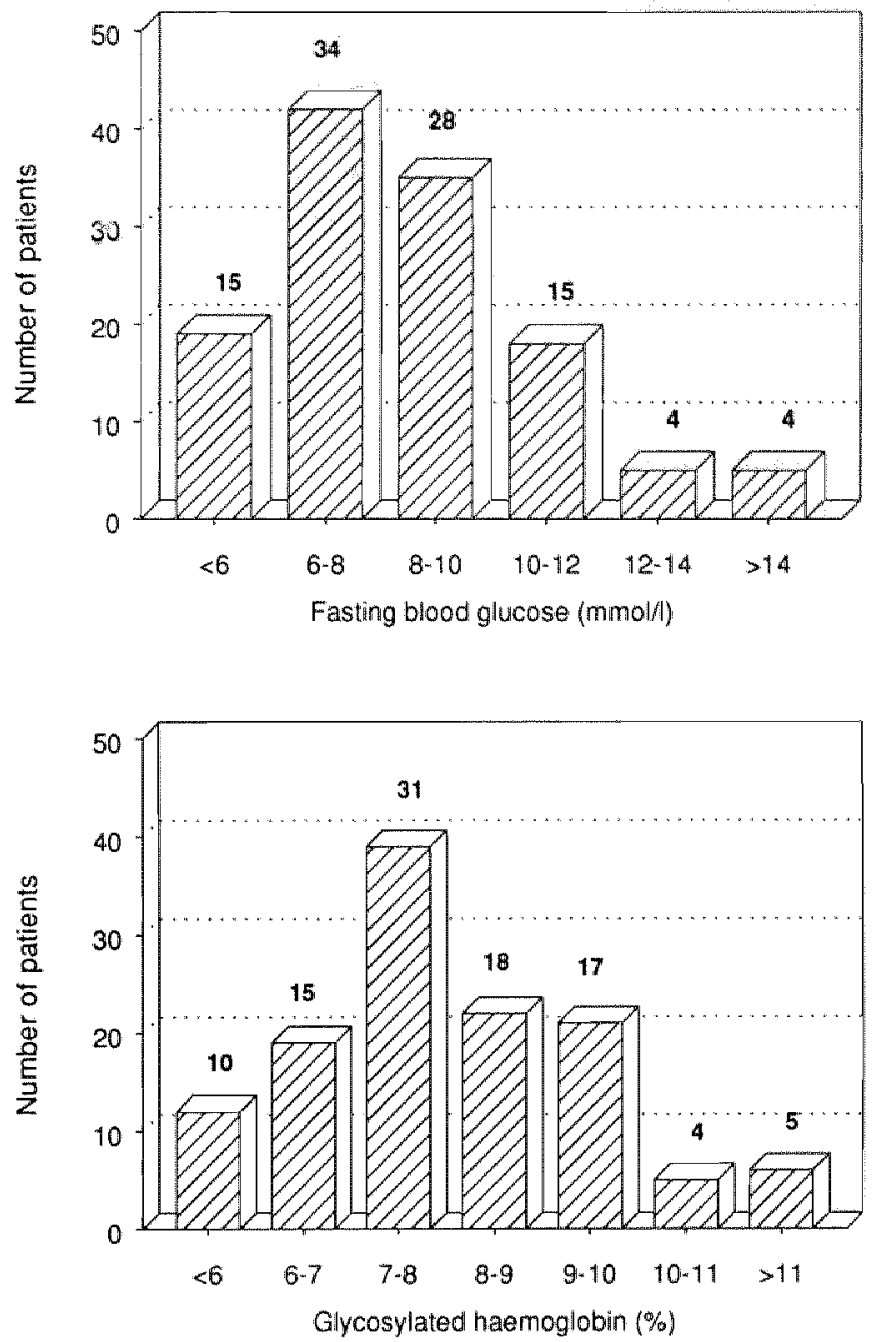

Figure 2. Distribution of fasting blood glucose and glycosylated haemoglobin ( $\mathrm{HbA}_{1 \mathrm{c}}$ ) in all 124 patients. Data shown above the bars indicate the percentage of patients in a certain subgroup.

Antihypertensive agents were used by 57 (46\%) of the patients; 10 of them took a combination of 2 or more drugs (table 4). When the use of antihypertensive agents, diuretics and anti-anginosal therapy was combined, 83 patients $(67 \%)$ took medication that was prescribed for a reason related to a cardiovascular abnormality (hypertension, angina pectoris, congestive heart failure). Twenty-five patients took no medication in addition to their specific diabetes therapy. 
Table 3. Characteristics of patients: secondary complications.

\begin{tabular}{|c|c|c|c|}
\hline & $\begin{array}{l}\text { Diet/ } \\
\text { oral agents } \\
(n=65)\end{array}$ & $\begin{array}{l}\text { Insulin } \\
(n=59)\end{array}$ & $\begin{array}{l}\text { All } \\
\text { patients } \\
(n=124)\end{array}$ \\
\hline \multicolumn{4}{|l|}{ Retinopathy } \\
\hline - background & 4 & 6 & 10 \\
\hline - exsudative/preproliferative & 10 & 15 & 25 \\
\hline of whom lasercoagulation & 8 & 10 & 18 \\
\hline \multicolumn{4}{|l|}{ Macroangiopathy } \\
\hline - angina pectoris (a.p.) & 24 & 23 & 47 \\
\hline - myocardial infarction (a.m.i.) & 13 & 14 & 27 \\
\hline$-a . p_{.}+a \cdot m i_{.}$ & 26 & 25 & 51 \\
\hline - E.C.G.: definite ischaemia & 14 & 13 & 27 \\
\hline possible ischaemia & 15 & 20 & 35 \\
\hline - cerebrovascular accident & 9 & 9 & 18 \\
\hline - hypertension & 38 & 31 & 69 \\
\hline - peripheral vascular disease & 21 & 22 & 43 \\
\hline - amputations & 3 & 4 & 7 \\
\hline \multicolumn{4}{|l|}{ Nephropathy } \\
\hline - microalbuminuria & 11 & $20^{*}$ & 31 \\
\hline - overt proteinuria & 9 & 9 & 18 \\
\hline - serum creatinine $>120 \mu \mathrm{mol} / 1$ & 5 & 5 & 10 \\
\hline \multicolumn{4}{|l|}{ Neuropathy } \\
\hline - peripheral polyneuropathy score 1 & 1 & 4 & 5 \\
\hline score 2 & 7 & 5 & 12 \\
\hline score 3 & 22 & 23 & 45 \\
\hline
\end{tabular}

p $<0.05$ ws. tablet-treated patients

Table 5 lists the metabolic control and presence of complications in the patients with different levels of albumin excretion (normo-, micro- or macroalbuminuria). Patients with albuminuria had slightly longer duration of diabetes, and were generally older. Compared to the normoalbuminuric group blood glucose control was slightly worse in the microalbuminuric, but not in the macroalbuminuric group, whereas lipid levels were comparable. With progression from normo- to macroalbuminuria, higher levels of blood pressure and serum creatinine were found, as well as higher prevalence of (treated) hyperten- 
Table 4. Characteristics of patients: concomitant medication.

\begin{tabular}{|c|c|c|c|}
\hline 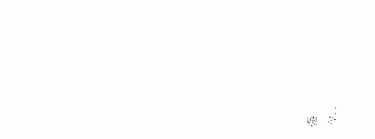 & $\begin{array}{l}\text { Diet/ } \\
\text { oral agents } \\
(n=65)\end{array}$ & $\begin{array}{l}\text { Insulin } \\
(n=59)\end{array}$ & $\begin{array}{l}\text { All } \\
\text { patients } \\
(n=124)\end{array}$ \\
\hline Antihypertensive agents & 32 & 25 & 57 \\
\hline - one drug & 26 & 21 & 47 \\
\hline of whom + diuretics & & & 21 \\
\hline - two drugs & 4 & 4 & 8 \\
\hline of whom + diuretics & & & 4 \\
\hline - three drugs & 2 & 0 & 2 \\
\hline \multicolumn{4}{|c|}{ class of antihypertensive agent } \\
\hline - beta blockers & 13 & 11 & 24 \\
\hline - calcium entry blockers & 10 & 10 & 20 \\
\hline - ACE-inhibitors & 13 & 5 & 18 \\
\hline - vasodilators & 0 & 2 & 2 \\
\hline - others & 2 & 1 & 3 \\
\hline Diuretics & 18 & 19 & 37 \\
\hline Anticoagulant therapy & 14 & 14 & 28 \\
\hline - coumarines & & & 12 \\
\hline - aspirin & & & 15 \\
\hline - dipyridamol & & & 4 \\
\hline Digoxin & 7 & 8 & 15 \\
\hline Long-acting nitrates & 9 & $17^{*}$ & 26 \\
\hline Lipid lowering agents & 1 & 5 & 6 \\
\hline
\end{tabular}

* $p<0.05$ vs. diet/tablet-treated patients

sion, peripheral vascular disease, polyneuropathy and retinopathy. The prevalence of coronary heart disease was the same in the three groups.

When our data in hospital-treated patients were compared to a recent survey of patients, belonging to the practices of four general practitioners (25), more of our patients were treated with insulin ( $48 \%$ vs. $24 \%$, table 6), whereas the prevalence of hypertension, coronary heart disease and cerebrovascular disease was higher. No differences in peripheral vascular disease or proteinuria was found. 
Table 5. Characteristics and observations in the 124 type 2 diabetic patients subdivided by albumin excretion rate.

\begin{tabular}{|c|c|c|c|c|}
\hline & $\begin{array}{l}\text { Normo } \\
\text { albuminuriat } \\
(\text { (rim }=75)\end{array}$ & $\begin{array}{l}\text { Micro } \\
\text { albuminuria } \\
(n=31)\end{array}$ & $\begin{array}{l}\text { Macro } \\
\text { albuminuria } \\
(n=18)\end{array}$ & \\
\hline Female/male & $43 / 32$ & $17 / 14$ & $8 / 10$ & \\
\hline Age (years) & $62 \pm 11$ & $69 \pm 10^{*}$ & $67 \pm 9$ & \\
\hline Duration (years) & $5(1-32)$ & $11(1-28)^{*}$ & $12(2-30)$ & \\
\hline Body mass inder $\left(\mathrm{kg} / \mathrm{m}^{2}\right)$ & $27.8 \pm 5.1$ & $27.3 \pm 4.1$ & $28.2 \div 4.6$ & \\
\hline Fasting blood glucose (mmol/h) & $8.0 \pm 2.6$ & $8.8 \pm 2.3^{*}$ & $8.6 \pm 3.7$ & \\
\hline $\mathrm{HbA} 1 \mathrm{c}(\%)$ & $7.7 \pm 1.3$ & $8.4 \pm 1.6^{*}$ & $8.4 \pm 2.0$ & \\
\hline Cholesterol (mmol/l) & $6.4 \pm 1.2$ & $6.3 \pm 1.1$ & $6.7 \pm 1.1$ & \\
\hline "Trigllycerides (mmal/l) & $2.05 \pm 1.12$ & $2.78 \# 1.95$ & $2.36 \pm 1.42$ & \\
\hline HDL-cholesterol (mmol/l) & $1.16 \pm 0.36$ & $1.08 \pm 0.31$ & $1.07 \pm 0.27$ & \\
\hline \multicolumn{5}{|l|}{ Blood pressure (mmHg) } \\
\hline systolic & $146 \pm 17$ & $151 \pm 21$ & $159 \pm 17^{*}$ & \\
\hline diastolic & $81 \pm 9$ & $80 \pm 9$ & $85 \pm 10^{*}$ & \\
\hline Serum creatinine ( $\mu \mathrm{mol} / \mathrm{l})$ & $84 \pm 20$ & $93 \pm 23$ & $98 \pm 28^{*}$ & \\
\hline \multicolumn{5}{|l|}{ Presence of: } \\
\hline Hypertension & $33(44 \%)$ & $21(68 \%)$ & $15(83 \%)$ & $x^{2}(2)=11.5, p=0.0031$ \\
\hline Coronary heart disease & $37(49 \%)$ & $14(45 \%)$ & $8(44 \%)$ & $x^{2}(2)=0.24, p=0.89$ \\
\hline Cerebrovascular disease & $7(9 \%)$ & $6(19 \%)$ & $5(28 \%)$ & $\mathrm{x}^{2}(2)=4.76, \mathrm{p}=0.093$ \\
\hline Peripheral vascular disease & $14(19 \%)$ & $18(58 \%)$ & $11(61 \%)$ & $x^{2}(2)=21.5, p=0.000$ \\
\hline Peripheral polyneuropathy & $30(40 \%)$ & $18(58 \%)$ & $14(78 \%)$ & $x^{2}(6)=12.1, p=0.06$ \\
\hline Background retinopathy & $4(6 \%)$ & $3(10 \%)$ & $3(18 \%)$ & \\
\hline Exsudative rotinopathy & $8(11 \%)$ & $9(29$ 政) & $8(47 \%)$ & $x^{2}(4)=17.0, p=0.0019$ \\
\hline
\end{tabular}

Data as mean $\pm \mathrm{SD}$, or median (range);

" $\mathrm{p}<0.05$ vs. normoalbuminuria;

* angina pectoris + myoc.infarction + Minnesota code group 1 
Table 6. Comparison of the 124 hospital-clinic patients with patients treated by their family physician.

Hospital

124

$65 \pm 11$

$56 / 68$

$27.7 \pm 4.8$

$9(1-32)$

$9 / 56 / 59$

$8.3 \pm 2.7$

$8.0 \pm 1.5^{\mathrm{a}}$

$89 \pm 22$

$6.4 \pm 1.2$

$1.12 \pm 0.34$

$2.28 \pm 1.43$

$149 \pm 19$

$81 \pm 9$

$57(46 \%)$

$37(29 \%)$

Number of patients on diuretics

Presence of:

Hypertension

Coronary heart disease

Cerebrovascular disease

Peripheral vascular disease

Amputations

Proteinuria $>500 \mathrm{mg} / 24 \mathrm{~h}$
G.P.

137

$69 \pm 11$

$53 / 84$

$27.6 \pm 4.5$

$7.5(0.5-40)$

$23 / 84 / 30$

$10.8 \pm 3.9$

$8.9 \pm 2.9^{b}$

$92 \pm 67$

$6.7 \pm 1.3$

$1.3 \pm 0.6$

$2.2 \pm 1.5$

$149 \pm 18$

$86 \pm 9$

$41(30 \%)$

$43(31 \%)$

$53(38 \%)$

$54(40 \%)^{\# \# \#}$

$8(6 \%)$

$71(52 \%)$

$1(1 \%)$

22 (16\%)

\footnotetext{
\# angina pectoris + myoc infarction + Minnesota code group 1;

\# idem + Minnesota code group 2;

a normal values 4.2-6.2\% (HPLC-method);

${ }^{b}$ normal values $3.5-5.5 \%$ (affinity chromatography)
} 


\section{DISCUSSION}

In this hospital-based survey, the majority of type 2 diabetic patients was treated with oral agents or insulin in adjunct to their dietary advices. Their metabolic control was however not adequate. Mean glycosylated haemoglobin of all patients was $8.0 \%$, which was higher in the tablet- and insulin-treated patients. In part this is caused by the difficulties to obtain adequate blood glucose control in type 2 diabetic patients (29): inadequate metabolic control is often the reason for referral by the general practitioner to an internist or endocrinologist. In addition, a considerable number of our patients had been treated with insulin for only a short period, and therefore had not yet reached stable metabolic control. In agreement with the European Consensus (30) we consider a patient eligible for insulin therapy, when his $\mathrm{HbA}_{1 \mathrm{c}}$ level repeatedly exceeds $8.0 \%$ despite maximal doses of oral hypoglycaemic agents.

In comparison with a recently published survey of type 2 diabetic patients belonging to the practices of 4 general practitioners in a rural area in the east of the Netherlands (25), a larger number of our patients ( $48 \% v s .22 \%)$ was treated with insulin. With this more difficult therapy metabolic control was better. Extrapolating from the data of Verhoeven (25) this means that one quarter of the Dutch type 2 diabetic patients are being treated with insulin. In addition, again based on the data of Verhoeven (25) and those of Jonker (31), at least $20 \%$ of patients treated by their G.P.'s show such poor metabolic control that they should be treated with insulin. Organisation of diabetes care is very important in this respect; routine care in general practice for type 2 diabetic patients was shown to be less satisfactory than care by the hospital clinic (32). Institution of general practice mini-clinics improved regular review and screening for complications compared to routine care in the general practices (33).

The prevalence of vascular abnormalities in our patients was slightly higher than that reported in the G.P. population. This high prevalence of coronary artery disease $(48 \%)$, hypertension $(56 \%)$, cerebrovascular disease $(15 \%)$ and peripheral artery disease $(35 \%)$ implies a tendency for clustering of more complicated patients with type 2 diabetes in a hospital-clinic. This may be caused by the necessity of more aggressive treatment after vascular problems have been diagnosed, for instance the institution of insulin therapy because of diabetic foot problems, or worsening of control after myocardial infarction. Otherwise, patients in poor control are likely to be referred by their G.P. for treatment advice and insulin therapy.

In general, a two- to three-fold increase of morbidity and mortality attributed to coronary heart disease is demonstrated in diabetic patients over 45 years of age compared with the non-diabetic population (34). The prevalence of CHD is 
already 3 times elevated in newly-diagnosed non-insulin-dependent diabetes as compared with control subjects (35), and may be as high as $30-40 \%$ among patients with longer term diabetes (1). More than $40 \%$ of our patients suffered from coronary artery disease.

Peripheral vascular disease (PVD) is often found in diabetic patients compared to non-diabetic individuals. Peripheral vascular disease is evidenced by the presence of intermittent claudication, absence of dorsalis pedis pulse, or arterial calcification. Sequelae may be serious infections or ulcers, gangrene and amputation (36). The presence of PVD has been shown to predispose for acute cardiovascular events, such as myocardial infarction and stroke. The vessels most frequently involved are those below the knee, while the occlusions are often multisegmental. The reported incidence and prevalence figures vary because of differences in definition of PVD, the type of diabetes in the patients studied, their age, and diabetes treatment. It is estimated that $6-10 \%$ of type 2 diabetic patients have evidence of PVD at the moment of diagnosis, while after 20 years of diabetes this figure averages $45 \%$ (or even higher among smokers). Other studies (37) give even higher prevalence figures: absence of $\geq 2$ peripheral vascular pulses was noted in $60 \%$ of the diabetic patients between 60 and 79 years, against $40 \%$ in the non-diabetic individuals. In our patients, these results are less outspoken. This may be due to a lower mean age of our patients; $30 \%$ was younger than 60 years. Further, non-invasive techniques such as Doppler studies may considerably increase the number of patients identified to have vascular abnormalities. These investigations are not routinely used for the follow-up of diabetic patients, and usually only performed during evaluation of patients for intermittent claudication, leg ulcers e.a. Although in 7 patients an amputation was performed, in 3 of them this was the consequence of an infectious problem.

Prevalence of hypertension was $54 \%$ in the male and $58 \%$ in the female patients. Teuscher et al (38) reported a hypertension prevalence of $34 \%$ in patients with late-onset (after the age of 30 years) diabetes, who were under treatment by their primary care physician. Sprafka et al (19) found a prevalence of physician-defined hypertension in $34 \%$ of male and $57 \%$ of female patients with type 2 diabetes.

Especially in the patients with elevated urinary albumin excretion a higher prevalence of hypertension, cerebrovascular and peripheral vascular disease and retinopathy was found in comparison to normoalbuminuric patients. This is in agreement with other reports. Allawi and Jarrett (39) demonstrated higher blood pressure levels in type 2 diabetic pattents with overnight albumin excretion rate $10 \mu \mathrm{g} / \mathrm{min}$ in comparison with patients with lower albumin excretion. Marshall and Alberti (40) found a significant relation between albumin excre- 
tion and systolic blood pressure and retinopathy and peripheral vascular disease, whereas others demonstrated increasing albumin excretion in patients with increasing severity of retinopathy (41). Proteinuria and albuminuria are strongly associated with mortality $(42,43,44)$. Therefore, determination of microalbuminuria may identify patients with high risk of acute cardiovascular events, and form a basis for more aggressive therapeutic interventions (normalization of elevated blood pressure and cholesterol levels) to prevent such complications.

It has previously been shown that diabetic patients with hypercholesterolaemia are at very high risk of developing coronary heart disease (24) and dying from cardiovascular causes (44) in comparison to non-diabetic subjects and diabetic subjects with normal cholesterol levels. During a follow-up period of 7 years, the incidence of coronary heart disease was $28 \%$ in diabetic patients with serum cholesterol above $7.3 \mathrm{mmol} / \mathrm{l}$ against $5 \%$ in the diabetics with cholesterol levels below $5.5 \mathrm{mmol} / \mathrm{l}$. The corresponding figures for non-diabetic men were $9.4 \%$ and $2.4 \%$, respectively. Similar data are reported from the Prospective Cardiovascular Münster (PROCAM) study (23). In our survey, total and LDL-cholesterol were considerably higher, and HDL-cholesterol was lower compared to non-diabetic individuals. Furthermore, although metabolic control was good in the diet-treated patients, they tended to have higher total cholesterol and triglyceride levels, and lower HDL-cholesterol compared to insulin-treated patients. Considering the high prevalence of cardiovascular disease these findings reappraise the tremendous impact of hypercholesterolaemia as a risk factor in diabetic patients, and urges for extensive efforts to normalize serum cholesterol (45).

Due to the presence of severe complications use of medication in addition to the specific antidiabetic therapy is very frequent. Antihypertensive or anti-anginosal agents are being used by almost $50 \%$ of the patients. Sixty-seven percent of the patients take medication that is prescribed for a reason related to a cardiovascular abnormality. This number is quite similar to that of other reports $(25,46)$. Only 25 patients take no additional medication at all. Twenty percent of the patients used beta-blockers, and $30 \%$ took diuretics. Both types of drugs have deleterious effects on glucose and lipid metabolism: they may worsen blood glucose control, and elevate cholesterol and triglyceride levels $(47,48)$. Further, beta-blockers may impair the recognition of and recovery from hypoglycaemia, which risk is more substantial in insulin-treated patients. As ACE-inhibitors and calcium-entry blockers show less or no negative metabolic effects (49), these are considered at present the first-line antihypertensive agents in diabetic patients. 
We conclude that the occurrence of vascular abnomalities is high in patients with type 2 diabetes mellitus, both among the patients of our hospital outpatient-clinic, as well as in the patients in the general practice. The demonstration of microalbuminuria already is a strong indicator for such complications. Considering the apparent clustering of risk factors as poor metabolic control, obesity, hypertension and dyslipidaemia, attaining optimal blood glucose control forms only one of the aims of treatment in order to prevent life-limiting vascular complications. Striving for normal $\mathrm{HbA}_{1 \mathrm{c}}$ levels seems futile without concomitant adequate treatment of elevated blood pressure and hypercholesterolaemia.

\section{REFERENCES}

1. Panzram $G$. Mortality and survival in type $I$ (non-insulin-dependent) diabetes mellitus. Diabetologia 1987; 30: 123-131.

2. Jarrett RJ. Epidemiology and public health aspects of non-insulin-dependent diabetes mellitus. Epidemiol Rev 1989; 11: 151-171.

3. Keen H, Jarrett RJ, Fuller JH, McCartney P. Hyperglycaemia and arterial disease. Diabetes 1981; 30 (suppl): $49-53$.

4. Pirart J. Diabetes mellitus and its degenerative complications: a prospective study of 4400 patients observed between 1947 and 1973. Diabetes Care 1978;1: 168-188 and 252-263.

5. Brand FN, Abbott RD, Kannel WB. Diabetes, intermittent claudication, and risk of cardiovascular events the Framingham study. Diabetes 1989; 38: 504-509.

6. Kannel WB. Lipids, diabetes and coronary heart disease: insights from the Framingham Study. Am Heart J 1985; 110: 1100-1107.

7. Fuller MH, Shipley MJ, Rose G, Jarrett RJ, Keen H. Mortality from coronary heart disease and stroke in relation to degree of glycaemia: the Whitehall study. Br Med J1983;287: $867-870$.

8. Greene DA. Acute and chronic complications of diabetes mellitus in older patients. Am J Med 1986; 80 (suppl. 5a): 36-53.

9. Kreines K, Johnson E, Albrink M, et al. The course of peripheral vascular disease in non-insulin-dependent diabetes. Diabetes Care 1985; 8: 235-243.

10. Beach KW, Bedford GR, Bergelin RO. Progression of lower arterial occlusive disease in type II diabetes mellitus. Diabetes Care 1988; 11: 464-472.

11. Abbott RD, Brand FN, Kannel WB. Epidemiology of some peripheral arterial findings in diabetic men and women: experiences from the Framingham study. Am J Med 1990; 88: 376-381.

12. Blankenship GW, Skyler JS. Diabetic retinopathy: a clinical survey. Diabetes Care 1978; 1: $127-131$.

13. Chase HP, Jackson WE, Hoops SL, et al. Glucose control and the renal and retinal complications of insulin-dependent diabetes. JAMA 1989; 261: 1155-1160. 
14. Hiller $\mathrm{R}$, Sperduto RD, Podgor MJ, Ferris FL, Wilson PWF. Diabetic retinopathy and cardiovascular disease in type II diabetics. The Framingham heart study and the Framingham eye study. Arr J Epidemiol 1988; 128: 402-409.

15. Klein $\mathrm{R}$, Klein BEK, Mosis $\mathrm{SE}$, Davis MD, De Mets DL. The Wisconsin Epidemiologic study of diabetic retinopathy. III. Prevalence and risk of diabetic retinopathy, when age at diagnosis 30 or more years. Arch Ophthalmol 1984; 102: $527-532$.

16. Selby JV, FitzS Immons SC, Newman JM, Katz P, Sepe S, Showstack J. The natural history and epidemiology of diabetic nephropathy implications for prevention and control. JAMA $1990 ; 263 ; 1954-1960$.

17. Cooper ME, Frauman A, O'Brien RCO, Seeman E, Murray RML, Jerums G. Progression of proteinuria in type 1 and type II diabetes. Diabetic Med 1988; 5: 361-368.

18. Klein R, Klein BEK, Moss SE, Demets DL. Blood pressure and hypertension in diabetes. Am J Epidemiol 1985 122: 75-89.

19. Sprafka JM, Bender AP, Jagger HG. Prevalence of hypertension and associated risk factors among diabe ric individuals. The Three-City Study. Diabetes Care 1988; 11: 17-22.

20. Uusitupa $M$, Sitonen O. The relationship of cardiovascular risk factors to the prevalence of coronary heart disease in newly diagnosed type II (non-insulin-dependent) diabetes. Diabetologia $1985 ; 28: 653-659$.

21. Reaven GM. Abnormal lipoprotein metabolism in non-insulin-dependent diabetes mellitus. Am J Med 1987; 83 (suppl.3A): 31-40.

22. Billingham MS, Milles JJ, Bailey CJ, Hall RA. Lipoprotein subfraction composition in non-insulin -dependent diabetes treated by diet, sulphonylurea, and insulin. Metabolism $1989 ; 38: 850-857$.

23. Assmann G, Schulte H. Diabetes mellitus and hypertension in the elderly: concomitant hyperlipidemia and coronary heart disease risk. Am J Cardiol 1989; 63; 33H-37H.

24. Rosengren A, Welïn L, Tsipogianni A, Wilhelmsen L. Impact of cardiovascular risk factors on coronary heart disease and mortality among middle aged diabetic men: a genera] population study. Br Med J 1989; 299: 1127-1131.

25. Verhoeven $S$. Treatment, follow-up and metabolic regulation of patients with diabetes mellitus type II and the prevalence of late complications in this group of patients. Thesis, Rotterdam/Heerde, 1989.

26. Rose GA, Blackburn H, Gillum RF, Prineas RJ. Cardiovascular survey methods. 2nd edn. Geneva: World Health Organization, 1982.

27. Boulton AJM, Knight $G$, Dury J, Ward JC. The prevalence of symptomatic diabetic neuropathy in an insulin-treated population. Diabetes Care 1985; 8: 125-128.

28. Johnson RN, Metcalf PA, Baker JR. Fructosamine: a new approach to the estimation of serum glycosylprotein. An index of diabetic control. Clinica Chim Acta 1982; 127: 87-95.

29. Peacock 1 , Tattersall RB. The difficult choice of treatment for poorly controlled maturity onset diabetes: tablets or insulin. Br Med J 1984; 288: 1956-1959.

30. Alberti KGMM, Gries FA. Management of non-insulin-dependent diabetes mellitus in Europe: a consensus view. Diabetic Med 1988; 5: 275-281.

31. Jonker JJ, Rozendaal AA. Tweejaars resultaten van het Diabetes Centrum Rotterdam (DCR). Tijdschr Therapie Geneesmiddel Onderzoek 1988; 13: 209-220.

32. Hayes TM, Harries J. Randomised controlled trial of routine hospital clinic care versus routine general practice care for type II diabetics. Br Med J 1984; 289: 728-730. 


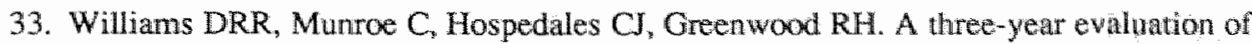
the quality of diabetes care in the Norwich community care scheme. Diabetic Med 1990 ; 7: 74-79.

34. Kannel WB, McGee DL. Diabetes and cardiovascular risk factors: the Framingham study. Circulation $1979 ; 59: 8-13$.

35. Uusitupa $M$, Siitunen $\mathrm{O}$, Aro A, Pyöralla $\mathrm{K}$. Prevalence of coronary heart disease, left ventricular failune and hypertension in middle-aged, newly diagnosed type 2 (non-insulin* dependent) diabetic subjects. Diabetologia $1985 ; 28: 22-27$.

36. Levin ME, Sicard GA. Peripheral vascular disease in the person with diabetes. In: Ellenberg and Rifkin's Diabetes mellitus: Theory and Practice. Rifkin H, Porte D Ir, Eds. 4th Edition, Elsevier Science Publishing Co., New Hyde Park, NY, 1990.

37. Pyörälä K, Laakso M. Macrovascular disease in diaberes mellitus. In: Mann Jl, Pyörila $\mathbb{K}$, Teuscher $\mathbb{K}$, eds. Diabetes in epidemiological perspective. Churchill-Livingstone, Edinburgh-London, 1983: 183-231.

38. Teuscher A, Egger M, Herman JB. Diabetes and hypertension blood pressure in clinical diabetic patients and a control population. Arch Intern Med 1989; 149: 1942-1945.

39. Allawi J, Jarrett RJ. Microalburninuria and cardiovascular risk factors in type 2 diabetes mellitus. Diabetic Med 1989; 7: 115-118.

40. Marshall SM, Alberti KGMM. Comparison of the prevalence and associated features of abnormal albumin excretion in insulin-dependent and non-insulin-dependent diabetes. $Q$ J Med 1989; 70:61-71.

41. Agardh $\mathrm{E}$, Torffit $\mathrm{O}$, Agardh $\mathrm{C}-\mathrm{D}$. Putative risk factors associated with retinopathy in patients with diabetes diagnosed at or after 30 years of age. Diabetic Med 1989; 6: 724-727.

42. Mogensen CE. Microalbuminuria predicts clinical proteinuria and early mortality in maturity-onset diabetes. New Engl J Med 1984; 310: 356-360.

43. Jarrett RJ, Viberti GC, Argyropoulos A, Hill RD, Mahmud U, Murells T. Microalbuminuria predicts mortality in non-insulin-dependent diabetes. Diabetic Med 1984; 1; 17-20.

44. Morrish NJ, Stevens LK, Head J, Fuller JH, Jarrett RJ, Keen H. A prospective study of mortality among middle-aged diabetic patients (the London cohort of the WHO Multinational Study of Vascular Disease in Diabetics) II: associated risk factors. Diabetologia $1990 ; 33: 542-548$.

45. Recognition and management of hyperlipidemia in adults: policy statement of the

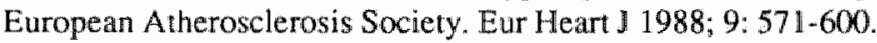

46. Gram J, Damsgaard EM. Drug consumption in elderly diabetics. Diab Res Clin Pract $1989 ; 7: 293-298$.

47. Lardinois CK, Neuman SL. The effects of antihypertensive agents on serum lipids and lipoproteins. Arch Intern Med 1988; 148: 1280-1288.

48. Kaplan NM, Rosenstock J, Raskin P. A differing view of treatment of hypertension in patients with diabetes mellitus. Arch Intern Med 1987; 147: 1160-1162.

49. Kingma PJ, Simons JPFHA, Nieuwenhuijzen Kruseman AC, Wolffenbuttel BHR. Calcium entry blockers and their effects on glucose metabolism. Neth J Med 1990; 36:32-38. 


\section{APPENDIX}

\section{General questions}

Personal:

- name and sex

- date of birth

- lime of diagnosis of diabetes

- diabettes in pregnancy

Other diseases that diabetes mellitus that are known to be present:

- hypertemsion

- cardiovascular diseases (myocardial infarction, angina pectoris)

- cerebrovascular events

- kidney diseases

- other important complaints and discases

Use of medication:

- anthypertensi we agenss

- diuretics

- anticoagulants

- corticosteroids

- other drugs (specified)

\section{Simoking:}

- duration and amount

Present therapy of diabetes:

- oral thypoglycaemic agents or insulin

- duration of and dose of treatment

Questions related to ischaemic hear disease:

- are there complaints of chest pain, prowoked by exercise or cold?

- was the patient previously been evaluated because of cardiac complaints?

- was there a hospital admittance because of: myocardial infarction or impending infarction, or was cardiac bypass surgery performed?

- does the patient use medication because of cardiac complaints?

Questions related to cerebrovascular disease:

- loss of power or movement in arm or leg, or speech disturbances for a short period of time

- was the patient previously been evaltated because of such complaints?

- carotid artery surgery

- previous cardiac surgery (valve replacement)

Questions related to peripheral vascular disease:

- are there complaints of pain in one or both legs during walking, and does this pain subside when holding still?

- is the walking distance limited because of pain
- in one or both legs?

- are the any complants of cold feet?

- was surgery performed on the blood vessels in legs or abdomen?

Questions related to mephropathy:

- are there known diseases of kidney or urinary tract?

- did the paltient suffer from kidney stones?

- were there previous urinary tract infections?

- is the patient known to have diabetic nephropathy?

- does the patient have an indwelling bladder catheter?

- any previous surgery to the urinary tract?

Questions related to retinopathy:

- are there problems with seeing?

- hospital admittance because of eye problems: what was the diagnosis and treatment

- use of medication because of eye problems

- known to have other (non-diabetic) eye disease

Questions related to neuropathy:

- peripheral:

pricking or burning sensations in feet or legs complaints present during the day or the night can the patient walk longer distances?

if not: stop walking after what distance do small skin wounds heal rapidly?

- autonomic: complaimts of recurrent diarrhoea is there still need to urinate after miction?

\section{Physical examination}

\section{General:}

- height and length

- blood pressure supine and standing

Vascular examination:

- pulsations (and murmurs) of: carotid artery femoral antery popliteal artery posterior tibial artery dorsal pedal artery

Neurologic examination:

- loss of muscle strength

- reflexes.

- vibration sense

Retinopathy:

- visual acuity

- retinal abnormalities

Inspection of the feet:

- abnormalities of color

- skin abnormalities (edema, nails, infection, small wounds)

- anatomical abnomalities (clawfoot, valgus) 
CHAPTER

\section{Clinical characteristics and management of diabetic patients residing in a nursing home}

Bruce H.R. Wolffenbuttel, Susan van Vliet, André J.F. Knols, Wilbert L.H. Slits, Jean-Pierre J.E. Sels, Arie C. Nieuwenhuijzen Kruseman

Submitted 
In 38 diabetic patients, chronically admitted to a nursing home, the clinical situation and presence of secondary diabetic complications were assessed, and their macrovascular complications and degree of glycaemic control compared with those in ambulatory diabetic patients, matched for age, sex, known duration of diabetes, and specific antidiabetic therapy. No differences in blood glucose control, plasma triglycerides, blood pressure and serum creatinine were observed between both groups of patients. Plasma cholesterol levels were higher in the ambulatory patients $(6.4 \pm$ 1.0 vs. $5.6 \pm 1.1 \mathrm{mmol} / \mathrm{l}, \mathrm{p}=0.008$ ). Twenty-two nursing home patients had suffered from stroke, against 4 ambulatory patients. Hypertension was found in almost $50 \%$ of all patients, whereas its prevalence was the highest in the stroke patients (69 vs. 36\%, $p<0.01$ ). In the nursing home patients peripheral vascular abnormalities, skin necrosis or leg ulcers and recurrent urinary tract infections were frequently encountered, whereas in the ambulatory patients cardiac complaints were more prevalent. Use of medication, especially diuretics and anticoagulant agents, was higher in the nursing home patients. Diabetes and the sequelae of its macrovascular complications may greatly impair the quality of life of the diabetic patient, and place a large financial and personal burden on the health care in general. Better identification of diabetic patients with high risk of stroke is necessary. 


\section{INTRODUCTION}

Diabetes and its complications may greatly impair the quality of life of the elderly diabetic patient ( 1 ), and place a large burden of costs on health care in general. Diabetes is one of the major risk factors for cardiovascular disease. Admission of diabetic patients to a nursing home is often necessary for permanent care or for the purpose of psychological and somatic rehabilitation after a cardiovascular event. Previous studies have indicated that about $15 \%$ of patients in nursing homes have diabetes mellitus (2). One-third of them is treated with insulin. The exact reasons for admission to a nursing home may vary considerably. The presence of micro- and macrovascullar diabetic complications forms a causative or promoting factor. Diabetic patients in a nursing home show a high prevalence of macrovascular abnormalities, leading to signs and symptoms of coronary, cerebral and peripheral vascular insufficiency, as well as a high prevalence of visual abnormalities, including diabetic retinopathy, maculopathy, and cataract $(2,3)$. Furthermore, a high incidence of infections, both of the skin and of the urinary tract, was reported in such patients (2).

To get an impression about the clinical conditions predisposing for admission to a nursing home, we held a survey among diabetic patients, admitted to a nursing home, to characterize their clinical situation, the presence of secondary macrovascular complications and facilities necessary for the management of these patients. The severity of vascular complications and degree of glycaemic control in these patients were compared with those in ambulatory diabetic patients, carefully matched for age, sex, known duration of diabetes, and specific antidiabetic therapy.

\section{MATERIALS AND METHODS}

\section{Patients}

Of 55 patients with diabetes mellitus according to the WHO criteria (4), who were chronically admitted to two nursing homes in the city of Maastricht (total population 470 patients), thirty-eight participated in the study. The mean age of the patients was $77 \pm 9$ (range 58-92) years. There were 9 male and 29 female patients. The clinical characteristics of this group of patients are summarized in table 1. In 17 patients the assessments outlined below were not performed. Reasons for this were the presence of psychogeriatric illnesses, malignancy or diminished life expectancy less than 2 years, or refusal by the patient. Age, 
diabetes duration and presence of vascular complications of the latter group was not different from the patients studied.

\section{Assessments}

For each patient, the following information was recorded by means of a detailed history, review of the notes of previous hospital admissions and charts from the outpatient clinic, and present nursing home patient charts: the reason for admission to the nursing home, previous illnesses and medical events, presence of secondary diabetic complications (vascular, neurologic, nephrologic) and present medication on prescription (excluding vitamin supplements and laxatives). Data on retinal abnormalities were to limited to allow analysis. Routine physical examination was performed, with special attention for systolic and diastolic (Korotkov V) blood pressures, heart rate, peripheral vascular abnormalities, gangrene and amputations, and neurologic examination (vibration sense, reflexes).

Laboratory evaluation included urine analysis for white cells and protein, serum creatinine, as well as plasma lipid determinations (total cholesterol and triglycerides). Blood glucose control was assessed by determination of glycosylated haemoglobin ( $\mathrm{HbA}_{\mathrm{lc}}$ ), serum fructosamine, and fasting blood glucose level. Fasting plasma free insulin and $C$-peptide levels were measured to determine residual islet B-cell function, and to ascertain type of diabetes. In addition, an electrocardiogram was made.

\section{Comparison with hospital-treated patients}

The clinical characteristics and the degree of blood glucose control of the nursing home diabetic patients were compared with a group of elderly ambulatory diabetic patients, matched as closely as possible for age, sex, time from diagnosis of diabetes, and antidiabetic therapy. Those patients were selected from a large group of diabetic outpatients treated in the Department of Internal Medicine of the University Hospital Maastricht.

\section{Laboratory determinations}

Blood glucose was measured in venous whole blood with an automated hexokinase method. Serum fructosamine was determined on the Cobas Bio analyser according to Johnson et al. (5) after alkalinising and reduction with nitroblue tetrazolium (Sigma). Calibration was performed with 1-desoxy-1-morpholinofructose (Sigma) in an albumin solution. The reference values of this assay are 
lower than those of the commercially-available Fructosamine Roche kit, due to the use of a different standard and reductor. Comparison with the Roche kit was excellent $(r=0.98 ; y=1.16 x+2, p<0.001)$. Between-assay of our fructosamine determination is $4 \%$. HbAlc was determined with high pressure liquid chromatography (DIAMAT, Bio-Rad Laboratories, Richmond, Ca., USA, normal values $4.4-6.2 \%$, between-assay cv $2.6 \%$ ). Plasma cholesterol and triglycerides were determined by enzymatic methods. Plasma free insulin (Pharmacia, Uppsala, Sweden) and C-peptide (Mallinckrodt, FRG) levels were measured with radio-immunoassay. Between-assay variation of insulin-RIA was $7.5 \%$, and C-peptide $9 \%$.

The electrocardiogram was assessed for the presence of definite or probable ischaemia according to the Minnesota code (6). Q- and QS-abnormalities (Minnesota codes 1-1, 1-2,7-1) were considered definite signs of myocardial infarction, minor Q-QS changes (code 1-3) and ST-segment and T-wave abnormalities (Minnesota codes 4-1 through 4-4, if accompanied by 5-1 or 5-2 or 5-3) were considered possible ischaemia.

\section{Statistical analyses}

All data are reported as means $\pm \mathrm{SD}$. Differences between group means were tested with one-way analysis of variance, with Student-Newman-Keuls correction for multiple comparisons, or by non-parametric test (Wilcoxon), when data were not normally distributed. For variables involving categorical classifications, chi-square and Fisher's exact tests (two-sided) are used. P-values less than 0.05 were considered statistically significant.

\section{RESULTS}

The clinical characteristics of both groups of diabetic patients are depicted in table 1. Four nursing home patients were treated with diet alone, whereas 19 received oral hypoglycaemic agents as well. Nine of the nursing home patients received biguanides (metformin), alone $(n=3)$ or in addition to sulphonylurea $(n=6)$. Matching for this therapy was not completely possible, because of the small number of matching ambulatory diabetic patients treated with metformin $(n=5)$. Fifteen nursing home patients used insulin, for a median period of 20 months. Daily insulin dose was $39 \pm 15 \mathrm{U}$. Based on the levels of fasting C-peptide, one nursing home patient was classified as having insulin-dependent (type 1) diabetes. 
Table 1. Clinical characteristics of the parients studied.

\begin{tabular}{|c|c|c|c|c|}
\hline & \multicolumn{2}{|c|}{ NURSING HOME } & \multicolumn{2}{|c|}{ AMBULATORY } \\
\hline & $\begin{array}{l}\text { Diet and/or } \\
\text { oral agents } \\
(n=23)\end{array}$ & $\begin{array}{l}\text { Insulin } \\
(n=15)\end{array}$ & $\begin{array}{l}\text { Diet and/or } \\
\text { oral agents } \\
(n=22)\end{array}$ & $\begin{array}{l}\text { Insulin } \\
(n=16)\end{array}$ \\
\hline Age (years) & $78 \pm 8$ & $77 \pm 10$ & $77 \pm 7$ & $78 \pm 9$ \\
\hline Male: fiemale & $5: 18$ & $4: 11$ & $6: 16$ & $3: 13$ \\
\hline Body mass index $>27 \mathrm{~kg} / \mathrm{m}^{2}$ & 5 & 5 & 8 & 10 \\
\hline $\begin{array}{l}\text { Known duration of } \\
\text { diabetes (years) }\end{array}$ & $\begin{array}{l}10 \\
(1.5-30)\end{array}$ & $\begin{array}{l}13 \\
(1-50)\end{array}$ & $\begin{array}{l}11 \\
(1-22)\end{array}$ & $\begin{array}{l}16 \\
(1-32)\end{array}$ \\
\hline $\begin{array}{l}\text { Duration of insulin } \\
\text { therapy (months) }\end{array}$ & & $\begin{array}{l}20 \\
(10-84)\end{array}$ & & $\begin{array}{l}24 \\
(1-108)\end{array}$ \\
\hline Units insulin & & $39 \pm 15$ & & $34 \pm 13$ \\
\hline
\end{tabular}

Mean $\pm S D$, or median (range)

Table 2. Metabolic and bloodpressure data in the nursing home and ambulatory diabetic patients.

\begin{tabular}{|c|c|c|c|c|}
\hline & \multicolumn{2}{|l|}{ NURSING HOME } & \multicolumn{2}{|c|}{ AMBULATORY } \\
\hline & $\begin{array}{l}\text { Diet and/or } \\
\text { oral agents } \\
(n=23)\end{array}$ & $\begin{array}{l}\text { Insulin } \\
(n=15)\end{array}$ & $\begin{array}{l}\text { Diet and/or } \\
\text { oral agents } \\
(n=22)\end{array}$ & $\begin{array}{l}\text { Insulin } \\
(n=16)\end{array}$ \\
\hline Fasting blood glucose (nmol/1) & $6.2 \pm 1.9$ & $9.3 \pm 3.7^{\#}$ & $8.3 \pm 2.2^{\$}$ & $8.0 \pm 3.1$ \\
\hline Serum fruclosamine (mmol/l) & $1.22 \pm 0.18$ & $1.34 \pm 0.16$ & $1.47 \pm 0.32^{\$}$ & $1.42 \pm 0.38$ \\
\hline Glycosylated haemoglobin $(\%)$ & $7.3 \pm 1.5$ & $8.1 \pm 1.3$ & $8.1 \pm 1.6$ & $8.2 \pm 1.8$ \\
\hline Fasting plasma insulin (pmol/l) & $62(30-210)$ & $88(44-163)$ & N.D. & N.D. \\
\hline Fasting plasma C-peptide (pmol/l) & $830(360-2190)$ & $490(10-2710)^{*}$ & N.D. & N.D. \\
\hline Plasma cholesterol (mmol//) & $5.7 \pm 1.2$ & $5.4 \pm 1.0$ & $6.7 \pm 1.0^{\$}$ & $6.1 \pm 1.0$ \\
\hline Plasma triglycerides (mmol/) & $2.00 \pm 1.18$ & $1.57 \pm 0.88$ & $1.89 \pm 0.90$ & $1.60 \pm 0.74$ \\
\hline Serum creatinine $(\mu \mathrm{mol} / \mathrm{l})$ & $89 \pm 32$ & $97 \pm 46$ & $96 \pm 23$ & $92 \pm 28$ \\
\hline Systolic blood pressure ( $\mathrm{mm} \mathrm{Hg}$ ) & $1.54 \pm 23$ & $141 \pm 21$ & $153 \pm 12$ & $148 \pm 22$ \\
\hline Diastolic blood pressure (mm Hg) & $89 \pm 11$ & $84 \pm 14$ & $80 \pm 6^{\$}$ & $84 \pm 9$ \\
\hline
\end{tabular}

* $\mathrm{p}<0.05,{ }^{\#} \mathrm{p}<0.01 \mathrm{ws}$, tablet-treated nursing home patients;

$\$ p<0.01$ vs. nursing home patients; N.D. = not determined 
Although fasting blood glucose levels were the lowest in the nursing home patients, treated with diet and oral agents, no overall differences in blood glucose control, as determined by serum fructosamine and $\mathrm{HbA}_{\mathrm{tc}}$, were observed (table 2). Plasma cholesterol levels were higher in the ambulatory patients $(6.4 \pm 1.0 \mathrm{v}, 5.6 \pm 1.1 \mathrm{mmol} / \mathrm{l}, \mathrm{p}=0.008)$, whereas plasma iriglycerides, blood pressure and serum creatinine did not differ.

Table 3 shows the prevalence of the associated medical problems which were found in both groups of patients. No differences were found between diabetic patients treated with oral agents and those on insulin. Prevalence of macrovascular complications, especially cerebrovascular accidents, was extremely high in the nursing home patients. Sixteen patients had suffered an extensive cerebrovascular accident, leading to hemiplegia. In most of the cases this was the reason for admittance to the nursing home. Only 4 ambulatory patients $(p<0.001)$ had previously experienced a cerebrovascular problem. The prevalence of previous myocardial infarction or complaints suggesting angina pec-

Table 3. Medical problems in the nursing home and ambulatory diabetic patients.

\begin{tabular}{|c|c|c|c|c|c|c|}
\hline & \multicolumn{3}{|c|}{ NURSING HOME } & \multicolumn{3}{|c|}{ AMBULATORY } \\
\hline & \multicolumn{2}{|c|}{ or oral agents } & \multirow{2}{*}{$\begin{array}{l}\text { Total } \\
(n=38)\end{array}$} & \multicolumn{2}{|c|}{$\begin{array}{l}\text { Diet and/ Insulin } \\
\text { or oral agents }\end{array}$} & \multirow{2}{*}{$\begin{array}{l}\text { Total } \\
(n=38)\end{array}$} \\
\hline & $(n=23)$ & $(n=1.5)$ & & $(n=22)$ & $(n=16)$ & \\
\hline Hypertension & $12(52 \%)$ & $7(47 \%)$ & $19(50 \%)$ & $7(33 \%)$ & $10(62 \%)$ & $17(45 \%)$ \\
\hline \multicolumn{7}{|c|}{ History of myocardial infarction } \\
\hline or angina pectoris & $6(26 \%)$ & $3(20 \%)$ & $9(24 \%)$ & $12(57 \%)^{*}$ & $6(38 \%)$ & $18(47 \%)^{*}$ \\
\hline \multicolumn{7}{|l|}{ ECG-changes definite } \\
\hline ischatemia $^{b}$ & $7(30 \%)$ & $3(20 \%)$ & $10(26 \%)$ & $6(27 \%)$ & $5(31 \%)$ & $11(29 \%)$ \\
\hline Cerebrowascular accident & $15(65 \%)$ & $7(47 \%)$ & $22(58 \%)$ & $0(0 \%)^{\&}$ & $4(25 \%)$ & $4(11 \%)^{8}$ \\
\hline \multicolumn{7}{|l|}{ Periphera] wascular disease } \\
\hline - peripheral pulses absent & $19(83 \%)$ & $10(67 \%)$ & $29(76 \%)$ & $4(19 \%)^{\&}$ & $9(56 \%)$ & $13(34 \%)^{8}$ \\
\hline - amputiations & $4(17 \%)$ & $5(33 \%)$ & $9(24 \%)$ & $1(5 \%)$ & $4(25 \%)$ & $5(13 \%)$ \\
\hline Overt proteinuria & $6(26 \%)$ & $4(27 \%)$ & $10(26 \%)$ & $4(19 \%)$ & $3(19 \%)$ & $7(18 \%)$ \\
\hline Microalbuminuria & $8(35 \%)$ & $4(27 \%)$ & $12(32 \%)$ & $4(19 \%)$ & $4(25 \%)$ & $8(21 \%)$ \\
\hline Urinary tract infections & $17(74 \%)$ & $12(80 \%)$ & $29(76 \%)$ & $1(5 \%)^{\%}$ & $5(31 \%)^{\#+}$ & $6(16 \%)^{2}$ \\
\hline Uninary bladder catheter & $6(26 \%)$ & $2(13 \%)$ & $8(21 \%)$ & $0(0 \%)^{*}$ & $0(0 \%)^{*}$ & $0(0 \%)^{\prime \prime}$ \\
\hline
\end{tabular}


Table 4. Use of prescriptional medication in the nursing home and ambulatory patients.

\begin{tabular}{|c|c|c|c|c|c|c|}
\hline & \multicolumn{3}{|c|}{ NURSING HOME } & \multicolumn{3}{|c|}{ AMBS ULATORY } \\
\hline & $\begin{array}{l}\text { Diet and/or } \\
\text { oral agents } \\
(n=23)\end{array}$ & $\begin{array}{l}\text { Insulin } \\
(n=15)\end{array}$ & $\begin{array}{l}\text { Total } \\
(n=38)\end{array}$ & $\begin{array}{l}\text { Diet and/or } \\
\text { oral agents } \\
(n=22)\end{array}$ & $\begin{array}{l}\text { Insulin } \\
(n=16)\end{array}$ & $\begin{array}{l}\text { Total } \\
(n=38)\end{array}$ \\
\hline Number of prescription & 3 & 3 & 3 & 2 & 1. & 1 \\
\hline drugs (median, range) & $0 \cdot 6$ & $0-11$ & $0-11$ & $0-4$ & $0-7$ & $0-7$ \\
\hline Antihypertensive agents & $8(35 \%)$ & $5(34 \%)$ & $13(34 \%)$ & $5(24 \%)$ & $3(18 \%)$ & $8(21 \%)$ \\
\hline Diuretic drugs & $13(57 \%)$ & $8(54 \%)$ & 21. $(55 \%)$ & $6(29 \%)$ & $6(35 \%)$ & $12(32 \%)^{*}$ \\
\hline Digitalis & $5(22 \%)$ & $3(20 \%)$ & $8(21 \%)$ & $3(14 \%)$ & $3(18 \%)$ & $6(16 \%)$ \\
\hline Anticoagulant agents $^{a}$ & $14(61 \%)$ & $6(40 \%)$ & $20(53 \%)$ & $4(19 \%)^{\#}$ & $1(6 \%)^{*}$ & $5(13 \%)^{\&}$ \\
\hline
\end{tabular}

a includes acenocoumarol, aspirin and dypiridamol;

${ }^{*} \mathrm{p}<0.05,{ }^{\mathrm{p}}<<0.01,{ }^{*} \mathrm{p}<0.001$, vs. nursing home patients

toris was lower in the nursing home patients than in ambulatory patients ( $p<0.05$ ). Peripheral arterial disease, as assessed on clinical grounds by palpation of peripheral pulses, was present in 29 nursing home patients. This finding may overestimate the true prevalence of arterial disease, because in 6 patients marked ankle edema was present, which made palpation of the pulses difficult. In 13 patients necrosis or decubitus of the skin at the sacrum or heels was found, and in 9 patients previously amputations were performed ( 5 patients with toe-amputations, 3 with lower leg and 1 with upper leg amputation). Absence of peripheral pulsations was less prevalent in the ambulatory patients $(\mathrm{p}<0.001)$. No differences in proteinuria were observed, although the prevalence of proteinuria may be overestimated in the nursing home patients, of whom 8 have permanent urinary bladder catheter, and who experienced more frequent urinary tract infections. The use of medication (diabetes therapy not included) was significantly less in the ambulatory patients. Especially diuretics and anticoagulant therapy were more frequently prescribed in the nursing home patients.

Age, duration of diabetes, number of patients on insulin therapy, blood glucose control and serum lipids were not different, when the 26 patients who had suffered a cerebrovascular event (CVA-group) were compared with the 50 patients without cerebrovascular disease (table 5). The proportion of patients with cardiac complaints or pathologic ECG was slightly, but not significantly smaller in the CVA group. Eighteen of the 26 patients with a CVA were known to have or being treated for hypertension, against 18 of the other group 
( $<<0.01$ ); actual blood pressure levels were similar (150/87 ws: $149 / 82 \mathrm{~mm} \mathrm{Hg}$ ). More CVA patients used anticoagulant therapy (15 vs. 10 patients, p<0.001).

\section{DISCUSSION}

The number of patients suffering from diabetes in our nursing home population $(12 \%)$ was similar to that reported in the literature (2). All but one were diagnosed as having non-insulin-dependent (type 2) diabetes. Forty percent of them was treated with insulin. Most patients were fairly controlled, considering their average $\mathrm{HbA}_{\mathrm{ic}}$ of $7.6 \%$. Blood glucose control was comparable to that of a group of age-, sex- and therapy-matched diabetic patients, treated at the outpatient-clinic of a large teaching-hospital. Plasma cholesterol levels were higher in the ambulatory patients. This may in part be explained by the slightly higher proportion of obese ambulatory patients, and perhaps the larger number of nursing home patients treated with metformin.

A striking finding in the nursing home patients is the very high prevalence of macroangiopathic complications. This comprises especially cerebrovascular accidents, which were found in 22 of the 38 patients, and peripheral arterial disease, ascertained by physical examination, and present in 29 patients. This finding is not surprising, because such vascular abnormalities may lead to hemiplegia or amputations, decrease daily functioning, and form the main reasons for admittance to the nursing home, either for revalidation or for permanent stay. Surprisingly, the prevalence of coronary artery disease, as estimated from cardiac complaints and use of antianginal medication was lower in the nursing home patients than in the ambulatory patients. This can in part be explained by the limited mobility of the patients; thus, exertional chest pain will seldomly be reported. Secondly, it may be argued that those diabetic patients developing severe coronary atherosclerosis will have died prematurelly from myocardial infarction before reaching an elderly age or before developing cerebrovascular complications. Silent ischaemia and silent myocardial infarction are known to be more common in elderly patients (7), and are even more prevalent in diabetic patients due to reduced pain sensations because of neuropathy (8). It is, however, expected that this occurs to the same extent in both the nursing home and the ambulatory patients. Coronary artery disease was more prominent in the ambulatory patients, who had less cerebrovascular and peripheral arterial disease. Coronary heart disease represents the most common form of vascular disease and the most prominent cause of death in type 2 diabetes (9). It may be postulated from our data that macrovascular disease in diabetic patients is expressed in at least two different forms, either as coronary 
Table 5. Metabolic data and prewalence of complications in diabetic patients with $(n=26)$ and without $(n=50)$ signs of cerebrovascular abnormalities.

\begin{tabular}{lll}
\hline & $\begin{array}{l}\text { With CVA } \\
(\mathrm{n}=26)\end{array}$ & $\begin{array}{l}\text { Without CVA } \\
(\mathrm{n}=50)\end{array}$ \\
\hline Fasting blood glucose (mmol/l) & $7.8 \pm 2.5$ & $7.8 \pm 2.9$ \\
Serum fructosarnine (mmol/l) & $1.32 \pm 0.25$ & $1.39 \pm 0.31$ \\
Glycosylatted haemoglobin $(\%)$ & $7.8 \pm 1.6$ & $8.0 \pm 1.6$ \\
Plasma cholesterol (mmol/1) & $6.1 \pm 1.3$ & $6.0 \pm 1.0$ \\
Plasma triglycerides (mmol/l) & $2.11 \pm 1.15$ & $1.64 \pm 0.78$ \\
Serum creatinine (umol/l) & $92 \pm 43$ & $94 \pm 24$ \\
Systidiastiblood pressure (mm Hg) & $150 / 87$ & $149 / 82$ \\
Hypertension & $18(69 \%)$ & $18(36 \%)$ \\
History of myocardial infarction & & $20(40 \%)$ \\
or angina pectoris & $7(27 \%)$ & $16(32 \%)$ \\
Abriormal ECG & $5(19 \%)$ & $24(48 \%)$ \\
Peripheral pulses absent & $18(69 \%)$ & \\
\hline
\end{tabular}

${ }^{b}$ Minnesota codes $1-1,1-2,7-1 ;{ }^{\#}$ p $<0.01$ ws. CVA patients

artery disease, or as peripheral-cerebrovascular abnormalities. In comparison with our data, Mooradian et al reported a lower prevalence of cerebrovascular $(32 \%)$ and peripheral vascular $(26 \%)$ disease, and a higher prevalence of angina or myocardial infarction $(60 \%)$ in their study of medical problems in nursing home diabetic patients (3). This discrepancy may in part be caused by methodological differences: their survey was mainly based on clinical history data suggestive of macroangiopathy.

The atherosclerotic process is more common in the diabetic than in the non-diabetic individual, appears at a younger age, and progresses more rapidly (10). It is almost as common in women as in men (11). In diabetic peripheral vascular disease (PVD), the vessels most frequently involved are those below the knee, the tibials and peroneals, and their smaller branches. At time of diagnosis (when hyperglycaemia usually is present for a number of years) $8 \%$ of type 2 diabetic patients have evidence of PVD. After 10 years the cumulative incidence averages $30 \%$ (11), and after 20 years even $50 \%$ (10). In the Framingham study diabetes was associated with a two- to threefold excess risk of intermittent claudication (12). About $50 \%$ of nontraumatic amputations are performed on diabetic patients. Stroke occurs two to six times more frequently 
in diabetic patients compared with non-diabetic subjects (13). Type 2 diabetic patients show a 2- to 4-fold increase in risk for death from cerebrovascular disease compared to non-diabetic persons. Stroke accounts for $15 \%$ of all deaths in patients with type 2 diabetes (14). The extent and degree of brain damage, as well as short term mortality after an ischaemic stroke is higher in diabetic patients than in non-diabetic persons, probably due to the deleterious effects of hyperglycaemia itself (15). Diabetic stroke patients more often have a history of hypertension than diabetic control patients without stroke (16), which is confirmed in the present study. A greater proportion of diabetic patients, who have recovered from stroke, will be dependent on others for daily living activities, or admitted to a nursing home for continuous care (15).

In a Dutch survey among type 2 diabetic patients of four general practitioner practices (17) evidence of cerebrovascular disease was found in $13 \%$ of the diabetic patients compared to $6 \%(\mathrm{p}=0.09)$ in non-diabetic control subjects of similar age, whereas peripheral vascular abnormalities, defined as 2 non-palpable foot arteries, were found in $52 \%$ of diabetic and $21 \%$ of non-diabetic individuals $(\mathrm{p}<0.001)$. Peripheral abnormalities were more prevalent -as can be expected- in the group of patients older than 70 years. Complaints indicating coronary artery disease (Rose questionnaire) were found in 41/134 (32\%) of diabetic and 26/128 (20\%) of non-diabetic persons, whereas electrocardiographic signs of myocardial ischaemia (Minnesota codes 1-1, 1-2, and 7-1) were found in $18 \%$, and $16 \%$, respectively. Significantly more diabetic persons were treated with diuretics, beta-blocking agents and anticoagulant drugs. These prevalence data, collected in a population of diabetic patients treated by GP's, are nearly similar to the prevalence of vascular abnormalities found in the ambulatory patients treated in our hospital. Thus, the data of our ambulatory patients are representative for the population of patients with type 2 diabetes in general.

As a consequence of limitation of mobility in the nursing home patients, perhaps together with periods of poorer blood glucose control and urinary bladder dysfunction, recurrent urinary tract infections, decubitus and skin infections were seen in about $70 \%$ of them. Eight patients needed a permanent urinary bladder catheter, which again increases the predisposition for infections.

Most of the patients admitted to the nursing home will reside there permanently, only 10-20\% will recover to such an extent that they can return to their homes. In the first half year after we performed our survey 2 of the 38 patients were able to leave the nursing home, whereas 7 patients died, 5 of them due to an acute cardiovascular event. Yearly costs of the stay in a nursing home average 80,000 Dutch guilders per person. An additional problem in Western 
health care is the limited number of nursing home beds, and the waiting list for admission. This makes it very difficult to discharge patients from a hospital to a nursing home, placing a larger burden on the hospital staff, and in turn causing large waiting lists for hospital admission, and more often the impossibility for acute admissions.

We conclude that a cerebrovascular accident is the most frequent cause for admission of diabetic patients to a nursing home. In this group of patients peripheral vascular abnormalities, hypertension, skin necrosis or leg ulcers, and recurrent urinary tract infections were frequently encountered. Use of medication, especially diuretics and anticoagulant drugs, was high. In a group of sex-, age and diabetes therapy-matched ambulatory patients cardiac complaints were more prevalent. Blood glucose control was virtually similar in both groups, although body mass index and plasma cholesterol were higher in the ambulatory patients. Diabetes and its macrovascular complications may greatly impair the quality of life of the diabetic patient, and place a large financial and personal burden on the health care in general. Better identification of diabetic patients with high risk of stroke is necessary.

\section{REFERENCES}

1. Tattersall RB. Diabetes in the elderly - a neglected area? Diabetologia 1984; 27: 167-173.

2. Mooradian AD, Osterweil D, Petrasek D, Morley JE. Diabetes mellitus in elderly nursing home patients. A survey of clinical characteristics and management. J Am Geriatr Soc 1988; 36: 391-396.

3. Morley JE, Mooradian AD, Rosenthal MJ, Kaiser FE. Diabetes mellitus in the elderly: is it different? Am J Med 1987; 83: 533-538.

4. WHO Expert Committee on diabetes mellitus second report. World Health Organization Techn. Rep. Serv. Geneva, 1985.

5. Johnson RN, Metcalf PA, Baker JR. Fructosamine: a new approach to the estimation of serum glycosylprotein. An index of diabetic control. Clinica Chim Act 1982; 127:, 87-95.

6. Rose GA, Blackburn H, Gillum RF, Prineas RJ. Cardiovascular survey methods. 2nd ed. Geneva: World Health Organization, 1982.

7. Coodley EL. Clinical spectrum and diagnostic techniques of coronary heart disease in the elderiy. J Am Geriatr Soc 1988; 36: 447-456.

8. Parmley WW. Prevalence and clinical significance of silent myocardial ischernia. Circulation 1989; 80 (suppl. IV): 68-73.

9. Jarrett RJ. Epidemiology and public health aspects of non-insulin-dependent diabetes mellitus. Epidemiol Rev 1989; 11: 151-171.

10. Levin ME, Sicard GA. Peripheral vascuiar disease in the person with diabetes. In: Ellenberg and Rifkin's Diabetes mellitus theory and practice, Rifkin, H., Porte Jr, D., eds, Elsevier Science Publishing Co, New York, 1990: 768-791. 
11. Kreines $\mathrm{K}$, Johnson $\mathrm{E}$, Albrink $\mathrm{M}$, et al. The course of peripheral vascular disease in non-insulin-dependent diabetes. Diabetes Care 1985; 8: 235-243.

12. Brand FN, Abbott RD, Kannel WB. Diabetes, intermittent claudication, and risk of cardiovascular events the Framingham study. Diabetes 1989; 38: 504-509.

13. Roccella EJ, on behalf of the Working Group on Hypertension in Diabetes. Statement on Thypertension in diabetes mellitus. Arch Intern Med 1987: 147: 830-842.

14. Panzram G. Mortality and survival in type 2 (non-insulin-dependent) diabetes mellitus. Diabetologia $1987 ; 30: 123 m 131$.

15. Pulsinelli WA, Levy DE, Sigsbee B, Scherer P, Plum F. Increased damage after ischemic stroke in patients with hyperglycemia with or without established diabetes mellitus. Am J Med 1983; $74: 540-544$.

16. Lithner F, Asplund K, Eriksson S, Hagg E, Strand T, Wester P-O. Climical characteristics in diabetic stroke patients. Diabete \& Metabolisme 1988; 14:15-19.

17. Verhoeven $\mathrm{S}$. Treatment, follow up and metabolic regulation of patients with diabetes mellitus type II and the prevalence of late complications in this group of patients. Thesis, Rotterdam/Heerde, 1989.

\section{ACKNOWLEDGMENTS}

The authors thank the medical staff of the Klevarie and Zeven Bronnen nursing homes for their support and cooperation. 


\section{The value of fasting blood glucose and serum fructosamine in the evaluation of metabolic control in type 2 diabetic patients}

Bruce H.R. Wolffenbultel, Jean-Pierre J.E. Sels, Frank H.W. Jungbauer, Paul P.C.A. Menheere, Arie C. Nieuwenhuijzen Kruseman

Submitted 
The value of fasting blood glucose (FBG) and serum fructosamine (SF) to reliably predict glycaemic control as measured by glycosylated haemoglobin (HbA $1 c, \mathrm{HPLC}$-method) was assessed during routine hospital visits in 264 type 2 diabetic patients on various treatments. Seventeen patients used diet only (group 1), and 126 took tablets in addition (group 2), while 89 were using insulin (group 3), and 32 insulin + sulphonylurea (group 4). Their mean age was $66 \pm 11$ years, known median duration of diabetes 10 (range 1-41) years, and body mass index $27.0 \pm 4.2 \mathrm{~kg} / \mathrm{m}^{2} ; 109$ patients were obese. All patients were on the same treatment for at least 2 months. $\mathrm{HbA}_{\mathrm{lc}}$ and $\mathrm{SF}$ correlated equally well in all four patient groups $(r=0.77-0.78, p<0.001)$. Correlation between FBG and $\mathrm{HbA}_{1 \mathrm{c}}$ was 0.67 for all patients $(\mathrm{p}<0.001)$. This was higher in group $1(r=0.75)$, compared to groups $2-4(r=0.70,0.59$, and 0.52 , respectively). Correlation between $\mathrm{FBG}$ and $\mathrm{SF}$ was, although significant, even weaker $(r=0.44$ to $r=0.65, p<0.001)$. In the obese patients correlation between the 3 variables was slightly better than in normal-weight patients. The within-subject correlations between the three glycaemic measures were considerably lower. In all patients a $\mathrm{FBG}<8.0 \mathrm{mmol} / \mathrm{l}$ correctly predicted $\mathrm{HbA}$ lc below $7.5 \%$ in $64 \%$ of cases. This predictive value was $96,66,52$ and $50 \%$ in groups 1-4. A FBG above $8.0 \mathrm{mmol} / \mathrm{l}$ was associated with a $\mathrm{HbA}_{1 \mathrm{c}}$ below $7.5 \%$ in $55,16,16$, and $10 \%$ of measurements, respectively. Circadian variation of serum fructosamine, collected under standardized conditions in 15 hospitalized type 2 diabetic patients, was $6 \%$, and of $\mathrm{HbA}_{1 c}$ less than $2 \%$. We conclude that in type 2 diabetic patients a normal FBG is a poor predictor of long-term adequate glycaemic control as assessed by

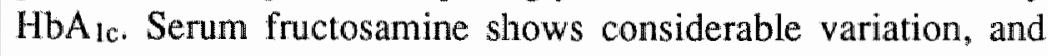
has no clinical advantage over $\mathrm{HbA}_{\mathrm{lc}}$ measurements. 


\section{INTRODUCTION}

Many general practitioners treating patients with diabetes mellitus evaluate the degree of metabolic control by measurements of fasting or postprandial blood glucose levels, and occasionally of glycosylated haemoglobin or -as recently became more popular- serum fructosamine (SF). Fructosamine is the name for the ketoamine products of Amadori rearrangement of glycosylated plasma proteins (1-3). The quantitative determination of SF depends on the colorimetric measurement of reduction of nitroblue tetrazolium. The assay has gained its increasing popularity because of its low price and easily automated analysis. Fructosamine levels have been reported to be useful for the measurement of short-term (approx imately 2 to 3 weeks) changes in blood glucose control $(4,5)$.

A good correlation between serum fructosamine and glycosylated haemoglobin ( $\mathrm{HbA}_{\| \mathrm{c}}$ ) has been consistently found in cross-sectional investigations in both type 1 and type 2 diabetic patients (5-8). However, there remains debate how adequately normal blood glucose or fructosamine levels actually predict adequate long-term blood glucose control as assessed by $\mathrm{HbA}_{1 \mathrm{c}}$ determination. Agreement between both measures has been reported to be $72 \%$ or less $(7-10)$, and within-subject variance was lower for $\mathrm{HbA}_{1 \mathrm{c}}$ (11). Further, factors such as travel to the hospital clinic or family physician, treatment with oral hypoglycaemic agents or insulin, and short-term changes in dietary carbohydrate intake may influence the clinical usefulness of fasting blood glucose (FBG) and $\mathrm{SF}^{\mathrm{F}}$ determinations.

We assessed the relation between simultaneously and sequentially determined levels of blood glucose, serum fructosamine and glycosylated haemoglobin, and the value of FBG and SF measurements to reliably predict glycaemic control as measured by $\mathrm{HbA}_{\mathrm{lc}}$ during routine hospital visits in type 2 diabetic patients on various treatments. Further, the circadian fluctuations of serum fructosamine and $\mathrm{HbA}_{1 \mathrm{c}}$ were studied in hospitalized patients.

\section{MATERIALS AND METHODS}

\section{Patients}

Only type 2 diabetic patients, attending the outpatient-clinic of the Department of Internal Medicine of the University Hospital Maastricht, were studied. No patient had severe kidney function abnormalities (serum creatinine above 140 $\mu \mathrm{mol} / \mathrm{l}$ or creatinine clearance below $40 \mathrm{ml} / \mathrm{min}$ ) or liver enzyme elevations. No patient was treated with corticosteroids. 


\section{Protocol 1: cross-sectional study}

From 264 patients (see table 1) blood was obtained at repeated -at least twooccasions by venipuncture after an overnight fast and before taking insulin or oral hypoglycaemic agents, for determination of fasting blood glucose, serum fructosamine and $\mathrm{HbA}_{1 \mathrm{c}}$. A total of 971 determinations were evaluated. Seventeen patients used diet only (group 1), 126 took oral agents in addition (group 2 ), while 121 were treated with insulin alone (group $3, \mathrm{n}=89$ ) or in combination with sulphonylurea (group $4, n=32$ ) for at least six months.

\section{Protocol 2: sequentiall study}

During an 18 months period, 105 patients (age $66 \pm 10$ years, body mass index, BMI $27.6 \pm 4.5 \mathrm{~kg} / \mathrm{m}^{2}$, median time since diagnosis of diabetes 10 (range 1-40) years, 41 males and 64 females) were followed prospectively. Blood was obtained by venipuncture during each visit to the outpatient clinic, at intervals of 1 to 4 months, for determination of fasting blood glucose, serum fructosamine and $\mathrm{HbA}_{1 \mathrm{c}}$. At least five determinations were made during this period. Seven patients used diet only, 70 took oral agents in addition, while 28 were treated with insulin alone $(n=17)$ or in combination with sulphonylurea $(n=11)$. Type of treatment was not altered during this period, although dose adjustments were made.

Table 1. Demographic variables of the 264 patients with type 2 diabetes.

\begin{tabular}{|c|c|c|c|c|c|}
\hline & $\begin{array}{l}\text { A.ll } \\
(n=264)\end{array}$ & $\begin{array}{l}\text { Group } 1 \\
(n=17)\end{array}$ & $\begin{array}{l}\text { Group } 2 \\
(n=126)\end{array}$ & $\begin{array}{l}\text { Group } 3 \\
(n=89)\end{array}$ & $\begin{array}{l}\text { Group } 4 \\
(n=32)\end{array}$ \\
\hline Males/females & $106 / 158$ & $7 / 10$ & $54 / 72$ & $31 / 58$ & $14 / 18$ \\
\hline Age (years) & $66 \pm \| 1$ & $66 \pm 12$ & $64 \pm 11$ & $69 \pm 10$ & $67 \pm 10$ \\
\hline Body mass index $\left(\mathrm{kg} / \mathrm{m}^{2}\right)$ & $27.0 \pm 4.2$ & $27.2 \pm 5.8$ & $27.0 \pm 4.2$ & $26.7 \pm 3.6$ & $27.8 \pm 5.1$ \\
\hline $\begin{array}{l}\text { Duration of diabetes } \\
\text { (years) }\end{array}$ & $\begin{array}{l}10 \\
(1-41)\end{array}$ & $\begin{array}{l}2 \\
(1-16)\end{array}$ & $\begin{array}{l}8 \\
(1-40)\end{array}$ & $\begin{array}{l}14 \\
(1-41)\end{array}$ & $\begin{array}{l}10 \\
(3-28)\end{array}$ \\
\hline $\begin{array}{l}\text { Duration of insulin therapy } \\
\text { (yeats) }\end{array}$ & & & & $\begin{array}{l}2 \\
(1-22)\end{array}$ & $\begin{array}{c}1 \\
(1-7)\end{array}$ \\
\hline
\end{tabular}

Data as mean $\pm \mathrm{SD}$, or median (range) 


\section{Protocol 3: profilles}

In 15 hospitalized patients (age $63 \pm 13$ years, BMI $29.7 \pm 6.8 \mathrm{~kg} / \mathrm{m}^{2}$, time since diagnosis of diabetes 5 (range 1-28) years, 3 males, 12 females) five determinations of blood glucose, serum fructosamine and $\mathrm{HbA}_{1 \mathrm{c}}$ were made during one day. Ten patients used oral agents, 5 were on insulin. Blood was taken through an indwelling catheter at 8.00 in the fasting state, and at 11.00,15.00, 19.00 and 23.00 hours, after $30 \mathrm{~min}$ rest in the supine position.

\section{Analytical procedures}

Blood glucose was measured in venous whole blood with an automated hexokinase method. Serum fructosamine was determined according to Johnson (1) after alkalinising and reduction with nitroblue tetrazolium (Sigma) on the Cobas Bio analyser. Calibration was performed with 1-desoxy-1-morphilinofructose (DMF, Sigma) in an albumin solution. The reference values of this assay are lower than those of the widely-used Fructosamine Roche kit, due to the use of a different standard and reductor. The same standards were in use during the last three years. Comparison with the Roche kit was excellent ( $r=0.98 ; y=1.16 x+2$, $\mathrm{p}<0.001$ ). Between-assay coefficient of variation of our fructosamine determination is $4 \% . \mathrm{HbA}_{1 \mathrm{c}}$ was determined with high pressure liquid chromatography (DIAMAT, Bio-Rad Laboratories, Richmond, Ca., USA). Normal values are 4.4-6.2\%, between-assay $\mathrm{cv}$ is $2.6 \%$.

\section{Calculations and statistical analyses}

Results are expressed as mean $\pm \mathrm{SD}$, or median and range when data were not normally distributed. Calculations were performed with the SPSS/PC+ version 3.1 statistical software package (SPSS Inc, Chicago, IL, USA). Fasting blood glucose, serum fructosamine and $\mathrm{HbA}_{1 c}$ measurements were compared between and within subjects by Pearson's correlation coefficient based on least-squares regression analysis. Between-subject correlation was estimated as the correlation coefficient between the observations of all glycaemic variables for each patient pooled across all patients. Within-subject correlation was estimated by calculating the correlation coefficient between the observations of blood glucose, serum fructosamine and $\mathrm{HbA}_{1 \mathrm{c}}$ for each patient. The agreement between the measures of blood glucose control was assessed using two control categories to represent acceptable or poor control. Acceptable control was defined as fasting blood glucose below $8.0 \mathrm{mmol} / \mathrm{l}$, and $\mathrm{HbA} A_{1 \mathrm{c}}$ below $7.5 \%$ (4 SD above mean normal value) (12). The prognostic power of fasting blood glucose and 
serum fructosamine to predict the presence of an acceptable $\mathrm{HbA}_{\text {ic }}$ value was calculated. The different treatment groups were compared with one-way analysis of variance, with Student-Newman-Keuls correction for multiple comparisons. P values $<0.05$ were considered statistically significant.

\section{RESLLTS}

\section{Results of protocol 1}

Table 1 shows the relevant demographic variables of the patient cohort studied in protocol 1. Sixty percent of patients were females. Average age was 66 years, with a range of 28 to 84 years. Figures $1 \mathrm{~A}$ to $\mathrm{IC}$ depict the distribution of fasting blood glucose, serum fructosamine and $\mathrm{HbA}_{1 c}$ among the patients studied. A HbAic level below $7.5 \%$ was found in $23.9 \%$ of patients, and fasting blood glucose below $8.0 \mathrm{mmol} / 1$ was present in $38.1 \%$. $\mathrm{HbA}$ ic and serum fructosamine (figure $2 \mathrm{C}$ ) proved to correlate equally well in all four patient groups, with $\mathrm{r}$-coefficient varying from 0.77 (groups 1,3 and 4) to 0.78 (group 2, all $\mathrm{p}<0.001$ ). Correlation between fasting blood glucose levels and $\mathrm{HbA}_{1 \mathrm{c}}$ was 0.67 for all patients ( $<<0.001$, figure $2 \mathrm{~B})$. This correlation was the highest in group 1. $(r=0.75)$, and lower in the groups $2-4(r=0.70,0.59$, and 0.52 , respectively). Correlation between fasting blood glucose levels and serum fructosamine (figure $2 \mathrm{~A}$ ) was, although significant, even weaker $(r=0.44$ to $r=0.65, p<0.001)$. In the obese patients, defined as body mass index above $27.0 \mathrm{~kg} / \mathrm{m}^{2}$ correlation between the 3 variables was slightly better than in normal-weight patients, as shown in table 2 .

In all patients a fasting blood glucose $<8.0 \mathrm{mmol} / 1$ correctly predicted a HbA ic level lower than $7.5 \%$ in $64 \%$ of determinations (table 3 ). This predictive value was $96,66,52$ and $50 \%$ in groups $1-4$. A fasting blood glucose above 8.0 mmol/l was associated with a $\mathrm{HbA}_{1 \mathrm{c}}$ above $7.5 \%$ in $45,84,84$, and $90 \%$ of measurements, respectively. Table 4 lists the sensitivity, specificity and positive and negative predictive values of fasting blood glucose level to correctly predict $\mathrm{Hb} \mathrm{A}_{1 \mathrm{c}}$.

\section{Results of protocol 2}

Within-subject correlation coefficients between the measures of glycaemic control, calculated from at least five consecutive measurements, showed a wide scatter. Correlation between fasting blood glucose and both other measures was rather weak. Intra-individual correlation between serum fructosamine and 
Table 2. Between-subject correlation coefficients for the three measures of blood glucose control in the different patient groups.

\begin{tabular}{|c|c|c|c|c|c|c|c|}
\hline & \multirow[b]{2}{*}{ : } & \multicolumn{2}{|c|}{ FBG vs. SF } & \multicolumn{2}{|c|}{ FBG vs. HbAlc } & \multicolumn{2}{|c|}{ SF us. HbAlc } \\
\hline & & $\begin{array}{l}\text { non- } \\
\text { obese }\end{array}$ & obese & $\begin{array}{l}\text { non- } \\
\text { obese }\end{array}$ & obese & $\begin{array}{l}\text { non- } \\
\text { obese }\end{array}$ & obese \\
\hline All patients & & 0.58 & 0.63 & 0.64 & 0.70 & 0.76 & 0.82 \\
\hline Group 1 & & 0.71 & 0.65 & 0.75 & 0.74 & 0.86 & 0.84 \\
\hline Group 2 & & 0.66 & 0.65 & 0.69 & 0.72 & 0.74 & 0.82 \\
\hline Group 3 & & 0.45 & 0.60 & 0.51 & 0.70 & 0.75 & 0.78 \\
\hline Group 4 & & 0.46 & 0.48 & 0.59 & 0.49 & 0.74 & 0.81 \\
\hline
\end{tabular}

Significance for all r-values: $\mathrm{p}<0.001$

$\mathrm{HbA} 1 \mathrm{c}$ showed a variation from $\mathrm{r}=-0.85$ to $\mathrm{r}=0.99$, but mean correlation was $0.62(\mathrm{p}<0.05)$. No differences of within-subject correlation was found between the four treatment groups.

\section{Results of protocol 3}

Figure 3 shows the circadian changes of mean blood glucose (3A), serum fructosamine (3B) and glycosylated haemoglobin (3C). Serum fructosamine showed a significant $(\mathrm{p}<0.05)$ increase after breakfast (at $11.00 \mathrm{am})$. Intra-individual coefficient of variation (CV) of the 5 measurements of serum fructosamine varied from 1.0 to $11.0 \%$ (median $6 \%$ ), and of glycosylated haemoglobin from 0.5 to $4.1 \%$ (median $1.3 \%, \mathrm{p}<0.05$ compared to $\mathrm{CV}$ of serum fructosamine). Overall $\mathrm{CV}$ of $\mathrm{SF}$ and $\mathrm{HbA}_{\mathrm{lc}}$ were $6.3 \%$ and $2.2 \%$, respectively. Correction of serum fructosamine for plasma total protein or albumin did not affect variation coefficient. Intra-individual CV of total protein was $4.5 \%$ $(0.8-10.9 \%)$, and of albumin $5.4 \%$ (range $2.7-12.3 \%$ ), and overall $\mathrm{CV}$ values were $5.1 \%$ and $6.1 \%$, respectively.

\section{DISCUSSION}

In our type 2 diabetic patients the correlation between serum fructosamine and glycosylated haemoglobin was equally high irrespective of a patient"s treatment. Correlation between fasting blood glucose and $\mathrm{HbA}_{\mathrm{lc}}$ was the highest in 

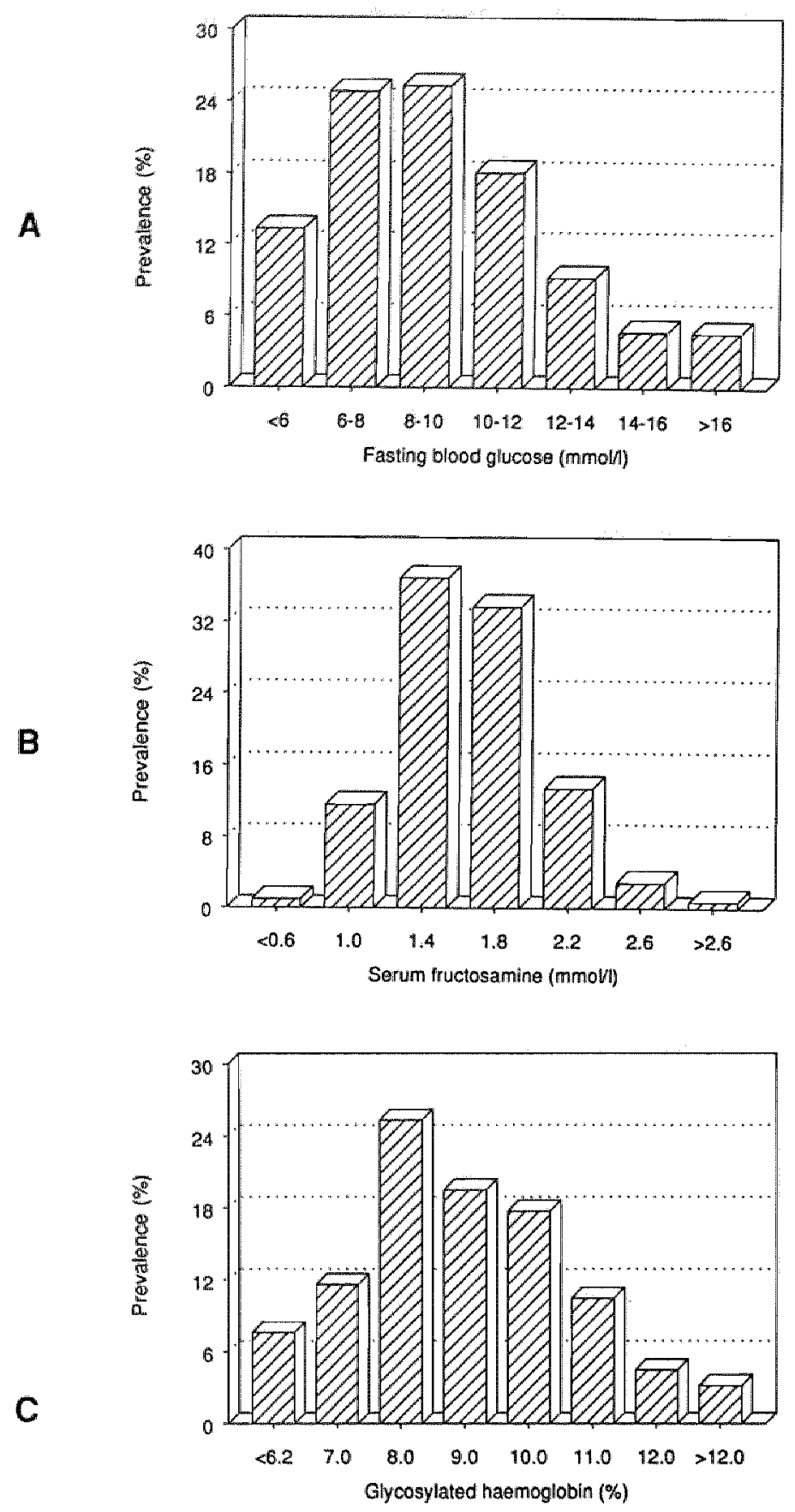

Figure 1. Distribution of fasting blood glucose (A), serum fructosamine (B) and glycosylated haemoglobin (C) among the patients studied. 


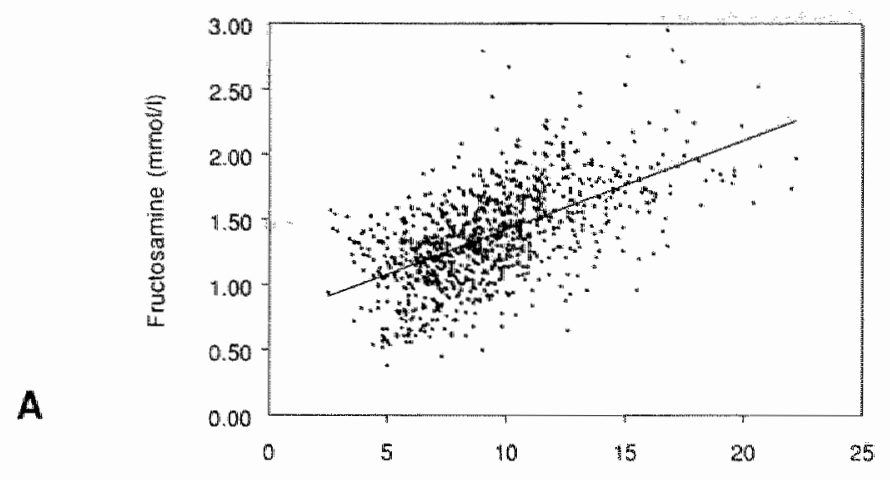

Fasting blood glucosie (mmolly)

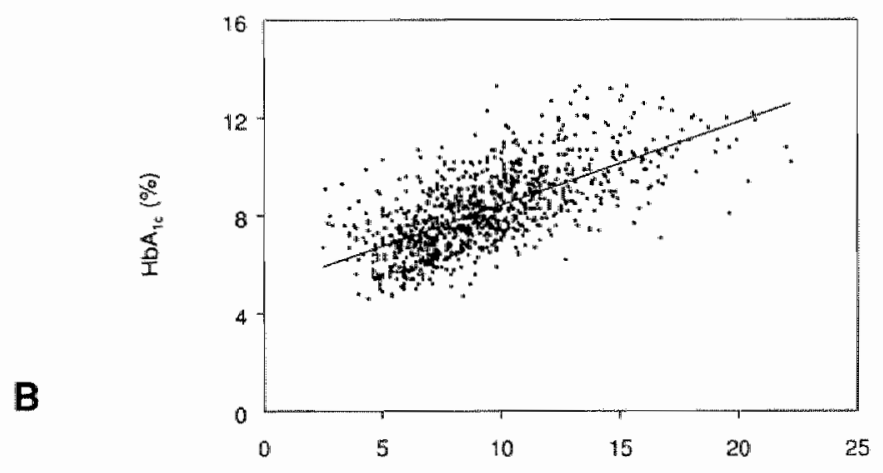

Fasting blood glucase (mmol/h)

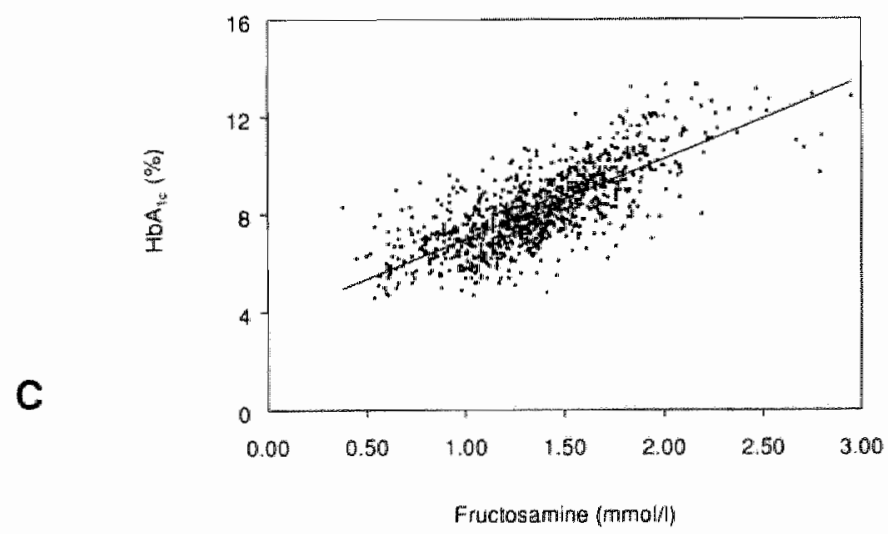

Figure 2. Relation between the three measures of blood glucose control in 264 patients followed during one year. Each point represents one individual time point for a patient. Correlations were as follows: (A) fasting blood glucose vs. fructosamine: $r=0.59$; (B) fasting blood glucose $v s$. $\mathrm{Hb} A_{1 c} \mathrm{r}=0.67$; (C) $\mathrm{HbA}_{\mathrm{lc}} v$ s. fructosamine: $r=0.78$; all correlations $\mathrm{p}<0.001$. 
Table 3. Cross-tabulation of lewels of fasting blood glucose and glycosylated haemoglobin in the four different treatment groups (separate deteminations).

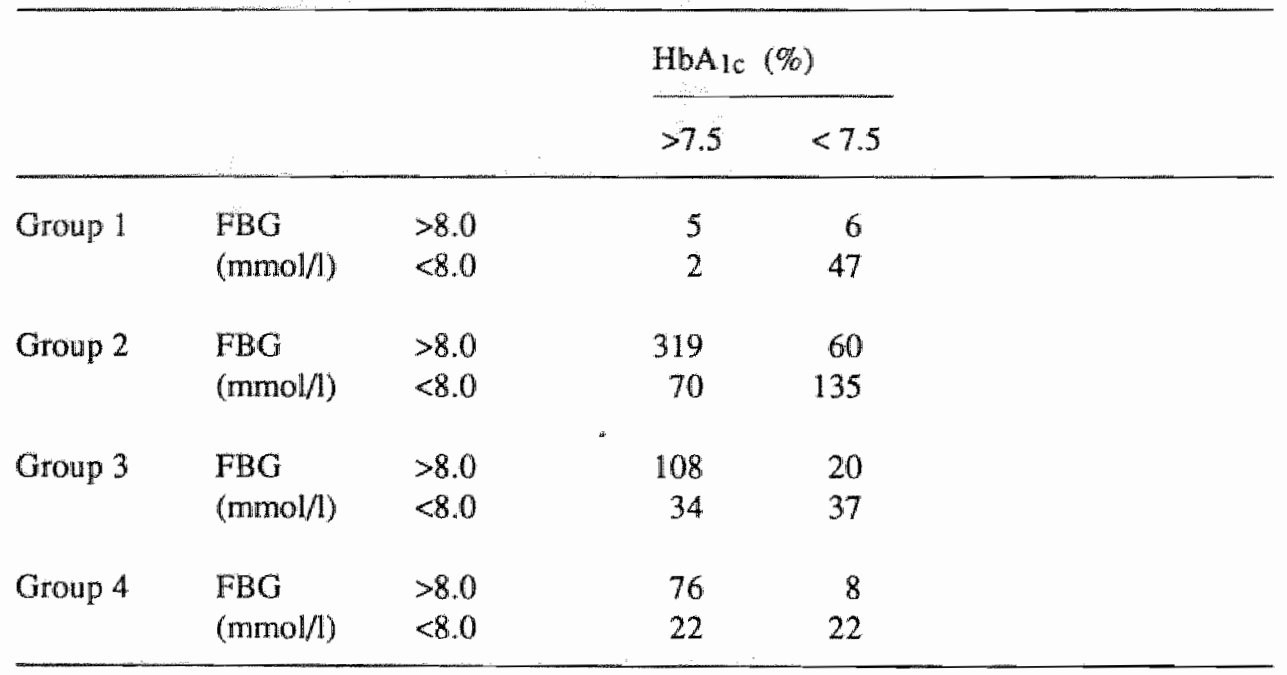

Table 4. Diagnostic criteria evaluating the value of fasting blood glucose levels to adequately predict glycosylated haemoglobin levels in the different treatment groups.

\begin{tabular}{lllll}
\hline & Sensitivity & Specificity & Pos.pred value. & Neg.pred. value \\
\hline All patients & 80 & 72 & 84 & 65 \\
Group 1 & 71 & 89 & 45 & 96 \\
Group 2 & 82 & 69 & 84 & 66 \\
Group 3 & 76 & 65 & 84 & 52 \\
Group 4 & 78 & 73 & 90 & 50 \\
\hline
\end{tabular}

Pos.pred. value: the power of a FBG-level $>8.0$ mmol/ $/$ to correctly predict $\mathrm{HbA}$ Ic $>7.5 \%$ Neg.pred.walue: the power of a FBG-level $<8.0 \mathrm{mmol} / \mathrm{l}$ to correctly predict $\mathrm{Hb}$ Alc $<7.5 \%$

diet-treated patients, and significantly lower in insulin-treated patients. In all patient groups, correlation between fasting blood glucose and serum fructosamine was lower. In cross-sectional studies a significant correlation was demonstrated between serum fructosamine and glycosylated haemoglobin, with correlation coefficients varying from $r=0.47$ to $r=0.80(3,5-9,12)$. The present study confirms these results. 
Table 5. Within-subject correlation coefficients for fasting blood glucose, senum fuctosamine and glycosylated haemoglobin in 105 type 2 diabetic patients.
n
FBG $v s . S F$
FBG vs. HbAlc
SF vs. HbAlc

\begin{tabular}{lrlll}
\hline All patients & 105 & $0.40(0.29-0.51)$ & $0.45(0.36-0.54)$ & $0.62(0.57-0.67)^{d}$ \\
Group 1 & 7 & $-0.06(-0.56-0.45)$ & $0.16(-0.35-0.66)$ & $0.70(0.49-0.91)^{k}$ \\
Group 2 & 70 & $0.47(0.38-0.57)$ & $0.51(0.42-0.60)$ & $0.62(0.55-0.70)$ \\
Group 3 & 17 & $0.37(0.07-0.66)$ & $0.42(0.14-0.70)$ & $0.64(0.56-0.72)^{k}$ \\
Group 4 & 11 & $0.33(-0.04-0.70)$ & $0.35(0.05-0.64)$ & $0.55(0.38-0.72)$
\end{tabular}

Data as mean ( $95 \%$ CI);

\& $\mathrm{p}<0.001 \mathrm{w}$, other two correlations

A better way to describe the relation between the different glycaemic measures is to determine the correlation based on several measurements within the same individual. These within-subject correlations were much lower compared to the correlations for the entire patient group (table $2 \mathrm{vs}$. 5). For instance, analysis of the correlation between fructosamine and $\mathrm{HbA}_{1 c}$ comprises both patients with a significant positive correlation, patients with no correlation, and patients with a significant negative correlation.

Although calculation of correlation coefficients readily yields significant results when a large number of patients is studied, in daily practice it is more useful to assess the power of a measure to discriminate between good and poor glycaemic control (i.e. $\mathrm{HbA}_{1 \mathrm{c}}$ below or above $7.5 \%$ ). In our hands a fasting blood glucose level above $8.0 \mathrm{mmol} / \mathrm{l}$ correctly predicted $\mathrm{HbA}$ ic levels exceeding $7.5 \%$, and thus inadequate control, in the majority $(84 \%)$ of our patients. However, normal blood glucose levels (below $8.0 \mathrm{mmol} / \mathrm{l}$ ) predicted good control in only $65 \%$ of patients. The best predictive power was observed in diet-treated patients. In $50 \%$ of determinations in insulin-treated patients a fasting blood glucose level below $8.0 \mathrm{mmol} / \mathrm{l}$ was accompanied by a $\mathrm{Hb} \mathrm{A}_{\mathrm{Ic}}$ above $7.5 \%$. This situation is unacceptable in clinical situations, and implies that determination of fasting blood glucose only may lead to false conclusions concerning long-term blood glucose control in type 2 diabetic subjects.

Serum fructosamine is regarded as a potential alternative or even a replacement of $\mathrm{HbA}_{1 \mathrm{c}}$ for routine clinical use in both type 1 and type 2 diabetic patients $(14,15)$. The fructosamine assay, in use in our laboratory, is an adaptation of the Fructosamine Roche kit, with a different albumin standard. This standard was the same throughout the last 3 years, whereas the commercially available kit 

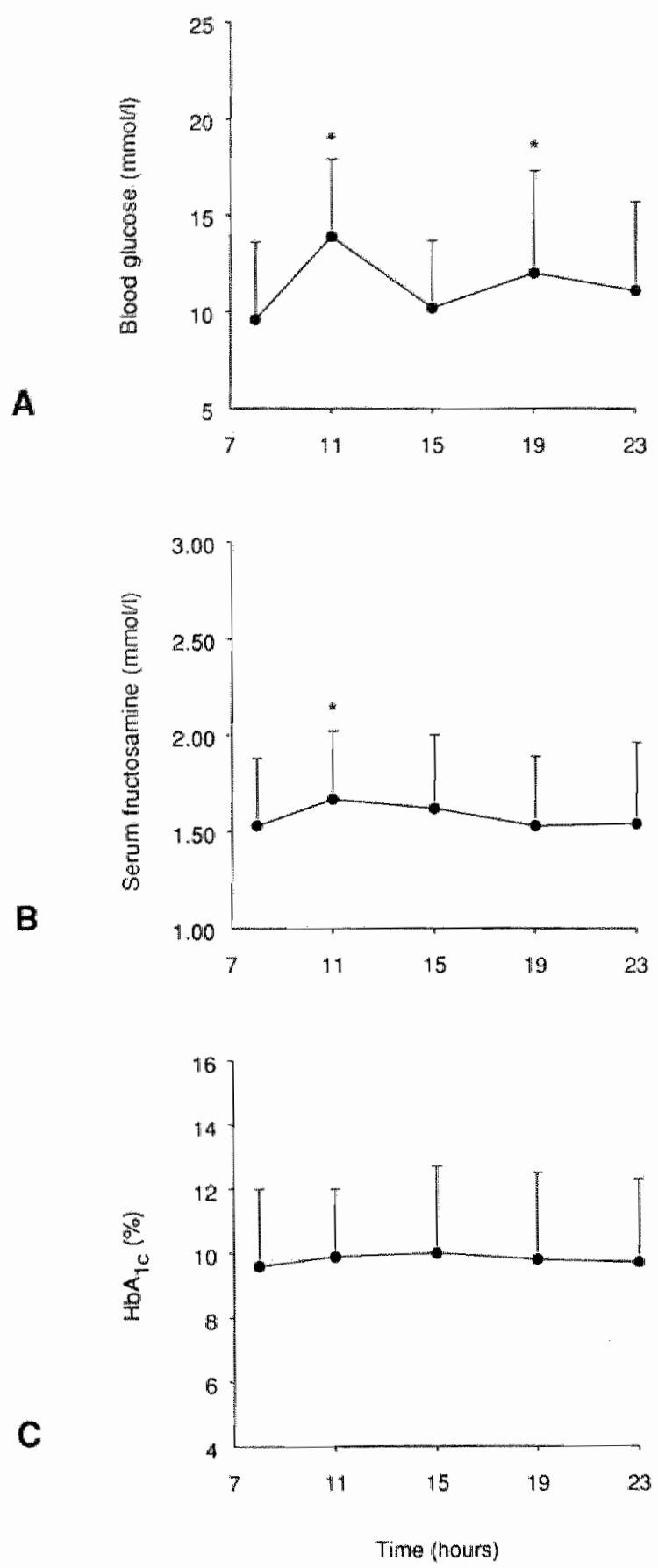

Figure 3. Circadian course of blood glucose (A), serum fructosamine (B) and glycosylated haemoglobin (C) in 15 hospitalized type 2 diabetic patients. 
Table 6. Causes of discrepancy between fasting blood glucose and glycosylated haemoglobin determinations.

1. Short-term improvement or worsening of metabolic control,

either by the diabetic sate itself,

or by non-compliance, or short-term compliance with diet or drugs

2. Insufficient postprandial insulin release,

leading to exaggerated postprandial hyperglycaemia

3. Errors in $\mathrm{HbA} \mathbb{1 c}$ measurement, depending on method (23):

- abnormal haemoglobin variants $(\mathrm{HbF}, \mathrm{HbS})$

- haemolytic anaemia

- renal failure

- hyperlipoproteinaemia

- sample storage conditions

4. Errors in blood glucose measurements:

- reflectance meters

suffered from inacceptable variation of the standards. The modification, however, yielded different reference values for the healthy and diabetic population. The variation of serum fructosamine can be large. Changes in serum albumin may affect fructosamine concentration sufficiently to invalidate its use as a stable index of glycaemic control (16-18). Within-subject CV was estimated to be $11 \%$, whereas between-subject variation may reach $20 \%(9,11)$. Orthostasis and venous congestion may considerably further increase variation, one study reporting a $10 \%$ increase of serum fructosamine after $10 \mathrm{~min}$. walking (19). Although some authors suggest that blood samples need not be obtained in the fasting state $(13,15)$, a circadian rhythm of SF was reported, with a significant postprandial increase, lowest values at 6 a.m. and highest values at 6 p.m. (10). Especially the latter finding prompts for standardized blood collection. Therefore, our circadian measurements were made in blood samples, collected through an indwelling catheter, with the patient in rest in the supine position for $30 \mathrm{~min}$. Despite this standardized blood collection circadian variation of serum fructosamine ranged from 1 to $11 \%$, which is significantly higher than the observed variation of $\mathrm{HbA}_{\mathrm{Ic}}$, as measured by an automated HPLC-method. In addition, the postprandial increase of SF levels (10) was confirmed in our material. Others have also concluded that $\mathrm{HbA}_{\mathrm{lc}}$ is a more appropriate index of blood glucose control for patients attending outpatient-clinics, considering the analytical deficiencies of serum fructosamine assays $(9,11)$. The low price for 
serum fructosamine determinations has been brought forward to promote its more extensive use in clinical medicine $(13,15)$. Indeed, the costs of $\mathrm{HbA}_{1 c}$ determinations (materials and personnel) with the automated HPLC-method are somewhat higher ( $4.10 \mathrm{vs}$. 2.40 Dutch guilders, table 7). Despite this difference, the fructosamine assay appears not to be the method of choice to assess glycaemic control in (elderly) diabetic patients (9), but it may complement the use of glycosylated haemoglobin.

The discussion which measurements are to be used in the evaluation of patients with type 2 diabetes in general practice has revived with the introduction of the European Consensus statement (12), and a Dutch Standard of Care (20), especially designed for use by the general practitioner (GP). Measurement of $\mathrm{HbA}_{1 \mathrm{c}}$ in addition to regular blood glucose determinations is generally recommended every 2 to 4 months (12). Some authors, however, state that the GP's are by far capable of assessing patient compliance, and that $\mathrm{HbA}_{1 \mathrm{c}}$ determinations are not needed for the routine care of patients in general practice (20). This attitude not only falsely assumes that non-compliance of patients with the diabetic regimen is readily recognized, but also disregards other factors that may limit the sole use of blood glucose measurements (table 6). Larsen and Horder (21) observed that two-thirds of patients, who were followed by their $\mathrm{GP}$, had $\mathrm{HbA}_{1 \mathrm{c}}$ values above the acceptable level, despite random postprandial blood glucose levels, measured with reflectance meters, below $10 \mathrm{mmol} / 1$. In an earlier survey we found that $15 \%$ of tablet-treated patients had fasting hyperglycaemia above $10 \mathrm{mmol} / \mathrm{l}$, yet exhibited daytime glucose levels similar to or lower than the fasting level, leading to only slightly elevated $\mathrm{HbA}_{I c}$ levels. On the reverse, a considerable number of patients may show (near)-normal fasting blood glucose, but postprandial glucose increases exceeding $15.0 \mathrm{mmol} / \mathrm{l}$. As-

Table 7. Costs of one determination of serum fructosamine and HbAlc.

Serum fructosamine

dfl. 0.90

df. 1.50

dfl. 0.40
HbAlc by HPLC

df1. 3.90

dfl. 0.20

dff. 1.80

Costs of manpower

Equipment costs

dfl. 40

* serum fructosamine is deternined on Cobas Bio analyser or comparable equipment, which is usually available in a laboratory setting; for HbA lc the HPLC-system (DIAMAT, BioRad) has to be purchased. 
suming that the latter combination means non-compliance of the patient may lead to incorrect therapeutic advices. Especially in insulin-treated patients determination of blood glucose levels both in the fasting and in the postprandial state, and of $\mathrm{HbA}_{1 \mathrm{c}}$ in addition (22), are necessary to adequately assess blood glucose control, and adjust insulin treatment. In all cases of discrepancy between $\mathrm{FBG}$ and $\mathrm{HbA}_{1 \mathrm{c}}$ its cause must be ascertained. Self-monitoring of blood glucose by the patient may be very helpful in this respect.

\section{REFERENCES}

1. Johnson RN, Metcalf PA, Baker JR. Fructosamine: a new approach to the estimation of serum glycosylprotein. An index of diabetic control. Clin Chim Acta 1982; 127: 87-95.

2. Armbuster DA. Fructosamine: structure, analysis and clinical usefulness. Clin Chem $1987 ; 33: 2153-2163$.

3. Koskinen P, Irjala $\mathrm{K}$, Viikari J, et al. Serum fructosamine in the assessment of glycaemic control in diabetes mellitus. Scand J Clin Lab Invest 1987; 47: 285-292.

4. Ashby JP, Frier BM. Is serum fructosamine a clinically useful test? Diabetic Med 1988; 5: $118-121$.

5. Lapolla A, Poli T, Barison A, Fedele D. Fructosamine assay: an index of medium-term metabolic control parameters in diabetic disease. Diab Res Clin Pract 1988; 4: 231-235.

6. Cefalu WT, Mejia E, Puente GR, Fleishhacker D, Macaulay K. Correlation of serum fructosamine activity in type I diabetic children. Am J Med Sci 1989; 297: 244-246.

7. Smart LM, Howie AF, Young RJ, Walker SW, Clarke BF, Smith AF. Comparison of fructosamine with glycosylated hemoglobin and plasma proteins as measures of glycemic control. Diabetes Care 1988; 11: 433-436.

8. Mercelina LFE, Degenaar CP, Nieuwenhuijzen Kruseman AC. Bepaling van de waarden van nuchter bloedglucose en het serum fructosamine voor beoordeling van de glucoseregulering bij patiënten met niet van insuline afhankelijke diabetes mellitus. Ned Tijdschr Geneeskd 1989; 133; 1887-1890.

9. Winocour PH, Bhatnagar D, Kalsi P, Hillier VF, Anderson DC. An analysis of glycosylated blood proteins and blood glucose profiles over one year in patients with type 1 diabetes. Diabetic Med 1989; 6: 709-716.

10. Hay U, Sedlmayer A, Müller MM, Dorda W, Schernthaner G. Kritische Evaluation von Fructosamin als Kontrollparameter in der Beurteilung der diabetischen Stoffwechseleinstellung. Klin Wochenschr 1989; 67: 379-385.

11. Howey JEA, Bennet WM, Browning MCK, Jung RT, Fraser CG. Clinical utility of assays of glycosylated heamoglobin and serum fructosamine compared: use of data on biological variation. Diabetic Med 1989; 6: 793-796.

12. Alberti KGMM, Gries FA. Management of non-insulin-dependent diabetes mellitus in Europe: a consensus view. Diabetic Med 1988; 5: 275-281.

13. Negoro H, Morley JE, Rosenthal MJ. Utility of serum fructosamine as a measure of glycemia in young and old diabetic and non-diabetic subjects. Am J Med 1988; 85: 360-364. 
14. Cefallu WT, Prather KL, Murphy WA, Parker TB. Clinical evaluation of senum fructosanine in monitoring elderly outpatient diabetics. J Am Geriatrics Soc 1989; 37 : 833-837.

15. Morley JE. Fructosamine or glycated hemoglobin? I Am Geriatrics Soc 1989; 37: 911-912.

16. McCance DR, Coulter D, Smye M, Kennedy L. Effect of fluctuations in albumin on serum fructosamine assay. Diabetic Med 1987; 4: 434-436.

17. Dominiczak MH, Orrell JM, Finlay WEI. The effect of hypoalbuminaemia, hyperbilinubinaemia and renal failure on serum fructosamine concentration in non-diabetic individuals. Clin Chim Acta 1989; 182: 123-130.

18. Flückiger R, Woodthianed T, Berger W. Evaluation of the fructosamine test for the measurement of plasma protein glycation. Diabetologia 1987; 30: 648-652.

19. Jarausch $J$, Akpan W, Von Mollendorf E, Wittenbrink-Dix A, Mittmann D, Raab D. Impact of orthostasis on fructosamine values. Wiener Klin Wochenschr 1990; 102 ssuppl. 180): $39-41$.

20. Nederlands Huisartsen Genootschap. Standaard Diabetes Mellitus type II. Huisarts \& Wetenschap 1989; 32: 7-13.

21. Larsen ML, Horder M. Metabolic evaluation of non-insulin-dependent diabetes in primary heal th care - the clinical usefulness of glycated haemoglobin measurements. Scand I Prim Health Care 1989; 7: 167-171.

22. Pecoraro RE, Koepsell TD, Chen MS, Lipsky BA, Belcher DW, Inui TS. Comparative clinical reliability of fasting plasma glucose and glycosylated hemoglobin in non-insulindependent diabetes mellitus. Diabetes Care 1986; 9: 370-375.

23. Goldstein DE, Little RR, Wiedmeyer HM, Eryland ID, McKenzie EM. Glycated hemoglobin; methodologies and clinical applications. Clin Chem 1986; 32: B64-B70.

\section{ACKNOWLEDGMENTS}

The authors thank mr. L. Habets, chief analyst of the Clinical Chemistry Department, for his advices and support. 
CHAPTER

\section{5}

\section{Limitations of diet therapy in patients with non-insulin-dependent (type 2) diabetes mellitus}

Bruce H.R. Wolffenbuttel, Rob F.A. Weber, Peter M. van Koetsveld, Louis Verschoor

International Journal of Obesity $1989 ; 13: 173-182$ 
Sixty-one patients with type 2 diabetes mellitus and fasting blood glucose of $12.0 \pm 0.6 \mathrm{mmol} / 1$ were studied before and after intensified dietary treatment in an outpatient setting. At the start of the study 33 patients were obese (body mass index $>27.0 \mathrm{~kg} / \mathrm{m}^{2}$ ). Twenty patients had newly-diagnosed diabetes, median known duration of diabetes in the others was 5 years. Islet B-cell function was measured by the release of C-peptide after i.v. injection of 1 $\mathrm{mg}$ glucagon (area under the curve of C-peptide $=\mathrm{C}$-peptide AUC), as well as calculated according to the formulae of Matthews. Insulin action was determined by measurement of fasting blood glucose and free fatty acids (NEFA) concentrations. Nonobese patients showed more severe beta-cell deficiency than the obese ones (C-peptide AUC $2586 \pm 158$ vs. $3294 \pm 277$ pmol/1.15min), and did not improve in metabolic control during treatment. In the obese patients three response patterns to treatment were observed: weight loss and improvement in metabolic control accompanied primarily with increased beta-cell function or increased insulin action, or worsening of metabolic control. Those with less impaired beta-cell function and shorter known duration of diabetes showed the most favourable response. In conclusion: 1) non-obese type 2 diabetic patients with fasting glucose levels above $10 \mathrm{mmol} / \mathrm{l}$ do not improve on dietary treatment alone. 2) in obese patients weight reduction is essential and results in metabolic improvement, irrespective of the preceeding fasting blood glucose concentrations. Improved beta-cell function as well as increased insulin action are responsible for this improvement. 


\section{INTRODUCTION}

Non-insulin-dependent (type 2) diabetes mellitus is a heterogeneous disorder, characterized by excessive hepatic glucose production and impaired insulinmediated peripheral glucose utilization, as well as disturbances in the recognition of glucose and the secretion of insulin by the pancreatic B-cells (1-5). Treatment of patients with type 2 diabetes mellitus aims to relieve complaints due to the hyperglycaemic state, and to normalize intermediary metabolism and body weight (5). A proper diet is still the main mode of therapy. Dietary advice, however, varies from suggestions to avoid rapidly-absorbed simple sugars and to restrict the amount of calories in overweight patients to more rigid regimens of detailed prescribed diets. Dietary therapy leading to successfull weight reduction in obese patients results in an improvement of glucose metabolism (6-9). This is characterized by a reduction of hepatic glucose output $(10,11)$ and improvement of peripheral insulin sensitivity (11). The reports on changes of the secretory response of insulin to various stimuli have been contradictory. Appropriate weight reduction, however, is not achieved easilly without hospitalization of the patient and the use of aggressive dietary interventions, including supplemented fasting with a very low caloric regimen. The long-term results of dietary treatment in non-obese patients with type 2 diabetes are disappointing $(12,13)$.

In the current study we investigated the effects of dietary management on glucose metabolism and beta-cell function in obese and non-obese patients with type 2 diabetes under circumstances more comparable with everyday practice.

\section{MATERIALS AND METHODS}

\section{Study design}

Sixty-one patients with type 2 diabetes mellitus according to the WHO criteria (12), who gave informed consent, entered the study. Patients with impaired kidney function (serum creatinine level $>120 \mu \mathrm{mol} / \mathrm{l}$ ), severe hypertension (diastolic blood pressure $>110 \mathrm{~mm} \mathrm{Hg}$ and/or systolic blood pressure $>200$ $\mathrm{mm} \mathrm{Hg}$ ), liver dysfunction (transaminases and/or $\gamma \mathrm{GT}$ more than two times the upper limits of normal), alcoholism or therapy with corticosteroids were excluded.

A full history and physical examination of each patient was obtained at the first visit. Patients with a body mass index (BMI) higher than $27.0 \mathrm{~kg} / \mathrm{m}^{2}$ were considered obese. Therapy with oral hypoglycaemic agents and other medica- 
tion that might have an effect on carbohydrate-metabolism, if instituted before entering the study, was not changed during the study period. Besides routine laboratory investigations, which included the measurement of fasting blood glucose and fasting plasma insulin on two consecutive days, blood was drawn for the determination of glycosylated haemoglobin $\left(\mathrm{HbA}_{\|}\right)$and free fatty acids (NEFA). After an overnight fast, insulin secretion was studied by determining C-peptide levels after the intravenous injection of $1 \mathrm{mg}$ glucagon (15). Blood was drawn before, and 5,10 and 15 minutes after the injection of glucagon.

Thereafter, patients were carefully instructed about dietary measures by a dietician and individual diet prescriptions were given depending on a patient's physical activity and body weight. Mono- and disaccharides were excluded from the diet. Non-obese patients were prescribed a weight-maintaining diet, containing $55 \%$ carbohydrate, $30 \%$ fat and $15 \%$ protein, divided into 3 meals and 3 snacks. Energy content varied from 4788 to $10560 \mathrm{~kJ}$ (1140 to $2515 \mathrm{kcal}$ ) per day. Energy content of the diets of the obese patients was restricted, and varied from 3210 to $6175 \mathrm{~kJ}(765$ to $1470 \mathrm{kcal})$ per day, with the same distribution of carbohydrate, fat and protein. In almost all patients this meant a more strict diet prescription than their preceeding food intake. To both nonobese and obese patients the importance of diet was emphasized in a comparable manner, by the dietician as well as the treating physician. Further, regular physical exercise was encouraged. Therapeutic goals were fasting blood glucose levels below $7.0 \mathrm{mmol} / \mathrm{l}$ and a body mass index below $27.0 \mathrm{~kg} / \mathrm{m}^{2}$.

All patients were seen monthly by the same physician and by a dietician in the outpatient-clinic. Check-ups comprised measurements of body weight, glucose profile, and $\mathrm{HbA}_{1}$. Additional and/or more frequent check-ups were made if dictated by the condition of the patient.

In the non-obese patients, in whom no reduction of weight is desired, modifications of the diet as described might be expected to achieve effects within a number of weeks. In contrast, in the obese patients significant weight loss is desired, in which case a longer period of diet therapy is necessary. Thus, the non-obese patients were restudied (baseline measurements and glucagon-test) after 3 months, and those with overweight after six months.

For comparison glucagon-stimulated secretion of $\mathrm{C}$-peptide was also measured in 18 non-obese ( 9 males and 9 females, age 18-48 years) and 12 obese ( 4 males and 8 females, age 17-49 years) control subjects. 


\section{Analy tical procedures}

Blood glucose concentrations were measured in venous whole blood by an automated hexokinase method. Plasma free insulin concentrations were determined by radio-immunoassay (Immuno Nuclear Corporation, USA; interassay coefficient of variation $8.5 \%$ ). Plasma C-peptide levels were determined using radioimmunoassay according to Heding (16) (Novo Research Institute, Denmark, antibody M1230; interassay coefficient of variation 10\%). Glycosylated haemoglobin $\left(\mathrm{HbA}_{1}\right)$ was measured by column chromatography (Bio-Rad Laboratories, Richmond, $\mathrm{Ca}$., USA). Free fatty-acids were determined by a colorimetric method (17).

\section{Calculations and statistical analyses}

Beta-cell function (BCF) was assessed in two ways:

1. As the release of C-peptide after i.v. injection of $1 \mathrm{mg}$ glucagon, calculated as the area under the curve (C-peptide AUC);

2. From the fasting levels of blood glucose (FBG), insulin (FIRI) and C-peptide (FCP), by calculating the following formulae (18):

Islet $\mathrm{B}$-cell function (insulin) $=20 \times$ FIRI $/ 7 \times(F B G-3.5)$, and

Islet B-cell function (C-peptide) $=0.286 \times \mathrm{FCP} /(\mathrm{FBG}-3.5)$,

in which formulae insulin and C-peptide are expressed as pmol/l.

Relative insulin resistance was calculated as the proposed formula

$\mathrm{R}=\mathrm{FIRI} / 7 \times\left(22.5 \times \mathrm{e}^{-\ln F B G}\right)$, which formula can be simplified as

$\mathrm{R}=(\mathrm{FIRI} \times \mathrm{FBG}) / 7 \times 22.5$.

Data are presented as mean \pm SEM, or median value when data were not normally distributed. The paired t-test was used to compare data before and after treatment, when data were normally distributed and Wilcoxon's paired test was used, when data were not normally distributed. Linear regression analysis was used to determine the relationship between two variables. P-values $<0.05$ were considered to be statistically significant.

\section{RESULTS}

\section{Parameters at entry}

Of the 61 patients 33 were obese (body mass index, BMI, range 27.1 -45.9 , mean $31.7 \pm 0.8 \mathrm{~kg} / \mathrm{m}^{2}$ ) and 28 non-obese (BMI range 18.8-27.0, mean $23.6 \pm 0.4$ $\mathrm{kg} / \mathrm{m}^{2}$ ). Age ranged from 24 to 80 years (median 59 years). Sixteen of the 
non obese and 14 of the obese were males. Twenty of the 61 patients were newly-diagnosed, the others had a known duration of diabetes varying from six months to twenty-two years (median 5 years). None had ever received insulin. Eight of the obese and thirteen of the non-obese patients were treated with oral hypoglycaemic agents at the start of the study.

As shown in table 1 , fasting blood glucose did not differ between obese (range 6.2-26.5, mean $11.9 \pm 0.8 \mathrm{mmol} / \mathrm{l}$ ) and non-obese patients (range 6.619.7 , mean $12.2 \pm 0.6 \mathrm{mmol} / \mathrm{l}$ ). Seven patients had fasting blood glucose levels $<7.0 \mathrm{mmol} / 1$ ( 3 non-obese, 4 obese), but postprandial levels $>11.0 \mathrm{mmol} / \mathrm{l}$. Fasting levels of $C$-peptide were significantly higher $(p<0.05)$ in the obese patients compared to the non-obese, as was the C-peptide/glucose ratio. Fasting levels of insulin were not different. The release of C-peptide after glucagon (C-peptide AUC) was significantly $(\mathrm{p}<0.05)$ higher in the obese patients. However, in both obese and non-obese patients C-peptide AUC was diminished compared to the results obtained in the control groups with corresponding body mass index. Calculated insulin resistance and islet B-cell function were similar in both patient groups, but markedly lower compared to control subjects. C-peptide AUC of both patient groups correlated with $B C F c p(r=0.57, p<0.01)$ and with BCFiri $(r=0.46, p<0.01)$. Serum NEFA-levels were similar in both patient groups, but markedly elevated compared to controls.

Table 1. Laboratory findings of 61 patients with type 2 diabetes before entering the study.

\begin{tabular}{|c|c|c|c|c|}
\hline & $\begin{array}{l}\text { Non-obese } \\
(n=28)\end{array}$ & $\begin{array}{l}\text { Obese } \\
(n=33)\end{array}$ & $\begin{array}{l}\text { Non-obese } \\
\text { controls } \\
(\mathrm{n}=18)\end{array}$ & $\begin{array}{l}\text { Obese } \\
\text { controls } \\
(n=12)\end{array}$ \\
\hline Fasting blood glucose (mmol/l) & $12.2 \pm 0.6^{*}$ & $11.9 \pm 0.8^{*}$ & $4.4 \pm 0.1$ & $4.4 \pm 0.1$ \\
\hline Glycosylated hamoglobin (\%) & $12.2 \pm 0.4^{*}$ & $11.9 \pm 0.5^{*}$ & $6.5 \pm 0.1$ & $6.7+0.2$ \\
\hline Fasting plasma insulin (pmol/l) & $82 \pm 10^{*}$ & $102 \pm 11$ & $54 \pm 4$ & $105 \pm 15$ \\
\hline Fasting plasma C-peptide (pmol/l) & $529 \pm 43$ & $680 \pm 56^{\$}$ & $461 \pm 33$ & $812 \pm 67$ \\
\hline FCP/FBG (pmol/mmol) & $44 \pm 5^{*}$ & $62 \pm 6^{* \$}$ & $106 \pm 7$ & $195 \pm 16$ \\
\hline C-peptide AUC (pmol/h. 15min) & $2586 \pm 158^{*}$ & $3294 \pm 277^{* \$}$ & $3853 \pm 339$ & $4965 \pm 519$ \\
\hline Islet B-cell function (insulin) (\%) & $39 \pm 9^{*}$ & $44 \pm 6^{*}$ & $207 \pm 29$ & $455 \pm 113$ \\
\hline Islet B-cell function (C-peptide) (\%) & $23 \pm 4$ & $31 \pm 5^{*}$ & $170 \pm 18$ & $311 \pm 60$ \\
\hline Relative insulin resistance & $5.8 \pm 0.6^{*}$ & $7.3 \pm 1.0^{*}$ & $1.5 \pm 0.1$ & $2.9 \pm 0.4$ \\
\hline NEFA $(\mathrm{mmol} / \mathrm{l})$ & $1.02 \pm 0.10^{*}$ & $0.94 \pm 0.09^{*}$ & $0.44 \pm 0.03$ & $0.47 \pm 0.08$ \\
\hline
\end{tabular}

${ }^{\$} \mathrm{p}<0.05$ compared to non-obese patients; $" \mathrm{p}<0.05$ compared to controls 
Table 2. Results of dietary treatment.

\begin{tabular}{|c|c|c|c|c|}
\hline & \multicolumn{2}{|c|}{ Non obese $(\mathrm{n}=2 \mathrm{I})$} & \multicolumn{2}{|c|}{ Obese $(n=29)$} \\
\hline & before & after & before & after \\
\hline Body mass index $\left(\mathrm{kg} / \mathrm{m}^{2}\right)$ & $24.0 \pm 0.4$ & $24.1 \pm 0.4$ & $31.9 \pm 0.8$ & $30.3 \pm 0.7^{*}$ \\
\hline Fasting blood glucose (mmol/) & $11.4 \pm 0.6$ & $11.9 \pm 0.8$ & $11.9 \pm 0.8$ & $10.6 \pm 0.8^{*}$ \\
\hline Glycosylated haemoglobin (\%) & $11.8 \pm 0.5$ & $11.7 \pm 0.5$ & $12.1 \pm 0.5$ & $10.6 \pm 0.5^{*}$ \\
\hline Fasting plasma insulin (pmol/1) & $86 \pm 11$ & $75 \pm 10$ & $107 \pm 15$ & $87 \pm 11$ \\
\hline Fasting plasma C-peptide (pmol/1) & $523 \pm 45$ & $575 \pm 57$ & $692 \pm 62$ & $736 \pm 53$ \\
\hline $\mathrm{FCP} / \mathrm{FBG}(\mathrm{pmol} / \mathrm{mmol})$ & $52 \pm 8$ & $55 \pm 8$ & $66 \pm 8$ & $82 \pm 8^{*}$ \\
\hline C-peptide AUC (pmol/1.15min) & $2537 \pm 163$ & $2799 \pm 281$ & $3169 \pm 293$ & $3770 \pm 291^{*}$ \\
\hline Islet B-cell function (insulin) (\%) & $43 \pm 11$ & $33 \pm 6$ & $47 \pm 7$ & $54 \pm 8$ \\
\hline Islet B-cell function (C-peptide) $(\%)$ & $25 \pm 5$ & $25 \pm 5$ & $31 \pm 5$ & $53 \pm 11^{* *}$ \\
\hline Relative insulin resistance & $5.8 \pm 0.7$ & $5.6 \pm 0.8$ & $7.8 \pm 1.1$ & $6.0 \pm 1.1^{*}$ \\
\hline $\mathrm{NEFA}(\mathrm{mmol} / \mathrm{l})$ & $0.95 \pm 0.09$ & $0.87 \pm 0.09$ & $1.02 \pm 0.10$ & $0.73 \pm 0.06^{*}$ \\
\hline
\end{tabular}

* $<<0.05$ compared to pre-treatment

\section{Non-obese patients}

Of the 28 non-obese patients, 7 could not be studied after three months (six had to be treated with insulin, one was lost from follow-up). Table 2 shows the changes observed in the 21 patients restudied after 3 months. Dietary management did not lead to improvement in fasting blood glucose or $\mathrm{HbA}_{1}$ levels. Islet B-cell function did not change.

\section{Obese patients}

Of the 33 obese patients, 4 could not be studied after six months (one had to be given insulin, 3 were lost from follow-up). Thus, 29 patients were restudied after six months. As shown in table 2, BMI dropped significantly $(\mathrm{p}<0.05)$. Five patients reached a BMI below $27.0 \mathrm{~kg} / \mathrm{m}^{2}$. An increase in body weight was seen in 7 patients, the maximal increase was $2 \mathrm{~kg}$. Seventeen of the 22 patients who lost weight showed a decrease of fasting blood glucose levels, while these levels increased in 5 of the 7 who gained weight (figure 1).

Eight patients reached fasting blood glucose within the therapeutic goal of $<7.0 \mathrm{mmol} / \mathrm{l}$. Changes of $\mathrm{HbA}_{1}$-levels were comparable. On an average, plasma insulin levels decreased $40 \%$ in 19 of the 22 patients in whom weight reduction 


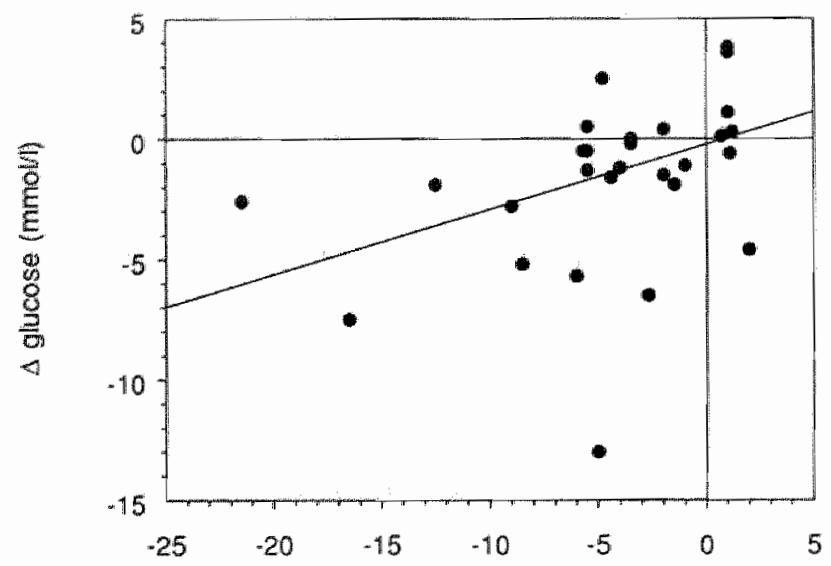

$\Delta$ body weight $(\mathrm{kg})$

Figure 1. Relationship between the decrease in fasting blood glucose levels $(\mathrm{mmol} / \mathrm{l})$ and the decrease in body weight $(\mathrm{kg})$ in 29 obese patients after six months of diet $(r=0.38, p=0.04)$

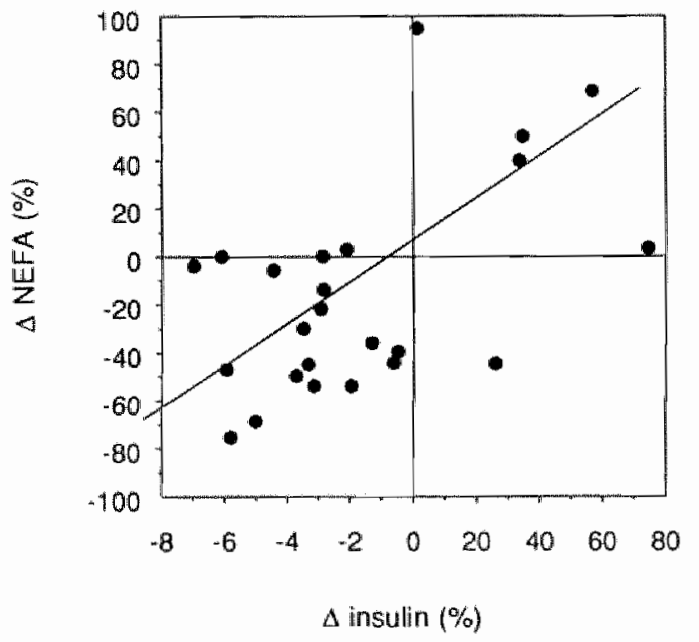

Figure 2. Relationship between the percentage change of fasting plasma insulin levels (FIRI) compared to percentage change in free fatty acid (NEFA) levels in 24 obese patients after six months' of diet $(r=0.61 . p=0.002)$.

was achieved, and increased $28 \%$ in 5 of the 7 patients who gained weight. The decrease of NEFA-levels correlated significantly with the decrease of body weight $(p<0.05)$, and also with the decrease of insulin levels (figure 2 ). 
The obese patients were subdivided on the basis of changes in their metabolic control and islet B-cell function (table 3). In 9 a decrease in fasting blood glucose (two repeated measurements) was observed together with a decrease in C-peptide release after glucagon; they were separately analysed as subgroup 1 . In 10 others the decrease in fasting blood glucose was accompanied by an increase in C-peptide AUC (subgroup 2). Ten patients showed an increase in fasting blood glucose, in 9 of them (defined as subgroup 3) this increase occurred in the presence of an increase in C-peptide AUC. Figure 3 depicts the changes in islet $\mathrm{B}$-cell function compared to the changes in fasting blood glucose in the different subgroups. In subgroup 1 the decrease in C-peptide AUC was accompanied by significant decreases in fasting $C$-peptide $(p<0.05)$ and insulin $(p<0.05)$ levels and also of NEFA-levels $(p<0.005)$ (table 4$)$. Patients of subgroup 2 had a lower median fasting blood glucose and body mass index at the start of the study. Their NEFA-levels did not decrease significantly. Their increase in C-peptide AUC was parallelled by a significant increase of calculated islet B-cell function (C-peptide). In subgroup 3 median levels of fasting blood glucose $(p<0.01)$ and $C$-peptide $(p<0.05)$ increased, whereas NEFA-levels remained unchanged. Body mass index increased in 4 out of these 9 patients, whereas in both other groups only one patient gained some weight. However, NEFA increased in all 4 patients who gained weight, but decreased in 4 of the 5 patients who lost weight. Median time since diagnosis of diabetes was different between the groups: this was less then 1 year in subgroup 1, and 3.5 and 6 years $(\mathrm{p}<0.05)$ in subgroups 2 and 3 , respectively.

Table 3. Subgrouping of patients according to changes in fasting blood glucose and glucagonstimulated C-peptide release.

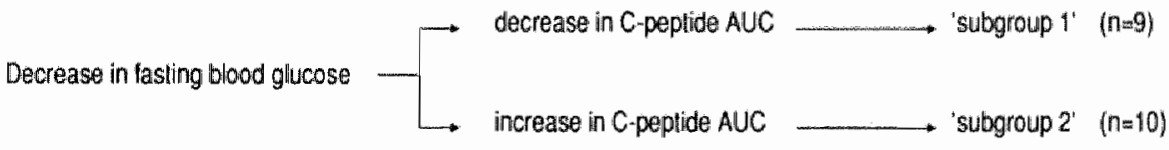

Increase in fasting blood glucose
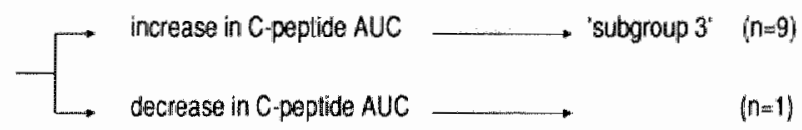


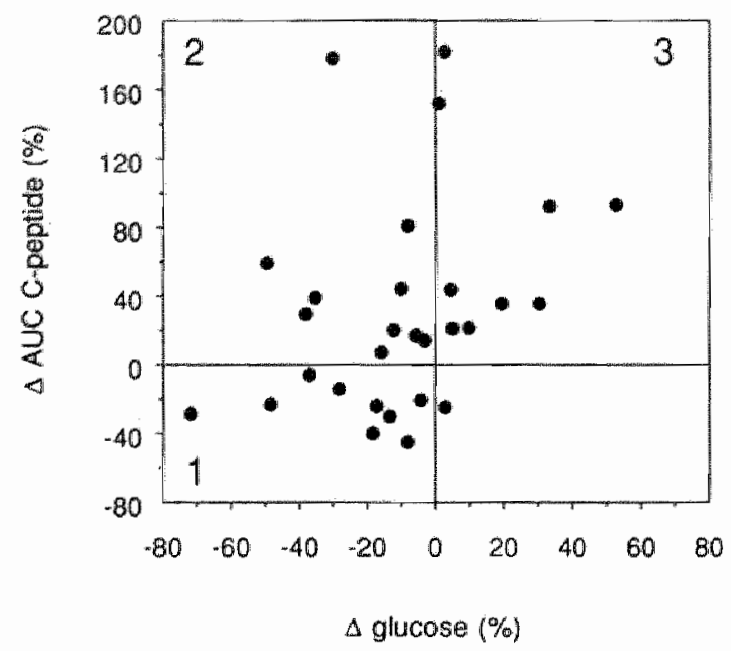

Figure 3. Relationship between the percentage change of fasting blood glucose compared to percentage change in islet $\mathrm{B}$-cell function, estimated by calculating the area under the curve of C-peptide (C-peptide AUC) after intravenous injection of $1 \mathrm{mg}$. glucagon, in 29 obese patients after six months of diet. Three subgroups can be discerned:

group 1: patients in whom fasting blood glucose and C-peptide AUC decreased;

group 2: patients in whom fasting blood glucase decreased and C-peptide AUC increased; group 3: patients in whom fasting blood glucose and C-peptide AUC increased.

\section{DISCUSSION}

In this study, intensified dietary treatment did not improve glucose or NEFA metabolism or islet B-cell function in the non-obese patients with type 2 diabetes and fasting blood glucose levels above $10 \mathrm{mmol} / \mathrm{l}$. Previously we have shown that in a subset of these patients a slight improvement in beta-cell function could be found (19). This was however not reflected by better metabolic control. In general, the results of diet treatment in non-obese patients are disappointing: Sonksen and co-workers (12) found that only 13 out of 38 newly presenting, untreated diabetic patients within $130 \%$ of desirable body weight responded to dietary measures; the mean weight of the responders was significantly higher. Other studies $(13,20)$ confirmed these results. Thus, it might be argued that in non-obese patients, additional therapy with oral hypoglycaemic agents or insulin should be started earlier.

In contrast, strict dietary therapy resulted in improved metabolic control in 19 of the 29 obese patients, especially in those patients who succeeded in losing weight. However, in only eight of them the therapeutic goal of fasting blood 
Table 4. Results of dietary treatment in 28 obese patients.

\begin{tabular}{|c|c|c|c|c|c|c|}
\hline \multirow[b]{2}{*}{ a } & \multicolumn{2}{|c|}{ Subgroup 1} & \multicolumn{2}{|c|}{ Subgroup 2} & \multicolumn{2}{|c|}{ Subgroup 3} \\
\hline & $\begin{array}{l}\text { entry } \\
(n=9)\end{array}$ & 6 months & $\begin{array}{l}\text { entry } \\
(n=10)\end{array}$ & 6 months & $\begin{array}{l}\text { entry } \\
(n=9)\end{array}$ & 6 months \\
\hline Fasting blood glucose (mmol/) & 13.4 & $8.3^{\$}$ & 10.9 & $9.1^{\text {将 }}$ & 11.3 & $143^{H}$ \\
\hline C-peptide AUC (pmol/1.15min) & 4343 & $3729^{\#}$ & 2540 & $3646^{\$}$ & 2056 & $3968^{\$}$ \\
\hline Number of patients with weight loss & $8 / 9$ & & $8 / 10$ & & $5 / 9$ & \\
\hline Body mass index $\left(\mathrm{kg} / \mathrm{m}^{2}\right)$ & 31.2 & $29.4^{\#}$ & 28.8 & $27.2^{*}$ & 31.2 & 29.8 \\
\hline Known duration of diabetes (yrs) & $<1$ & & 3.5 & & $6^{* *}$ & \\
\hline Glycosylated haemoglobin $(\%)$ & 11.1 & $9.3^{\#}$ & 13.5 & $12.1 *$ & 12.6 & 11.6 \\
\hline Fasting plasma C-peptide (pmol/l) & 1031 & $715^{*}$ & 550 & 573 & 518 & $747^{*}$ \\
\hline Fasting plasma insulin (pmol/1) & 126 & $95^{*}$ & 81 & 60 & 70 & 66 \\
\hline Islet B-cell function (insulin) (\%) & 36 & 62 & 28 & 54 & 22 & 17 \\
\hline Islet B-cell function (C-peptide) (\%) & 30 & 48 & 22 & $29^{*}$ & 22 & 24 \\
\hline Relatĩve insulin resistance & 9.0 & $3.8^{*}$ & 4.6 & 2.7 & 5.5 & 6.5 \\
\hline $\mathrm{NEFA}(\mathrm{mmol} / \mathrm{l})$ & 1.22 & $0.59^{\$}$ & 0.88 & 0.68 & 0.85 & 0.82 \\
\hline
\end{tabular}

All data represent median values.

* $p<0.05$, \# $p<0.01, \$ p<0.005$ compared to pre-treatment;

** $\mathrm{p}<0.05$ compared to sub-group 1

glucose less than $7.0 \mathrm{mmol} / \mathrm{l}$ was reached within six months, while in only five a body mass index below the target of $27.0 \mathrm{~kg} / \mathrm{m}^{2}$ was reached. In general, islet B-cell function improved significantly in these patients (table 2). The decrease of free fatty acids correlated well with the decrease in body weight and fasting blood glucose. Since it has been shown previously that elevated levels of NEFA are a reflection of peripheral insulin resistance (21), the relative decrease of serum NEFA in our patients and the decreasing fasting insulin levels (figure 2) imply both a diminished resistance and enhanced insulin action.

It might be argued that a longer period of dietary treatment could have resulted in further reduction of weight and improvement of diabetic control. The proper period of dietary therapy without the prescription of additional medication still has to be established. Hadden et al (6) investigated the metabolic effects of intensive dietary management in 57 obese patients with type 2 diabetes. They found that after six months 42 of these patients had fasting glucose values below $8 \mathrm{mmol} / \mathrm{l}$. Wales (7) reported more disappointing effects 
of treatment of 182 patients (both obese and non-obese) with diet alone, prescribed in a normal clinicall practice, without intensive education programs. Although comparisons between obese and non-obese patients are not given, a significantly greater improvement in glucose tolerance was observed in those patients who lost weight during the 3 months follow-up. Others reported good effects of very low-calorie dietary therapy $(8,11)$. Recently, Hadden and coworkers (22) reported a prospective study concerning 223 newly-diagnosed type 2 diabetic patients. Eighty percent of them were treated by diet only for six years. The mean fasting blood glucose of these patients, which was $11.3 \pm 0.3$ $\mathrm{mmol} / \mathrm{l}$ prior to therapy, was maintained at $8 \mathrm{mmol} / \mathrm{l}$ for two years, but rose gradually to levels of $10 \mathrm{mmol} / \mathrm{l}$.

We studied our obese patients in 3 subgroups (table 3 ). The patients in subgroup 1, who showed a decrease in fasting blood glucose levels and C-peptide release, had diabetes which was recently diagnosed. In these patients there was evidence of marked insulin resistance, as assessed by high levels of free fatty acids and by a gross elevation of the calculated resistance, in the presence of moderate to severe hyperglycaemia. Further, they showed high fasting plasma $C$-peptide and insulin levels, and marked $C$-peptide release after glucagon. Dietary treatment resulted in a significant improvement in metabolic control, reflected by a $40 \%$ decrease in fasting blood glucose and almost normalization of NEFA. In subgroup 2 improvement in islet B-cell function was more prominent, whereas insulin resistance decreased only slightly. In contrast, the 9 patients in subgroup 3, who did not improve metabolic control, had a longer known duration of diabetes. Four of them actually gained weight during the treatment period. One might expect an increase in insulin resistance in these patients. Indeed, NEFA-levels increased in all 4 patients who gained weight, but decreased in 4 of the 5 patients who lost weight. Thus it seems that changes in NEFA are not only dependent on changes in fasting blood glucose, as previously described (23), but also on changes in body weight. The increase in basal and stimulated $C$-peptide release, that was found in these patients, was probably -at least in part-caused by the increase of fasting blood glucose levels.

Exact quantification of residual islet B-cell function remains difficult. The estimation of islet B-cell function and insulin resistance by calculation of formulae derived from a mathematical model recently has received much attention (18). In our study we compared the formulae on islet B-cell function, using fasting insulin or $\mathrm{C}$-peptide concentration, with the $\mathrm{C}$-peptide release measured after i.v. injection of glucagon. Both appeared to correlate well in obese and non-obese patients prior to diet therapy. However, discordant changes did occur during therapy in the obese patients, as shown in table 4 . Various factors can account for the differences between calculated and measured (C-peptide AUC) 
islet B-cell function. The stimulated C-peptide release may be dependent on the ambient blood glucose levels. Furthermore, it has been shown that hyperglycaemia potentiates the insulin response to other stimuli, as shown for arginine (24), to a greater degree in normal subjects than in diabetic subjects. Although the formulae of Matthews do take the ambient glucose level into account, their use should be validated in both untreated and treated diabetic patients. Changes in body weight may also be of influence on the interpretation. In addition, since there may be differences in insulin kinetics in diabetic patients compared to controls (25), the estimation of islet B-cell function using the determination of C-peptide might be preferred.

In summary, in a population of patients with type 2 diabetes mellitus defects in islet B-cell function and insensitivity to insulin were shown. Strict dietary measures did not result in improvement of metabolic control in the non-obese patients with moderate hyperglycaemia. In the obese patients three response patterns to treatment were observed: in two-thirds of patients weight loss was achieved with improvement in blood glucose control accompanied either with increased insulin action (subgroup 1) or with increased islet B-cell function (subgroup 2). In the other patients metabolic control worsened, probably due to increased insulin resistance in spite of an increased islet B-cell function. To a certain extent the pattern of response could be predicted on the basis of residual islet B-cell function and the known duration of diabetes.

\section{REFERENCES}

1. Unger RH, Grundy S. Hyperglycaemia as an inducer as welt as a consequence of impaired islet cell function and insulin resistance: implications for the management of diabetes. Diabetologia 1985; $28: 119-121$.

2. Efendic S, Luft R, Wajngot A. Aspects of the pathogenesis of type 2 diabetes. Endocrine Rev $1984 ; 5: 395-410$.

3. DeFronzo RA, Ferrannini E, Koivisto V. New concepts in the pathogenesis and treatment of noninsulin-dependent diabetes mellitus. Am J Med 1983; 74 (suppl): 52-81.

4. Ward WK, Bolgiano DC, McKnight B, Halter JB, Porte Jr D. Diminished B cell secretory capacity in patients with non-insulin -dependent diabetes mellitus. J Clin Invest 1984; 74 : 1318-1328.

5. Skyler IS. Non-insulin-dependent diabetes mellitus: a clinical strategy. Diabetes Care 1984; 7 (suppl. 1): 118-129.

6. Hadden DR, Montgomery DAD, Skelly RJ, et al. Maturity onset diabetes mellitus: response to intensive dietary management. Br Med J 1975;2: 276-278.

7. Wales JK. Treatment of type 2 (non-insulin-dependent) diabetic patients with diet alone. Diabetologia $1982 ; 23: 240-245$. 
8. Hughes TA, Gwyne JT, Switzer BR, Herbst C. White G. Effects of caloric restriction and weight loss on glycemic control, insulin relcase and resistance, and atherosclerotic risk in obese patients with type II diabetes mellitus. Am J Med 1984; 77: 7-17.

9. Lipson $L G$, Lipson $M$. The therapeutic approach to the obese maturitymonset diabetic patient. Arch Intern Med 1984; 144: 135-138.

10. Bogardus C, Ravussin E, Robbins DC, Wolfe RR, Horton ES, Sims EAH. Effects of physical training and dief therapy on carbohydrate metabolism in patients with glucose intolerance and non-insulin-dependent diabetes mellitus. Diabetes 1984; 33: 311-318.

11. Henry $\mathrm{RR}_{4}$ Wallace $\mathrm{P}$, Olefsky JM. Effects of weight loss on mechanisms of hyperglycemia in obese non-insulin-dependent diabetes mellitus. Diabetes 1986; 35:990-998.

12. Sonksen PH, Lowy C, Perkins JR, Lim HS. Non-insulin-dependent diabetes: 10-year outcome in relation to initial response to diet and subsequent sulfonylurea therapy. Diabetes Care 1984; 7 (suppl. 1): 59-66.

13. Taylor $\mathrm{KG}$, John WG, Matthews KA, Wright AD. A prospective study of the effect of 12 months treatment on serum lipids and apolipoproteins A-I and B in type 2 (non-insulindependent) diabetes. Diabetologia $1982 ; 23 ; 507-510$.

14. WHO Expert Committee on Diabetes Mellitus. Technical Report Series 646, 1980. Geneva: World Health Organization.

15. Poulsen $\mathrm{S}$, Billesbolle $\mathrm{P}$, Kolendorf $\mathrm{K}$, Thorsteinsson $\mathrm{B}$. The C-peptide response to glucagon injection in IDDM and NIDDM patients. Horm Metabol Res 1985; 17: 39-40.

16. Heding LG. Radioimmunological determination of human C-peptide in serum. Diabetologia 1975; 11:541-548.

17. Laturell $\mathrm{S}$, Tibbling $\mathrm{G}$. Colorimetric micro-determination of free fatty acids in plasma. Clin Chim Acta 1967; 16:57-62.

18. Matthews DR, Hosker JP, Rudenski AS, Naylor BA, Treacher DF, Turner RC. Homeostasîs model assessment: insulin resistance and b-cell function from fasting plasma glucose and insulin concentrations in man. Diabetologia 1985; 28: 412-419.

19. Wolffenbuttel BHR, Weber RFA, Verschoor L. Improved insulin secretion in NIDDM by strict dietary control not accompanied by weight reduction. Diab Res Clin Pract 1985; 1: $\$ 607$.

20. UK Prospective Study of therapies of maturity-onset diabetes. I. Effect of diet, sulphonylurea, insulin or biguanide therapy on fasting plasma glucose and body weight over one year. Diabetologia 1983; $24: 404-411$.

21. Fraze E, Donner CC. Swislocki ALM, et al Ambient plasma free fatty acid concentrations in non-insulindependent diabetes mellitus: evidence for insulin resistance. $\mathbb{C}$ Clin Endocrinol Metab 1985; 61: 807-811.

22. Hadden DR, Blair ALT, Wilson EA, et al. Natural history of diabetes presenting age 40-69 years: a prospective study of the influence of intensive dietary therapy. Quart I Med 1986; 59:579-598.

23. Bogardus C, Lillioja S, Howard BV, Reaven GM, Mott D. Relationships between insulin secretion, insulin action, and fasting plasma glucose concentrations in nondiabetic and non-insulin-dependent diabetic subjects. J Clin Invest 1984; 74: 1238-1246.

24. Ward WK, Beard JC, Halter JB, Pfeifer MA. Porte D Jr. Pathophysiology of insulin secretion in non-insulin dependent diabetes mellitus. Diabetes Care 1984; 7; 491-502.

25. Vasquez B, Reaven GM, Andrews WJ. Elevated in wivo insulin clearance in Pima indians with non-insulin dependent diabetes mellitus. Diabetes 1985; 34:671-676. 


\section{CHAPTER}

\section{6}

Treatment of patients with type 2 diabetes failing on dietary therapy - Oral hypoglycaemic agents or insulin?

\section{A randomized crossover study}

Bruce H.R. Wolffenbuttel, Rob F.A. Weber, Peter M. van Koetsveld, Lilian Weeks, Louis Verschoor

Diabetic Medicine 1989; 6: 520-525 
In 13 non-obese patients with type 2 diabetes mellitus who failed to achieve adequate blood glucose control on dietary treatment (fasting blood glucose 13.4 $\pm 2.7( \pm \mathrm{SD}$ ) mmol/l, glycosylated haemoglobin $13.0 \pm 1.7 \%$ ), the effects of 6 months insulin or sulphonylurea therapy on blood glucose control and lipid metabolism were compared in a randomized crossover study. Three patients, who showed a clear improvement on insulin (median glycosylated haemoglobin fell from 14.7 to $8.6 \%$ ), withdrew from the study prematurely because of subjective and objective signs of hyperglycaemia after crossover from insulin to sulphonylurea. Daily dose after 6 months was $2000 \mathrm{mg}$ tolbutamide $(n=3), 18 \pm$ $1 \mathrm{mg}$ glibenclamide $(\mathrm{n}=7)$, or $34 \pm 3 \mathrm{U}$ insulin. On insulin, fasting $(8.0 \pm 1.9 \mathrm{mmol} / \mathrm{l})$ and postprandial blood glucose $(10.4 \pm 2.7$ $\mathrm{mmol} / \mathrm{l})$, and glycosylated haemoglobin $(9.5 \pm 1.1 \%)$ were lower than on sulphonylurea $(11.0 \pm 3.4 \mathrm{mmol} / \mathrm{h}, 14.4 \pm 4.8 \mathrm{mmol} / \mathrm{l}$ and $11.0 \pm 2.5 \%$ respectively, $\mathrm{p}<0.05$ in each case). Median increase in body weight was greater on insulin ( $4.2 \mathrm{~kg} v s .1 .1 \mathrm{~kg}, \mathrm{p}<0.05)$. Six patients experienced improved well-being on insulin compared with sulphonylurea. Median plasma non-esterified fatty acids decreased from $0.82 \mathrm{mmol} / 1$ to $0.48 \mathrm{mmol} / 1$ (sulphonylurea) and $0.64 \mathrm{mmol} / \mathrm{l}$ (insulin, both $\mathrm{p}<0.05$ ). HDL-cholesterol was higher after insulin $(1.12 \pm 0.40 \mathrm{mmol} / \mathrm{l})$ than after sulphonylurea $(0.94 \pm 0.25 \mathrm{mmol} / \mathrm{l}, \mathrm{p}<0.05)$, and the LDL:HDL cholesterol ratio $(3.27 \pm 1.07$ vs. $3.90 \pm 1.08)$ and VLDL-triglycerides $(0.67 \pm 0.22$ vs. $1.13 \pm 0.40 \mathrm{mmol} / \mathrm{l}$ ) were lower (both $\mathrm{p}<0.05$ ). A C-peptide response after intravenous glucagon of below $5.0 \mathrm{nmol} / \mathrm{l}$ per $15 \mathrm{~min}$ identified those patients, who had better blood glucose control with insulin. 
The treatment of patients with type 2 diabetes remains difficult. Dietary modification and regular physical exercise form the basis of treatment (1). Despite this, normoglycaemia is not achieved in a considerable number of patients. Therapy with oral hypoglycaemic agents or insulin may then be warranted. Although many patients with type 2 diabetes may have frank hyperglycaemia, specific symptoms are seldom experienced, or are not recognized as such. Thus, educating and motivating the patient for additional treatment is essential.

The comparative effects of sulphonylurea and insulin treatment on glucose metabolism and insulin action have recently come more into focus (2). Sulphonylureas stimulate the release of endogenous insulin and probably improve peripheral insulin action (3). In patients in whom intensified insulin treatment produces (near)normoglycaemia, an improvement of islet B-cell function and insulin action have been demonstrated $(4,5)$. However, treatment with exogenous insulin might result in considerable peripheral hyperinsulinaemia (4). Furthermore, patients often hesitate to commence the uncomfortable therapy of insulin injections.

Only a few investigators have directly studied the effects of both treatment modalities in subgroups of type 2 diabetic patients failing on dietary therapy $(2,6)$. In the current study we compared the effect of sulphonylurea treatment with that of insulin on glucose and lipid metabolism and islet B-cell function in non-obese patients with type 2 diabetes, poorly controlled on diet alone. Further, we tried to assess which parameters could predict the efficacy of either treatment in the individual patient.

\section{PATIENTS AND METHODS}

\section{Patients}

Thirteen non-obese patients (age $61 \pm 3$ years, body mass index, BMI $24.1 \pm 0.6$ $\mathrm{kg} / \mathrm{m}^{2}$, median time since diagnosis of diabetes 5 (range 1-22) years, 6 malles) with type 2 diabetes ( 7 ) participated. The study was approved by the University Hospital ethical committee. All patients were islet-cell antibody negative, had no ketonuria, and no family history of type 1 diabetes. They were hyperglycaemic with fasting blood glucose concentrations above $8.0 \mathrm{mmol} / \mathrm{l}$, and had a stable body weight and blood glucose control during a 3-month run-in period. In this period patients received dietary prescription depending on their physical activity. Diet contained $55 \%$ carbohydrates, with exclusion of monosaccharides 
and disaccharides, $30 \%$ fat and $15 \%$ protein. Regular physical exercise was encouraged. No patient had impaired kidney function (creatinine clearance $<40$ $\mathrm{ml} / \mathrm{min}$ ), severe hypertension (diastolic blood pressure $105 \mathrm{~mm} \mathrm{Hg}$ ), or elevated liver enzymes, or was being treated with corticosteroids. Concomitant drug therapy was not changed during the study.

\section{Measurements}

A full history and physical examination of each patient was obtained at the first visit. Besides routine laboratory investigations, which included measurement of fasting blood glucose on 2 consecutive days, and blood glucose $2 \mathrm{~h}$ after breakfast and lunch (postprandial blood glucose), blood was drawn for the determination of glycosylated haemoglobin $\left(\mathrm{HbA}_{1}\right)$, non-esterified fatty acids (NEFA) and lipids. Islet B-cell function was assessed after an overnight fast by measuring fasting plasma insulin and $\mathrm{C}$-peptide levels, as well as plasma C-peptide levels 5,10 , and $15 \mathrm{~min}$ after intravenous injection of $1 \mathrm{mg}$ glucagon (8).

\section{Study design}

The effects of sulphonylurea versus insulin therapy was studied in a crossover study. Patients were randomly assigned to start with either therapy. Six patients initially started with sulphonylureas, and switched to insulin after 6 months. In the remainder the opposite regimen was followed. Insulin treatment comprised two daily injections (before breakfast and dinner) of intermediate-acting insulin (Monotard HM or Protaphane HM, Novo Industri, Bagsvaerd, Denmark), supplemented with fast-acting insulin (Actrapid HM), when postprandial blood glucose levels exceeded $11.0 \mathrm{mmol} / \mathrm{L}$. Sulphonylurea therapy consisted of tolbutamide, given in two doses of 500-1000 $\mathrm{mg}$. When adequate control could not be achieved with this drug, glibenclamide was given in two doses of $2.5-10 \mathrm{mg}$. Goals of therapy were fasting blood glucose $<8.0 \mathrm{mmol} / 1$, and/or $\mathrm{Hb} \mathrm{A}_{1}<9.0 \%$. Instructions on insulin injection technique and, in the majority of patients, self-monitoring of blood glucose, were given by a specialist nurse. All patients visited the outpatient-clinic 2 and 4 weeks after beginning therapy, and thereafter monthly, when measurements of body weight, glucose profile, and $\mathrm{HbA}_{1}$ were made. For comparison, glucagontests and lipid determinations were performed in 18 non-obese ( $9 \mathrm{M}, 9 \mathrm{~F}$, aged $18-48$ years) control subjects. 


\section{Analytical procedures}

Blood glucose was measured in venous whole blood by an automated hexokinase method. $\mathrm{HbA}_{1}$-concentration (normal $4.5-7.6 \%$ ) was measured by column chromatography (Bio-Rad Laboratories, Richmond, CA., USA). Plasma insulin was determined by radio-immunoassay after polyethyleneglycol pretreatment (Immuno Nuclear Corporation, Stillwater, MS, USA). Plasma C-peptide levels were determined by radioimmunoassay (9) (antibody M1230, Novo Research Institute, Bagsvaerd, Denmark). Between-assay variation of insulin-RIA was $7.5 \%$, and C-peptide $9 \%$. NEFA were determined by a colorimetric method (10). Lipoproteins were separated by ultracentrifugation, and cholesterol and triglycerides were determined in the separate layers with enzymatic methods (Boehringer, Mannheim, FRG).

\section{Calculations and statistical analyses}

For each patient blood glucose control after 6 months insulin was compared with that after sulphonylurea by calculating the difference between the respective $\mathrm{HbA}_{1}$-concentrations. Islet $\mathrm{B}$-cell function was assessed in 3 ways:

1. As the increment of C-peptide $5 \mathrm{~min}$ after the iv injection of $1 \mathrm{mg}$ glucagon;

2. As the incremental area under the response curve (AUC) of C-peptide, calculated by the trapezoidal rule;

3. From the fasting levels of blood glucose and insulin by calculating the degree of impairment of B-cell function (B) using the formula based on a mathematical model $(11,12)$. Relative insulin resistance $(R)$ was calculated with a formula based on the same model (11).

Results are expressed as mean $\pm \mathrm{SD}$, or median and range when data were not normally distributed. For statistical evaluations Student's paired t-test and Wilcoxon's paired test were used to compare data before and after treatment. Results in the non-diabetic subjects were compared with those of the diabetic patients using Student's unpaired t-test. The effect of period and treatment order was evaluated as described by Hills and Armitage (13). Correlations were obtained using linear regression analysis. 


\section{Variables at entry}

Details of metabolic variables at the start of the study are given in table 1 . Fasting blood glucose was 8.7 to $18.5 \mathrm{mmol} / \mathrm{l}(13.4 \pm 2.7 \mathrm{mmol} / \mathrm{l})$, and postprandial blood glucose 10.0 to $26.7 \mathrm{mmol} / \mathrm{h}(17.6 \pm 4.9 \mathrm{mmol} / \mathrm{l})$. $\mathrm{HbA}_{1}$ was 10.3 to $15.3 \%(13.0 \pm 1.7 \%)$. Fasting $\mathrm{C}$-peptide and insulin levels were not different from control subjects, but the C-peptide:glucose ratio was greatly diminished. Islet B-cell function, estimated by the C-peptide increment 5 min after glucagon, and the release of C-peptide during the first $15 \mathrm{~min}$ after glucagon was greatly diminished ( $p<0.001$ ) compared with control subjects, as was calculated islet B-cell function. Serum NEFA and total and VLDL-triglyceride levels were markedly $(p<0.001)$ elevated. LDL-cholesterol (LDL-C) was higher, whereas HDL-cholesterol $($ HDL-C) was significantly lower $(p<0.05)$ than in control subjects (table 1).

\section{The effects of therapy}

In 3 patients who received insulin initially, subjective and objective signs of hyperglycaemia occurred after they changed from insulin to sulphonylurea. This necessitated the reinstitution of insulin therapy, within 1 month after crossover in 1 patient, and after 3 months in the other 2 . These 2 patients were completely evaluated at that time. Individual data of the 3 patients are shown in table 2.

Thus, complete crossover results are given for 10 patients. Daily sulphonylurea dose after 6 months was $18 \pm 1 \mathrm{mg}$ glibenclamide $(\mathrm{n}=7)$, and $2000 \mathrm{mg}$ tolbutamide $(n=3)$. Mean dailly insulin dose after 6 months was $34 \pm 3$ (range 22-52) U. Median body weight had increased 1.1 (range -3.0 to 5.5 ) $\mathrm{kg}$ after 6 months sulphonylurea, and 4.2 (range -3.6 to $6.0 \mathrm{~kg}, \mathrm{p}<0.05$ compared with sulphonylurea) after insulin. During sulphonylurea, fasting blood glucose decreased to $9.8 \pm 1.9 \mathrm{mmol} / \mathrm{l}$ after 2 months. Fasting blood glucose then gradually increased again to $11.0 \pm 3.4 \mathrm{mmol} / \mathrm{l}$ after 6 months. With insulin therapy, fasting blood glucose decreased to $9.7 \pm 2.7 \mathrm{mmol} / 1$ after 2 months, and to 7.4 $\pm 2.0 \mathrm{mmol} / \mathrm{l}$ and $8.0 \pm 1.9 \mathrm{mmol} / \mathrm{l}$ after 5 and $6 \mathrm{months}$ (table 3 ). Fasting blood glucose values were significantly lower on insulin than on sulphonylurea therapy for the whole group $(\mathrm{p}<0.01)$. HbAl showed comparable changes. The individual data of these variables are plotted in figure 1 . Six of the 10 patients reported improved well-being, less tiredness, increased energy and a decrease 
Table 1. Metabolic variables, islet B-cell function, and plasma lipids in 13 type 2 diabetic patients at start of the study, compared with 18 weight-matched control subjects.

Diabetic patients

Control subjects

Fasting blood glucose (mmol/1)

$\begin{array}{ll}13.4 \pm 2.7^{\&} & 4.4 \pm 0.3 \\ 17.6 \pm 4.9^{\&} & 4.5 \pm 0.4 \\ 13.0 \pm 1.7^{\&} & 6.5 \pm 0.5 \\ 475(213-890) & 448(293-738) \\ 46(24-134) & 50(38-87) \\ 365(1.77-593)^{\&} & 852(368-2265) \\ 3.7(2.0-5.7)^{\&} & 11.3(4.2-26.2) \\ 18(8-39)^{\&} & 152(111-537) \\ 4.5(1.4-11.3)^{\&} & 1.4(1.0-2.3) \\ 0.82(0.58-2.6)^{\&} & 0.48(0.10-0.75) \\ 3.67 \pm 0.84^{\$} & 2.76 \pm 0.66 \\ 0.93 \pm 0.21^{*} & 1.26 \pm 0.46 \\ 4.07 \pm 1.43^{\&} & 2.45 \pm 0.91 \\ 2.35 \pm 1.00^{\$} & 1.01 \pm 0.35 \\ 0.86(0.26-4.5)^{*} & 0.43(0.18-1.32)\end{array}$

Postprandial blood glucose (mmol/l)

Glycosylated thaemoglobin (\%)

Fasting plasma C-peptide (pmol//)

Fasting plasma insulin (pmol/1)

C-peptide increment 5 min (pmol/l)

C-peptide AUC (nmol/1.15min)

$\mathrm{B}$ (\% islet B-cell function)

$R$ (relative insulin resistance)

NEFA (mmol/1)

LDL-cholesterol (mmol/l)

HDL-cholesterol (mmol/1)

LDL:HDL cholesterol ratio

Triglycerides ( $\mathrm{mmol} / \mathrm{l}$ )

VLDL-triglycerides (mmol/l)

Mean $\pm S D$, or median (range);

* $\mathrm{p}<0.05,{ }^{\$} \mathrm{p}<0.005,{ }_{\mathrm{p}<0.001}$ compared to control subjects

Table 2. Blood glucose control and measures of islet B-cell function in 3 patients who withdrew from the study.

\begin{tabular}{llll}
\hline & Baseline & Insulin & Sulphonylurea \\
\hline Fasting blood glucose (mmol//) & $12.0-18.5$ & $4.4-8.6$ & $12.1-16.7$ \\
Post-prandial blood glucose (mmol/1) & $18.3-28.2$ & $10.1-15.6$ & $19.3-26.5$ \\
Glycosylated haemoglobin (\%) & $13.3-15.3$ & $8.1-10.0$ & $11.5-12.6$ \\
Fasting plasma insulin (pmol//) & $37-93$ & $63-102$ & $38-63$ \\
Fasting plasma C-peptide (pmol/1) & $461-837$ & $453-695$ & $815-958$ \\
C-peptide AUC (nmol/1.15min) & $2.1-4.3$ & $2.7-11.2$ & $5.6-7.7$ \\
\hline
\end{tabular}

Data are presented as range.

${ }^{a}$ Only measured in 2 patients, 3 months after crossover from insulin to sulphonylureas 
in urine production during insulin therapy compared with sulphonylurea. Severe hypoglycaemia necessitating medical assistance was not observed.

\section{Islet B-cell function}

Fasting C-peptide, the fasting C-peptide:glucose ratio, the increment of C-peptide 5 min after glucagon, and C-peptide AUC did not change significantly (table 3). Fasting plasma free insulin levels only increased during the insulin period ( $\mathrm{p}<0.05$ compared with sulphonylurea). The calculated islet $\mathrm{B}$-cell function did not change during sulphonylurea therapy, neither did calculated relative insulin resistance.

Table 3. Comparison of insulin and sulphonylurea therapy in 10 non-obese patients: effects on blood glucose control, measures of islet B-cell function, and plasma lipids.

\begin{tabular}{|c|c|c|}
\hline & Sulphonylurea & Insulin \\
\hline Fasting blood glucose (mmol/l) & $\begin{array}{l}11.0 \pm 3.4 \\
(5.6-14.9)\end{array}$ & $\begin{array}{l}8.0 \pm 1.9^{\# 8} \\
(5.0-11.8)\end{array}$ \\
\hline Post-prandial blood glucose (mmol/l) & $\begin{array}{l}14.4 \pm 4.8 \\
(7.4-21.1)\end{array}$ & $\begin{array}{l}10.4 \pm 2.7^{\$ \$} \\
(7.3-14.5)\end{array}$ \\
\hline Glycosylated haemoglobin (\%) & $\begin{array}{l}11.0 \pm 2.5^{*} \\
(7.0-14.9)\end{array}$ & $\begin{array}{l}9.5 \pm 1.1 \\
(7.7-11.0)\end{array}$ \\
\hline Fasting plasma C-peptide (pmol/l) & $612(209-960)$ & $410(208-829)$ \\
\hline Fasting plasma insulin (pmol/1) & $63(25-103)$ & $72(42-181)$ \\
\hline $\mathrm{C}$-peptide increment $5 \min (\mathrm{pmol} / \mathrm{l})$ & $503(241-1554)$ & $372(172-947)$ \\
\hline C-peptide AUC (nmol/1 per 15-min) & $6.4(2.4-18.8)$ & $4.0(1.3-10.6)$ \\
\hline $\mathrm{B}$ (\% islet $\mathrm{B}-$ cell function) & $22(7-107)$ & \\
\hline $\mathbb{R}$ (relative insulin resistance) & $3.4(2.0-8.4)$ & \\
\hline $\mathrm{NEFA}(\mathrm{mmol} / \mathrm{l})$ & $0.48(0.31-1.38)^{*}$ & $0.64(0.35-0.85)^{*}$ \\
\hline LDL-cholesterol (mmol/l) & $3.57 \pm 0.92$ & $3.42 \pm 0.85$ \\
\hline HDL-cholesterol (mmol/l) & $0.94 \pm 0.25$ & $1.12 \pm 0.40^{s}$ \\
\hline LDL:HDL cholesterol ratio & $3.90 \pm 1.08$ & $3.27 \pm 1.07 \$$ \\
\hline Triglycerides (mmol/l) & $1.79 \pm 0.45$ & $1.51 \pm 0.38$ \\
\hline VLDL-triglycerides (mmol/l) & $1.13 \pm 0.40$ & $0.67 \pm 0.22^{\&}$ \\
\hline
\end{tabular}

Mean $\pm \mathrm{SD}$, or median (range);

* $p<0.05$, " $p<0.01$ compared with pre-treatment;

$\$ \mathrm{p}<0.05,{ }^{*} \mathrm{p}<0.01$ compared with sulphonylurea therapy 


\section{Plasma lipids}

The effects of therapy on lipid metabolism are given in table 3. NEFA showed a marked decrease $(\mathrm{p}<0.05$ ) with both treatments. Compared with baseline, the levels of LDL-cholesterol and HDL-cholesterol, as well as total triglycerides did not change. However, HDL-cholesterol was higher $(p<0.05)$, and the LDL:HDL cholesterol ratio $(p<0.05)$, and VLDL-triglycerides $(p<0.01)$ were lower after insulin than after sulphonylurea.

\section{Islet B-cell function and effect of therapy}

Figure 2 shows the relationship between C-peptide AUC and therapy outcome, as assessed by the difference between $\mathrm{HbA}_{1}$ after 6 months insulin and that after sulphonylurea. The data of 12 patients are presented, including the two patients who were evaluated only 3 months after switching from insulin to sulphonylurea. C-peptide AUC correlated well with this difference in $\mathrm{HbA}_{1}(r=0.70$, $\mathrm{p}=0.012$ ). A low C-peptide secretory capacity, reflected by an C-peptide AUC below $5.0 \mathrm{nmol} / \mathrm{l} .15 \mathrm{~min}$ identified those patients, who exhibited better blood glucose control on insulin therapy than on sulphonylurea. A similar correlation was found between the difference in $\mathrm{HbA}_{1}$ and the increment of $\mathrm{C}$-peptide 5 min after glucagon $(r=0.64, p=0.022)$.

\section{DISCUSSION}

There are few studies which compare the effects of sulphonylurea and insulin on blood glucose control in type 2 diabetic patients who have failed on dietary therapy. Tolazamide and insulin equally improved blood glucose control in obese patients (2). In non-obese newly-diagnosed type 2 diabetic patients insulin therapy resulted in better blood glucose control and improved islet B-cell response to oral glucose to a greater extent than sulphonylureas (6). There were, however, some differences in pre-study blood glucose control: the mean fasting blood glucose was $10.0 \mathrm{mmol} / \mathrm{l}$ in the former, and $12.9 \mathrm{mmol} / \mathrm{l}$ in the latter study. In the U.K. Prospective Diabetes Study $(14,15)$ the effects of oral hypoglycaemic agents and insulin have been reported in a large parallel study in newly-diagnosed diabetic patients, who failed to achieve normal fasting plasma glucose levels after dietary therapy. An equal effect of sulphonylurea and insulin on blood glucose control in both obese and non-obese palients was found. As a group the patients studied had comparatively moderate hyper- 

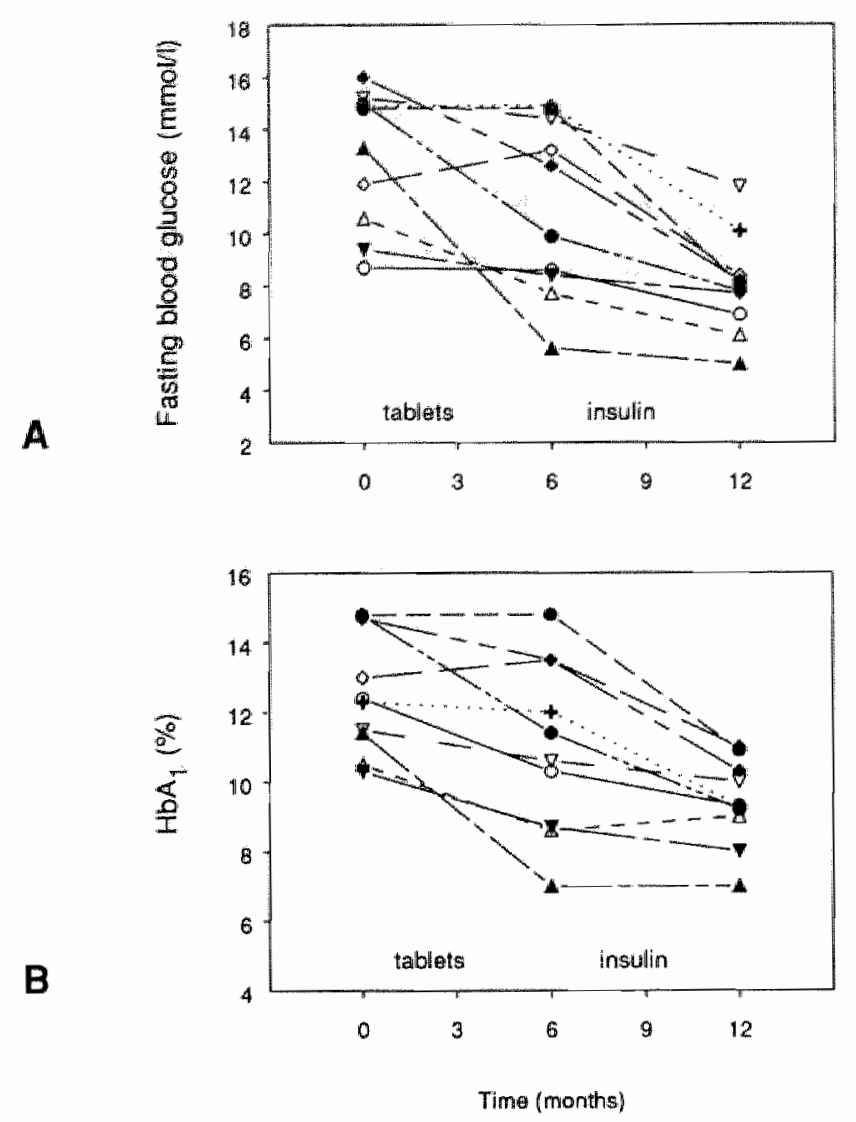

Figure 1. Course of fasting blood glucose (A) and glycosylated haemoglobin (B) during therapy with sulphonylurea ('tablets') and insulin in the 10 individual patients who completed the study.

glycaemia at the start of the treatment period (mean fasting plasma glucose 8.5 $\pm 1.9 \mathrm{mmol} / \mathrm{l})$.

In our non-obese type 2 diabetic patients we found significantly better blood glucose control, as measured by fasting and postprandial blood glucose and $\mathrm{HbA}_{1}$, on insulin than on sulphonylurea therapy, together with a clear improvement in clinical well-being. There was a moderate increase in body weight with both treatments, higher with insulin. Measures of islet B-cell function did not change, whereas fasting insulin levels did increase. HDL-cholesterol was significantly higher, and the LDL:HDL cholesterol ratio and VLDL-triglycerides were lower on insulin than on sulphonylurea therapy. 


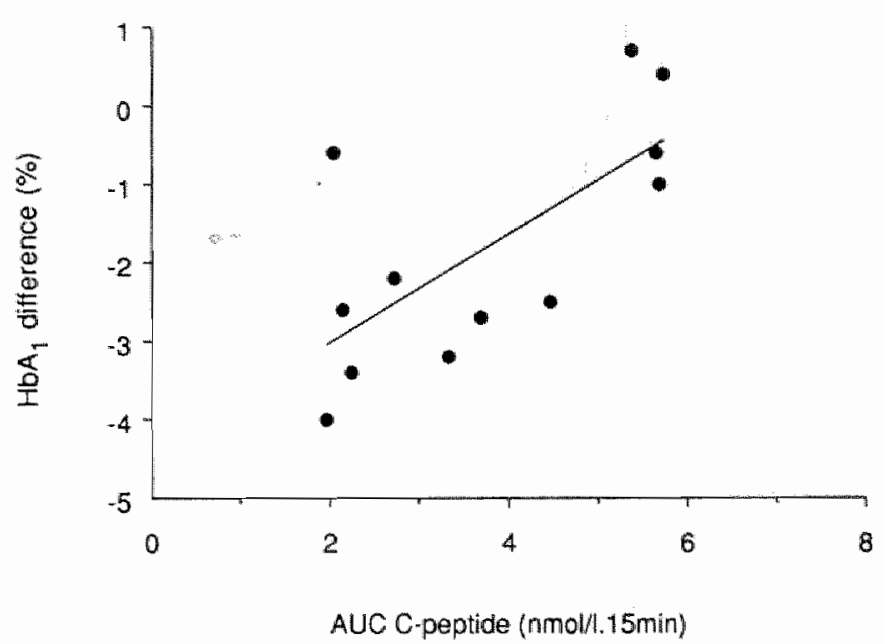

Figure 2. The relationship between the incremental C-peptide response after i.v. glucagon (C-peptide $\mathrm{AUC}$ ) and the difference between $\mathrm{HbA}_{1}$ after insulin and $\mathrm{HbA}$ after sulphonylurea therapy in 12 patients with type 2 diabetes. Ten of these are patients who completed the study; 2 additional patients were evaluated after having used only 3 months sulphonylurea therapy. Linear regression yields a r-value of $0.70, p=0.012$.

Despite our efforts, only in 7 of the 13 patients it was possible to achieve adequate blood glucose control (fasting blood glucose $<8.0 \mathrm{mmol} / \mathrm{l}$ ) on insulin, and only 2 achieved adequate control on sulphonylurea. It is known that most patients with type 2 diabetes do not report or even recognize hyperglycaemic complaints, despite the fact that they may be in rather bad control. Although our patients had reported no or only mild hyperglycaemic symptoms during dietary therapy, they experienced improved well-being as soon as blood glucose control was improved. The initial lack of symptoms of hyperglycaemia may negatively influence dietary and drug compliance.

Ten of the 13 patients had fasting blood glucose levels above $11.0 \mathrm{mmol} / \mathrm{l}$. On clinical grounds our patients were classified as non-insulin-dependent patients in whom adequate dietary treatment failed to normalize glycaemic control. Although their fasting insulin and C-peptide levels were similar to those of control subjects matched for body weight, a lower C-peptide response after glucagon was found. Earlier studies $(6,15)$ suggested that in such patients maximal-dose sulphonylurea therapy does not always normalize blood glucose control. Our data support this. However, in clinical practice sulphonylurea therapy would commonly be prescribed to these patients in order to achieve better control while avoiding insulin injections. Although good responders to oral hypoglycaemic agents generally have better islet B-cell function than poor 
responders, some patients with low insulin secretory capacity can respond favourably to oral agents. Others with good islet B-cell function will not (16). Since we found the lowest blood glucose values in our patients after 2-3 months of sulphonylurea, the effects of this therapy in a given patient can be assessed within a few months. When blood glucose control does not normalize, insulin therapy is warranted. Nevertheless, patients with only moderate hyperglycaemia often hesitate to start insulin therapy.

Determination of residual islet B-cell function can be useful to identify patients who might benefit from insulin therapy $(17,18)$, or to distinguish between individuals with type 1 or type 2 diabetes $(19,20)$. Usually, only fasting and 6 min post-glucagon values of C-peptide are used. All our patients with a C-peptide release after glucagon below 5.0 nmol/1.15min exhibited better blood glucose control on insulin than on sulphonyllureas. Other measures of islet B-cell function (fasting C-peptide levels, the C-peptide:glucose ratio) did not have any discriminatory power, nor did the calculated islet B-cell function. The formulae for these calculations are based on computer model predictions for the quantification of residual islet B-cell function of diet-treated diabetic patients in the basal state (11). The validity of these formulae for the interpretation of data collected in diabetic patients treated with insulin or oral hypoglycaemic agents still has to be determined. Based on our present findings we propose the use of the glucagon stimulationtest with measurement of C-peptide response over at least $15 \mathrm{~min}$, both for the quantification of residual islet B-cell function, and to decide which patients with type 2 diabetes, having failed on dietary therapy, should receive insulin. The C-peptide increment after 5 min can also be used for this purpose, but this variable has a slightly less discriminatory power.

After insulin therapy the plasma HDL-cholesterol was higher and VLDLtriglycerides were lower than after sulphonylurea. There were no differences in LDL-cholesterol between treatments. Previous studies on the effects of insulin treatment and the resulting improvement in blood glucose control on HDLcholesterol have yielded controversial results, as reviewed by Reaven (21). It is not yet known whether improvement of blood glucose control will also improve the lipid profile. In our small group of patients no correlation could be found between the improvement in HDL-cholesterol and changes in fasting blood glucose, $\mathrm{Hb} \mathrm{A}_{1}$, insulin levels or islet $\mathrm{B}$-cell function.

In conclusion, insulin therapy was superior to sulphonylurea in non-obese patients with type 2 diabetes who were markedly hyperglycaemic despite dietary therapy. By determination of $\mathrm{C}$-peptide release after glucagon it was possible to identify those patients in whom insulin therapy resulted in better blood glucose control than sulphonylurea. 


\section{REFERENCES}

1. Skyler JS. Non-insulin-dependent diabetes mellitus: a clinical strategy. Diabetes Care 1984; 7 (suppl. 1): 118-129.

2. Firth RG, Bell PM, Rizza RA. Effects of tolazamide and exogenous insulin on insulin action in patients with non-insulin-dependent diabetes mellitus. New Engl J Med 1986; 314: 1280-1286.

3. Gerich JE. Sulfonylureas in the treatment of diabetes mellitus. Mayo Clin Proc 1985; 60: 439-443.

4. Garvey WT, Olefsky JM, Griffin J, Hamman RF, Kolterman OG. The effect of insulin treatment on insulin secretion and insulin action in type II diabetes mellitus. Diabetes $1985 ; 34: 222-234$.

5. Ginsberg H, Rayfield EJ. Effect of insulin therapy on insulin resistance in type ll diabetic subjects-evidence for heterogeneity. Diabetes 1981; 30:739-745.

6. Samanta A, Burden AC, Kinghom A. A comparative study of sulphonylurea and insulin therapy in non-insulin-dependent diabetics who had failed on diet therapy. Diabetes Res 1987; 4: 183-185.

7. WHO Expert Committee on Diabetes Mellitus. Technical Report Series 727, 1985. Geneva: World Health Organization.

8. Poulsen $S$, Billesbolle $\mathbb{P}$, Kolendorf $K$, Thorsteinsson $B$. The C-peptide response to glucagon injection in IDDM and NIDDM patients. Horm Metabol Res 1985; 17: 39-40.

9. Heding LG. Radioimmunological determination of human C-peptide in serum. Diabetologia 1975; 11:541-548.

10. Laurell $S$, Tibbling G. Colorimetric micro-determination of free fatty acids in plasma. Clin Chim Acta 1967; 16:57-62.

11. Matthews DR, Hosker JP, Rudenski AS, Naylor BA, Treacher DF, Turner RC. Homeostasis model assessment: insulin resistance and b-cell function from fasting plasma glucose and insulin concentrations in man. Diabetologia 1985; 28:412-419.

12. Rudenski AS, Hadden DR, Atkinson AB et al. Natural history of pancreatic islet B-cell function in type 2 diabetes mellitus studied over six years by homeostasis model assessment. Diabetic Med 1987; 5: 36-41.

13. Hills $\mathrm{M}$, Ammitage P. The two-period cross-ower clinical trial. Br J Clin Phamacol 1979; $8: 7-20$.

14. UK Prospective study of therapies of maturity-onset diabetes: 1. Effect of diet, sulphony. lurea, insulin or biguanide therapy on fasting plasma glucose and body weight ower one year. Diabetologia $1983 ; 24: 404-411$.

15. UK Prospective study of therapies of maturity-onset diabetes: II. Reduction in Hba Ic with basal insulin supplement, sulfonylurea, or biguanide the rapy. Diabetes $1985 ; 34: 793-798$.

16. Lebovitz HE Oral hypoglycemic agents. In: The Diabetes Annual/3, eds. Alberti KGMM and Krall L.P. Amsterdam, Elsevier, 1987, 72-93.

17. Malmquist $J$, Birgerstam $G$. Assays of pancreatic B cell secretory products: utility in investigative and clinical diabetology. Scand J Clin Lab Invest 1986; 46: 705-713.

18. Koskinen $P$, Viikari J, Irjala K, Kaihola HL, Seppala P. C-peptide determination in the choice of treatment in diabetes mellitus. Scand J Clin Lab Invest 1985; 45; 589-597. 
19. Katzeff HL, Savage PJ, Barclay-White B, Nagulesparan M, Bennett PH. C-peptide measurement in the differentiation of type 1 (insulin-dependent) and type 2 (non-insulindependent) diabetes mellitus. Diabetologia 1985; 28: 264-268.

20. Tumer RC, Holman RR, Matthews DR, O'Rahilly SP, Rudenski AS, Braund WJ Diabetes nomenclature: classification or grading of severity? Diabetic Med $1986 ; 3: 216-220$.

21. Reaven GM. Abnormal lipoprotein metabolis m in non-insulin-dependent diabetes mellitus. Am J Med 1987; 83 (suppl.3A): 31-40. 


\section{Insulin therapy in type 2 diabetic patients with secondary failure to oral hypoglycaemic agents}

Bruce H.R. Wolffenbuttel, Rob F.A. Weber, Lilian Weeks, Peter M. van Koetsveld, Louis Verschoor

Diabetes Research 1990; 13: 79-84 
In 26 type 2 diabetic patients with failure to diet and sulphonylureas (fasting blood glucose levels $>8.0 \mathrm{mmol} / \mathrm{l}$ ) the effects of insulin therapy on blood glucose control, islet B-cell function and plasma lipids were studied. Age was $58 \pm 11$ (SD) years, median duration of diabetes 6.5 , range 1-24 years, and body mass index 24.5 , range $18.9-36.3 \mathrm{~kg} / \mathrm{m}^{2}$. Six patients were obese. Therapy comprised twice daily injections of intermediate-acting insulin with additional fast-acting insulin when necessary. After 6 months, insulin dose was $39 \pm 10 \mathrm{U}$ in the non-obese patients. Their fasting (14.0 $\pm 2.7 \mathrm{mmol} / \mathrm{l})$ and post-prandial blood glucose $(17.9 \pm 4.5 \mathrm{mmol} / \mathrm{l})$ and glycosylated haemoglobin $\left(\mathrm{HbA}_{1}, 13.0 \pm\right.$ $2.0 \%$ ) declined to $7.7 \pm 1.6 \mathrm{mmol} / 1,10.6 \pm 2.6 \mathrm{mmol} / \mathrm{l}$ and $9.5 \pm$ $1.0 \%$, respectively $(\mathrm{p}<0.001)$. Median body weight increase was $3.7 \mathrm{~kg}(\mathrm{p}<0.001)$. The changes in body weight correlated well with the changes in fasting blood glucose $(r=-0.75, p<0.01)$ and $\mathrm{HbA}_{1}(\mathrm{r}=-0.73, \mathrm{p}<0.01)$. Fasting plasma insulin levels increased $(\mathrm{p}<0.01)$, whereas fasting plasma $\mathrm{C}$-peptide and $\mathrm{C}$-peptide release after glucagon did not change. Free fatty acids, LDL-cholesterol, total and VLDL-triglycerides showed a significant $(p<0.05)$ decrease during insulin treatment. In the 6 obese patients insulin dose after 6 months was $44 \pm 18 \mathrm{U}$. Their fasting blood glucose fell from $11.3 \pm 2.2$ to $8.8 \pm 2.7 \mathrm{mmol} / \mathrm{l}(\mathrm{p}<0.01)$, and $\mathrm{HbA}_{1}$ decreased from $10.7 \pm 1.1 \%$ to $9.8 \pm 1.3 \%$ ( $p<0.01)$. Body weight remained unchanged. Fasting $\mathrm{C}$-peptide levels decreased $(p<0.01)$, whereas insulin levels nor lipid parameters showed significant changes. Almost all patients reported improved wellbeing. One patient had a hypoglycaemic period, requiring medical assistance. We conclude that insulin therapy in type 2 diabetic patients failing on sulphonylurea therapy greatly improved metabolic control with a slight improvement of lipid profile, despite a concomitant gain of weight. 


\section{INTRODUCTION}

Dietary modification and regular physical exercise form the basis of treatment of patients with type 2 diabetes (1-3). Despite this, normoglycaemia is not easily achieved in a considerable number of patients $(3,4)$. Additional therapy with oral hypoglycaemic agents, for instance sulphonylureas, is generally recommended (5). However, the duration of clinical effectiveness of sulphonylureas is limited. The incidence of so-called secondary failure $(6,7)$ to oral agents is about $10 \%$ per year. In patients compliant with diet, who show deterioration of blood glucose control on oral hypoglycaemic agents, temporary or permanent insulin therapy is warranted. This treatment however poses new problems, such as weight gain, and the risk of hypoglycaemias (8). Further, the occasional necessity of administering high insulin doses, especially in obese patients (9), may result in high peripheral insulin levels, which are associated with an increased risk for the development of atherosclerosis and hypertension (10). Finally, it is essential to educate and motivate patients for insulin therapy. Many patients with secondary failure may have frank hyperglycaemia and are prone to develop diabetic complications more rapidly, yet specific symptoms due to the hyperglycaemia seldomly are experienced (11).

Various insulin injection schemes have been proposed (12), such as once daily regimens of long-acting insulin on waking or retiring (13-15), or twice daily injections. In a small number of patients even multiple subcutaneous injections or CSII have been employed $(7,8)$. In the current study we investigated the effects of conventional twice-daily insulin treatment, started at the outpatient-clinic, on blood glucose control, islet B-cell function and plasma lipids in type 2 diabetic patients with secondary failure to sulphonylurea therapy.

\section{MATERIALS AND METHODS}

\section{Patients}

Twenty-six patients with type 2 diabetes (16), who were referred by their general practitioner because of inadequate blood glucose control, entered the study. All patients were hyperglycaemic (fasting blood glucose $>8.0 \mathrm{mmol} / \mathrm{l}$ ), despite diet and maximal doses of glibenclamide or gliclazide. Twenty patients were non-obese, defined as body mass index (BMI) below $27.0 \mathrm{~kg} / \mathrm{m}^{2}$. Their age ranged from $32-76$ years $(60 \pm 11$ years), and time since diagnosis of diabetes $1-24$ years (median 6 years). Ten of them were males. Six patients were 
obese (BMI $31.2 \pm 2.9 \mathrm{~kg} / \mathrm{m}^{2}$ ), with age 29-61 years (median 55 years), and time since diagnosis 4.5-20 years (median 7 years). All patients were islet-cell antibody negative.

During an initial 3-month run-in period patients received diet prescriptions depending on their physical activity. Mono-and disaccharides were restricted. The diet contained $55 \%$ carbohydrates, $30 \%$ fat and $15 \%$ protein. Regular physicall exercise was encouraged. During this period all patients had a stable body weight and blood glucose control. No patient had impaired kidney function (creatinine clearance $<40 \mathrm{ml} / \mathrm{min}$ ), severe hypertension (diastolic blood pressure $105 \mathrm{~mm} \mathrm{Hg}$ ), elevated liver enzymes, or was being treated with corticosteroids. Concomitant therapy, such as antihypertensive treatment and diuretics, were not changed during the study period.

\section{Measurements}

A full history and physical examination of each patient was obtained at the first visit. Laboratory investigations included the measurement of fasting blood glucose on two consecutive days and of blood glucose 2 hours after breakfast and lunch (yielding average postprandial blood glucose), and the determination of glycosylated haemoglobin $\left(\mathrm{HbA}_{1}\right)$, free fatty acids (NEFA) and plasma lipids. Islet B-cell function was assessed after an overnight fast by measuring plasma C-peptide levels before, and 5, 10 and $15 \mathrm{~min}$ after intravenous injection of $1 \mathrm{mg}$ glucagon (17). Between two and four days later patients underwent a meal test, employing the breakfast they would normally eat according to their individual diet prescription. Blood glucose and plasma insulin were determined before (in the fasting state), and 2 hours after the start of breakfast. Oral hypoglycaemic agents were taken just prior to the meal.

\section{Study design}

During the run-in period patients were instructed in insulin injection technique and-in the majority of patients-home-monitoring of blood glucose, by a specialist nurse in the outpatient clinic. Insulin treatment comprised two daily doses (before breakfast and before supper) of intermediate-acting insulin (Monotard HM or Protaphane HM, Novo Industri, Bagsvaerd, Denmark), supplemented with short-acting insulin (Actrapid HM) when postprandial blood glucose levels exceeded $11.0 \mathrm{mmol} / \mathrm{l}$. Goals of the therapy were fasting blood glucose levels $<8.0 \mathrm{mmol} / \mathrm{l}$, and/or $\mathrm{Hb} \mathrm{A}_{1}<9.0 \%$. 
All patients visited the outpatient clinic 2 and 4 weeks after beginning of insulin therapy, and thereafter monthly. Check-ups comprised measurements of body weight, glucose profile, and $\mathrm{HbA}_{1}$. Insulin dose was adjusted according to the results of blood glucose monitoring. After 6 months insulin therapy, measurements performed at baseline were repeated. Breakfasts were identical to the meals taken before the institution of insulin therapy. Now insulin was administered, half an hour before the start of the meal.

For comparison breakfast and glucagon-tests and determinations of plasma lipids were performed in 18 non-obese $(9 \mathrm{M}, 9 \mathrm{~F}$, age $18-48$ years) and 12 obese (4M, $8 \mathrm{~F}$, aged $17-49$ years) control subjects.

\section{Analytical procedures}

Blood glucose was measured in venous whole blood by an automated hexokinase method. $\mathrm{HbA}_{1}$-concentration (normal values 4.5-7.6\%) was measured by column chromatography (Bio-Rad Laboratories, Richmond, CA., USA). Plasma free insulin was determined by radio-immunoassay after polyethyleneglycol pretreatment (Immuno Nuclear Corporation, Stillwater, MS, USA). Plasma C-peptide levels were determined using radioimmunoassay (18) (antibody M1230, Novo Research Institute, Bagsvaerd, Denmark). Between-assay variation of insulin-RIA was $7.5 \%$, of C-peptide $9 \%$. Free fatty-acids (NEFA) were determined by a colorimetric method (19). Lipoproteins were separated by ultracentrifugation, and cholesterol and triglycerides were measured in the separate layers with enzymatic methods (Boehringer, Mannheim, FRG).

\section{Calculations and statistical analyses}

Islet B-cell function was assessed in three ways:

1. as the ratio of fasting plasma C-peptide and blood glucose levels;

2. by the increment of C-peptide $5 \mathrm{~min}$ after iv injection of $1 \mathrm{mg}$ glucagon;

3. as the incremental area under the response curve (AUC) of C-peptide, calculated with the trapezoidal rule. Since it is known that the ambient blood glucose level influences the amount of C-peptide released, the ratio of C-peptide AUC and fasting blood glucose was also calculated.

Results are expressed as means $\pm S D$, or median and range when data were not normally distributed. The Student's paired t-test and Willcoxon's paired test were used when appropriate. Linear regression analysis was used to determine the relationship between two variables. P-values $<0.05$ were considered to be statistically significant. 


\section{Non-obese patients}

Details of the various variables in the non-obese patients just prior to the start of insulin therapy are given in table 1-3. Fasting blood glucose was 8.4 to 18.5 $\mathrm{mmol} / 1(14.0 \pm 2.7 \mathrm{mmol} / \mathrm{l})$, postprandial blood glucose was 7.4 to $28.2 \mathrm{mmol} / \mathrm{l}$ $(17.9 \pm 4.6 \mathrm{mmol} / \mathrm{l})$, and $\mathrm{HbA}_{1}$ was 8.7 to $18.1 \%(13.0 \pm 2.1 \%)$. Median fasting C-peptide was 483 (range $132-890 \mathrm{pmol} / \mathrm{l}$ ), fasting insulin levels were 8 to 134 $\mathrm{pmol} / 1$ (median $45 \mathrm{pmol} / \mathrm{l}$ ). Islet $\mathrm{B}$-cell function was significantly lower $(\mathrm{p}<0.001)$ than in control subjects. NEFA, LDL-cholesterol, total plasma and VLDL-triglycerides were significantly higher compared with control subjects, and HDL-cholesterol was lower.

\section{The effects of therapy}

\section{Metabolic control}

Daily insulin dose in the 20 non-obese patients after 6 months was $39 \pm 10$ (range 22 to 58 ) U. Median body weight increase was 4.5 (range -2.0 to +10.7 ) $\mathrm{kg}$. Two patients lost some weight, although their blood glucose control improved. The changes in fasting and postprandial blood glucose and $\mathrm{HbA}_{1}$ are depicted in table 1.

Eleven patients achieved the desired goal of fasting blood glucose $<8.0$ $\mathrm{mmol} / \mathrm{l}$, while two patients still had fasting blood glucose above $10.0 \mathrm{mmol} / \mathrm{l}$ after 6 months. Eight patients achieved $\mathrm{HbA}_{1}$ values $<9.0 \%$. Seven patients still were marked hyperglycaemic with fasting blood glucose above $8.0 \mathrm{mmol} / \mathrm{l}$, and postprandial blood glucose above $11.0 \mathrm{mmol} / \mathrm{l}$. These seven patients had slightly higher blood glucose just prior to the start of insullin therapy compared with the other 13 patients (fasting blood glucose: $15.5 \pm 2.1 \mathrm{ws} .13 .2 \pm 2.8 \mathrm{mmol} / \mathrm{l}$, $p=0.08$, and postprandial blood glucose: $20.8 \pm 4.0$ vs. $16.4 \pm 4.2 \mathrm{mmol} / \mathrm{l}$, $\mathrm{p}=0.04$ ). Their age, body mass index, duration of diabetes and islet $\mathrm{B}$-cell function, however, were not different. Also, their insulin dose after 6 months was similar ( 44 vs. $37 \mathrm{U}$ ). Figure 1 depicts the changes in fasting blood glucose in the individual patient in relation to the change in body weight. Both variables correlated significantly $(r=-0.75, p<0.01)$, a larger decrease in fasting blood glucose implying a larger increase in body weight. A similar relation was found between change in body weight and $\mathrm{Hb} \mathrm{A}_{1}(\mathrm{r}=-0.73, \mathrm{p}<0.01)$. 
Table 1. Effects of twice daily insulin therapy on body weight and blood glucose control in 20 non-obese patients with type 2 diabetes failing on sulphonylurea therapy.

\begin{tabular}{|c|c|c|c|}
\hline \multirow[b]{2}{*}{$\infty$} & \multirow[b]{2}{*}{ baseline } & \multicolumn{2}{|l|}{ insulin } \\
\hline & & 3 months & 6 months \\
\hline Weight change $(\mathrm{kg})$ & & $+2.9^{\#}$ & $+4.5{ }^{d x}$ \\
\hline median (range) & & $-2.0-6.2$ & $-2.0+10.7$ \\
\hline Fasting blood glucose (mmol/l) & $14.0 \pm 2.7$ & $8.7 \pm 2.1^{\#}$ & $7.7 \pm 1.7$ \\
\hline Postprandial blood glucose (mmol/h) & $17.9 \pm 4.6$ & $11.0 \pm 2.9^{\text {t }}$ & $10.6 \pm 2.6$ \\
\hline Glycosylated haemoglobin $(\%)$ & $13.0 \pm 2.1$ & $10.9 \pm 1.4$ & $9.5 \pm 1.0^{\& \#}$ \\
\hline
\end{tabular}

Mean $\pm \mathrm{SD}$, or median (range)

\& $\mathrm{p}<0.001$ compared to 3 months;

\# $\mathrm{p}<0.001$ compared to pre-treatment

Table 2. Effects of twice daily insulin therapy on parameters of islet $B$-cell function in the 20 non-obese patients.

\begin{tabular}{llll}
\hline & before & insulin & controls \\
\hline Fasting plasma C-peptide (pmol/l) & 483 & 310 & 448 \\
Fasting plasma C-peptide/blood glucose & $132-890$ & $104-829$ & $293-738$ \\
& $33.6^{\mathrm{c}}$ & $45.1^{\mathrm{c}}$ & 109 \\
Fasting plasma insulin (pmol/l) & $8.1-74$ & $12.7-106$ & $63-149$ \\
Post-prandial plasma insulin (pmol/l) & 45 & $66^{*}$ & 50 \\
& $8-134$ & $28-198$ & $38-87$ \\
C-peptide AUC (nmol/1.15-min) & 106 & $131^{*} \mathrm{~b}$ & 71 \\
& $43-269$ & $76-692$ & $38-269$ \\
C-peptide AUC/fasting blood glucose & $2.9^{\mathrm{c}}$ & $3.9^{\mathrm{c}}$ & 11.3 \\
& $0.4-9.0$ & $0.9-11.2$ & $4.1-26.2$ \\
C-peptide increment 5 min (pmol/1) & $0.2^{\mathrm{c}}$ & $0.5^{\mathrm{c}}$ & 2.8 \\
& $0.1-0.7$ & $0.1-2.4$ & $1.0-6.0$ \\
& $367^{\mathrm{c}}$ & $342^{\mathrm{c}}$ & 852 \\
& $42-1559$ & $76-947$ & $368-2265$ \\
\hline
\end{tabular}

Median (range);

* p<0.05, " p<0.01 compared to baseline;

a $p<0.05,{ }^{b} p<0.01,{ }^{c} p<0.001$ compared to controls 
Table 3. Effects of 6 months insulin therapy on lipid parameters in the 20 non-obese patients.

\begin{tabular}{llll}
\hline & before & insulin & controls \\
\hline NEFA (mmol/l) & $0.92 \pm 0.39^{\mathrm{c}}$ & $0.59 \pm 0.23^{\#}$ & $0.44 \pm 0.12$ \\
LDL-cholesterol (mmol/l) & $3.54 \pm 1.06^{\mathrm{b}}$ & $3.22 \pm 0.97^{*}$ & $2.76 \pm 0.66$ \\
HDL-cholesterol (mmol/l) & $0.93 \pm 0.25^{\mathrm{a}}$ & $0.95 \pm 0.36^{\mathrm{a}}$ & $1.26 \pm 0.46$ \\
LDL/HDL-cholesterol ratio & $3.95 \pm 1.36^{\mathrm{c}}$ & $3.59 \pm 1.28^{\mathrm{b}}$ & $2.45 \pm 0.91$ \\
Triglycerides (mmol/1) & $1.85 \pm 0.80^{\mathrm{c}}$ & $1.45 \pm 0.43^{\mathrm{b}}$ & $1.01 \pm 0.35$ \\
VLDL-triglycerides (mmol/l) & $1.07 \pm 0.50^{\mathrm{c}}$ & $0.65 \pm 0.29^{*}$ & $0.63 \pm 0.20$ \\
\hline
\end{tabular}

Mean $\pm S D$

* $\mathrm{p}<0.05$, " $\mathrm{p}<0.01$ compared to baseline;

${ }^{a} \mathrm{p}<0.05,{ }^{b} \mathrm{p}<0.01,{ }^{c} \mathrm{p}<0.001$ compared to controls

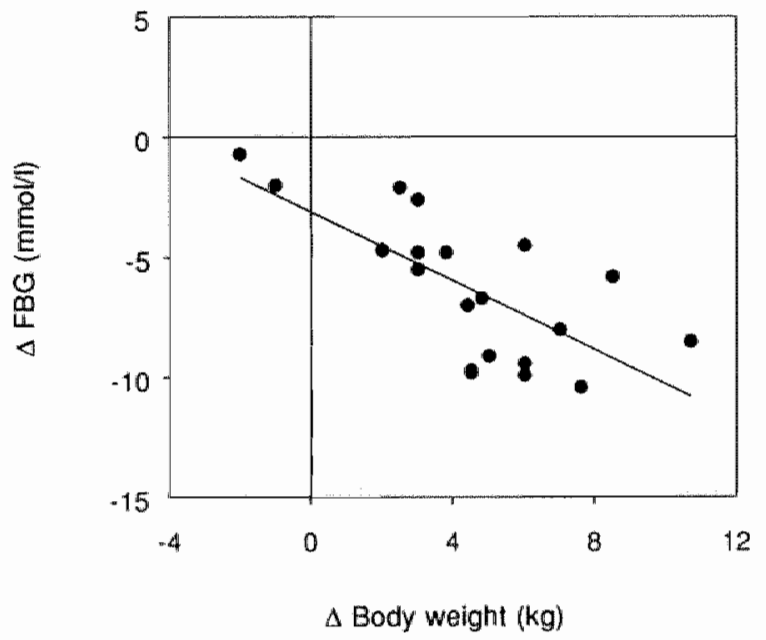

Figure 1. Changes in body weight are significantly $(r=-0.75, p<0.01)$ related to changes in fasting blood glucose levels (FBG) after 6 months insulin therapy in 20 non-obese patients with type 2 diabetes mellitus, failing on oral therapy.

Islet B-cell function

After 6 months of insulin therapy there was a significant increase in fasting $(p<0.01)$ and post-breakfast $(p<0.05)$ levels of plasma insulin. No changes in the various parameters of islet $B$-cell function were observed. 


\section{Lipids}

The effects of therapy on the parameters of lipid metabolism are given in table 3. There was a significant decrease in plasma LDL-cholesterol, the LDL/HDLcholesterol ratio, as well as NEFA, total and VLDL-triglycerides. LDL-cholesterol, VLDL-triglycerides and NEFA reached levels comparable to values, found in non-diabetic individuals. No significant correlation was found between the improvement in blood glucose control or the increase in plasma insulin levels, and the changes in the various lipid parameters.

\section{Obese patients}

Figure 2 shows the course of blood glucose and $\mathrm{HbA}_{1}$ in the six obese patients. At the start of insulin treatment they were less hyperglycaemic than the nonobese: fasting blood glucose $11.3 \pm 2.2 \mathrm{mmol} / 1$, postprandial blood glucose 14.8 $\pm 1.9 \mathrm{mmol} / \mathrm{l}$, and $\mathrm{HbA}_{1} 10.7 \pm 1.1 \%$. Insulin dose after 6 months was $44 \pm 18$ (range 20-78) U. Body weight did not change significantly: two patients managed to lose some weight while on insulin, whereas two patients gained 3.0 and $4.8 \mathrm{~kg}$, respectively. Fasting blood glucose after 6 months was $8.8 \pm 2.7 \mathrm{mmol} / \mathrm{l}$, post-prandial blood glucose was $13.2 \pm 2.8 \mathrm{mmol} / \mathrm{l}$, and $\mathrm{HbA}_{1}$ was $9.8 \pm 1.3 \%$. One patient (BMI $30.4 \mathrm{~kg} / \mathrm{m}^{2}$ ) showed a clear deterioration of blood glucose control. Fasting C-peptide decreased in all patients (median value from 849 to $253 \mathrm{pmol} / \mathrm{l}$ ); fasting and postprandial plasma insulin levels did not change significantly. Results of glucagon-tests and plasma lipids were available in 5 of the 6 patients. C-peptide AUC decreased in 4 of these 5 (from 5.0 to 2.6 $\mathrm{nmol} / 1.15 \mathrm{~min})$. HDL-cholesterol increased in 4 of the 5 patients, from $1.07 \pm$

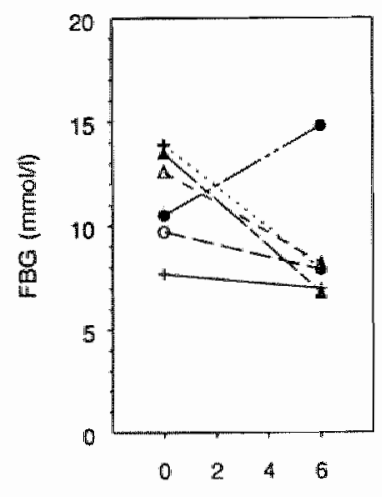

Months

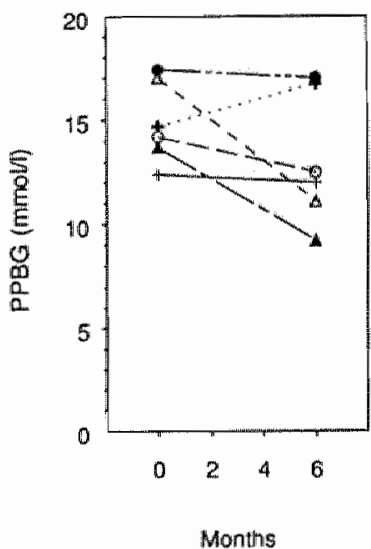

Monthis

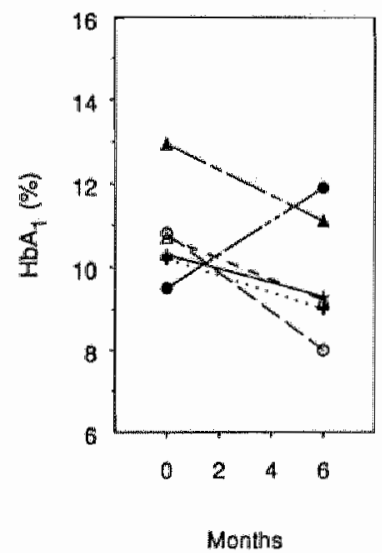

Figure 2. Changes in fasting (FBG) and postprandial blood glucose (PPBG), and $\mathrm{HbA_{1 }}$ after 6 months insulin therapy in 6 obese patients with type 2 diabetes mellitus, failing on oral therapy. 
0.19 to $1.16 \pm 0.28 \mathrm{mmol} / \mathrm{l}$. Due to the small number of observations these changes were not statistically significant. The other lipid parameters did not change.

\section{History}

Almost all patients experienced an improvement in well-being, together with a decrease in symptoms of hyperglycaemia. One non-obese patient experienced one episode of hypoglycaemia, necessitating medical assistance. He recovered without sequelae after intravenous administration of glucose.

\section{DISCUSSION}

Our non-obese patients with secondary failure to oral hypoglycaemic agents had normal fasting insulin and C-peptide levels, compared to control subjects. However, these are insufficient, when the level of fasting blood glucose was taken into account. After stimulation with glucagon, insulin secretory capacity proved to be greatly diminished compared to control subjects. Hence, these patients can be classified as 'insulin deficient' (21), and they need insulin to achieve good metabolic control ('insulin requiring'). In the present study, a simple regimen comprising twice-daily insulin injections significantly improved blood glucose control. The improvement of blood glucose control in the individual patient was directly correlated with the increase in body weight, that was observed in these patients. This implies that more severe hyperglycaemia reflects a more catabolic state, which is reversed by insulin therapy. Aimost all patients reported improved well-being, and disappearance of hyperglycaemic symptoms. Such symptoms often were previously not recognized as such. No severe complications of insulin therapy were seen. Only one episode of severe hypoglycaemia, demanding medical assistance, was witnessed. Although blood glucose control was greatly improved, seven patients did not reach the desired level of glycaemia. It was not possible to identify these patients prior to the start of insulin treatment on basis of duration of diabetes, islet B-cell function, body weight or age, in comparison with well-controlled diabetic patients. In such patients more intensive efforts are needed, for instance multiple injection regimes and repeated education and instruction in self-regulation, to achieve optimal blood glucose control. In 5 of the 6 obese patients a similar improvement in blood glucose control was achieved, without significant increase in body weight. Thus, obesity does not seem to be a contraindication for institution of 
insulin treatment, when therapy with oral hypoglycaemic agents does not result in adequate control.

Various insulin administration schemes have been advocated in diabetic patients with secondary failure to oral hypoglycaemic agents. Once-daily regimens employing long acting insulin have been shown to improve glycaemic control in severely hyperglycaemic patients, but they often fail to normalize fasting and postprandial hyperglycaemia, and even may produce significant hypoglycaemias in the afternoon or during the night $(14,15)$. A basal insulin supplement was shown to normalize fasting blood glucose in 15 patients (obese and non-obese) with varying levels of blood glucose control, but such normalization did not always result in near-normal $\mathrm{HbA}_{1}$ levels (23). Although it was suggested that achieving normal fasting blood glucose levels in type 2 diabetic patients is more important than control of postprandial hyperglycaemia $(15,23)$, no epidemiologic studies support this 'concept'. We feel that maintaining near-normoglycaemia throughout the day while avoiding the risk of hypoglycaemias is warranted, because of the relationship between mean level of glycaemia $\left(\mathrm{HbA}_{1}\right)$ and the occurrence of (micro)vascular complications $(7,24-26)$. In the non-obese patients lipid metabolism had improved significantly after 6 months insulin therapy. Previous studies on the effects of insulin treatment and the resulting improvement in blood glucose control on lipid metabolism have yielded controversial results (27). As in our patients, correction of hyperglycaemia per se was shown to reduce triglyceride levels. This was explained by enhanced catabolic rate and decreased production of VLDL (27). In agreement with earlier reports (28), we did not find changes in HDL-cholesterol levels. However, insulin therapy was shown to enhance $\mathrm{HDL}_{2}$-cholesterol levels in type 2 diabetic patients failing to sulphonylurea therapy (29). In our patients, no correlation was found between the improvement of the various lipid parameters and changes in fasting blood glucose, $\mathrm{HbA}_{1}$, or fasting or post-prandial insulin levels in our patients.

We conclude that insulin therapy in type 2 diabetic patients failing on sulphonylurea therapy greatly improved blood glucose control with a slight improvement of lipid profile. Twice-daily administration of intermediate-acting or a mixture of fast- and intermediate-acting insulin can be safely instituted on an outpatient base as first regimen in such patients. In the majority of patients this regimen can optimize blood glucose control. More complicated regimens, such as multiple daily injections or combination of insulin and oral hypoglycaemic agents may be warranted in the younger type 2 diabetic patients, in whom the twice-dlaily regimen fails to restore adequate control. 
1. Skyler JS. Non-insulin-dependerit diabetes mellitus: a clinical strategy. Diabetes Care 1984; 7 (uppl. 1): 118-129.

2. Wolffenbuttel BHR, Weber RFA, Koetsveld PM van, Verschoor L. Limitations of die: therapy in non-insulin dependent diabetes mellitus. Int J Obesity $1989 ; 13: 173-182$.

3. Defronzo RA Ferrannini E, Koivisto V. New concepts in the pathogenesis and treatment of noningulin-dependent diabetes mellitus. Am J Med 1983; 74 (suppl): 52-81.

4. Hadden DR, Blair ALT, Wilson. EA et al. Natural history of diabetes presenting age 40-69 years: a prospective study of the influence of intensive dietary therapy. Quart J Med 1986; 59: $579-598$.

5. Gerich JE. Sulfonylureas in the treatment of diabetes mellitus. Mayo Clin Proc 1985; 60: $439-443$.

6. Groop LC, Pelkonen R, Koskimies S, Botlazzo GF, Doniach D. Secondary failure to treatment with oral antidiabetic agents in non-insulin-dependent diabetes. Diabetes Care 1986; 9: 129-133.

7. Heine RJ. Insullin treatment of non-insulin-dependent diabetes mellitus. In: Baillière's Clinical Endocrinology and Metabolism, Non-insulin-dependent diabetes. Nattrass $\mathrm{M}$, Hale PJ, Eds. London, 1988.

8. Garvey WT, Olefsky JM, Griffin J, Hamman RF, Kolterman OG. The effect of insulin treatment on insulin secretion and insulin action in type $\mathbb{I}$ diabetes mellitus. Diabetes $1985 ; 34: 222-234$.

9. Ginsberg $H$, Rayfield EJ. Effect of insulin therapy on insulin resistance in type II diabetic subjects-evidence for heterogeneity. Diabetes $1981 ; 30: 739-745$.

10. Stout RW. The role of insulin in atherosclerosis in diabetics and nondiabetics. Diabetes 1981; 30 (suppl 2): 54-57.

11. Tattersall RB. Diabetes in the elderly - a neglected area? Diabetologia $1984 ; 27: 167-173$.

12. Tattersall RB, Scott AR. When to use insulin in the maturity onset diabetic. Postgrad Med J $1987 ; 63: 859-864$.

13. Riddle MC, Hart JS. Which patients might benefit from combining a sulfonylurea with insulin? (letter) Diabetes Care 1985; 8: 205.

14. Roland IM, Lewin IG, O'Brien AD, Markanday S, Kurtz AB, Corrall RJM. A comparative study of once daily insulin injection regimes in the treatment of elderly diabetics. Diabetes Res 1987; 4: 131-134.

15. Tindall H, Bodansky HJ, Stickland M, Wales JK. A strategy for selection of elderly type 2 diabetic patients for insulin therapy, and a comparison of two insulin preparations. Diabetic Med 1988; 5: 533-536.

16. WHO Expert Committee on Diabetes Mellitus. Technical Report Series 727, 1985. Geneva: World Health Organization.

17. Poulsen $S$, Billesbolle $P$, Kolendorf $\mathbb{K}$, Thorsteinsson $B$. The C-peptide response to glucagon injection in IDDM and NIDDM patients. Horm Metabol Res 1985; 17:39-40.

18. Heding LG. Radioimmunological determination of human $\mathbb{C}$-peptide in serum. Diabetologia $1975 ; 11: 541-548$.

19. Laurell $S$, Tibbling $G$. Colorimetric micro-detemination of free fatty acids in plasma. Clin Chim Acta 1967; 16: 57-62. 
20. Matthews DR, Hosker JP, Rudenski AS, Naylor BA. Treacher DF, Turner RC. Honeostasis model assessment: insulin resistance and b-cell function from fasting plasma glucose and insulin concentrations in man. Diabetologia $1985 ; 28: 412-419$.

21. Ward WK, Bolgiano DC, McKnight B, Halter JB, Porte Jr D. Diminished B cell secretory capacity in patients with mon-insulin-dependent diabetes mellitus. J Clin Invest 1984; 74: 1318-1328.

22. Bogardus C, Lillioja S, Howard BV, Reaven GM, Mott D. Relationships between insulin secretion, insulin action, and fasting plasma glucose concentrations in nondiabetic and non-insulin-dependent diabetic subjects. J Clin Invest $1984 ; 74: 1238-1246$.

23. Holman RR, Steemson J, Turner RC. Sulphonylurea failure in type 2 diabetes: treatment with a basal insulin supplement. Diabetic Med 1987; 4: 457-462.

24. Unger RH. Meticulous control of diabetes: benefits, risks and precautions. Diabetes 1982; 31: 479-483.

25. Pirart J. Diabetes mellitus and its degenerative complications: a prospective study of 4400 patients observed between 1947 and 1973. Diabetes Care 1978; 1: 168-188 and 252-263.

26. Singh BM, Rutter ID, Fitzgerald. MG. The natural history of non-insulin-dependent diabetes mellitus. In: Baillière's Clinical Endocrinology and Metabolism, Non-insulindependent diabetes. Nattrass M, Hale PJ, Eds. London, 1988.

27. Reaven GM. Abnormal lipoprotein metabolism in non-insulin-dependent drabetes mellitus. Am J Med 1987; 83 (suppl.3A): $31-40$.

28. Hollenbeck CB, Chen Y-DI, Greenfield MS, Lardinois CK, Reaven GM. Reduced plasma high density lipoprotein-cholesterol concentrations need not increase when hyperglycemia is controlled with insulin in non-insulin-dependent diabetes mellitus. I Clin Endocrinol Metabol 1986; 62: 605-608.

29. Razenberg PPA, Venekamp WJRR, Sikkenk AC, Heine RJ, van der Veen EA. Effects of insulin treatment in type II diabetes on insulin sensitivity and insulin responsiveness. Diab Res Clin Pract 1985; 1 (suppl. 1): 465. 


\section{CHAPTER}

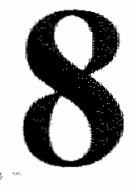

\section{Combination of insulin and sulphonylurea in patients with type 2 diabetes mellitus and failure on oral therapy}

The effects of different treatment regimens

Bruce H.R. Wolffenbuttel, Gabriëlle J.W.M. Rondas-Colbers, Paul P.C.A. Menheere, Jean-Pierre J.E. Sels, Arie C. Nieuwenhuijzen Kruseman

In part published in the European Journal of Internal Medicine 1989; 1: 89-95 
We compared the effects of different insulin-administration schemes on glucose and lipid-metabolism in 52 patients with type 2 diabetes (mean \pm SD age $69 \pm 9$ years, body mass index $25.7 \pm$ $5.5 \mathrm{~kg} / \mathrm{m}^{2}$, median time since diagnosis of diabetes 9 (range $1-34$ ) years, 21 malles), who were poorly controlled despite diet and maximal doses of oral hypoglycaemic agents. Twice-daily insulin injections (scheme A) were compared with regimens of oncedaily insulin (before breakfast, scheme $\mathrm{C}$, or at bedtime, scheme B) in combination with glibenclamide. So far, 47 patients have completed the study. Five patients in regimen $B$ and 4 patients in group $\mathrm{C}$ required a second injection of insulin. Almost all patients reported improved well-being and diminished hyperglycaemic complaints. No severe hypoglycaemias were observed. Body weight increase was moderate (mean $+4.2 \mathrm{~kg}$ ). In the whole group of patients, fasting blood glucose decreased from $14.6 \pm 2.3$ $\mathrm{mmol} / \mathrm{l}$ to $8.5 \pm 2.2 \mathrm{mmol} / \mathrm{l}(\mathrm{p}<0.001)$, and $\mathrm{HbA} \mathrm{Ic}_{\mathrm{c}}$ fell from 10.9 $\pm 1.4 \%$ to $8.1 \pm 1.4 \%(\mathrm{p}<0.001)$. Twenty-one patients reached $\mathrm{HbA}_{1 \mathrm{c}}$ levels below $8.0 \%$, and 17 below $7.5 \%$. Patients on regimen A reached the best improvement of blood glucose control, the decrease of fasting and mean blood glucose was $42 \%$ and $49 \%$, respectively, while $\mathrm{HbA}_{1 c}$ decreased by $27 \%$. They injected, however, the largest amount of insulin (mean 42U). Both in patients on insulin alone and in those treated with insulin + glibenclamide, significant increases of HDL-cholesterol were observed (from $1.10 \pm 0.31$ to $1.24 \pm 0.32 \mathrm{mmol} / \mathrm{l}$, and from $1.03 \pm$ 0.27 to $1.14 \pm 0.32 \mathrm{mmol} / \mathrm{l}$, respectively). Further, plasma triglycerides and non-esterified fatty acids decreased significantly. Total cholesterol decreased only in the patients treated with insulin alone (from $7.08 \pm 1.42$ to $6.26 \pm 1.15 \mathrm{mmol} / \mathrm{l}$, $\mathrm{p}<0.01$ ). Apolipoproteins AI, AII and B did not show any significant changes. We conclude that therapy with twice-daily insulin injections markedly improved blood glucose control and plasma lipids. Combination of insulin with glibenclamide resulted with an equal improvement of metabolic control, with lower doses of insulin, but with less improvement of plasma lipids. The increase of HDL-cholesterol without concomitant increase of apolipoproteins AI and AII suggests enrichment of the HDL-particle with cholesterol during insulin therapy. 


\section{INTRODUCTION}

Patients with type 2 diabetes mellitus are usually treated with diet in combination with oral hypoglycaemic agents, when diet therapy alone fails to normalize glucose metabolism ( 13 ). Some patients do not achieve adequate control with such therapy. Insulin treatment is the available option $(4,5)$. Insulin therapy may diminish hyperglycaemic complaints and improve blood glucose control. It was also shown previously that intensive insulin therapy can improve islet $\mathrm{B}$-cell function and peripheral insulin action (6). However, especially in the obese patients weight gain may pose a problem. Further, the resulting peripheral hyperinsulinemia might be of importance, since increased plasma insulin levels are considered to be an independent risk factor for the development of atherosclerosis $(8,9)$. In addition, the incidence of hypoglycaemias during this therapy is reported to be greater than during oral therapy $(10)$.

Various insulin regimens have been proposed (5). Although twice-daily administration (before breakfast and diner) is frequently advocated, many physicians rely on only one injection in the morning, often because patient acceptance of insulin therapy is thought to be better with one injection. During the last few years interest in the combination of insulin with sulphonylurea therapy has revived (11). Such a combination might be beneficial, by reducing the dose of insulin needed, and thus possibly diminishing the degree of peripheral hyperinsulinaemia. The injection of intermediate-acting insulin at bedtime, together with daytime sulphonylurea use, was especially advocated (12). By this way excessive hepatic glucose production, which is dominant during evening and night and leads to pronounced fasting hyperglycaemia, should be suppressed almost completely. Weight gain might be less with this therapy. However, negative results of combined therapy on HDL-cholesterol have been described (13).

In this study, we compared the effect of three insulin-administration schemes on glucose and lipid-metabolism in patients with type 2 diabetes, who are poorly controlled with maximal doses of oral hypoglycaemic agents. The results obtained in the first 52 patients are presented. 


\section{Patients}

Until now, 52 patients (mean \pm SD age $69 \pm 9$ years, body mass index, BMI 25.7 $\pm 5.5 \mathrm{~kg} / \mathrm{m}^{2}$, median time since diagnosis of diabetes 9 (range 1-34) years, 21 males) with type 2 diabetes according to the WHO-criteria (14) entered the study. All were poorly controlled despite diet and maximal doses of oral hypoglycaemic agents ( $15 \mathrm{mg}$ glibenclamide daily, or -in some patients- glibenclamide with metformin). Poor blood glucose control was defined as a fasting blood glucose concentration (mean of last 3 measurements within 2 months) above $8.0 \mathrm{mmol} / 1$. A complete history and physical examination was performed to exclude intercurrent illness or cardiac, hepatic, renal or other endocrine disease. No patient had severe hypertension (diastolic blood pressure above 110 $\mathrm{mmHg}$ ), severely impaired kidney function (serum creatinine above 140 $\mu \mathrm{mol} / \mathrm{l}$, or creatinine-clearance below $40 \mathrm{ml} / \mathrm{min}$ ), or was treated with corticosteroids. All patients gave their informed consent before participating. The study was approved by the Ethical Committee of the Maastricht University Hospital.

\section{Study-design}

During a run-in period of at least 3 months oral therapy was continued, dietary treatment optimized, and instruction in self-monitoring of blood glucose -if possible- and insulin injections, as well as formal diabetes education, were given. The patients were block-randomized to three different treatment regimens for 6 months:

Regimen A: twice-daily (before breakfast and dinner) administration of NPHinsulin (Protaphane HM) using a pen-device (Novopen I or II). When postprandial blood glucose values exceeded $10.0 \mathrm{mmol} / \mathrm{l}$, fast-acting insulin (Actrapid HM) was supplemented. For this purpose a mixture of 30:70 Actrapid/Protaphane (Actraphane) was used.

Regimen B: combination of NPH-insulin, administered at bedtime, with glibenclamide during the day (10 $\mathrm{mg}$ at breakfast and $5 \mathrm{mg}$ at dinner). When blood glucose values during the day consistently exceeded $10.0 \mathrm{mmol} / \mathrm{l}$, a second injection of NPH-insulin before breakfast was added.

Regimen $C$ : combination of NPH-insulin once daily, administered before breakfast, in combination with glibenclamide during the day $(10 \mathrm{mg}$ at breakfast and $5 \mathrm{mg}$ at dinner). When postprandial blood glucose values during the day consistently exceeded $10.0 \mathrm{mmol} / \mathrm{l}$, actraphane was used instead. When post- 
dinner blood glucose levels exceeded $10.0 \mathrm{mmol} / \mathrm{l}$, a second injection of NPHinsulin before dinner was added.

Insulin dose was adjusted on the base of blood glucose measurements made at home by the patients. Goals of therapy were fasting blood glucose levels $<7.0$ $\mathrm{mmol} / \mathrm{l}$, and postprandial blood glucose values below $10.0 \mathrm{mmol} / \mathrm{l}$, and $\mathrm{HbA}$ ic levels below $8.0 \%$.

\section{Measurements}

At baseline, blood was drawn for the determination of glycosylated haemoglobin $\left(\mathrm{HbA}_{1 \mathrm{c}}\right)$, serum fructosamine, non-esterified fatty acids (NEFA), plasma lipids, and apolipoproteins. Islet B-cell function was assessed after an overnight fast by measuring fasting plasma insulin and C-peptide levels, as well as plasma C-peptide levels $5,10,15$ and $30 \mathrm{~min}$ after injection of $1 \mathrm{mg}$ glucagon.

\section{Follow up}

All patients visited the outpatient clinic 2 and 4 weeks after beginning insulin therapy, and thereafter monthly, when measurements of body weight, glucose profile, $\mathrm{HbA}_{\mathrm{lc}}$ and serum fructosamine were made. They were asked to measure their blood glucose at home once a week (morning, before lunch, before dinner, evening) using a reflectance meter (Glucometer II, Bayer-Ames, FRG). After six months baseline measurements were repeated.

For comparison, glucagontests and lipid determinations were performed in non-obese control subjects.

\section{Analytical procedures}

Blood glucose was measured in venous whole blood with an automated hexokinase method. Serum fructosamine was determined according to Johnson et al. (15) after alkalinising and reduction with nitroblue tetrazolium (Sigma) on the Cobas Bio analyser. Calibration was performed with 1-desoxy-1-morfolinofructose (Sigma) in a albumin solution. The reference values of this assay were lower than those of the widely-used Fructosamine Roche kit, due to the use of a different standard and reductor. Comparison with the Roche kit was excellent $(r=0.98 ; y=1.16 x+2, p<0.001)$. Between-assay coefficient of variation of our fructosamine determination is $4 \%$. HbA $1 \mathrm{c}$ was determined with HPLC (DIAMAT, Bio-Rad Laboratories, Richmond, Ca., USA). Normal values were 4.4$6.2 \%$, between-assay $\mathrm{cv}$ was $2.6 \%$. Plasma free insulin levels (IRI) were analyzed with radio-immunoassay (Pharmacia, Uppsala, Sweden) after poly- 
ethyleneglycol pretreatment, and plasma C-peptide was measured with radioimmunoassay (Mallinckrodt, FRG). Between-assay variation of insulin-RIA was $7.5 \%$, and C-peptide 9\%. Cholesterol (CHOD-PAP, Boehringer, Mannheim, FRG) and triglycerides (Triglycerid Rapid, Roche, Switzerland) were determined with enzymatic methods. HDL-cholesterol was measured after precipitation of VLDL and LDL with PEG 6000. Apolipoproteins AI, AII and B were determined with an immunoturbidimetric assay (Boehringer, Mannheim, FRG) on a Cobas Bio analyser. Intra- and interassay coefficient of variation were 1.9 and $6.9 \%$. Normal values of the apolipoproteins AI, AII and B for normolipidaemic males are $125 \pm 22,42 \pm 6$ and $77 \pm 16 \mathrm{mg} / \mathrm{dl}$, respectively, and for females $139 \pm 25,42 \pm 6$ and $76 \pm 15 \mathrm{mg} / \mathrm{dl}$.

\section{Calculations and statistical analyses}

Beta-cell function (BCF) was assessed in three ways:

1. as the release of C-peptide after i.v. injection of $1 \mathrm{mg}$ glucagon, calculated as the incremental area under the curve (C-peptide AUC);

2. from the fasting levels of blood glucose (FBG), insulin (FIRI) and C-peptide (FCP), by calculating the formulae of Matthews (16);

3. as the level of C-peptide $5 \mathrm{~min}$ after glucagon injection (C-peptide $5 \mathrm{~min}$ ).

All data are expressed as mean $\pm \mathrm{SD}$, or median and range, when not normally distributed. Calculations were performed with the SPSS/PC+ version 3.1 statistical software package (SPSS Inc, Chicago, IL, USA). Group differences in base-line variables were compared by one-way analysis of variance for continuous variables and chi-square tests for categorical variables. Student-NewmanKeuls test was applied to correct for multiple comparisons. Changes of blood glucose control between the treatment groups ( $\mathrm{HbA}_{1 \mathrm{c}}$, serum fructosamine, fasting and mean blood glucose) and lipid variables were compared by analysis of variance; when the changes were not normally distributed, Kruskal-Wallis analysis of variance was used. Linear regression analysis was used to determine the relationship between two variables. P-values below 0.05 were considered statistically significant. 


\section{Baseline data}

Body mass index (BMi) was significantly higher among females $(27.3 \pm 5.9 \mathrm{vs}$. $23.2 \pm 3.7 \mathrm{~kg} / \mathrm{m}^{2}, \mathrm{p}=0.008$ ). The degree of blood glucose control was similar between both sexes. Females had higher levels of fasting plasma C-peptide ( 964 \pm 518 vs. $626 \pm 289 \mathrm{pmol} / \mathrm{l}, \mathrm{p}=0.0094)$, insulin $(94 \pm 56 \mathrm{vs} .59 \pm 23 \mathrm{pmol} / \mathrm{l}$, $\mathrm{p}=0.0103$ ), as well as parameters of islet B-cell function (calculated islet B-cell function, C-peptide AUC, and C-peptide5min), whereas lipid variables were comparable.

When patients older than 70 years were compared with those under 70 years, no differences were found in blood glucose control, islet B-cell function and plasma lipids, although duration of diabetes was longer in the older age group (15 vs. 9 years, $\mathrm{p}=0.0011)$, while BMI was lower $(23.8 \pm 4.2$ vs. $27.2 \pm 6.1$ $\mathrm{kg} / \mathrm{m}^{2}, \mathrm{p}=0.0262$ ).

The baseline data of all patients in the initial treatment groups are listed in tables 1 and 2. Patients in group 2 were slightly younger, and had a shorter known duration of diabetes. Patients in group 1 had lower body mass index. All other variables were similar between the 3 groups. No differences in islet B-cell function or plasma lipids were observed.

Table 1. Demographic variables and blood glucose control at baseline in the 3 treatment groups.

\begin{tabular}{lllll}
\hline & $\begin{array}{l}\text { Group 1 } \\
n=23\end{array}$ & $\begin{array}{l}\text { Group 2 } \\
n=15\end{array}$ & $\begin{array}{l}\text { Group 3 } \\
n=14\end{array}$ & $\begin{array}{l}\text { Controls } \\
n=18\end{array}$ \\
\hline Age (years) & $70 \pm 9$ & $63 \pm 9^{*}$ & $73 \pm 6$ & - \\
Malle/female & $11 / 12$ & $5 / 10$ & $5 / 9$ & $9 / 9$ \\
Known duration of diabetes (years) & $9(1-34)$ & $6(2-15)^{*}$ & $14(6-27)$ & 0 \\
Body mass index (kg/m $\left.{ }^{2}\right)$ & $23.6 \pm 4.6^{\sharp}$ & $27.7 \pm 6.5$ & $26.9 \pm 4.8$ & - \\
Fasting blood glucose (mmol/1) & $14.5 \pm 1.5$ & $14.9 \pm 2.1$ & $14.1 \pm 3.3$ & $4.1 \pm 0.3$ \\
Mean blood glucose (mmol/1) & $17.8 \pm 2.5$ & $17.0 \pm 2.6$ & $17.8 \pm 3.3$ & $4.5 \pm 0.4$ \\
Serum fructosamine (mmol/l) & $2.17 \pm 0.59$ & $1.85 \pm 0.27$ & $1.99 \pm 0.47$ & - \\
Glycosylated haemoglobin (\%) & $11.3 \pm 1.3$ & $10.5 \pm 1.2$ & $10.9 \pm 1.6$ & $5.2 \pm 0.5$ \\
\hline
\end{tabular}

Data are shown as mean $\pm \mathrm{SD}_{n}$

* $p<0.05$ compared to both other groups, $"$ p $<0.05$ compared to group 2. 
Table 2. Islet B-cell function and lipid variables at baseline in the 3 treatment groups.

\begin{tabular}{|c|c|c|c|c|}
\hline & $\begin{array}{l}\text { Group } 1 \\
n=22\end{array}$ & $\begin{array}{l}\text { Group } 2 \\
n=15\end{array}$ & $\begin{array}{l}\text { Group } 3 \\
n=14\end{array}$ & $\begin{array}{l}\text { Controls } \\
n=18\end{array}$ \\
\hline $\begin{array}{l}\text { Fasting plasma C-peptide } \\
\qquad(\mathrm{pmol} / 1)\end{array}$ & $\begin{array}{l}615 \\
190-1990\end{array}$ & $\begin{array}{l}888 \\
385-2350\end{array}$ & $\begin{array}{l}870 \\
530-2285\end{array}$ & $\begin{array}{l}551 \\
370-820\end{array}$ \\
\hline $\begin{array}{l}\text { Fasting plasma insulin } \\
\qquad(\mathrm{pmol} / \mathrm{l})\end{array}$ & $\begin{array}{l}64 \\
26-151\end{array}$ & $\begin{array}{l}75 \\
37-212\end{array}$ & $\begin{array}{l}67 \\
47-286\end{array}$ & $\begin{array}{l}46 \\
32-66\end{array}$ \\
\hline $\begin{array}{l}\text { C-pepitide } 5 \text { min } \\
\text { (pmol/1) }\end{array}$ & $\begin{array}{l}975 \\
330-2540\end{array}$ & $\begin{array}{l}1440 \\
600-3000\end{array}$ & $\begin{array}{l}1320 \\
550-4260\end{array}$ & $\begin{array}{l}1759 \\
1240-2620\end{array}$ \\
\hline $\begin{array}{l}\text { C-peptide AUC } \\
\text { (nmol/1.30min) }\end{array}$ & $\begin{array}{l}4.9 \\
1.58-18.55\end{array}$ & $\begin{array}{l}5.6 \\
1.20-18.61\end{array}$ & $\begin{array}{l}7.9 \\
0.72-32.59\end{array}$ & $\begin{array}{l}29.8 \\
19.8-45.1\end{array}$ \\
\hline C-peptide AUC/blood glucose & $\begin{array}{l}346 \\
115-1262\end{array}$ & $\begin{array}{l}348 \\
91-1604\end{array}$ & $\begin{array}{l}621 \\
44-2217\end{array}$ & $\begin{array}{l}7345 \\
5016-10620\end{array}$ \\
\hline $\begin{array}{l}\text { BCF C-peptide } \\
(\%)\end{array}$ & $\begin{array}{l}16 \\
4-48\end{array}$ & $\begin{array}{l}26 \\
10-49\end{array}$ & $\begin{array}{l}24 \\
11-55\end{array}$ & $\begin{array}{l}150 \\
100 \cdot 312\end{array}$ \\
\hline $\begin{array}{l}\mathrm{BCF} \text { insulin } \\
(\%)\end{array}$ & $\begin{array}{l}16 \\
5-42\end{array}$ & $\begin{array}{l}18 \\
10-44\end{array}$ & $\begin{array}{l}20 \\
11-69\end{array}$ & $\begin{array}{l}120 \\
84-159\end{array}$ \\
\hline $\begin{array}{l}\text { Non-esterified fatty acids } \\
\qquad(\mathrm{mmol} / \mathrm{l})\end{array}$ & $1.00 \pm 0.31$ & $1.04 \pm 0.39$ & $1.09 \pm 0.36$ & $0.48 \pm 0.12$ \\
\hline $\begin{array}{l}\text { Total cholesterol } \\
\qquad(\mathrm{mmol} / \mathrm{l})\end{array}$ & $7.1 \pm 1.4$ & $6.3 \pm 1.4$ & $6.1 \pm 1.4$ & $5.0 \pm 0.4$ \\
\hline $\begin{array}{l}\text { HDL-cholesterol } \\
\qquad(\mathrm{mmol} / \mathrm{l})\end{array}$ & $1.09 \pm 0.31$ & $1.03 \pm 0.27$ & $1.02 \pm 0.28$ & $1.40 \pm 0.29$ \\
\hline $\begin{array}{l}\text { Triglycerides } \\
\text { (mmol/1) }\end{array}$ & $\begin{array}{l}2.41 \\
1.11-11.4\end{array}$ & $\begin{array}{l}1.72 \\
0.83-9.09\end{array}$ & $\begin{array}{l}1.98 \\
1.04-6.41\end{array}$ & $\begin{array}{l}1.50 \\
0.51-2.00\end{array}$ \\
\hline
\end{tabular}

Data are shown as mean $\pm \mathrm{SD}$, or median (range)

\section{Follow-up after 6 months}

Of the 52 patients, 47 were fully evaluable after 6 months. One patient died four months after the start of insulin therapy due to a myocardial infarction. Two patients withdrew because of intercurrent diseases, while 2 patients did not yet complete the 6 months study period. Five patients in regimen $B$ required a second injection of insulin because of marked daytime hyperglycaemia, whereas 4 patients on regimen $C$ required an additional pre-dinner injection of insulin because of significant hyperglycaemia in the evening. 

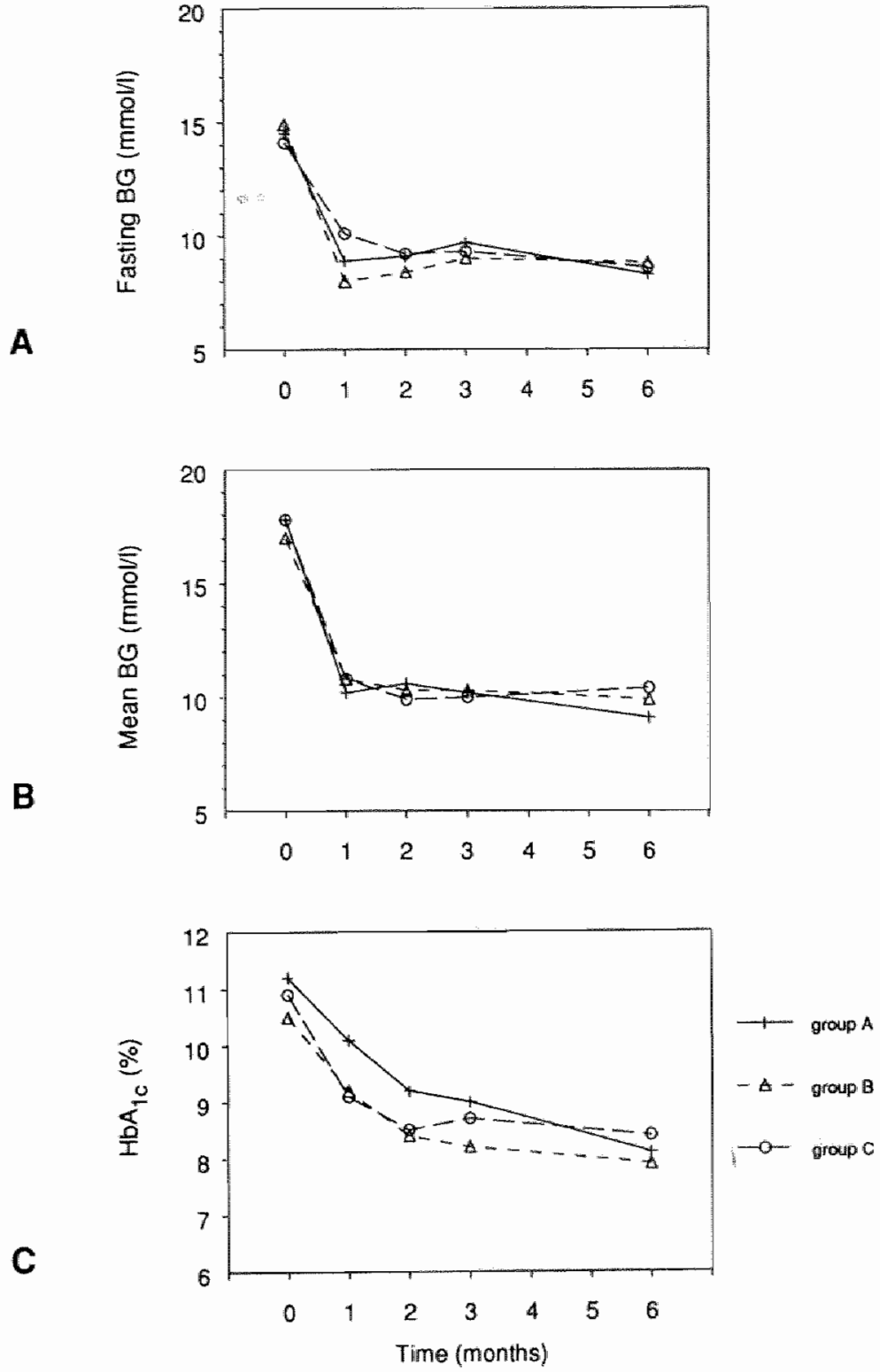

Figure 1. Course of fasting (A) and mean blood glucose (B) and HbA $A_{1 c}(C)$ in the different treatment groups.

Patients who initially started with 1 injection, and had to switch to the 2 -injection regimen, showed lower fasting plasma C-peptide (median 725 vs. $900 \mathrm{pmol} / \mathrm{l}$ ) and insulin levels (median $63 \mathrm{vs} .79 \mathrm{pmol} / \mathrm{l}$ ) before insulin treat- 
ment compared to patients who continued with 1 injection. Also, C-peptide response after glucagon was lower ( 4.5 vs. $8.7 \mathrm{nmol} / 1.30 \mathrm{~min})$.

\section{Well-being}

Almost all patients reported improved well-being and diminished hyperglycaemic complaints, like thirst, polyuria and excessive noctumal urine production. No severe hypoglycaemias, necessitating medical assistance, were observed.

Table 3. Pre-treatment levels, and the mean of the absolute and percentual changes in body weight and variables of blood glucose control after 6 months treatment with insulin $(+1-$ sulphonylurea).

\begin{tabular}{lll}
$\begin{array}{l}\text { Regimen A } \\
(n=22)\end{array}$ & $\begin{array}{l}\text { Regimen B } \\
(n=13)\end{array}$ & $\begin{array}{l}\text { Regimen C } \\
(n=12)\end{array}$ \\
\hline
\end{tabular}

\begin{tabular}{|c|c|c|c|}
\hline Patients with 2 injections & 22 & 5 & 4 \\
\hline Insulin dose 6 months $(U)$ & $42 \pm 12$ & $24 \pm 11^{\$}$ & $27 \pm 18^{\$}$ \\
\hline Body weight $(\mathrm{kg})$ & $66 \pm 13$ & $78 \pm 17^{\$}$ & $68 \pm 12$ \\
\hline absolute change & $+4.2^{\&}$ & $+4.1^{\#}$ & $+3.7^{*}$ \\
\hline percentage change & +6.6 & +5.3 & +5.5 \\
\hline Fasting blood glucose (mmol/f) & $14.6 \pm 1.5$ & $15.8 \pm 2.0$ & $13.6 \pm 3.2$ \\
\hline absolute change & $-6.2^{\&}$ & $-6.0^{\&}$ & $-5.8^{\#}$ \\
\hline percentage change & -42 & -40 & -39 \\
\hline Mean blood glucose (mmol/d) & $17.9 \pm 2.5$ & $17.6 \pm 3.7$ & $17.3 \pm 3.0$ \\
\hline absolute change & $-8.8^{\&}$ & $-6.8^{\#}$ & $-7.4^{\&}$ \\
\hline percentage change & -49 & -40 & -41 \\
\hline Serum fructosamine (mmol/l) & $2.17 \pm 0.61$ & $1.78 \pm 0.23$ & $1.96 \pm 0.56$ \\
\hline absolute change & $-0.89^{\&}$ & $-0.50^{\#}$ & $-0.58^{\#}$ \\
\hline percentage change & -38 & -26 & -24 \\
\hline Glycosylated haemoglobin (\%) & $11.4 \pm 1.3$ & $10.8 \pm 1.4$ & $10.3 \pm 1.5$ \\
\hline absolute change & $-3.2^{\&}$ & -2.5 & $-2.4^{\#}$ \\
\hline percentage change & -27 & -23 & -22 \\
\hline Number of patients attaining & 10 & 7 & 4 \\
\hline HbAlc level < $8.0 \%$ & & & \\
\hline
\end{tabular}

$\& p<0.001, " p<0.01$ compared to baseline, ${ }^{\$} p<0.05$ vs. regimen $A$ 


\section{Blood glucose control}

In the whole group of patients fasting blood glucose decreased from $14.6 \pm 2.3$ to $8.5 \pm 2.2 \mathrm{mmol} / \mathrm{l}(\mathrm{p}<0.001)$, and $\mathrm{HbA}$ Ic fell from $10.9 \pm 1.4$ to $8.1 \pm 1.4 \%$ ( $p<0.001$ ). Twenty-one patients reached $\mathrm{HbA}_{1 \mathrm{c}}$ levels below $8.0 \%$, and 17 levels below $7.5 \%$, which is 4 times the upper limit of normal of our assay. In the patients treated with one insulin injection daily, mean insulin dose after 6 months was lower compared to the patients on regimen $A$ (table 3 ). These

Table 4. Pre-treatment levels and mean changes in measures of plasma lipids after 6 months insulin therapy.

\begin{tabular}{|c|c|c|}
\hline & $\begin{array}{l}\text { Regimen } A \\
(n=22)\end{array}$ & $\begin{array}{l}\text { Regimen B-C } \\
(n=25)\end{array}$ \\
\hline $\begin{array}{l}\text { Non-esterified fatty acids ( } \mathrm{mmol} / \mathrm{l}) \\
\text { absolute change } \\
\text { percentage change }\end{array}$ & $\begin{array}{l}1.01 \pm 0.32 \\
-0.36^{\&} \\
-34\end{array}$ & $\begin{array}{l}1.09 \pm 0.34 \\
-0.56 \\
-51\end{array}$ \\
\hline $\begin{array}{c}\text { Cholesterol (mmol/) } \\
\text { absolute change }\end{array}$ & $\begin{array}{l}7.1 \pm 1.4 \\
-0.8 \#\end{array}$ & $\begin{array}{l}6.4 \pm 1.4 \\
-0.4\end{array}$ \\
\hline percentage change & -10 & -5 \\
\hline $\begin{array}{l}\text { HDL-cholesterol (mmol/1) } \\
\text { absolute change } \\
\text { percentage change }\end{array}$ & $\begin{array}{l}1.10 \pm 0.31 \\
0.14^{\#} \\
15\end{array}$ & $\begin{array}{l}1.03 \pm 0.27 \\
0.10^{* *} \\
11\end{array}$ \\
\hline Triglycerides (mmol/l) & $\begin{array}{l}2.42 \\
1.25-11.4\end{array}$ & $\begin{array}{l}2.04 \\
0.82-9.1\end{array}$ \\
\hline $\begin{array}{l}\text { absolute change } \\
\text { percentage change }\end{array}$ & $\begin{array}{l}-1.19^{\&} \\
-33\end{array}$ & $\begin{array}{l}-0.78^{\text {W }} \\
-21\end{array}$ \\
\hline Apolipoprotein AI (mg/dl) & $114 \pm 19$ & $110 \pm 18$ \\
\hline absolute change & +5 & +2 \\
\hline relative change & +4 & +2 \\
\hline Apolipoprotein AII (mg/dl) & $34 \pm 5$ & $33 \pm 7$ \\
\hline absolute change & 0 & 0 \\
\hline relative change & 0 & 0 \\
\hline Apolipoprotein B (mg/dl) & $101 \pm 26$ & $90 \pm 24$ \\
\hline absolute change & -12 & -2 \\
\hline relative change & -12 & -3 \\
\hline
\end{tabular}

${ }^{*} \mathrm{p}<0.05,{ }^{\#} \mathrm{p}<0.01,{ }^{\&} \mathrm{p}<0.001$ compared to pre-treatment 
patients on 2 injections (without addition of glibenclamide) reached the best improvement of blood glucose control, the decrease of fasting and mean blood glucose was $42 \%$ and $49 \%$, respectively, while $\mathrm{HbA}$ ic decreased by $27 \%$.

\section{C-peptide/insulin}

When all patients were considered together, fasting $C$-peptide levels decreased significantly by a mean of $25 \%$ after 6 months insulin therapy (from $835 \pm 459$ $\mathrm{pmol} / \mathrm{l}$ to $611 \pm 387 \mathrm{pmol} / \mathrm{l}, \mathrm{p}<0.001$ ), while fasting insulin levels were $40 \%$ higher $(102 \pm 48 \mathrm{pmol} / 1$ vs. $80 \pm 51 \mathrm{pmol} / \mathrm{l}, \mathrm{p}=0.003)$. A comparable increase in fasting insulin levels was observed in all treatment groups.

\section{Plasma lipids}

Both in patients on insulin alone and in those treated with insulin+glibenclamide, significant increases of HDL-cholesterol were observed (from $1.10 \pm$ 0.31 to $1.24 \pm 0.32 \mathrm{mmol} / \mathrm{l}$, and from $1.03 \pm 0.27$ to $1.14 \pm 0.32 \mathrm{mmol} / \mathrm{l}$, respectively). Further, plasma triglycerides and non-esterified fatty acids decreased significantly (table 4). Total cholesterol decreased in the patients treated with insulin only (from $7.08 \pm 1.42$ to $6.26 \pm 1.15 \mathrm{mmol} / \mathrm{l}, \mathrm{p}<0.01$ ). Apolipoproteins AI, AII and B did not show any significant changes.

\section{DISCUSSION}

The interim-analysis of our study shows the effectiveness of insulin therapy, alone or in combination with glibenclamide, to improve blood glucose control in type 2 diabetic patients with secondary failure to treatment with oral hypoglycaemic agents. In all 3 treatment groups a clear decrease of fasting and mean daily blood glucose, and of glycosylated haemoglobin was observed. The decrease of these measures was the largest in group A patients, treated with twice-daily insulin injections alone. However, insulin dose was also the highest in these patients, compared to the 2 groups who were treated with insulin combined with glibenclamide.

Of the patients, who were initially randomized for once-daily insulin injections in combination with glibenclamide, $9(36 \%)$ did not reach adequate improvement of metabolic control, and needed a second insulin injection. In the patients starting with bedtime insulin, this decision was made when fasting blood glucose levels were near-normal, but postprandial blood glucose levels 
exceeded $12 \mathrm{mmol} / \mathrm{l}_{;}$in the patients with moming insulin a second injection was added when evening blood glucose levels were unacceptably high.

Only in regimen A patients a significant decrease of total plasma cholesterol was observed, whereas triglycerides and NEFA decreased significantly, both in patients on insulin only and in patients treated with combined therapy. Also in both groups an increase of HDL-cholesterol was observed. However, total cholesterol and triglyceride levels remained elevated, and HDL-cholesterol remained lower compared to non-diabetic subjects, as was already demonstrated by others $(17,18)$. The increase of HDL-cholesterol without concomitant increase of apolipoproteins AI and AII suggests enrichment of the HDL-particle with cholesterol during insulin therapy. Our findings are in contrast with observations made by Stenman et al (13). They reported that during combined therapy HDL-cholesterol was significantly lower than with insulin alone. These observations were made in only 15 patients, who were treated with insulin alone (most of them only 1 injection), or insulin in combination with glibenclamide in a 4-month cross-over study. It is, however, difficult to draw firm conclusions on their findings, since the number of patients was rather low. The present study shows more positive results, but is still continuing, and more definite evaluations of the effects of combined therapy on plasma lipids will be made when an even larger number of patients has been studied.

Secondary failure to oral hypoglycaemic agents after an initial favourable response may occur in approximately $5-10 \%$ of patients on a yearly basis $(19,20)$. Insulin treatment is then the available option. It was shown previously that intensive insulin therapy improves insulin secretory capacity of the B-cells, enhances peripheral insulin action and suppresses excessive hepatic glucose production $(6,7,21)$. However, especially in the obese patients weight gain on insulin therapy can pose significant problems. Further, the resulting peripheral hyperinsulinaemia may be of importance, since increased plasma insulin levels are considered to be an independent risk factor for the development of atheros clerosis. Average increase of fasting insulin levels in our total patient group was $40 \%$. However, acceleration of diabetic complications due to (severe) hyperglycaemia in poorly controlled patients is in our view more relevant than the theoretical disadvantage of hyperinsulinaemia.

Groop et al (20) studied possible factors influencing secondary drug failure to treatment with oral hypoglycaemic agents. They reported that patients failing to sulphonylureas had a lower relative body weight, and lower basal and post-glucagon plasma C-peptide concentrations than patients who were well controlled. There was not a critical $\mathrm{C}$-peptide level discriminating between nonresponders and responders. The reported lower C-peptide levels, however, existed in the presence of higher blood glucose values $(13.9 \pm 0.4 \mathrm{mmol} / \mathrm{l}$ in 
nonresponders, agairst $7.1 \pm 0.2 \mathrm{mmol} / \mathrm{l}$ in responders). It is known that the level of glycaemia affects the measured basal $\mathrm{C}$-peptide and the $\mathrm{C}$-peptide increase after stimulation: higher blood glucose values potentiate the effect of other insulin secretagogues, such as glucagon and arginine. But, even with higher blood glucose levels lower C-peptide levels were found. Thus, calculation of the ratio of C-peptide and glucose might yield a much better discrimination between responders and nonresponders than comparing C-peptide levels alone. In a previous study we measured C-peptide levels before and during 15 min after intravenous injection of $1 \mathrm{mg}$ glucagon in type 2 diabetic patients failing on dietary therapy (22). An incremental area under the response curve of $<5.0 \mathrm{nmol} / 1.15 \mathrm{~min}$ identified those patients, who exhibited better blood glucose control on insulin therapy compared to treatment with sulphonylureas.

Nonresponders to sulphonylureas also have a higher frequency of auto-antibodies against pancreatic islet cells, thyroid microsomes and gastric parietal cells. They also show a lower prevalence of HLA-B7, the frequency of which is reduced in insulin-dependent diabetes, and a higher prevalence of HLA-B8, which is known to be increased in insulin-dependent diabetes. Hence, a subset of patients with specific immunologic characteristics can be determined with a high risk of secondary drug failure and subsequent insulin requirement.

Approximately 30 years ago it was recommended that insulin be combined with sulphonylureas in the treatment of type 2 diabetic patients poorly controlled with insulin alone (23). Thereafter a period followed, in which the sole use of higher doses of insulin was recommended rather than the combination with sulphonylureas (24). The results of the widely-criticized UGDP study, which suggested an increased risk of cardiovascular deaths in patients treated with sulphonylureas $(25,26)$ also contributed to this view. The last 5 years, however, show a revival of the combined therapy, although its usefulness still is debated (5). Table 5 gives a summary of recent publications, in which the combined therapy was studied. A direct comparison between the studies remains difficult, because of the different doses of sulphonylureas, the various doses and administration regimens of insulin that were used, and the varying degree of obesity of the patients who were studied. Hamelbeck and co-workers (27) reported in a randomized double-blind study that patients treated with the combination of insulin and glibenclamide required a lower insulin dose and exhibited better blood glucose control than patients using insulin and placebo. His and other studies clearly demonstrated that, although there are favourable effects of combined therapy, it is in general difficult to attain (near)normoglycaemia in the individual patient. Some studies have reported only transient beneficial effects of combined therapy. Osei et al (29) found only a moderate improvement in glycaemic control after 4 and 16 weeks of glibenclamide and insulin in 
severely hyperglycaemic patients (fasting blood glucose $15.9 \pm 1.5 \mathrm{mmol} / \mathrm{l}$ ). In addition, the lower glucose increase and higher C-peptide response after $75 \mathrm{~g}$ oral glucose load was only apparent at 4 weeks, and had disappeared at 16 weeks. In a shorter observation period of 8 weeks Groop et al (30) also noticed that the initial beneficial effect of combined therapy tended to cease with time. Later studies of his group showed that in insulin-treated type 2 diabetic patients addition of glibenclamide resulted in a better blood glucose control than placebo ( $\mathrm{HbA}_{1} 7.9 \pm 0.5$ vs. $9.6 \pm 0.7 \%$ ) after 4 months, while insulin dose could be reduced by $25 \%$. Fasting and post-meal plasma free insulin levels were not different.

Although the quantitative effects of combined therapy differ between studies, the improvement in blood glucose control and the reduction of insulin requirement seems primarily due to an increase in endogenous insulin secretion. Comparing insulin plus glibenclamide with insulin alone Simonson et al (34) did not find changes in basal hepatic glucose production, nor any improvement in the suppression of hepatic glucose production by insulin, or improvement of insulin sensitivity. In contrast, the increase of both basal and glucagon-stimulated C-peptide levels correlated well with the decrease in insulin requirement in their patients using combined therapy. Finally, combining sulphonylurea and insulin was successful only in those patients, who exhibited residual B-cell function, as estimated by fasting and post-glucagon C-peptide levels (36). Also in our patients, those who needed a second insulin injection showed lower fasting plasma $\mathrm{C}$-peptide and insulin levels and $\mathrm{C}$-peptide response after glucagon, thus had lower residual islet $\mathrm{B}$-cell function before the initiation of insulin treatment.

Riddle $(12,41,42)$ advocates the use of a regimen combining bedtime intermediate-acting insulin with daytime sulphonylurea. This approach aims at reducing fasting blood glucose values by suppression of the increased (nocturnal) hepatic glucose production and high nocturnal concentrations of free fatty acids, which may contribute to hepatic insensitivity to insulin and fasting hyperglycaemia. Taskinen et al (43) raised the possibility that the improvement in overall glycaemic control by administration of bedtime insulin is related to the suppression of plasma NEFA concentrations. This hypothesis remains to be proven; in contrast, our data show an equal reduction of fasting plasma NEFA concentrations irrespective of the mode of insulin treatment (moming, evening, or twice-daily injections). Other findings suggested that especially nonobese patients with short duration of diabetes might benefit from this regime (42). We conducted a pilot study employing this regime in 8 obese patients (BMI 28.3$43.1 \mathrm{~kg} / \mathrm{m}^{2}$ ) with secondary failure to sulphonylurea and biguanide therapy. In only four of them near-normalization of blood glucose control of longer dura- 


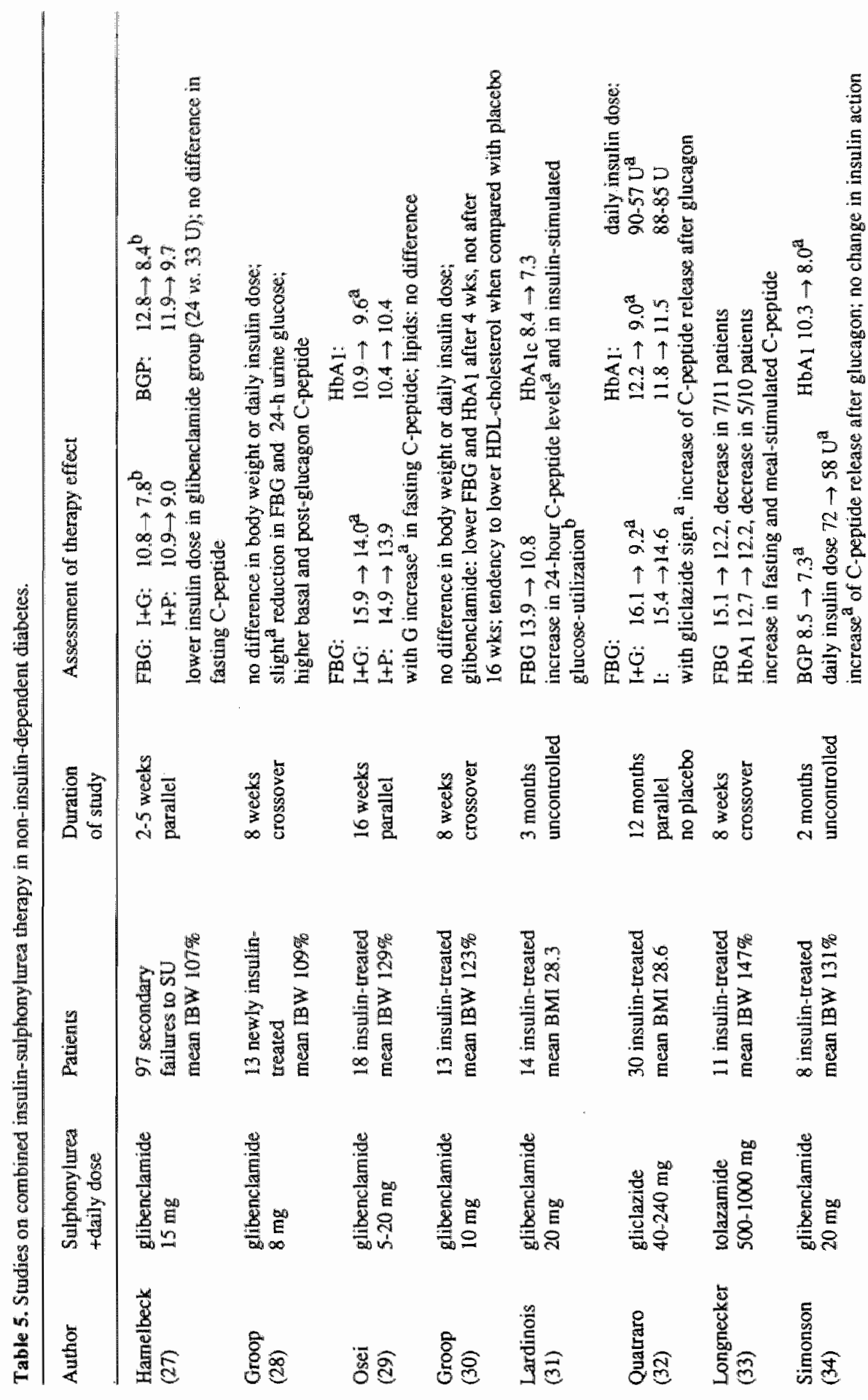




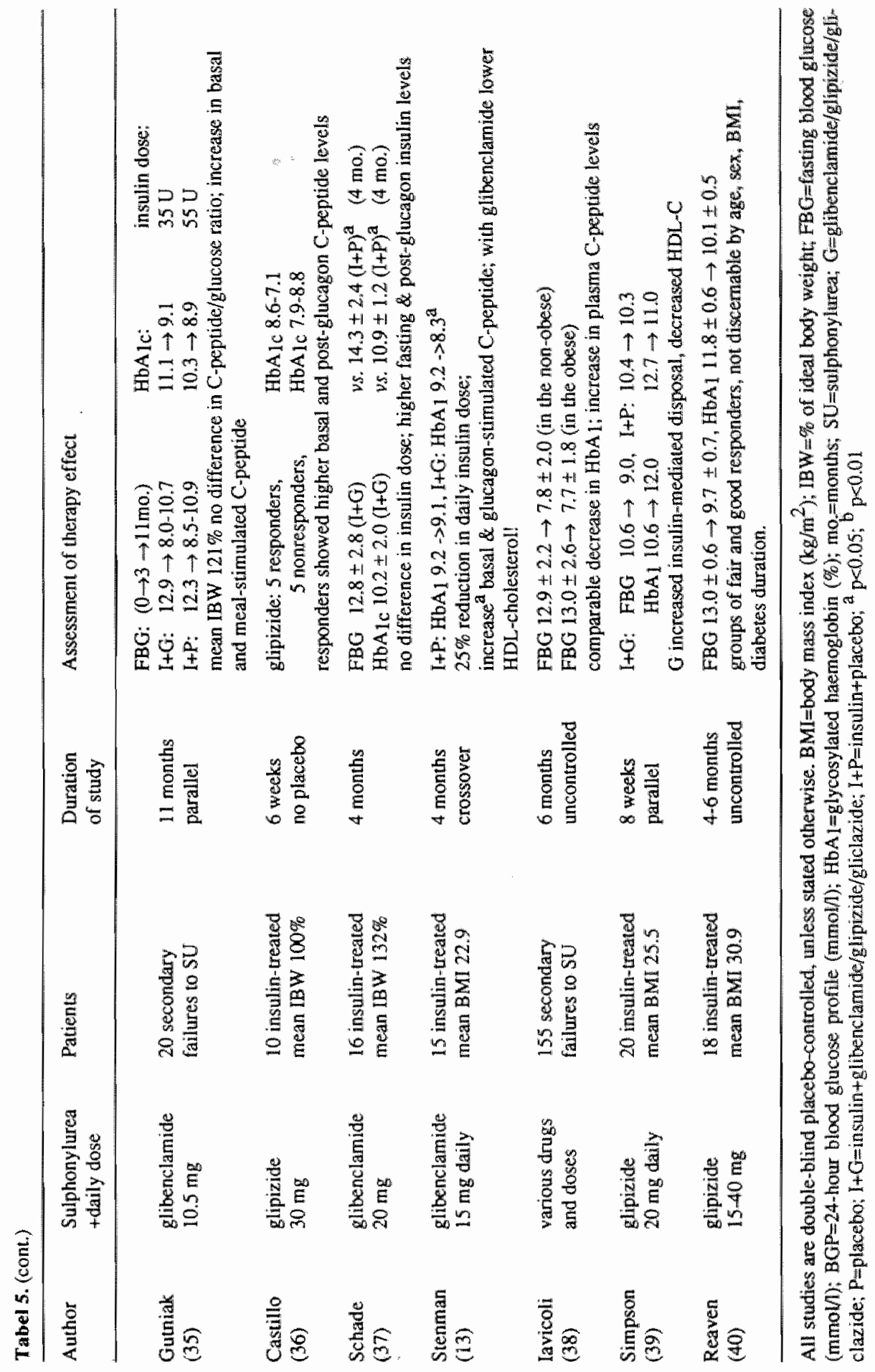


Table 6. Estimated costs of insulin and combined insulin-sulphonylurea therapy in parients with type 2 diabetes mellitus, when 2 daily injections are given with use of an insulin-pen.

\begin{tabular}{lll}
\hline & Insulin alone & $\begin{array}{l}\text { Insulin + } \\
\text { sulphonylurea }\end{array}$ \\
\hline Number of insulin injections & 2 & 1 or 2 \\
Amount of insulin (U/day) & 42 & 26 \\
Costs of: insulin & dfl. 2.22 & dfl. 1.37 \\
\multicolumn{1}{c}{ needles } & dfl. 0.58 & dfl. 0.38 \\
glibenclamide 15 mg daily & dfl. 0.00 & dfl. 1.66 \\
Total costs & dn. 2.80 & dff. 3.41 \\
\hline
\end{tabular}

Table 7. A practical approach to combined insulin-sulphonylurea therapy in patients with type 2 diabetes.

\section{A Patients witth failure to oral hypoglycaemic agents.}

1. Conversion to insulin therapy only (once or twice daily, long-or intermediate-acting $+/$ fast-acting)

or:

2. Addition of low dose insulin to existing sulphonylurea -therapy:

a. NPH - or Lente insulin before breakfast (ref. 33)

- start with 4-8 U

- adjust dose on basis of glucose profile

- give two injections when insulin dose $>28 \mathrm{U}$

or:

b. NPlu- or Lente insulin at bedtime (ref. 32)

- start with 4-8 U

- adjust dose on basis of fasting blood glucose

- add second injection before breakfast, when insulin dose $>40 \mathrm{U}$ or marked postprandial hyperglycaemia persists

\section{B. Insulin-treated type 2 diabetic patients.}

1. If poorly-controlled, add glibenclamide ( $5 \mathrm{mg}$. twice daily) to improve blood glucose control. 
tion was achieved, whereas marked postprandial hyperglycaemia necessitated the institution of a second (pre-breakfast) insulin injection in the others. Also in the present study, one-thirds of the patients starting with bedtime injections needed an additional morning injection of insulin. It therefore still needs to be determined which patients have the most benefit of this treatment regimen. Disadvantages may be the higher costs of combined therapy. Table 6 gives an estimate of the costs of treatment of the individual patient, as derived from the use of insulin and glibenclamide in our study. The possible positive effects on lipoprotein metabolism will be further explored during the continuation of this study.

In conclusion, the combined insulin-sulphonylurea therapy in patients with type 2 diabetes mellitus may have the following advantages:

1. lower insulin requirement.

2. improved and more stable blood glucose control.

3 . in some patients necessity of only one insulin injection.

4. less hyperinsulinaemia, and therefore possibly a lower risk for the progression of atherosclerosis.

5. by promoting insulin secretion a higher concentration of insulin is present 'intraportally'.

For use in daily clinical practice, some of the approaches have been summarized in table 7 and figure 2. 


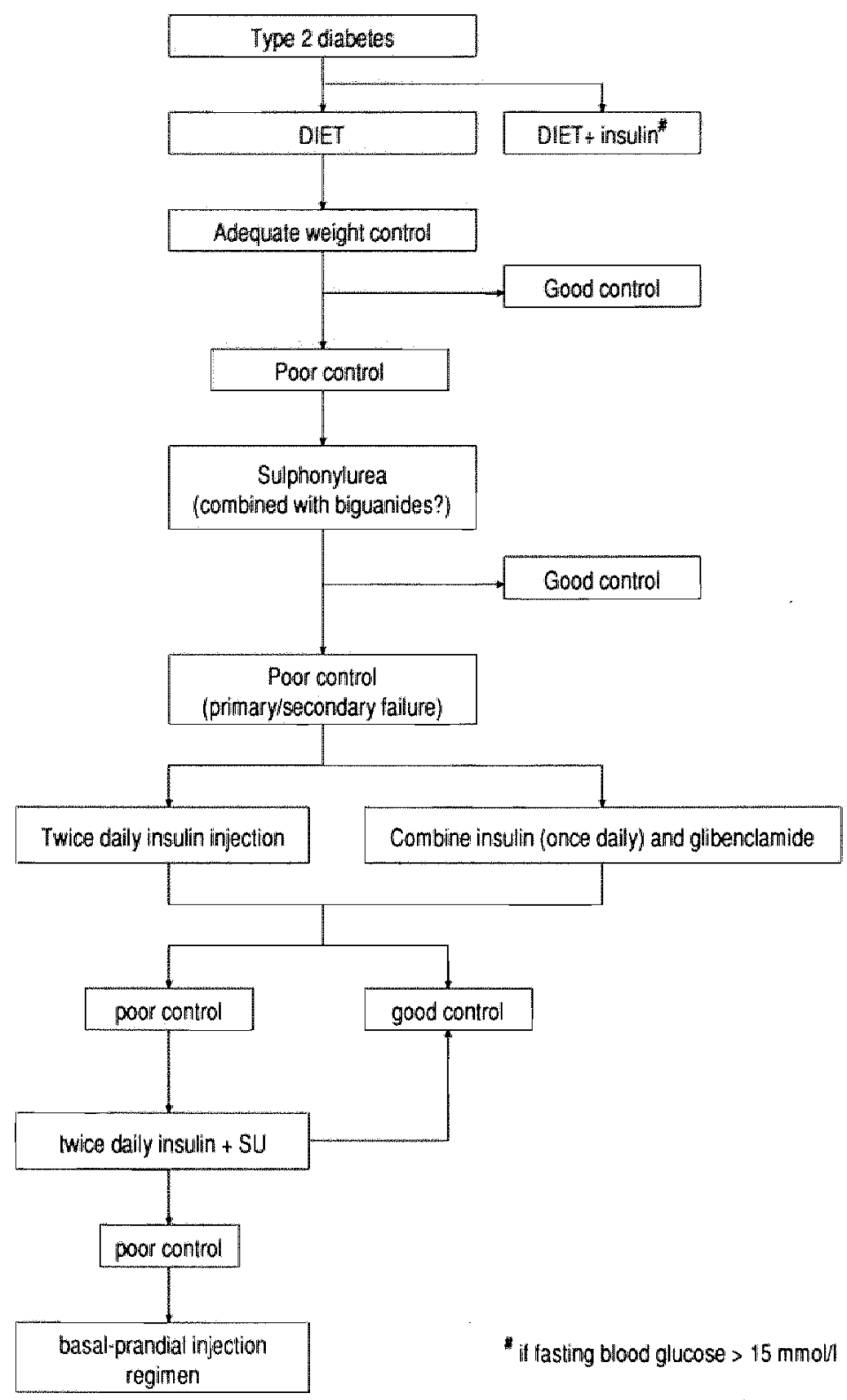

Figure 2. Schematic representation of therapy management in type 2 diabetes. Diet is the basis of treatment. In case of inadequate control (defined on an individualized approach) subsequent interventions comprise sulphonylurea, and combined therapy of insulin with sulphonylurea, or insulin alone. 


\section{REFERENCES}

1. Skyler JS. Non-insulin-dependent diabetes mellitus: a clinical strategy. Diabetes Cane 1984; 7 (suppl. 1): 118-129.

2. Gerich JE. Drug therapy-oral hypoglycemic agents. New Engl J Med 1989; 321:12311245 .

3. Wolfenbuttel BHR, Weber RFA, Koetsveld PM van, Verschoor L. Limitations of diet therapy in non-insulin dependent diabetes mellitus. Int J Obesity $1989 ; 13: 173-182$.

4. Heine RJ. Insulin treatment of non-insulin-dependent diabetes mellitus In: Bailliere"s Clinical Endocrinology and Metabolism, Non-insulin-dependent diabetes. Nattrass M, Hale PJ, Eds. London, $1,988$.

5. Tattersall RB, Scott AR. When to use insulin in the maturity onset diabetic. Postgrad Med J 1987;63: 859-864.

6. Kolterman OG, Olefsky JM. The impact of sulfonylurea treatment upon the mechanisms responsible for the insulin resistance in type II diabetes. Diabetes Care $1984 ; 7$, suppl.1: 81-88.

7. Garvey WT, Olefsky JM, Griffin J, Hamman RF, Kolteman OG. The effect of insulin treatment on insulin secretion and insulin action in type II diabetes mellitus. Diabetes. $1985 ; 34: 222-234$.

8. Montgomery BJ. High plasma insulin level a prime risk factor for heart disease. JAMA $1979 ; 241: 1665$.

9. Stout $\mathrm{RW}$. The role of insulin in atherosclerosis in diabetics and nondiabetics. Diabetes 1981; 30 (suppl 2): 54-57.

10. Nilsson A, Tideholm B, Kalen J, Katzman P. Incidence of severe hypoglycemia and its causes in insulin-treated diabetics. Acta Med Scand 1988; 224: 257-262.

11. Wolffenbuttel BHR. Combined use of insulin and oral hypoglycaemic agents in the treatment of patients with diabetes mellitus. Eur $\mathbb{I n t e r n}$ Med 1989; 1: 89-95.

12. Riddle MC, Hart JS, Bouma DJ, Phillipson BE, Youker G. Efficacy of bedtime NPH insulin with daytime sulfonylurea for subpopulation of type II diabetic subjects. Diabetes Care $1989 ; 12: 623-629$.

13. Stenman S, Groop PI, Saloranta C, Totterman KJ, Fyhrqvist F, Groop L. Effects of the combination of insulin and glibenclamide in type 2 (non-insulin-dependent) diabetic patients with secondary failure to oral hypoglycaemic agents. Diabetologia 1988; 31 : 206-213.

14. WHO Expert Committee on Diabetes Mellitus. Technical Report Series 727, 1985. Geneva: World Health Organization.

15. Johnson RN, Metcalf PA, Baker JR. Fructosamine: a new approach to the estimation of serum glycosylprotein. An index of diabetic control. Clin Chim Acta 1982; 127: 87-95.

16. Matthews DR, Hosker JP, Rudenski AS, Naylor BA. Treacher DF, Turner RC. Homeostasis model assessment: insulin resistance and b-cell function from fasting plasma glucose and insulin concentrations in man. Diabetologia 1985;28:412-419.

17. Bagdade JD, Buchanan WE, Kuusi $T$, Taskinen M-R. Persistent abnormalities in lipoprotein composition in noninsulin-dependent diabetes after intensive insulin therapy. Arteriosclerosis 1990; 10: 232-239. 
18. Lindstrom T, Arnqvist HU, Olsson AG. Effect of different insulin regimens on plasma lipoprotein and apolipoprotein concentrations in patients with non-insulin-dependent diabetes mellitus. Atherosclerosis 1990; 81: 137-144.

19. Thoelke H, Ratzmann KP. Häufigkeit des Sekundärversagens einer Sulfonylharnstofftherapie Epidemiologische Untersuchung. Dtsch Med Wschr 1989; 114: 580-583.

20. Groop LC, Pelkonen R, Koskimies S, Bottazzo GF, Doniach D. Secondary failure to treatment with oral antidiabetic agents in non-insulin-dependent diabetes. Diabetes Care 1986; 9: 129-133.

21. Ginsberg $H_{3}$ Rayfield EJ. Effect of insulin therapy on insulin resistance in type II diabetic subjects-evidence for heterogeneity. Diabetes 1981; 30: 739-745.

22. Wolffenbuttel BHR, Weber RFA, Van Koetsveld PM, Weeks $L$, Verschoor L. A randomized crossover study of sulphonylurea and insulin treatment in patients with type 2 diabetes poorly controlled on dietary therapy. Diabetic Medicine 1989; 6:520-525.

23. Lazarus SS, Volk BB. Physiological basis of the effectiveness of combined insulin-tolbutamide therapy in stabile diabetes. Ann $\mathbb{N}$ Y Acad Sci 1959; 82: 590-602.

24. Jackson WPU. Sulfonylureas in the management of human diabetes. In: Campbell GD. (ed). Oral hypoglycemic agents, pharmacology and therapeutics. Acad Press, New York, p. 135-192.

25. Feinstein AR. The persistent clinical failures and fallacies of the UGDP study. Clin Pharmacol Therap 1976; 19: 78-93.

26. Kolata GB. Controversy over study of diabetes drugs continues for nearly a decade. Science 1979; 203: 986-990.

27. Hamelbeck H, Klein W, Zoltobrocki M, Schoffling K. Glibenclamide-insulin combination in the management of secondary failure of sulfonylurea medication. Dtsch Med Wschr 1982; 107: 1581-1583.

28. Groop L, Harno K, Tolppanen EM. The combination of insulin and sulphonylurea in the treatment of secondary drug failure in patients with type II diabetes. Acta Endocrinol 1984; 106: 97-101.

29. Osei K, O'Dorisio TM, Falko JM. Concomitant insulin and sulfonylurea therapy in patients with type II diabetes: effects on glucoregulation and lipid metabolism. Am J Med 1984; 77: 1002-1009.

30. Groop L, Harno K, Nikkila EA, Pelkonen R, Tolppanen EM. Transient effect of the combination of insulin and sulfonylurea (glibenclamide) on glycemic control in non-insulin-dependent diabetics poorly controlled with insulin alone. Acta Med Scand 1985; 217: 33-39.

31. Lardinois CK, Liu GC, Reaven GM. Glyburide in non-insulin-dependent diabetes: its therapeutic effect in parients with disease poorly controlled by insulin alone. Arch Intern Med 1985; 145: 1028 1032.

32. Quatraro A, Consoli G, Ceriello A, Giugliano D. Combined insulin and sulfonylurea therapy in non-insulin-dependent diabetics with secondary failure to oral drugs: a one year follow-up. Diabete \& Metabolisme 1986; 12: 315-318.

33. Longnecker MP, Elsenthans VD, Leiman SM, Owen OE, Boden G. Insulin and a sulfonylurea agent in non-insulin-dependent diabetes mellitus. Arch Intern Med 1986; 146: $673-676$. 
34. Simonson DC, Delprato S, Castellino P, Groop L, DeFronzo RA. Effect of glyburide on glycaemic control, insulin requirement, and glucose metabolism in insulin-treated diabetic patients. Diabetes $1987 ; 36: 136-146$.

35. Gumiak M, Karlander $S G$, Efendic S. Glyburide decreases insulin requirements, increases beta-cell response to mixed meal, and does not affect insulin sensitivity: effects of shortand long-term combined treament in secondary failure to sulfonylurea. Diabetas Cane $1987 ; 10: 545-554$.

36. Castillo M, Scheen $\mathrm{AJ}_{2}$ Paolisso $\mathrm{G}$, Lefebvre PJ. The addition of glipizide to insulin therapy in type II diabetic patients with secondary failure to sulfonylureas is useful only in the presence of a significant residual insulin secretion. Acta Endocrinol 1987; 116: 364-372.

37. Schade DS, Mitchell WJ, Griego G. Addition of sulfonylurea to insulin treatment in poorly controlled type II diabetes a double-blind, randomized clinical trial. JAMA 1987; 257: 2441-2445.

38. Tavicoli $M$, Cucinotta $D$, De Mattia $G$, et al. Blood glucose control and insulin secretion improved with combined therapy in type 2 diabetic patients with secondary failure to orat hypoglycaemic agents. Diabetic Med 1988; 5: 849-855.

39. Simpson HCR, Sturley R, Stirling CA, Reckless JPD. Combination of insulin with glipizide increases peripheral glucose disposal in secondary failure type 2 diabetic patients. Diabetic Med 1990; 7: 143-147.

40. Reaven GM, Fraze E, Chen NY, Hollenbeck C, Chen Y-DI. The combined use of insulin and sulfonylurea therapy in patients with non-insulin dependent diabetes mellitus. Horm Metabol Res 1989; 21: 132-136.

41. Riddle MC. Evening insulin strategy. Diabetes Care 1990; 13: 676-686.

42. Riddle MC, Hart JS. Which patients might benefit from combining a sulfonylurea with insulin? (letter) Diabetes Care 1985; 8: 205-205.

43. Taskinen MR, Sane $T$, Helve $\mathbb{E}$, Karonen SL, Nikkila EA, Yki-Jarvinen H. Bedtime insulin for suppression of overnight free-fatty acid, blood glucose, and glucose production in NIDDM. Diabetes 1989; 38: 580-588. 
164 


\section{Determinants of the behaviour 'injecting insulin' in elderly patients with diabetes mellitus}

Bruce H.R. Wolffenbuttel, Constance H.C. Drossaert, Adriaan Ph. Visser

Submitted 
In patients with type 2 diabetes mellitus blood glucose control may gradually worsen despite diet and oral hypoglycaemic agents. We investigated which possible factors determine the decision for elderly type 2 diabetic patients to start with insulin therapy in this situation. According to Fishbein and Ajzen a attitude-behaviour model was constructed which included the determinants intention, attitude, subjective norm and self-efficacy. Fifty-three patients (age $68 \pm 9$ years) participated in the study: 26 already used insulin for 7 (1-12) months, 27 were tablet-treated but poorly-controlled (fasting blood glucose $>8.0$ mmol/l and glycosyllated haemoglobin $>8.0 \%$ ). A high correlation $(r=0.81, p<0.001)$ existed between the intention to and the actual use of insulin therapy. The main factor (70\%) explaining the intention towards insulin treatment was the subjective norm: patients are guided by the opinion of important other persons, especially the treating internist, the family physician and the diabetes nurse. Tablet-treated patients reported a negative opinion of their physician towards their treatment with insulin. Intention to behaviour was also determined by self-efficacy, e.g. expectations about the skills concerning injecting insulin. Self-monitoring of blood glucose and knowledge about diabetes positively influenced self-efficacy, attitude towards and intention to use insulin. Education needs to enforce the subjective norm and improve the patient's self-efficacy. A stimulating attitude of the treating physician towards insulin therapy is essential. 


\section{INTRODUCTION}

In patients with type 2 diabetes mellitus, insulin therapy may be needed, when diet and oral hypoglycaemic agents can no longer adequately control diabetes (1). Many patients with this so-called secondary failure are not motivated to switch to insulin injections. Several reasons are given for this reluctance: at first, patients often do not perceive complaints, not even in the presence of severe hyperglycaemia, and therefore do not think that insulin treatment will improve their well-being (2). Secondly, lack of knowledge concerning the relation between high blood glucose levels and the occurrence of secondary diabetic complications $(3,4)$ might influence the beliefs about insulin treatment. Thirdly, the perceived disadvantages of insulin therapy may outweigh in the patient's point of view the possible beneficial effects, and the patient may even be convinced that he or she is not capable to perform the difficult actions of injecting insulin. These views are often reinforced when a physician is reluctant -for whatever reason- to switch elderly patients to insulin therapy.

Despite this, a growing number of elderly type 2 diabetic patients is at present being treated with insulin. The use of insulin pens (5) makes the start of this treatment more easily. The present study was undertaken in order to evaluate which factors determine the decision of diabetic patients failing on oral therapy to accept to use insulin and whether these factors have to be the goal for specific education.

\section{PATIENTS AND METHODS}

\section{Patients}

Patients with type 2 diabetes (6), who were regularly seen by an internist/diabetologist at the outpatient-clinic of the Department of Internal Medicine, were elegible for the study, when they no longer responded to oral hypoglycaemic agents (tablet-group), or had started insulin therapy for this reason during the previous year (insulin-group). Failure to respond to oral therapy was defined as presence of fasting blood glucose levels $>8.0 \mathrm{mmol} / \mathrm{l}$, and glycosylated haemoglobin $\left(\mathrm{HbA}_{1 \mathrm{c}}\right)>8.0 \%$ with maximal doses of sulphonylurea. During a period of two months 56 consecutive patients were thus selected. Three patients refused to participate. Of the 53 remaining patients, 23 were men and 30 women, with a mean age ( $\pm S D$ ) of $68 \pm 9$ years. Twenty -six of them were using insulin. They were all treated by the same internists. Patients were interviewed by the same investigator (CHCD). Interviews took place at the outpatient-clinic 
just before the visit to the diabetologist, or at the patient's home at least two weeks after the last visit to the clinic. With 22 of the 27 tablet-users the advantages and drawbacks of insulin treatment was already discussed at -at least- one occasion.

\section{Design of the behaviour model}

For the analysis we used the theoretical model of Fishbein and Ajzen $(7,8)$. This 'theory of reasoned action' regards human behaviour as a rational one. In general, man considers the implications of his actions before he decides to engage or not to engage in a certain behaviour. Thus, a person's intention to (or not to) perform is the immediate determinant of the behaviour. Two basic determinants directly influence a person's intention: his attitude and the subjective norm. A person's attitude is the result of a balance between perceived advantages and disadvantages of a certain behaviour. Attitude is composed of two elements: several relevant beliefs, described as the expectations which outcome a certain behaviour will yield, and the evaluation of these beliefs. The subjective norm describes the influence of specific individuals or groups on the behaviour of a person. The subjective norm consists of two elements: normative beliefs, which are the perceived expectations of specific reference persons, for instance the mother, an other relative, or the physician, and the motivation to comply, which depicts whether the opinion of other persons indeed influences or changes intention. Examples of these determinants are given in table 1. In addition, the concept of self-efficacy $(9,10)$ has been implemented in the model. Although the patient may be convinced that insulin treatment is desirable, he/she may consider himself incapable to perform the behaviour and therefore have a negative intention towards insulin treatment. Self-efficacy comprises the expectations of a person that he will be able to perform the behaviour injecting insulin. Furthermore, we included those external variables, which are likely to be related to and of importance for the behaviour of injecting insulin, such as well-being, mode of treatment, and knowledge of diabetes (11).

\section{The questionnaire}

In a pilot study, 11 other type 2 diabetic patients were interviewed about aspects of insulin therapy to elicit the most important salient beliefs and normative beliefs. Six of these patients were treated with insulin, and five were 'secondary failures' to sulphonylureas. 
Table 1. Aspects of the Fishbein and Ajzen model.

Behaviour:

"starting insulin therapy"

Intention:

'do you intend to start or continue insulin therapy during the next 6 months?'

Belief:

'when I will inject insulin this will take a lot of time'

'when I will inject insulin I will feel better'

Evaluation of this belief." "spending a lot of time on my diabetes treatment does not bother me at all / does bother me very much"

Normative belief:

'my doctor thinks that II should be put on insulin'

Motivation to comply:

'when it comes to injecting insulin, the opinion of my

doctor is not/very important"

Attitude was measured with 14 thus-derived questions relating to both positive and negative consequences of injecting insulin. These consequences were evaluated on $a+2$ (very good) to -2 (very bad) scale. For each belief (b), the patients were asked to indicate the likelihood of certain consequences with a score from 0 (very unlikely) to +3 (very likely). A person's attitude was calculated by summation of the products of evaluation and likelihood of all 14 consequences. Summation yielded a reliable measure (Cronbach's alpha (12) $0.67)$.

Subjective norm was measured with 8 questions concerning important reference persons (partner, children, family physician, internist, diabetes nurse). Patients were asked to indicate the perceived opinion of these reference persons (normative belief) and how much they cared about these opinions (motivation to comply). By summating the products of normative beliefs and motivation to comply a person's subjective norm was calculated. Reliability testing proved that, after elimination of one item, this subjective norm scale was a reliable measure (Cronbach's alpha 0.74).

Self-efficacy was measured with 7 questions on technical aspects of administering insulin by injection. Respondents were asked to indicate in which degree they regard themselves capable to perform each aspect of the behaviour. The scores ranged from -2 (absolutely incapable) to +2 (absolutely capable). In addition, the behaviour injecting insulin was placed in three daily-life situations. Respondents were asked to indicate how capable they regarded them- 
selves to perform the behaviour in each situation, and further to indicate how often each situation would occur to them. Summation of the questions yielded a reliable measure (alpha coefficient 0.84 ).

The intention to behaviour was assessed by asking whether the patient intended to use or continue the use of insulin therapy during the next 6 months. Scores ranged from +2 (yes, certainly) to -2 (definitely not).

The physical variables recorded are body weight, blood glucose control, self-monitoring of blood glucose. On a $0-3$ scale respondents could indicate how frequent a certain complaint or symptom due to the presence of hyperglycaemia or due to specific diabetic complications had occurred during the preceeding 4 weeks. The combination of the answers to these 18 questions yielded a Symptom Score (Cronbach"s alpha 0.85).

Treatment variables comprised the actual therapy and the number of occasions during which insulin therapy was discussed between the physician and the patient. Personal variables included age, sex, marital and social status. The latter represented previous education, profession, and profession of the spouse. Twenty multiple-choice questions covering various aspects of diabetes were prepared in our clinic (alpha coefficient 0.77 ).

\section{Laboratory determinations}

Fasting blood glucose was measured in venous whole blood with an automated hexokinase method. HbA $\mathrm{ll}_{\mathrm{c}}$ was determined with HPLC (DIAMAT, Bio-Rad Laboratories, Richmond, Ca., USA). Normal values are 4.4-6.2\%, mean 5.3\%, between-assay cv $2.6 \%$.

\section{Statistical analyses}

All data are expressed as mean $\pm S D$. Differences between group means were tested with unpaired Student's t test or non-parametric test when appropriate. Corrections for multiple comparisons were made. Variables were compared by Pearson's correlation coefficient based on least-squares regression analysis. The predictive value of attitude, subjective norm, self-efficacy and the external variables for intention was determined stepwise with intention as dependent variable. External variables were only entered if they had a significant linear correlation with intention. The same procedure was performed for behaviour. 


\section{Diabetes and its therapy}

Six of the 26 patients on insulin took one daily injection, all in combination with sulphonylurea, 19 patients took two injections, whereas 1 was on a 4-injection regimen. Eleven of the 27 tablet-treated patients included in the study used sulphonylurea only, and 16 used both sulphonylurea and metformin. Known duration of diabetes was 8 (range 1-23) years in the patients on insulin, and 12 (range 1-30) years in the tablet-treated patients. Duration ( \pm SD) of insulin therapy was $7 \pm 3$ months, daily insulin dose was $36 \pm 13 \mathrm{U}$. "Their fasting blood glucose was $9.1 \pm 3.5 \mathrm{mmol} / \mathrm{l}$, and $\mathrm{HbA}_{1 \mathrm{c}} 8.5 \pm 1.9 \%$. Before the start of insulin therapy these values were $16.7 \pm 4.1 \mathrm{mmol} / \mathrm{l}$ and $11.3 \pm 1.8 \%$, respectively (both $p<0.001$ compared to values during insulin). Fasting blood glucose of the tablet-treated patients was $11.7 \pm 3.6 \mathrm{mmol} / \mathrm{h}$, and $\mathrm{HbA}_{\mathrm{lc}} 9.3 \pm 1.7 \%$ (both $\mathrm{p}<0.05$ compared to insulin-group). Seventeen patients on insulin and 1.0 tabletusers were regularly performing self-monitoring of blood glucose. Retinopathy was present in $20 \%$, and microalbuminuria or proteinuria was established in $45 \%$ of the patients.

\section{Attitude, subjective norm and self-efficacy}

Of all patients 10 had a negative attitude, and 41 a positive attitude towards injecting insulin. The scores on the determinants of the model is given in table 2. Attitude score, subjective norm and self-efficacy were higher in insulintreated patients.

The relations between the different components of the model is shown in figure 1. Intention and behaviour were strongly correlated, indicating that patients stating a positive intention towards insulin treatment really would perform the behaviour. The strongest relation was found between subjective norm and intention $(r=0.83, p<0.001)$. Attitude and self-efficacy showed a significant, but less strong relation with intention. The intention explained for $66 \%$ the behaviour. Stepwise regression revealed that $70 \%$ of this intention could be explained by the subjective norm, and an additional $5 \%$ by self-efficacy. Attitude yielded no significant additional explanation for the observed intention.

Table 3 gives an overview of the scores of insulin- and tablet-users regarding the various beliefs on insulin treatment. Tablet-users reported less positive expectations of benefit from insulin therapy. Both for insulin- and tablet-users the strongest reference persons are the treating intemist, the diabetes nurse and 
Table 2a. A verage scores on determinants of the attitude-behaviour model in type 2 diabetic patients on insulin $(n=26)$ and patients using oral hypoglycaemic agents $(n=27)$.

\begin{tabular}{lcc}
\hline & Insulin & Tablets \\
\hline Intention & 1.9 & $-0.9^{\#}$ \\
Autitude & 18.4 & $4.4^{\#}$ \\
Subjective norm & 16.5 & $0.4^{\#}$ \\
Self-efficacy & 21.4 & $7.8^{\#}$ \\
\hline
\end{tabular}

\# $p<0.01$ compared to insullin-group

Table $2 \mathrm{~b}$. A verage scores on determinants of the attitude-behaviour model in type 2 diabetic patients starting insulin within one month after the interview $(n=5)$ and patients continuing the use of oral hypoglycaemic agents $(n=22)$.

\section{Starting insulin Continuing tablets}

\begin{tabular}{lcc}
\hline Intention & 1.0 & $-1.4^{\#}$ \\
Attitude & 14.4 & $-7.8^{*}$ \\
Subjective norm & 16.8 & $-5.8^{\#}$ \\
Self-efficacy & 16.0 & $1.8^{*}$ \\
\hline
\end{tabular}

* $p<0.05,{ }^{*}<<0.01$ compared to patients starting insulin

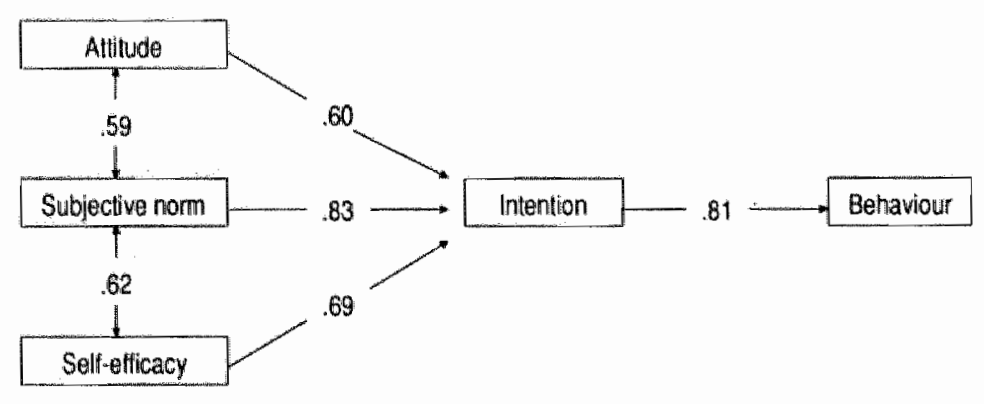

Figure 1. Individual correlations between the determinants of the behaviour 'injecting insulin"; all correlations are significant at the $p<0.01$ level. 
Table 3. Mean scores of insulin and tablet-users on bellefs (b), evaluations (e) and their product (b $x$ e) concerning injecting insulin.

consequence

$\frac{\text { beliefs }}{\text { insulin tablets }} \frac{\text { evaluations }}{\text { insulin tablets }} \frac{b x e}{\text { insulin tablets }}$

When I inject / would inject insulin:

- my bloodsugars will decrease

$\begin{array}{llllll}2.96 & 2.19^{*} & 1.27 & 1.96^{*} & 3.85 & 4.26 \\ 2.54 & 1.37^{*} & 1.96 & 1.85 & 4.96 & 2.48^{*} \\ 2.42 & 1.07^{*} & 1.96 & 1.93 & 4.77 & 2.15^{*} \\ 0.50 & 1.30 & -1.42 & -1.48 & -0.92 & -2.22\end{array}$

- the injection will hurt

- other people will notice that I have

diabetes

- It will cost me lots of time

$\begin{array}{llllll}0.46 & 0.96 & -0.69 & -1.11 & -0.46 & -1.22 \\ 1.73 & 2.63^{*} & -0.58 & -1.30 & -1.08 & -3.15 \\ 0.00 & 0.74^{*} & -0.85 & -1.00 & 0.00 & -0.74^{*} \\ 0.08 & 1.19^{*} & -1.19 & -1.48 & 0.00 & -1.44^{*}\end{array}$

- I will have to stay at home more

- I will have to adhere more strictly

to my diet

- I will have less thirst

$\begin{array}{llllll}1.42 & 1.22 & -1.50 & -1.48 & -1.96 & -1.92\end{array}$

- I will have to void less

$\begin{array}{llllll}2.00 & 0.96^{*} & 0.88 & 0.56 & 1.96 & 0.52\end{array}$

- I will feel less tired

1.46

1.15

1.08

0.93

1.42

1.31

1.07

1.92

1.78

2.62

2.15

- I will feel less tense

$\begin{array}{lll}1.04 & 0.78 & 1.69\end{array}$

1.48

1.62

1.48

- I will exporience less itch

$\begin{array}{lll}1.19 & 0.56 & 0.88\end{array}$

0.85

1.65

0.96

* $\mathrm{p}<0.05$ compared to insulin-group;

Ranges of score: beliefs: score 0 (very unlikely) to 3 (very likely); evaluations: score -2 (very negative) to +2 (very positive); b x e: score -6 to +6 (products)

the family physician (m.c. score 2.15-3.00, table 4). Relatives are only weakly motivating persons. Tablet-users reported a slightly negative opinion of their treating physician towards their using insulin, and a low score on their expectation to be capable to inject insulin (table 5).

Within one month after the interview, 5 tablet-treated patients started to use insulin. Their scores on intention, attitude, subjective norm and self-efficacy were significantly more positive than in the remaining patients of the tabletgroup (table $2 \mathrm{~b}$ ), and not different from the patients who already used insulin. 
Table 4. Mean scores of insulin and tablet-users on normative beliefs ( $n$.b.), motivation to comply (m.c.) and their product (n.b. x.m.) concerning injecting insulin.

\begin{tabular}{|c|c|c|c|c|c|c|}
\hline \multirow[t]{2}{*}{ persons } & \multicolumn{2}{|c|}{ normative belliefs } & \multicolumn{2}{|c|}{ motivation to comply } & \multicolumn{2}{|c|}{ n.b. $x$ m.c. } \\
\hline & insulin & tablets & insulin & tablets & insulin & tablets \\
\hline partner & 1.35 & $-0.59^{*}$ & 0.62 & 0.96 & 1.23 & -0.41 \\
\hline children & 1.38 & $0.07^{*}$ & 0.46 & 0.63 & 0.92 & 0.44 \\
\hline friends & 0.19 & 0.04 & 0.19 & 0.22 & 0.08 & 0.07 \\
\hline other diabetic patients & 0.42 & 0.07 & 0.50 & 0.93 & 0.46 & 0.37 \\
\hline family physician & 1.31 & $-0.26^{*}$ & 2.15 & 2.44 & 3.38 & $-0.37^{*}$ \\
\hline internist & 2.00 & $-0.04^{*}$ & 3.00 & 2.85 & 6.00 & $-0.15^{*}$ \\
\hline diabetes nurse & 1.54 & $0.11^{*}$ & 2.19 & 1.22 & 4.38 & $0.44^{*}$ \\
\hline
\end{tabular}

$p<0.05$ compared to insulin-group; Range of scores: normative beliefs: score -2 (very negative) to +2 (very positive); motivation to comply: score 0 (not important) to +3 (very important); n.b. x m.c.: score -6 to +6 (products)

Table 5. Mean scores of insulin and tablet-users on items of self-efficacy.

insulin tablets

Do you think that you are or will be capable to (a):

- puncture yourself

$1.730 .22^{\#}$

- inject your insulin

$1.73-0.33^{\text {\# }}$

- learn to inject insulin

$1.850 .59^{\text {\# }}$

- start with insulin therapy, when someone else will administer it

1.31

0.78

- have your syringe or insulin pen always available

2.00

$1.15^{\text {th }}$

- can watch the moments that you need to inject insulin

2.00

$1.30^{\text {料 }}$

- inject the correct amount of units

1.77

0.07 杖

Frequency of daily-life situations, and estimated capability to inject insulin in the circumstances (b):

- when you are on holidays

- when you are out visiting friends

- when you are out eating in a restaurant

* p<0.05;" p<0.01 compared to insulin-group;

Range of scores: (a). -2 (absolutelly not) to +2 (absolutely yes);

(b). -6 (absolutely not) to +6 (absolutely yes) 


\section{External variables}

Insulin-treated patients gave more correct answers on the 20 questions conceming diabetes knowledge than tablet-treated (13.0 vs. 10.2, $\mathrm{p}=0.011)$. However, when the three questions related to insulin therapy were omitted from the analysis, the difference no longer existed. A good correlation was found between knowledge and level of education $(r=0.47, p<0.01)$. The calculated Symptom Score was not different between insulin and tablet-users $(p=0.209)$. No single symptom occurred more in one of the groups. Thirty-five patients found themselves rather or very healthy, whereas 6 patients reported themselves as rather or very ill. No correlation was found between the determinants of the model and external variables as sex, age, educational and social status, duration of diabetes, perceived hyperglycaemic symptoms, blood glucose control and presence of secondary complications. However, a positive correlation existed between attitude and knowledge of diabetes $(r=0.50, p<0.01)$, and between attitude and the fact whether self-monitoring of blood glucose was performed $(\mathrm{r}=0.32, \mathrm{p}<0.05)$. Both variables were also strongly correlated with self-efficacy ( $r=0.52$ and $r=0.46$, respectively, both $p<0.01$ ).

\section{DISCUSSION}

This study is to our knowledge the first to report which factors determine the willingness of elderly type 2 diabetic patients, who are poorly controlled on tablets, to use insulin therapy. Various models have been employed to provide a better understanding of self-care behaviour of patients with diabetes mellitus. The widely-used Health Belief model $(13,14)$ has some drawbacks related to lack of uniformity of used definitions, the fact that influences of the social environment are considered of minor importance (15), and the lack of reliable and valid diabetes-specific measures (16). To study the behaviour 'injecting insulin' we used the Fishbein and Ajzen attitude-behaviour model. In this theory, the relation between the determinants attitude, subjective norm, and self-efficacy and the intention to perform a certain behaviour is described. The validity of the model has been proved several times for diabetes-related (17-19) and other kinds of health behaviour (20), and the derived information can be directly used for the development and subsequent evaluation of diabetes education programs (15). Other factors, such as level of knowledge, demographic variables and health locus of control $(21,22)$ are considered prerequisites in this model, and are incorporated as the 'external variables'. In our patients we found a high correlation $(r=0.81, p<0.001)$ between the intention to and the desired 
behaviour 'injecting insulin'. Persons with a positive intention were very likely to adopt the behaviour. This was found in retrospect, in the patients who already used insulin, and in addition also prospectively in those tablet-treated patients, who started insulin within one month after the interview. The subjective norm was the most important factor to explain the measured intention to commence insulin therapy. This implies that patients are guided in their willingness to accept insulin treatment by the opinion of important other persons. Especially the judgement of the treating internist and -to a lesser extent- the family physician and the diabetes nurse was regarded as very important in this respect. The opinion of relatives was less important in this respect. In contrast, tablet-treated patients reported a slightly negative opinion of their treating physician towards insulin therapy. In a study on diet compliance of diabetic patients the social norm was also found to be the strongest predictor of behavioural intention (17).

Intention was also determined by the factor self-efficacy. This determinant summarizes several skills related to the technique of injecting insulin. It appears that in particular patients who regard themselves capable to perform the behaviour 'injecting insulin' will progress to a positive intention. Learning to actually administer the injection, and establishing the correct amount of insulin are especially reported as difficult. It must be stressed that the type 2 diabetic patients studied are treated by endocrinologists at the outpatient clinic of a teaching hospital. A considerable number of them has been referred by their general practitioner for evaluation and treatment of their diabetes. In some instances, the possible institution of insulin therapy was the reason for referral; this was discussed with the patients on one or more occasions.

Fishbein and Ajzen state in their model that demographic variables and personality treats only have an indirect influence on the behaviour of a person through the attitude and the subjective norm. For practical purposes these variables are of importance, since they may form a direct entrance for education. It can be expected that patients with poor control who experience complaints will have a more positive attitude towards insulin therapy. The presence of secondary complications, or fear for these to develop may enhance the intention to start with insulin therapy in an earlier phase, although this will mainly occur when a physician has introduced this possibility of treatment. However, this factor may also have a negative influence: a patient can -for instance- regard himself uncapable to inject insulin because of poor vision, thereby lowering the intention. Further, lack of knowledge about diabetes and insulin therapy will lead to a more negative attitude. We found no correlation between perceived symptoms and intention, neither was any relation demonstrable between intention and several external variables, such as age, sex, 
education, social status, presence of eye complications, or duration of disease. However, patients with better knowledge of diabetes or performing self-monitoring of blood glucose showed a more positive attitude and intention. Thus, enforcing these external factors by education may positively influence intention towards insulin therapy. The high number of our patients already performing self-monitoring of blood glucose $(51 \%)$ is explained by our early use of this technique in diabetes education programs, monitoring progress during dietary therapy, and to prepare them for the conversion to insulin treatment.

The negative opinion on insulin therapy that tablet-users derive from their physician is not easily explained. All patients are treated by the same internists. With 22 of the 27 tablet-users the advantages and drawbacks of insulin treatment was already discussed at -at least-one occasion. A higher subjective norm was found among the patients, with whom insulin therapy had been discussed at repeated visits, and who subsequently started with insulin. This suggests that the subjective norm is built gradually with repeated discussions. Thus, several patient visits or educational sessions are needed to establish a stronger social norm and a more positive attitude towards insulin therapy. It can, however, not be ruled out that the low intention to behaviour and attitude of tablet-users is due to a poor perception of the given information. Another factor may be that their blood glucose control was less deranged than in the insulin-treated patients before this group started on insulin; the advice of the internist to start insulin therapy may be put to them less strongly.

We conclude that the Fishbein and Ajzen model is very useful to explain the behaviour 'injecting insulin'. For the willingness of type 2 diabetic patients to use insulin the opinion of other important persons, especially the internist/diabetologist, the family physician and the diabetes nurse, appeared the most significant factor. The patient's estimate to be able to perform the technique of injecting insulin adequately was a second major determinant. This implies that education of patients, in case such a change of therapy is advised, must aim to enforce the subjective norm and improve self-efficacy. Improving diabetes knowledge and stimulating self-monitoring of blood glucose may promote self-efficacy and thereby the intention to commence insulin therapy. A positive attitude of the treating physician towards insulin therapy is essential.

\section{REFERENCES}

1. Tattersall RB, Scott AR. When to use insulin in the maturity onset diabetic. Postgrad Med J $1987 ; 63: 859-864$.

2. Tattersall RB. Diabetes in the elderly; a neglected area? Diabetologia 1974; 27: 167-173. 
3. The DCCT Research Group: Diabetes Control and Complications Trial (DCCT): design and methodological considerations for the feasibility phase. Diabetes $1986 ; 35: 530-545$.

4. Tchobroutski $\mathrm{G}$. Relation of diabetic control to development of microvascular complications. Diabetologgia 1978: 15: 143-152.

5. Berger AS, Saurbrey $N$, Kuhl C Vilumsen J. Clinical experience with a new device that will simplify insulin injections. Diabetes Care 1985; 8: 73-76.

6. WHO Expert Committee on Diabetes Mellitus. Technical Report Series 727, 1985. Geneva: World Health Organization.

7. Fishbein M, Ajzen I. Belief, attitude, intention and behaviour; an introduction to theory and research. Reading, MS, Addison Wesley, 1975.

8. Ajzen I, Fishbein M. Understanding attitudes and predicting social behawiour. Englewood Cliffs, NJ, Prentice Hall, 1986.

9. Bandura A. Social Foundations of Thought and Action: A Social Cognitive Theory. Englewood Cliffs, NJ, Prentice Hall, 1986.

10. Strecher VJ, McEvoy De Vellis B, Becker MH, Rosenstock IM. The role of self-efficacy in achiewing health behaviour change. Health Educ Q 1986; 13: 73-91.

11. Jacobsen AM, Hauser ST. Behavioural and psychological aspects of diabetes. In Diabetes mellitus: Theory and Practice. 3rd Ed. Ellenberg M, Rifkin H, Eds., Elsevier Science Publishing Co, New Hyde Park, NY, 1990.

12. Cronbach LJ, Meehl PE. Construct validity in psychologicall tests. Psych Bull 1955; 4: 281-302.

13. Rosenstock IM. Understanding and enhancing patient compliance with diabetic regimens. Diabetes Care 1985; 8: 610-616.

14. Anderson LA. Health-care communication and selected psychosocial correlates of adherence in diabetes management. Diabetes Care 1990; 13 (suppl. 2): 66-76.

15. Janz NK, Becker MH. The health belief model: a decade later. Health Educ Q 1984; 11: $1-47$.

16. Lewis KS, Jennings AM, Ward JD, Bradley C. Health belief scales developed specifically for people with tablet-treated type 2 diabetes. Diabetic Med 1990; 7: 148-155.

17. Shenkel RJ, Rogers JP, Perfetto G, Levin RA. Importance of "significant others' in predicting cooperation with diabetic regimen. Int $J$ of Psychiatry in Med 1986; 15: 149-155.

18. De Weerdt I, Visser AP, Kok GJ, Van der Veen EA. Determinants of active self-cane behaviour of insulin treated patients with diabetes: implications for diabetes education. Soc Sci Med 1990; 30: 605-615.

19. De Weerdt I, Visser AP, Van der Veen EA. Attitude behaviour theories and diabetes education programmes. Patient Education and Counseling 1989; 14:3-19.

20. De Vries H, Kok GJ. From determinants of smoking behaviour to the implications for a prevention programme. Health Educ Res $1986 ; 1: 85-94$.

21. Ruzicki DA. Relationship of participation preference and health locus of control in diabetes education. Diabetes Care 1984; 7: 372-377.

22. Schlenk EA, Hart KL. Relationship between health locus of control, health value, and social support and compliance of persons with diabetes. Diabetes Care 1984; 7: 566 -574. 


\section{CHAPTER}

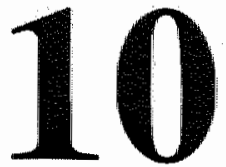

\section{General discussion}

\section{TYPE 2 DIABETES MELLITUS}

Non-insulin-dependent or type 2 diabetes mellitus is a heterogeneous disorder, characterized by impaired insulin secretion by the islet B-cells, diminished peripheral insulin action, and increased hepatic glucose production $(1,2)$. The major therapeutic goals in type 2 diabetic patients are to optimize blood glucose control, to reduce overweight and to normalize lipid disturbances and elevated blood pressure, in order to improve the well-being of the patient and reduce the risk for the development of late diabetic complications (3-5). Exercise (6) and diet, aiming at weight reduction (7-9) are the cornerstones of therapy. However, often pharmacologic treatment is necessary, in which case sulphonylurea (10), metformin or insulin may be employed (11).

\section{DIABETIC COMPLICATIONS}

Secondary complications are frequently observed in patients with type 2 diabetes mellitus. The role of diabetes as an independent risk factor for cardiovascular disease is well established (12). In patients, a two- to three-fold increase of morbidity and mortality attributed to coronary heart disease (CHD) is demonstrated $(13,14)$. A comparable increase of peripheral vascular disease is demonstrated (15). Microvascular abnormalities can be found in a considerable number of patients. Retinopathy is observed in 12 to $44 \%$ of diabetic patients 10 years after diagnosis. Diabetic nephropathy is less frequently found in type 2 compared to type 1 diabetic patients (14).

A number of risk factors for CHD can be demonstrated in diabetic patients. Twenty to $50 \%$ of them suffer from hypertension (16). Lipid abnormalities, comprising elevations of both LDL-cholesterol and VLDL-triglycerides, as 
well as decreases in the levels of HDL-cholesterol are reported to occur in at least $30 \%$ of patients (17). In diabetic patients elevated triglyceride levels seem to be an independent risk factor for the development of macrovascular disease.

In the Netherlands, only few data are available concerning the prevalence of late complications in type 2 diabetic patients (18). In comparison with patients who are under care by their family physician, a larger number of our hospitaltreated patients uses insulin ( $48 \%$ vs. $22 \%$ ). With this somewhat more difficult therapy, better metabolic control can be achieved. Based on epidemiologic data at least $20 \%$ of patients treated by their general practitioner show such poor metabolic control that they should be treated with insulin (18). In addition, the prevalence of vascular abnormalities in our patients was higher than that reported in the population in the general practice. This high prevalence of coronary artery disease (48\%), hypertension (56\%), cerebrovascular disease (15\%) and peripheral artery disease (35\%) implies a tendency for clustering of more complicated patients with type 2 diabetes in a hospital-clinic. This may be caused by the necessity of more aggressive treatment after a vascular problem has been diagnosed, for instance the institution of insulin therapy because of diabetic foot problems, or worsening of control after myocardial infarction. Otherwise, patients in poor control are more likely to be referred by their general practitioner for treatment advice and insulin therapy, although the criteria for good and poor control are often interpreted very liberally.

Especially in the patients with elevated urinary albumin excretion a higher prevalence of hypertension, cerebrovascular and peripheral vascular disease, neuropathy and retinopathy is found in comparison to normoalbuminuric patients, as described in chapter 2 . This is in agreement with other reports $(19,20)$. Not only the presence of macroproteinuria (urinary protein excretion $\geq 300$ $\mathrm{mg} / 24 \mathrm{~h}$ ), but already the presence of traces of albumin (microalbuminuria, albumin excretion $30-300 \mathrm{mg} / 24 \mathrm{~h}$ ) are strongly associated with subsequent mortality $(21,22)$. Therefore, determination of microalbuminuria can identify patients with high risk of acute cardiovascular events.

In diabetic patients, hypercholesterolaemia is associated with a very high risk of developing coronary heart disease and dying from cardiovascular causes in comparison to non-diabetic subjects and diabetic subjects with normal cholesterol levels $(23,24)$. In our studies, total and LDL-cholesterol were considerably higher, and HDL-cholesterol was lower compared to non-diabetic individuals. Furthermore, although metabolic control was good in the diettreated patients, they tended to have higher total cholesterol and triglyceride levels, and lower HDL-cholesterol compared to insulin-treated patients. 
In diabetic patients, who are chronically admitted to a nursing home, a higher prevalence of cerebrovascular disease, peripheral vascular abnormalities, skin necrosis or leg ulcers and recurrent urinary tract infections can be found compared to patients treated at the hospital outpatient-clinic (25). Hypertension is found in almost $50 \%$ of all patients, whereas its prevalence is the highest in the stroke patients. In the ambulatory patients cardiac complaints are more prevalent. Use of medication, especially diuretics and anticoagulant agents; is very high, not only in the nursing home patients, but also in the ambulatory patients. Only $25 \%$ of patients do not use any medication besides their specific diabetes-therapy. Thus, diabetes and the sequelae of its macrovascular complications may greatly impair the quality of life of the diabetic patient. Ischaemic heart disease is the great killer in these patients, and especially stroke and peripheral vascular disease are risk factors for admission to a nursing home. Better identification and preventive treatment of diabetic patients with high risk of ischaemic heart disease, stroke and peripheral vascular disease is necessary. This goal can only be reached, when regular screening and follow-up appointments of patients, either by the internist/diabetologist or by the general practitioner, comprise measurement of the abovementioned relevant measures (blood pressure, $\mathrm{HbA}_{1 c}$, plasma lipids, microalbuminuria), and more aggressive therapeutic interventions to normalize these variables. The current recommendations of the Dutch Standard of Care for General Practitioners do not fulfil these criteria (26).

\section{MONITORING OF METABOLIC CONTROL}

The measure most frequently used to monitor metabolic control in type 2 diabetic patients is the level of fasting blood glucose. It has been advocated to rely on this measure in all patients irrespective of their treatment (diet, oral agents, insulin) (27). Some outpatient and shared-care clinics have been especially organized to measure fasting blood glucose and perform the follow-up visit of the patient on the same morning. We and others $(28,29)$ have, however, demonstrated that the power of fasting blood glucose levels to correctly predict adequate metabolic control, as assessed by measurement of the 'Golden Standard', glycosylated haemoglobin $\left(\mathrm{HbA}_{1 \mathrm{c}}\right)$, with a very reliable and reproducible method, is rather poor, not only in insulin-treated patients, but also in diet- and tablet-treated patients. These findings have serious impact on the daily care for patients. On one hand, an additional measurement has to be performed, with an increase in costs, and the patient will have to visit the clinic or his doctor a few days in advance of the actual follow-up appointment to have the results availa- 
ble the day of his check-up. On the other hand, by measuring $\mathrm{HbA}_{1 \mathrm{c}}$ a considerable number of patients will be identified who are inadequately controlled, and need intensification of therapy. This point is also relevant for patients treated by their general practitioner (30). Starting with insulin injections in an earlier phase may very well improve patients" well-being, and prevent some of the later complications, especially in the younger patients.

Other measures of glycated proteins have been used to assess short- or long-term metabolic control. One of the more popular is the measurement of glycated serum proteins, the so-called serum fructosamine determination $(31,32)$. It has been introduced because of its presumed ease of measuring and automation of the assay, as well as its lower price. Lack of standardization is the main problem prohibiting the clinical utilization of this assay. The most frequently used commercially available kit has suffered considerable adaptations at least three times during the last five years. Further, it has become clear that serum fructosamine determinations show a considerable variation, as demonstrated in chapter 4 . Various factors contribute to this variation, such as the serum albumin level, the collection of blood (venous congestion, position of the patient), ambulation, and even circadian variations, which show an increase of fructosamine levels after breakfast. Therefore, in agreement with recent publications we tend to regard the serum fructosamine assay, although cheaper and easier to perform, not to be the long-awaited successor of the HbAlc assay.

\section{DIETARY THERAPY}

The effects of dietary measures has been the subject of a vast amount of studies (7-9). Diet in the diabetic patient has evolved from restriction of refined carbohydrates and careful assessment of every gram of food eaten to a more liberalized advice aiming at healthy eating habits, abolishing as much as possible (but not forbidding) refined sugars, fat, and our Western junk food. In general, results of strict dietary therapy have been rather disappointing. Weight reduction is absolutely necessary to attain and retain improvement of metabolic control. Intensified regimens including modified fasting periods during long hospital admissions have been shown to improve blood glucose control and dyslipidaemia considerably $(9,33,34)$, but the long-term benefits of such expensive treatments have been rather poor. We assessed the effects of dietary therapy applied in the everyday setting of control of patients at the outpatient clinic. It is confirmed that in the obese patients weight reduction is essential to result in metabolic improvement. This improvement is irrespective of the preceeding fasting blood glucose concentration. Those patients with less impaired 
B-cell function and shorter known duration of diabetes show the most favourable response. As in other studies, enhancement of beta-cell function and insulin action appear to be responsible for the improvement in blood glucose control. It may, however, also be interpreted that the smaller intake of carbohydrates and the resulting weight loss result in lower blood glucose levels, which in tum is responsible for the observed improvement of islet B-cell function and insulin action by reducing glucose toxicity.

\section{INSULIN THERAPY}

Despite diet, normoglycaemia is not achieved in a considerable number of patients. In such circumstances, therapy with oral hypoglycaemic agents or insulin may be warranted. The comparative effects of sulphonylurea and insulin treatment on glucose and lipid metabolism and insulin action have been the subject of a small number of studies. In mildly hyperglycaemic patients the effects of both treatments are comparable (35). However, insulin therapy is superior to sulphonylurea in patients who were more hyperglycaemic (36), as was demonstrated by us (chapter 6 ).

Sulphonylurea stimulate the release of endogenous insulin and probably improve peripheral insulin action (10). In patients, in whom intensified insulin treatment produces (near)normoglycaemia, an improvement of islet B-cell function and insulin action have been demonstrated (37-39). It has been argued that treatment with insulin results in considerable peripheral hyperinsulinaemia, thereby increasing the (theoretical) risk for developing atherosclerosis (40). In our studies, the average increase of fasting insulin levels approximated $40 \%$. However, acceleration of diabetic complications due to (severe) hyperglycaemia in poorly controlled patients is of more relevance than the theoretical disadvantage of hyperinsulinaemia.

It is still difficult to assess which patients, who are poorly controlled by diet only, will benefit the most from insulin therapy. Our study suggests that by determination of $\mathrm{C}$-peptide release after glucagon those patients can be identified in whom insulin therapy results in better blood glucose control than sulphonylurea (chapter 6).

When metabolic control is unsufficient with maximal doses of oral hypoglycaemic agents, insulin is the available option. It may be given alone, and substitute for the oral therapy, or be combined with sulphonylurea. A simple regimen comprising twice-daily administration of intermediate-acting or a mixture of fast- and intermediate-acting insulin significantly improves well-being and metabolic control with a slight concomitant improvement of plasma lipids. 
Insulin therapy can be safely instituted on an outpatient base, which is an atractive possibility in a Health Care system facing large medical costs. No severe complications of insulin therapy are seen. Care must be taken to avoid hypoglycaemias (41). In patients, who do not attain adequate control with 2 injections, more intensive efforts are needed, for instance multiple injection regimens and instruction in self-regulation. Obesity does not seem to be a contraindication for institution of insulin treatment, when therapy with oral hypoglycaemic agents does not result in adequate control (11).

Although short-term studies have demonstrated a more favorable response of blood glucose control with combination of insulin and sulphonylurea in comparison to insulin alone (better metabolic control, lower insulin dose needed, less insulin injections), long term results are not yet available (42-44). Combined therapy is more expensive, and also more difficult for the patient. Our short-term results indicate a lower insulin need, when insulin treatment is added to existing therapy with glibenclamide, in comparison with insulin alone, while metabolic improvement was identical. Severe hypoglycaemias were not observed. In contrast to other findings (for review see 42) HDL-cholesterol levels equally increased with both treatment modalities. There is a tendency that patients with a higher residual insulin secretion respond more favorably, as is also demonstrated by other investigators (45). The long term results of combined therapy, especially with regards to changes of plasma cholesterol levels, have to be awaited.

On the basis of our findings the recommendations of the Dutch Standard of Care for General Practitioners need extension (26). These do not recognize the need for immediate insulin treatment, when blood glucose is severely deranged, while treatment steps (switching to oral agents or insulin) proceed rather slowly.

\section{EDUCATION}

Several factors are involved in the decision for elderly diabetic patients to start with insulin therapy, when blood glucose control has become inadequate despite diet and oral hypoglycaemic drugs (46). Many patients are reluctant to switch to insulin injections. Patients often do not perceive complaints, not even in the presence of severe hyperglycaemia, and therefore do not think that insulin treatment will improve their well-being (47). The study of Alogna (48) shows that type 2 diabetic patients, who are classified as compliant with treatment advices, rate their diabetes more severely than those classified as noncompliant. The perceived disadvantages of insulin therapy (painful, time-consuming, strict schedules and eating hours, stuck to home) may outweigh in the patient's point 
of view the possible beneficial effects on glucose and lipid metabolism, and the patient may even be convinced that he or she is not capable to perform the difficult actions of injecting insulin (49). The main factor that explains the intention to commence insulin treatment appears to be the subjective norm. This means that patients are guided by the opinion of important other persons, in these circumstances especially the treating internist, and to a lesser extent the family physician and the diabetes nurse. Tablet-treated patients think that their physcician has a negative opinion towards their treatment with insulin. Intention to start insulin treatment is also determined by the determinant self-efficacy. This factor implies the patient's judgement of how well he can initiate and carry out the different tasks concerning injecting insulin. Self-monitoring of blood glucose with chemical strips and a higher knowledge about diabetes positively influence this self-efficacy, as well as the attitude towards and the intention to start insulin treatment. Earlier studies have already demonstrated that the quality of patient-provider relationships are an important factor in achieving adherence to medical advice (50). Inconsistent or one-sided communication from health-care professionals to patients results in incorrect representation of their illness and inhibits treatment adherence (51). These findings imply that education of type 2 diabetic patients, who are switching to insulin therapy, needs to enforce the subjective norm and improve the patient's self-efficacy. A stimulating and motivating attitude of the treating physician towards insulin therapy is essential.

\section{FINAL REMARK}

In conclusion, the occurrence of vascular abnormalities in patients with type 2 diabetes mellitus is high and their level of metabolic control usually is poor. Considering the apparent clustering of risk factors as poor metabolic control, obesity, hypertension and dyslipidaemia, attaining optimal blood glucose control forms only one of the aims of treatment in order to prevent the vascular complications, which severely limit the quality of life. Striving for normal blood glucose and $\mathrm{HbA}_{1 c}$ levels seems futile without concomitant adequate treatment of elevated blood pressure and hypercholesterolaemia. To achieve these goals, proper education of the patients as well as their physicians is essential. 


\section{REFERENCES}

1. Defronzo RA. The triumvirate: beta-cell, muscle, liver: a collusion responsible for NIDDM. Diabetes 1988; 37:667-687.

2. Effendic $S$, Luff $R$, Wajngot $A$. Aspects of the pathogenesis of type 2 diabetes. Endocrine Rev 1984; 5: 395-410.

3. Alberti KGMM, Gries FA. Maragement of non-insulin-dependent diabetes mellitus in Europe: consensus view. Diabetic Med 1988; 5: 275-281.

4. Skyler JS. Non-insulin-dependent diabetes mellitus: a clinical strategy. Diabetes Care, 1984,7 (suppl.1):118-129.

5. Lipsion $\mathrm{LG}_{\mathrm{p}}$ Lipson $\mathrm{M}$. The therapeutic approach to the obese maturity-onset diabetic patient. Arch Intern Med 1984; 144: 135-138.

6. Schneider SH, Ruderman NB. Exercise and NIDDM. Technical Review. Diabetes Care $1990 ; 13: 785-789$.

7. Walles JK. Treatment of type 2 (non-insulin-dependent) diabetic patients with diet alone. Díabetologia 1982; $23: 240-245$.

8. Hadden DR, Montgomery DAD, Skelly RJ, et al. Maturity onset diabetes mellitus: response to intensive dietary management. $\mathrm{Br}$ Med J 1975; 2: 276-278.

9. Henry RR, Wallace P, Olefsky JM. Effects of weight loss on mechanisms of hyperglycemiat in obese non-insulin-dependent diabetes mellitus. Diabetes 1986; 35: 990-998.

10. Gerich JE Drug therapy-oral hypoglycemic agents. New Engl J Med 1989; 321: 1231 1245.

11. Heine RJ. Insulin treatment of non-insulin-dependent diabetes mellitus. In: Baillière"s Clinical Endocrinology and Metabolism, Non-insulin-dependent diabetes. Nattrass $M$, Halle PJ, Eds. London, 1988.

12. Nathan DM, Singer DE, Godine JE, Perlmuter LC. Non-insulin-dependent diabetes in older patients-complications and risk factors. Am J Med 1986; 81: 837-842.

13. Fein FS, Scheuer J. Heart disease in diabetes. In: Ellenberg and Rifkin's Diabetes mellitus: Theory and Practice. Rifkin H, Porte D Jr, Eds. 4th Edition, New Hyde Park, NY, Elsevier Science Publishing $\mathrm{Co}, 1990$.

14. Jarrett RJ. Epidemiology and public health aspects of non-insulin-dependent diaberes mellitus. Epidemiol Rev 1989; 11:151-171.

15. Levin ME, Sicard GA. Peripheral vascular disease in the person with diabetes. In: Ellenberg and Rifkin's Diabetes mellitus: Theory and Practice. Rifkin H, Porte D Jr, Eds. 4th Edition, New Hyde Park, NY, Elsevier Science Publishing Co 1990.

16. Drury PL. Non-insulin-dependent diabetes and hypertension. In: Baillière's Clinical Endocrinology and Metabolism, Non-insulin-dependent diabetes. Nattrass M, Hale PJ, Eds. London, 1988.

17. Betteridge DJ. Lipids, diabetes and vascular disease: the time to act. Diabetic Med 1989; 6: 195-218.

18. Verhoeven $S$. Treatment, follow-up and metabolic regulation of patients with diabetes mellitus type II and the prevalence of late complications in this group of patients. Thesis, Rotterdam/Heerde, 1989.

19. Allawi J, Jarrett RJ. Microalbuminuria and cardiovascular risk factors in type 2 diabetes mellitus. Diabetic Med 1989; 7: 1.15-118. 
20. Marshall SM, Alberti KGMM. Comparison of the prevalence and associated features of abnormal albumin excretion in insulin-dependent and non-insulin-dependent diabetes. $Q$ I Med 1989; 70:61-71.

21. Mogensen CE. Microalbuminuria predicts clinical proteinuria and early mortality in maturity-onset diabetes. New Engl J Med 1984; 310: 356-360.

22. Jarrett RJ, Viberti GC, Argyropoulos A, Hill RD, Mahmud U, Murells T. Microalbuminuria predicts mortality in non-insulin-dependent diabetes. Diabetic Med 1984; 1: 17.

23. Assmann G, Schulte H. Diabetes mellitus and hypertension in the elderly: concomitant hyperlipidemia and coronary heart disease risk. Am J Cardiol 1989;63: 33H -37H.

24. Rosengren $A$, Welin $L$, Tsipogianni $A$, Wilhelmsen $L$. Impact of cardiovascular risk factors on coronary heart disease and mortality among middle aged diabetic men: a general population study. Br Med J 1989; 299: 1127-1131.

25. Mooradian AD, Osterweil D, Petrasek D, Morley JE. Diabetes mellitus in elderly nursing home patients. A survey of clinical characteristics and management. I Am Geriat Soc 1988; 36: 391-396.

26. Rutten GEHM, Cromme PVM, Zuidweg J, Mulder Dzn JD. The general practitioner and diabetes type II. A justification for the NHG standard. Huisarts Wet 1989;32:7-13.

27. Holman RR, Turner RC. Optimizing blood glucose control in type 2 diabetes: an approach based on fasting blood glucose measurements. Diaberic Med 1988; 5: 582-588.

28. Winocour PH, Bhatnagar D, Kalsi P, Hillier VF, Anderson DC. An analysis of glycosylated blood proteins and blood glucose profiles over one year in patients with type 1 diabetes. Diabetic Med 1989; 6: 709-716.

29. Howey JEA, Bennet WM, Browning MCK, Jung RT, Fraser CG. Clinical utility of assays of glycosylated heamoglobin and serum fructosamine compared: use of data on biological variation. Diabetic Med 1989; 6: 793-796.

30. Larsen ML, Horder M. Metabolic evaluation of non-insulin-dependent diabetes in primary health care the clinical usefulness of glycated haemoglobin measurements. Scand I Prim Health Care 1989; 7: 167-171.

31. Johnson RN, Metcalf PA, Baker JR. Fructosamine: a new approach to the estimation of serum glycosylprotein. An index of diabetic control. Clin Chim Acta 1982; 127: 87-95.

32. Armbuster DA. Fructosamine: structure, analysis and clinical usefulness. Clin Chem $1987 ; 33: 2153-2163$.

33. Hughes TA, Gwynne JT, Switzer BR, Herbst $C_{n}$ White $G_{n}$ Effects of caloric restriction and weight loss on glycemic control, insulin release and resistance, and atherosclerotic risk in obese patients with type II diabetes mellitus. Am J Med 1984; 77: 7-17.

34. Uusitupa MU, Laakso M, Sarlund $\mathrm{H}$, Majander $\mathrm{H}$, Takala J, Penttila I. Effects of a very-low-calorie diet on metabolic control and cardiovascular risk factors in the treatment of obese non-insulin-dependent diabetics. Am J Clin Nutr 1990; $51: 768-773$.

35. Firth RG, Bell PM, Rizza RA. Effects of tolazamide and exogenous insulin on insulin action in patients with non-insulin-dependent dabetes mellitus. New Engl J Med 1986; 314: 1280-1286.

36. Samanta A, Burden AC, Kinghorn A. A comparative study of sulphonylurea and insulin therapy in non-insulin-dependent diabetics who had failed on diet therapy. Diabetes Res $1987 ; 4: 183-185$. 
37. Glaser $\mathrm{B}$, Leibowich $\mathrm{G}$, Wesher $\mathrm{R}$, Hartling $\mathrm{S}$, Binder $\mathrm{C}$, Cerasi $\mathrm{E}$. Improved beta-cell function after intensive inswlin treatment in severe non-insulin-dependent diabetes. Acta Findocrinol 1988; 118:365-373.

38. Garvey WT, Olefsky JM, Griffin J, Hamman RF, Kolterman OG. The effect of insulin treatment on insulin secretion and insulin action in type II diabetes mellitus. Diabetes $1985 ; 34: 222-234$

39. Crinsberg H, Rayfield EJ. Effect of insulin therapy on insullin resulstance in type II diabetic subjects-eviderice for heterogeneity. Diabetes $1981 ; 30: 739-745$.

40. Stout $\mathrm{RW}$. The role of insulin in atherosclerosis in diabetics and nondiabetics. Diabetes $1981 ; 30$ (suppl 2): 54-57.

41. Nilsson A, Tideholm B, Kalen J, Katzman P. Incidence of severe hypoglycemia and its causes in insulin-treated diabetics. Acta Med Scand 1988; 224: 257-262.

42. Wolffenbuttel BHR. Combined use of insulin and oral hypoglycaemic agents in the treatment of patients with diabetes mellitus. Eur J Intern Med 1989; 1: 89-95.

43. Bailley TS, Mezitis NHE. Combination therapy with insulin and sulfonylureas for type II diabetes. Diabetes Care 1990; 13: 687-695.

44. Lebovitz $H E$, Pasmantier $\mathbb{R}$. Combination insulin-sulfonylurea therapy. Diabetes Care $1990 ; 13: 667-675$

45. Castillo M, Scheen AJ, Paolisso G, Lefebvre PJ. The addition of glipizide to insulin therapy in type II diabetic patients with secondary failure to sulfonylureas is useful only in the presence of a significant residual insulin secretion. Acta Endocrinol 1987; 116: $364-372$.

46. Tattersall RB, Scott AR. When to use insulin in the maturity onset diabetic. Postgrad Med J 1987; 63: 859-864.

47. Tattersall RB. Diabetes in the elderly; a neglected area? Diabetologia 1974; 27: 167-173.

48. Alogna M. Perception of severity of disease and health locus of control in compliant and noncompliant diabetic patients. Diabetes Care 1980; 3: 533-534.

49. Jacobsen AM, Hauser ST. Behavioural and psychological aspects of diabetes. In Diabetes mellitus: Theory and Practice. 3rd Ed. Ellenberg M, Rifkin H, Eds. New Hyde Park, NY, Elsevier Publishing Co, 1983.

50. Roter DL, Hall JA, Katz NR. Patient-physician communication: a descriptive summary of the literature. Patient Education and Counselling 1988; 12: 99-119.

51. Anderson LA, Halter JB. Diabetes care in older adults: current issues in management and research. In: Geriatric Health Issues, p.35-73. 


\section{CHAPTER

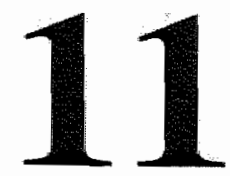

\section{Summary}

This thesis deals with the spectrum of secondary complications, that occur in patients with type 2 diabetes mellitus, and the effects of dietary and insulin treatment on glucose and lipid metabolism in these patients.

Chapter 1 gives an overview of the pathophysiologic mechanisms leading to hyperglycaemia and responsible for the development of late complications in persons with type 2 diabetes mellitus. A summary is given of the current insights in treatment of diabetes and the ways to achieve near-normal blood glucose control, and emphasizes the importance of other risk factors for the development of cardiovascular disease.

In chapter 2 the results of a survey among patients treated at the outpatient clinic of the Department of Internal Medicine of the University Hospital Maastricht are described. This study was performed in order to attain more information on the quality of metabolic control and presence of secondary complications in these patients. The presence of diabetic complications was assessed by specific questionnaires and detailed physical examination, and compared with a recently published survey among G.P. patients. As expected a higher proportion of our patients was treated with insulin $(48 \%$ vs. $24 \%$, $\mathrm{p}<0.01$ ). In addition, they showed a higher prevalence of hypertension ( $56 \% \mathrm{vs}$. $38 \%)$, coronary artery disease $(48 \%$ vs. 40$)$, and cerebrovascular disease (15\% vs. $6 \%$ ). $35 \%$ of our patients had signs of peripheral artery disease. Retinopathy was present in 35 patients ( $28 \%$ ), of whom 18 had received lasercoagulation treatment. Microalbuminuria was found in $25 \%$, and overt proteinuria in $14 \%$ of patients. The presence of microalbuminuria and proteinuria was a strong indicator for cardiovascular disease, polyneuropathy and retinopathy. The use of cardiovascular medication was high: 57 patients used antihypertensive therapy, 37 used diuretics, and 26 long-acting nitrates. Only 25 patients took no medication in addition to their diabetes therapy. This study confirms the clustering of risk factors for cardiovascular disease in type 2 diabetes mellitus. 
Chapter 3 describes the clinical situation and presence of secondary diabetic complications of 38 diabetic patients, chronically admitted to a nursing home. Their macrovascular complications and degree of glycaemic control were compared with those in ambulatory diabetic patients, matched for age, sex, known duration of diabetes, and specific antidiabetic therapy. No differences in blood glucose control, plasma triglycerides, blood pressure and serum creatinine were observed between both groups of patients, although plasma cholesterol levels were higher in the ambulatory patients. A high prevalence of cerebrovascular disease, peripheral vascular abnormalities, skin necrosis or leg ulcers and recurrent urinary tract infections was found in the nursing home patients. Hypertension was found in almost $50 \%$ of all patients, whereas its prevalence was the highest in the stroke patients. In the ambulatory patients cardiac complaints were more prevalent. Use of medication, especially diuretics and anticoagulant agents, was higher in the nursing home patients.

In chapter 4 the value of fasting blood glucose and serum fructosamine to reliably predict glycaemic control as measured by $\mathrm{HbA}_{1 \mathrm{c}}$ (HPLC-method) was assessed in 264 type 2 diabetic patients on various treatments. Correlation between fasting blood glucose and $\mathrm{HbA}_{1 \mathrm{c}}$ was slighly lower ( $\mathrm{r}=0.67$ for all patients $(p<0.001))$. This was higher in patients on diet $(r=0.75)$, compared to patients treated with sulphonylurea $(r=0.70)$, insulin $(r=0.59)$ and insulin + sulphonylurea $(r=0.52)$. Correlation between fasting blood glucose and serum fructosamine was, although significant, even weaker. The within-subject correlations between the three glycaemic measures were considerably lower. A fasting blood glucose level $<8.0$ mmol/l correctly predicted $\mathrm{HbA}_{1 \mathrm{c}}$ below $7.5 \%$ in only $64 \%$ of cases. There was a clear circadian variation of serum fructosamine, as assessed in 15 hospitalized patients. Thus, a normal fasting blood glucose level is a poor predictor of long term adequate glycaemic control as assessed by $\mathrm{Hb}_{1 \mathrm{ic}}$. Serum fructosamine determinations show considerable variation, and have no clinical advantage over $\mathrm{HbA}_{\mathrm{Ic}}$ measurements.

Chapter 5 describes a study of intensified dietary treatment in sixty-one ambulatory patients with type 2 diabetes mellitus and fasting blood glucose levels above $7 \mathrm{mmol} / \mathrm{l}$ (average $12.0 \pm 0.6 \mathrm{mmol} / \mathrm{l}$ ). At the start of the study 33 patients were obese. Non-obese patients showed more severe beta-cell deficiency than obese, and did not improve in blood glucose control during diet. In the obese patients three response patterns to treatment were observed: weight loss and improvement in metabolic control accompanied primarily with increased beta-cell function or increased insulin action, or worsening of metabolic control. Those with less impaired beta-cell function and shorter known duration 
of diabetes showed the most favourable response. Weight reduction was essential to obtain metabolic improvement, irrespective of the preceeding fasting blood glucose concentrations.

Chapter 6 describes the effects of 6 months insulin or sulphonylurea therapy on blood glucose control and lipid metabolism in a randomized crossover study in 13 non-obese patients with type 2 diabetes mellitus who failed to achieve adequate blood glucose control on dietary treatment. Three patients, who showed a clear improvement on insulin (median glycosylated haemoglobin fell from 14.7 to $8.6 \%$ ), withdrew from the study prematurely because of subjective and objective signs of hyperglycaemia after crossover from insulin to sulphonylurea, thus favoring the insulin treatment. In the other 10 patients, fasting and postprandial blood glucose levels, and glycosylated haemoglobin were lower during insulin than on sulphonylurea. Increase in body weight was somewhat greater on insulin therapy. Six patients experienced improved well-being on insulin compared with sulphonylurea. A significantly higher HDL-cholesterol level was found after insulin treatment than after sulphonylurea, whereas the LDL:HDL-cholesterol ratio and VLDL-triglycerides were lower. On the basis of C-peptide response after intravenous injection of glucagon those patients could be identified, who had better blood glucose control with insulin.

In chapter 7 it was shown that a simple regimen comprising twice-daily administration of intermediate-acting or a mixture of fast- and intermediate-acting insulin significantly improved blood glucose control with a slight concomitant improvement of plasma lipids. This improvement of blood glucose control in the individual patient was directly correlated with the increase in body weight, that was observed in these patients. This implies that more severe hyperglycaemia reflects a more catabolic state, which is reversed by insulin therapy. Insulin therapy could be safely instituted on an outpatient base. Almost all patients reported improved well-being, and disappearance of hyperglycaemic symptoms. Such symptoms often were previously not recognized as such. No severe complications of insulin therapy were seen. In the obese patients a comparable improvement in blood glucose control was achieved. Thus, obesity does not seem to be a contraindication for institution of insulin treatment.

In chapter 8 the possible advantages of more complicated treatment regimens, involving a combination of insulin and sulphonylurea was reported in type 2 diabetic patients with secondary failure to oral hypoglycaemic agents. A scheme comprising twice-daily insulin injections was compared with regimens of once-daily insulin in combination with glibenclamide. With both treatment regimens patients reported improved well-being and diminished hyperglycaemic complaints, while no severe hypoglycaemias were observed. The increase 
in bodly weight, and improvement of blood glucose control was comparable with all treatments. However, with combined therapy insulin dose was lower $(26 v s .42 \mathrm{U}$ ). With both treatments significant increases of HDL-cholesterol were observed, while plasma triglycerides and non-esterified fatty acids decreased. Total cholesterol decreased only in the patients treated with insulin alone. Apolipoproteins AI, AII and B did not show any significant changes. The increase of HDL-cholesterol without concomitant increase of apolipoproteins AI and AII suggest enrichment of the HDL-particle with cholesterol during insulin therapy.

Chapter 9 describes the factors which determine the decision for elderly diabetic patients to start with insulin therapy, when blood glucose control has become inadequate despite diet and oral hypoglycaemic drugs. According to Fishbein and Ajzen an attitude-behaviour model was constructed which included the determinants intention, attitude, subjective norm and self-efficacy. A high correlation existed between the intention to and the actual start or continuation of insulin therapy. The main factor that explained the intention to commence insulin treatment was the subjective norm. This means that patients are guided by the opinion of important other persons, in these circumstances especially the treating intemist, the family physician and the diabetes nurse. Tablet-treated patients reported a negative opinion of their physician towards their treatment with insulin. Intention was also determined by self-efficacy, e.g. expectations about the skills concerning injecting insulin. Self-monitoring of blood glucose and knowledge about diabetes positively influenced self-efficacy, attitude towards and intention to start insulin treatment. These findings imply that education needs to enforce the subjective norm and improve the patient's self-efficacy, and that a stimulating attitude of the treating physician towards insulin therapy is essential. 


\section{CHAPTER

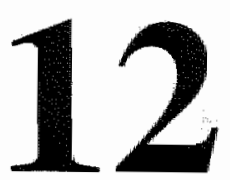

\section{Samenvatting}

Dit proefschrift exploreert het spectrum van de late complicaties, die kunnen ontstaan bij personen met diabetes mellitus type 2 , en beoordeelt de effecten van dieet-en insuline-therapie op glucose- en vetstofwisseling bij deze patiënten.

Hoofdstuk 1 geeft een overzicht van de pathofysiologische mechanismen, die leiden tot de hyperglycemie, en verantwoordelijk zijn voor het ontstaan van late complicaties bij personen met diabetes mellitus type 2. De huidige inzichten in de behandeling van diabetes, de manieren waarop bijna-normale bloedglucoseregulatie kan worden bereikt, en het belang van andere risicofactoren bij het ontwikkelen van hart- en vaatziekten worden besproken.

In hoofdstuk 2 worden de resultaten beschreven van een onderzoek naar de kwaliteit van metabole instelling en aanwezigheid van secundaire complicaties bij een aselecte steekproef van type 2 diabetes patiënten, die op de polikliniek van de afdeling Inwendige Geneeskunde worden behandeld. De aanwezigheid van complicaties werd vergeleken met de resultaten van een recent gepubliceerd inventarisatie-onderzoek onder patiënten in een huisartsenpraktijk. Naar verwachting bleek een groter aantal van onze patiënten met insuline te worden behandeld ( $48 \%$ vs. $24 \%, \mathrm{p}<0.01)$. Tevens bleek er een hogere prevalentie te bestaan van hypertensie ( $56 \%$ vs. $38 \%$ ), coronairlijden $(48 \%$ vs. $40 \%$ ), en cerebrovasculaire afwijkingen ( $15 \%$ vs. $6 \%)$. $35 \%$ van onze patiënten had tekenen van perifeer vaatlijden, terwijl retinopathie aanwezig was bij 35 patiënten $(28 \%)$; 18 van hen waren reeds met lasercoagulatie behandeld. Microalbuminurie werd geconstateerd bij $25 \%$, en manifeste proteinurie bij $14 \%$ der patiënten. De aanwezigheid van microalbuminurie en proteinurie bleek een goede indicator voor de aanwezigheid van cardiovasculaire afwijkingen, polyneuropathie en retinopathie. Het gebruik van cardiovasculaire medicatie was aanzienlijk: 57 patiënten gebruikten bloeddrukverlagende medicijnen, 37 gebruikten diuretica, en 26 lang-werkende nitraten. Slechts 25 patiënten gebruikten geen medicijnen naast hun specifieke antidiabetische behandeling. Dit 
onderzoek bevestigt de clustering van risicofactoren voor hart- en vaatziekten bij patienten met type 2 diabetes mellitus.

Hoofdstuk 3 beschrijft de metabole regulatie en aanwezigheid van secundaire complicaties bij 38 diabetes patiënten, die chronisch opgenomen waren in 2 Maastrichtse verpleegklinieken. De resultaten werden vergeleken met bevindingen bij een voor wat betreft leeftijd, geslacht, bekende duur van de diabetes en antidiabetische therapie vergelijkbare groep poliklinisch behandelde patiënten. De door ons onderzochte patiënten betroffen $15 \%$ van de populatie van de betrokken verpleeghuizen. Tussen beide groepen werden geen verschillen in diabetes instelling, plasma triglyceriden, bloeddruk en nierfunctie gevonden. De plasma cholesterolgehalten van de poliklinische patiënten waren hoger. 22 van de patiënten in de verpleegkliniek hadden een cerebrovasculair accident (CVA) doorgemaakt, tegen 4 poliklinische patiënten. Bij 18 van deze 22 patiënten had het CVA geleid tot hemiparese en verzorgingsbehoefte, en was dit de reden voor opname in de verpleegkliniek geweest. De prevalentie van hypertensie bedroeg $50 \%$, waarbij hypertensie frequenter voorkwam bij de CVA-patiënten, in vergelijking met de patiënten zonder cerebrovasculaire aandoeningen. De verpleegkliniek-patiënten hadden een hoge frequentie van perifeer vaatlijden $(76 \%)$ en amputaties $(24 \%)$, huidnecrose en ulcera cruris, en urineweginfecties (76\%), terwijl bij de poliklinisch behandelde patiënten cardiale klachten frequenter voorkwamen ( $47 \%$ vs. $24 \%, \mathrm{p}<0.01$ ). Medicatie-gebruik, met name van diuretica en antistollingsmiddelen, was hoger bij de verpleegkliniek-patiënten.

In hoofdstuk 4 wordt de waarde van het nuchtere bloedglucose en serum fructosamine gehalte beoordeeld om de kwaliteit van metabole controle te voorspellen. Een met de HPLC-methode bepaalde concentratie van geglycosyleerd hemoglobine is hierbij de 'gouden standaard'. In totaal werden 264 patiènten bestudeerd. De correlatie tussen nuchter bloedglucose en $\mathrm{HbA}_{\mathrm{lc}}$ was iets lager $(r=0.67$ voor alle patiënten $(p<0.001)$ ). Deze correlatie was het grootst bij met dieet behandelde patiënten ( $r=0.75$ ), in vergelijking met patiënten, die met tabletten $(r=0.70)$, insuline $(r=0.59)$ of insuline + sulfonylurea $(r=0.52)$ werden behandeld. De correlatie tussen nuchter bloedglucose en senum fructosamine was nog lager. De correlatie tussen de drie variabelen van glycemische controle binnen één persoon waren aanzienlijk lager. Een nuchter bloedglucose gehalte $<8.0 \mathrm{mmol} / \mathrm{l}$ voorspelde een $\mathrm{HbA}_{1 \mathrm{c}}$ lager dan $7.5 \%$ slechts correct in $64 \%$ van de gevallen. Er bestond een duidelijke variatie van het serum fructosamine gehalte gedurende de dag, met een significante postprandiale stijging om 10 uur 's ochtends. Het nuchtere bloedglucose gehalte heeft een matige voorspellende waarde voor het $\mathrm{Hb}_{\mathrm{lc}}$ gehalte. Het serum fructosamine vertoont 
gedurende de dag aanzienlijke variatie, en heeft geen woordelen boven de bepaling van het geglycosyleerd hemoglobine.

Hoofdstuk 5 beschrijft een onderzoek naar de effecten van intensieve dieet therapie bij 61 ambulante patiènten met type 2 diabetes mellitus met een nuchter bloedglucose-gehalte hoger dan $7.0 \mathrm{mmol} / \mathrm{l}$ (gemiddeld $12.0 \pm 0.6 \mathrm{mmol} / \mathrm{l}$ ). Bij aanvang van het onderzoek hadden 33 patiënten een overgewicht. Niet-obese patiënten toonden een emstiger defect in insuline-secretie dan obese patiènten. Tijdens dieet verbeterde hun glucose-regulatie niet. Bij de patiënten met overgewicht werden drie vormen van respons waargenomen: gewichtsverlies met verbetering van de metabole regulatie bij een verbetering van de residuele insuline-secretie dan wel een verbetering van de insuline-werking, of verslechtering van de glucose-regulatie. Diabeten met een hogere residuele insuline-secretie of met een korte duur van de diabetes toonden de meest gunstige respons. Gewichtsverlies was essenticel om een verbetering van de instelling te bereiken, onafhankelijk van de hoogte van het bloedglucose-gehalte.

In hoofdstuk 6 worden de effecten op glucose- en vetstofwisseling van 6 maanden behandeling met insuline vergeleken met sulfonylurea therapie in een gerandomizeerde cross-over studie bij 13 type 2 diabetes patiënten met een normaal lichaamsgewicht, die met dieet alleen niet goed gereguleerd waren. Drie patiënten vielen voortijdig uit de studie, vanwege hyperglycemische klachten nadat zij van insuline overgegaan waren naar tablet therapie. $\mathrm{Zij}$ toonden een sterke verbetering van metabole regulatie tijdens insuline, waarbij de mediane waarde van het geglycosyleerd hemoglobine daalde van 14.7 naar $8.6 \%$. $\mathrm{Bij}$ de overige 10 patiënten waren de nuchtere en postprandiale bloedglucose spiegels, en het geglycosyleerd hemoglobine lager gedurende insuline in vergelijking met tablet therapie. De toename van het lichaamsgewicht was tijdens insuline echter groter. Zes patiënten rapporteerden dat zij zich tijdens insuline therapie beter voelden dan tijdens tablet behandeling. Tijdens insuline was het HDL-cholesterol gehalte significant hoger, en de LDL:HDL-cholesterol ratio en het VLDL-triglyceriden gehalte waren lager. Op basis van de stijging van het plasma C-peptide gehalte na injectie van $1 \mathrm{mg}$ glucagon konden die patiênten worden geidentificeerd, die tijdens insuline beter gereguleerdl waren.

In hoofdstuk 7 wordt aangetoond dat een eenvoudig insuline schema met tweemaal daagse toediening van middellangwerkend insuline of een mengsel van middellangwerkende en snelwerkende insuline de diabetes instelling sterk verbeterde bij personen met falen op orale therapie. Er bleek een duidelijke relatie tussen de metabole verbetering en de toename van het lichaamsgewicht. $\mathrm{Bij}$ de meeste patiënten werd zonder problemen de insuline behandeling poliklinisch aangevangen. Bijna alle patiënten meldden een verbetering van het welbevinden, en een vermindering van, vaak niet tevoren als zodanig herkende, 
hyperglycemische klachten. Aangezien de 6 patiënten met overgewicht een vergelijkbare verbetering van de diabetes instelling toonden, is obesitas ons inziens geen reden om insuline behandeling achterwege te laten.

In hoofdstuk 8 worden de metabole effecten van combinatie van insuline met glibenclamide bestudeerd bij patiènten met secundair falen op orale therapie. Zowel met insuline alleen als met combinatie-therapie verbeterde het welbevinden van de patiënten en verdwenen hyperglycemische klachten; ernstige hypoglycemieën werden niet waargenomen. Er was bij beide behandelingsschema's een vergelijkbare toename van het lichaamsgewicht en daling van de bloedglucosegehalten. Echter, bij combinatie-therapie was de benodigde dosis insuline lager ( 26 vs. $42 \mathrm{E}$ ). Een significante stijging van het HDL-cholesterol, en daling van vrije vetzuren en triglyceriden werd waargenomen. Het totale cholesterolgehalte daalde alleen bij patiënten, die insuline gebruikten. Het gehalte van de apolipoproteinen AI, AII en B veranderde niet. De toename van het HDL-cholesterol zonder stijging van het apoAI gehalte betekent een verrijking van het HDL-partikel met cholesterol onder invloed van insuline.

In hoofdstuk 9 worden de factoren bestudeerd die de beslissing van een persoon met diabetes om insuline te gaan spuiten beinvloeden. Naar het model van Fishbein and Ajzen werd een attitude-gedrag model opgesteld, dat de determinanten intentie, attitude, subjectieve norm en self-efficacy omvatte. Er bestond een hoge correlatie tussen de intentie om insuline te gaan of blijven spuiten en het daadwerkelijk vertonen van dit gedrag. De belangrijkste factor die deze intentie bepaalde was de subjectieve norm. Dit betekent dat patiënten in aanzienlijke mate geleid worden door zgn. belangrijke andere personen, in dit geval de behandelend specialist, de huisarts, en de diabetesverpleegkundige. Patiënten die tabletten gebruikten rapporteerden een negatieve houding van hun behandelend arts ten aanzien van insuline therapie. De intentie werd tevens bepaald door de self-efficacy, dat will zeggen de mate waarin een individu verwacht om technisch moeilijke handelingen (prikken, juiste hoeveelheid insuline bepalen) goed te kunnen uitvoeren. Het zelf kunnen bepalen van het bloedglucosegehalte en kennis omtrent diabetes beinvloedden de self-efficacy, attitude en intentie positief. Educatie dient derhalve de subjectieve norm te versterken en de self-efficacy van een patiënt te verbeteren. Een stimulerende houding van de behandelende arts ten aanzien van insuline behandeling is essentieel. 


\section{CHAPTER}

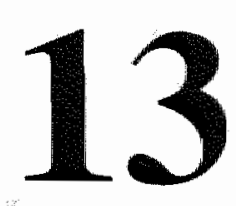

Evaluation and treatment of patients with type 2 diabetes

Practical guidelines 
Table 1. Instruction, treatment and follow-up of the type 2 diabetic patient.

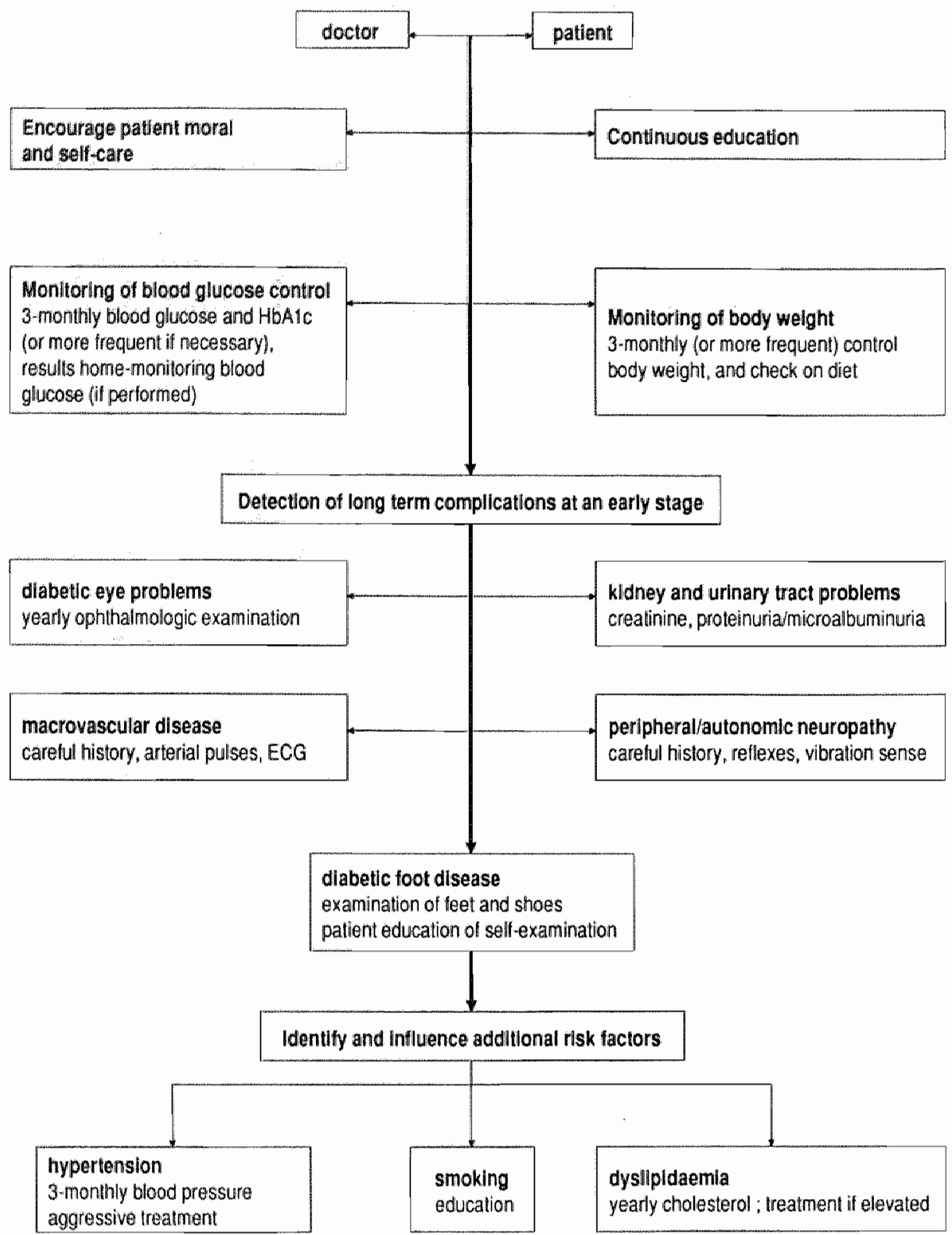


Table 2. Check-up in a patient with type 2 diabetes mellitus.

\section{First visit:}

Careful and extensive history

General physical examination

Body weight, blood pressure supine and standing

Fundoscopy + visual acuity (ophthalmologist)

Specific examination for neuropathy

Foot inspection

Fasting and postprandial blood glucose

HbAlc

Cholesterol, triglycerides, HDL cholesterol

Urine protein, microalbuminuria, ketone bodies

Urine microscopy and culture

Plasma creatinine

ECG

Dietary advice (dietician)

Advice for regular physical exercise

Start education

Self monitoring of blood glucose?

Monthly: (when control is poor or insulin treatment)

Body weight

Fasting (and postprandial?) blood glucose

Continue education

\section{Once every three months:}

As monthly, plus:

Blood pressure

$\mathrm{HbA} 1 \mathrm{c}$

Lipids, when elevated at a prior determination, or treated

\section{Yearly:}

Metabolic and physical examination as with first visit

Examination for late complications, including ophthalmologic investigation 

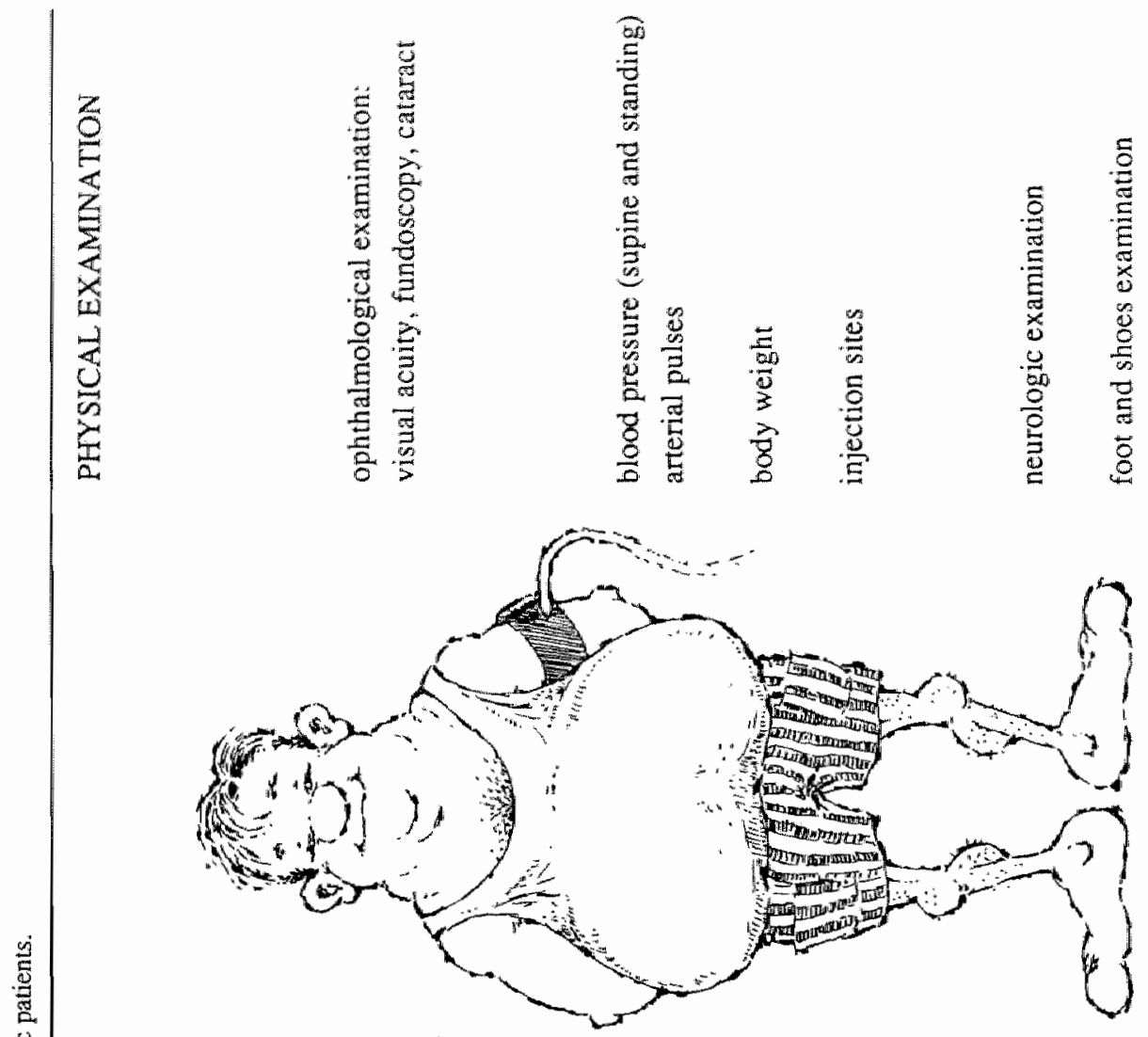

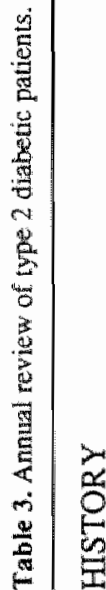

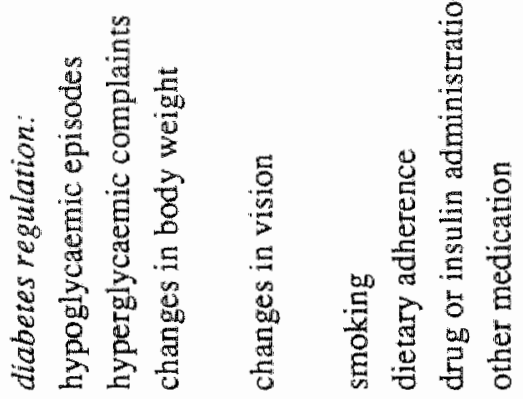

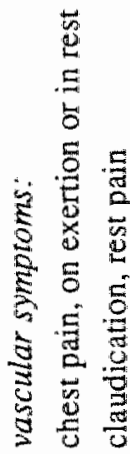

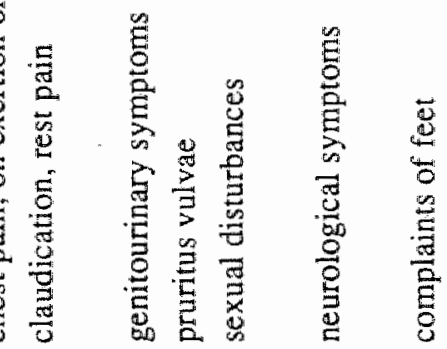


Table 4. Monitoring of treatment targets and cardiovascular risk factors in patients with type 2 diabetes mellitus.

Good Fair Poor

Body mass index $\left(\mathrm{kg} / \mathrm{m}^{2}\right)$

males

females

$22-25$

$25-27$

$>27$

$22-24$

$24-26$

$>26$

Blood glucose $(\mathrm{mmol} / \mathrm{l})^{1}$

\begin{tabular}{|c|c|c|c|}
\hline fasting & $4.4-6.7$ & $6.7-8.0$ & $>8.0$ \\
\hline post-prandial & $4.4-9.0$ & $9.0-12.0$ & $>12.0$ \\
\hline
\end{tabular}

HbAlc (\%)

$<7.5$

$7.5-9.0$

$>9.0$

Total cholesterol (mmol/)

$<5.2$

$5.2-6.5$

$>6.5$

HDL-cholesterol (mmol/l)

$>1.1$

$0.9-1.1$

$<9$

Triglycerides (mmol/1)

$$
<1.7
$$

$1.7-2.2$

$>2.2$

Blood pressure ( $\mathrm{mm} \mathrm{Hg}$ )

systolic

diastolic
$<140$

$<85$

$<30$

Microalbuminuria 24-hour urine (mg/24h)

early morning sample albumin/creatinin ratio

Cigarette smoking

1 dependent on age and therapy goal

After: Alberti KGMM, Gries FA. Management of non-insulin-dependent diabetes mellitus in Europe: a consensus view. Diabetic Med 1988; 5: 275-281. 


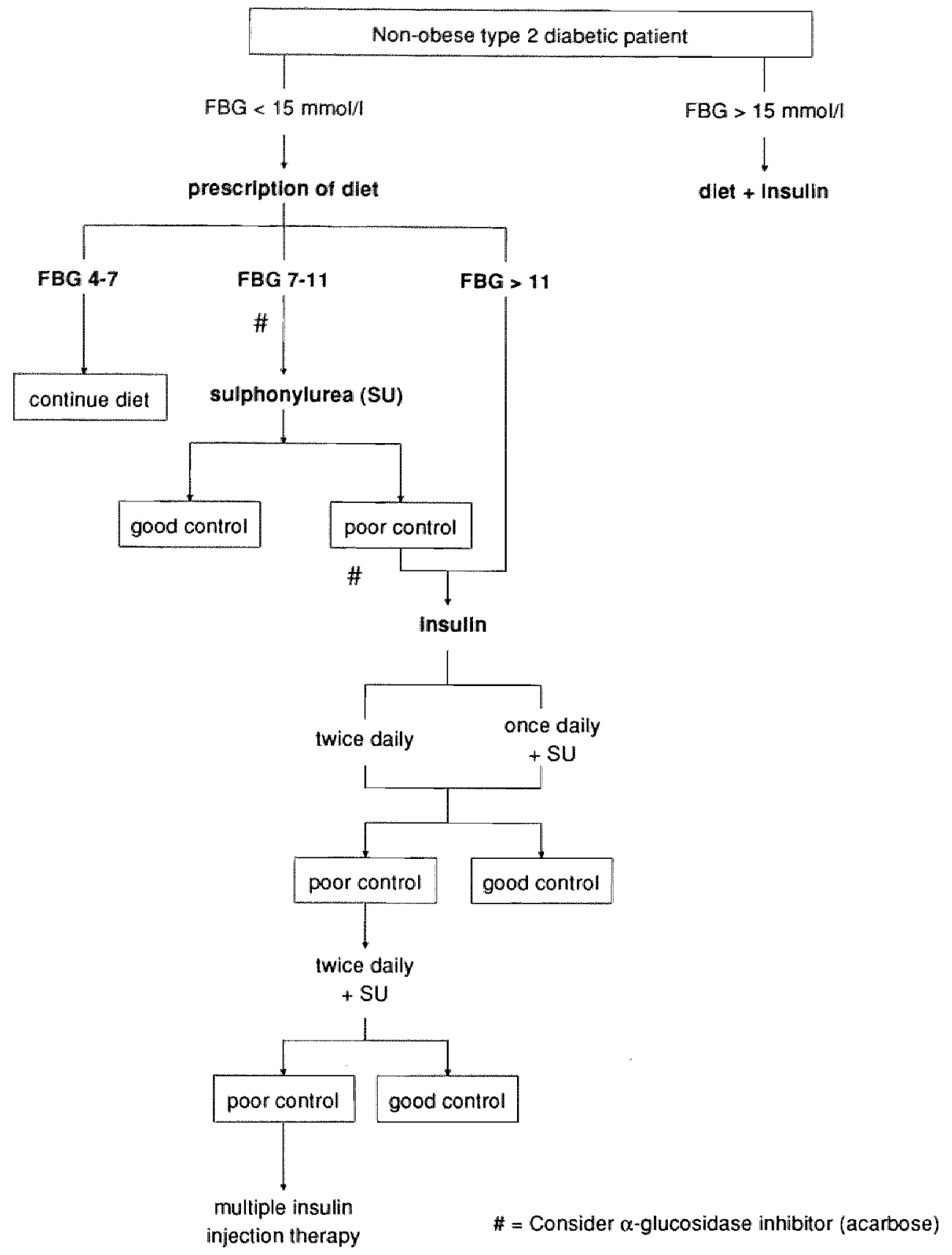

Fig 1. Treatment of type 2 diabetes mellitus: non-obese patients. 


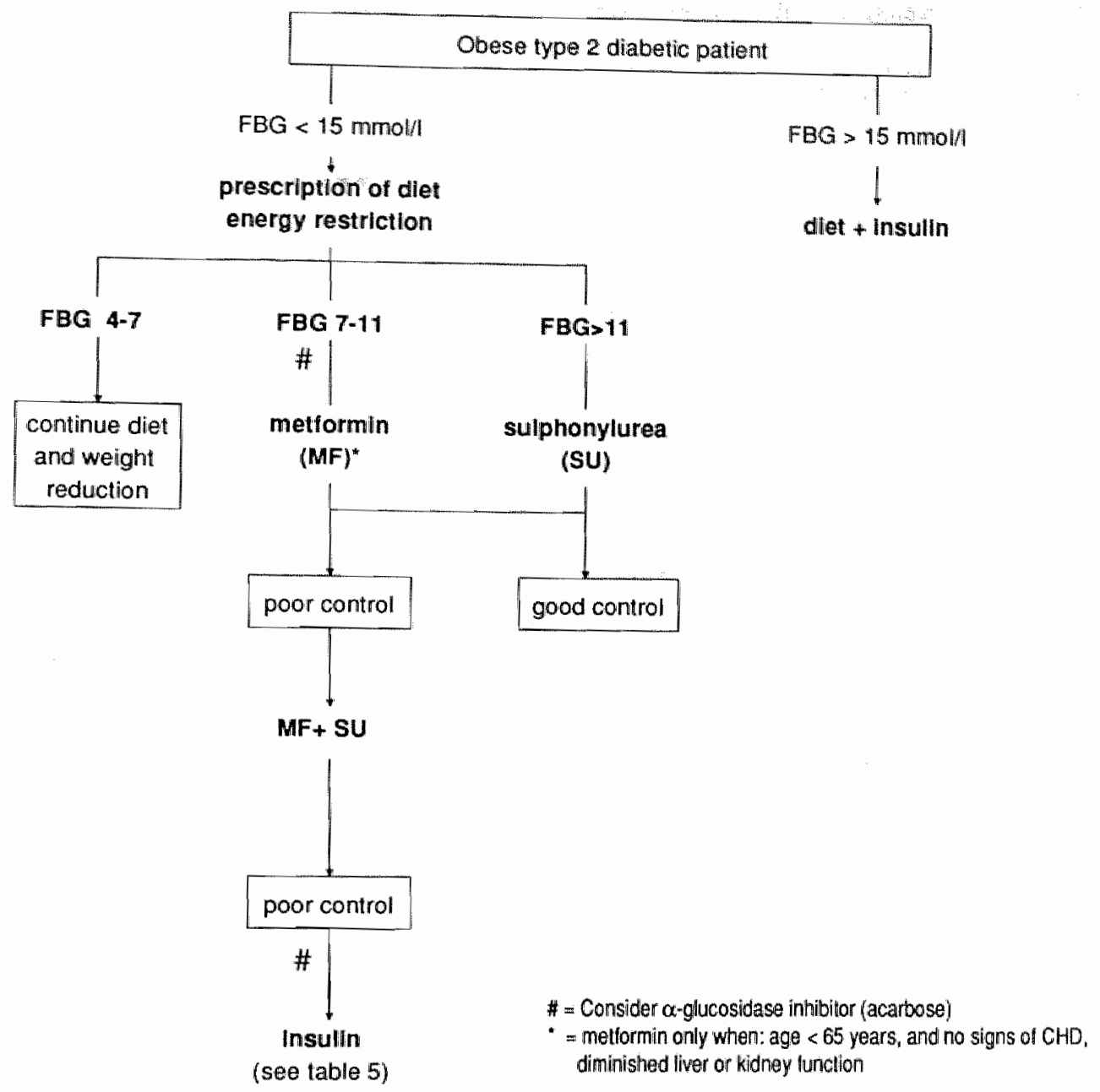

Fig 2. Treatment of type 2 diabetes mellitus: obese patients. 
Table 5 . Institution of insulin therapy in type 2 diabetes mellitus.

1. Insulin administration preferrably by means of an insulin-pen.

2. Out-patient institution of insulin therapy can be achieved only with proper instruction and motivation of the patient, and by preference when self-monitoring of blood glucose is possible.

When a patient is not capable to inject insulin him/herself, then assistance of registered nurses is essential.

3. Use an insulin administration scheme which is as easy as possible:

for instance:

twice-daily administration (before breakfast and supper) of a mixture of fast-acting and NPH-insulin.

or

once-daily injection of an insulin mixture in combination with glibenclamide before meals.

4. Adjust the amount of insulin in relation to the blood glucose determinations which are made by the patient.

5. Regularly check the most important variables:

- body weight

- blood glucose measurements

- insulin injection sites

- insulin injection technique

- possible hypoglycaemias 


\section{Nawoord}

Onderzoek als in dit proefschrift beschreven zou niet mogelijk geweest zijn zonder de hulp van zeer velen.

De welwillende en enthousiaste medewerking van alle patiënten was cruciaal.

Prof. dr. A.C. Nieuwenhuijzen Kruseman kent naast een kritisch oog en oor ook de gave om medewerkers zelfstandig, en toch solide gesteund, wetenschap te laten beoefenen.

Mijn opleider prof. dr. J.C. Birkenhäger ben ik dankbaar voor zijn stimulerende rol tijdens mijn opleiding tot internist.

I am very grateful to the two 'external referents' of this thesis, dr. Robert Turner from Oxford, United Kingdom, and prof. dr. Pierre Lefebvre, from Liège in Belgium, for their critical appraisal and suggestions for improvement of the manuscript.

Jean-Pierre Sels ben ik erkentelijk voor de samenwerking gedurende de afgelopen jaren.

Prof. dr. Pieter Verdouw was mijn mentor tijdens de eerste schreden op het gebied van het dierexperimentele onderzoek. Hij is bovenal degene, die mij heeft geleerd 'no-nonsense' proza te schrijven.

Dr. R.F.A. Weber en dr. L. Verschoor hebben bijgedragen aan enkele in dit boekje beschreven studies.

De collegae E. Jaspers, K. van Santen, A. Knols en W. Slits waren behulpzaam bij het onderzoek bij de verpleegkliniek-patiënten.

Dr. ir. Paul Menheere wil ik bedanken voor de samenwerking en de verantwoordelijkheid voor een groot aantal immunochemische bepalingen.

In het CKCL (hoofd: dr. B. Bleijenberg) van het AZR-'Dijkzigt', en het Klinisch Chemisch Laboratorium (hoofd: drs. C. Degenaar) van het AZM werden een groot aantal $\mathrm{HbA}_{1 c}$ en fructosamine bepalingen verricht. Lucien Habets, hoofdanalist, is met recht een belangrijke spil van dit laatste laboratorium.

Voor de immunochemische en lipid analyses hebben een aantal personen zich enorm ingezet: Peter van Koetsveld en Lilian Weeks in Rotterdam, en José Vrancken en haar collega's van het lab Immunochemie (Chemie 6) te Maastricht. Een speciaal woord van dank aan Gabriëlle Rondas, die met veel voortvarendheid de lipiden- en apoproteine bepalingen in Maastricht heeft opgezet.

Rob van Kimmenade, Constance Drossaert en Susan van Vliet ben ik dankbaar voor de plezierige samenwerking. 
De praktische begeleiding en instructie door de diabetes-verpleegkundigen Henny Walraven Borst, Bert Heinemans en Els Denis was onmisbaar.

De secretariële ondersteuning van Lilian Wishaupt was niet alleen voor dit proefschrift van belang, maar vormt de basis van de werkgroep Endocrinologie.

Mijn ouders wil ik danken voor hun stimulerende ondersteuning tijdens mijn studie, en de bijtijdse bijsturing van dierenarts naar 'gewoon' arts.

Susanne, Alain en Francien maakten het allemaal echt mogelijk. 


\section{Curriculum vitae}

De schrijver van dit proefschrift werd geboren op 19 september 1955 in het hart van Rotterdam. Na het behalen van het Gymnasium $B$ diploma aan het Gymnasium Erasmianum te Rotterdam werd in 1973 met de studie Geneeskunde aangevangen aan de tegenover dit gymnasium gelegen Medische Faculteit van de Erasmus Universiteit. Tijdens de studie is als keuze-praktikant en aansluitend als student-assistent onderzoek gedaan op het Laboratorium voor Experimentele Cardiologie van het Thoraxcentrum (hoofd: prof. dr. P.D. Verdouw). In 1980 werd het artsexamen afgelegd. In 1981 was hij werkzaam als arts-assistent Inwendige Geneeskunde in het Ikazia Ziekenhuis te Rotterdam. Het jaar 1982 werd wederom doorgebracht op de afdeling Experimentele Cardiologie, alwaar onderzoek werd verricht naar de effecten van calcium-antagonisten en bèta-blokkers op regionale myocardischemie. Hij volgde zijn opleiding tot internist in de afdeling Inwendige Geneeskunde III van het Academisch Ziekenhuis Rotterdam - "Dijkzigt" (opleider: prof. dr. J.C. Birkenhäger), alwaar hij aan een deel van het beschreven onderzoek heeft gewerkt. Vanaf 1 januari 1988 is hij geregistreerd als internist, en werkzaam in de werkgroep Endocrinologie (prof. dr. A.C. Nieuwenhuijzen Kruseman) van de afdeling Inwendige Geneeskunde (hoofd: prof. dr. J.A. Flendrig) van het Academisch Ziekenhuis Maastricht, alwaar het vervolgonderzoek plaats vond, en dit proefschrift werd afgerond. 